




\section{BERNARDINI \\ $T$ E $L$ E $S$ I I Confentini,}

UARII DE NATVRALIBVS $R E B V S$ L I B E E L I L I AB ANTONIO PERSIO EDITI.

Quorum alï nun quàm antea excufi, alij meliores facti prodeunt.

\section{$S V N T$ A V T E M H $I$}

De Cometis, \& Lacteo Circulo. $\}$

De his, quæ in Aere fiunt.

De Iride.

De Mari .
Quod Animal vniuerfum. DeVfu Refpirationis. De Coloribus. De Saporibus. De Somno.

$\checkmark$ nicuique libello appofitus eft capitum Index.

CVM PRIVILEGIO.
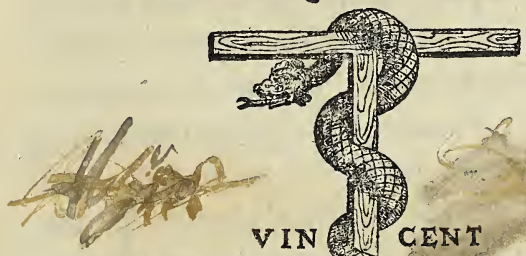

VIN CENT

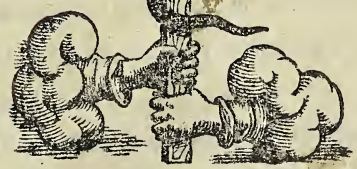

VENETIIS M. D. XC.

Apud Felicem Valgrifium. 


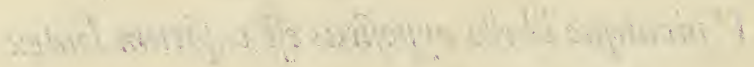

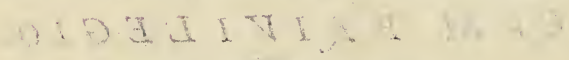
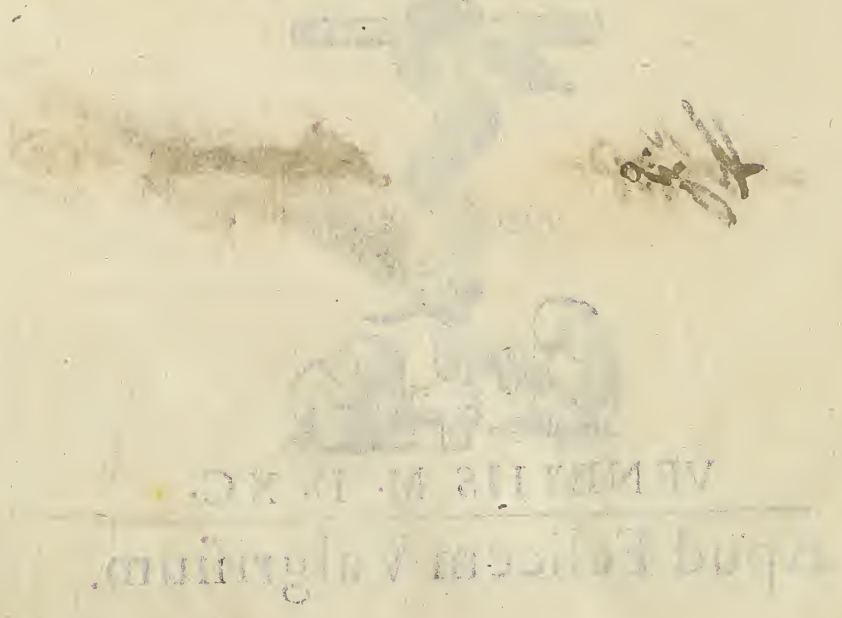


\section{A N T O N I V S P E R S I V $S$}

C A N D I D O L E C T O R I.

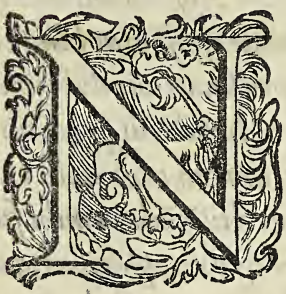

OVE $M$ bec Bernardini Telesï pbyfica opufcula, quorum tria tantum ante bac excuf a fue runt, eodem omnia volumine complexa, vt publici iuris efficienda curarim, id fuit caus $\int_{e}$ potifjimum, Candide lector, guod cum pauciffima corum exempla circum ferrentur, adeo vt ip $\{$ mibi, qui Telefio inter viuos agenti coniunctiffimus, ac, ni fallor, cariffimus fue:am, antequam wnius ex fingulis compos fierem, fudandum fuerit, buic malo guamprimum confulere nece]Jarium exiftimarim. T. mebam enim ego duorum alterum, vel fcilicet ne laboreshiperirent omnino, vel nequis cos tanquam proprï fibipartumingenï vindicans, fuum $\ddot{y} s$ nomen, $T$ eles $\ddot{y}$ expuncto nomine, in friberet, $\sigma$ vt fuatandem in commune proferret. Cuiufmodinon defuturos homines fuiffe vt mibi perfuaderem effecere multi, quos noni ego met confimilem lufiffe ludum.c Ac profecto nof tra bac tempefrate, $\sqrt{2}$ volla vnquam alia factum eft, malis hifce artibus profapientia utilicet. Vt autem rem planè intelligas, erant ex bis tres tantummodo, ut dixi excufi libri, De bis, qua in aere fiunt $\int$ cilicet unus, alter de mari, tertius de co lorum generatione.c Ac de mari guidem ille nonnullis an $\therefore$ Etior 
ctior capitibus tibi datur, que nos in ip fus calcem omnia reiecimus. Qui verò de coloribus eft, longè prodit alius, non verbis tätum, $\int e d \circlearrowright \sigma e n t e n t i j s$, atq; opinione. Cateri omnes nunc primum publicantur. Ex ijs, qui mibi à Tele fio miffi fuere. (Junt autem, bi, de fomno, de faporibus, de bis, qua in aere, de mari,) bilongè alijs emendatiores exbibentur, reliqui autě, quos aliunde e pifcatus fum (cu ranit cos mibi Fräcifcus Mutus, praftanti vir doctrina, ac Telefiana philo ophia cognitione baud leni praditus) ijnon folum alicubi imperfecti, verumetiä tam malè exa sait, ac mendosè ex Cripti erant, ut diuinädum mibi fue rit in plerifg; locis. Cum antem in ijs exemplaribus, que nacti fumus,loci nulli neq; Arifotelis,neq; Galeni,neq; aliorum, gui a Telefio laudantur autbores, neg; in contextu, neque in margine notati extarent, Nos eos omnes in turm commodum, etmice Lector ad oram criuf que libelli ritè adfcrip fimus. cAd bac fchernata quedam in libello de iride $a b$ authore nominata, vel faltem fubintellecta, quod nallum eorum in nofiris codicibus weftigin extaret, accurate delineawimus, ut facilius id, quo de agi tur, intelligeres.cAtó; hac nos tibi tanqwam in alieno folo (vt cum noftris loguar iurifconfultis) elaborauimus, pro pediem te in noftro accepturi, aique ex agello ingeniolino fri, qua tibifortè non ingrata videantur, multoliberalius deprompturi.Quod reliquum eft, Lector bumaniflme, quo nobifcum abillius Japientiffimi viri manibus gra tiam aliquam in eas, ac magis vtilitati publice confula. mus, fi fortè meliores, quàm noftri funt, codices fueris nactus, ut or ego meliores edere pofjim, mibicos, quafo Candidus imperti,finon, bis utere mecum . Vale. 


\section{INDEX OPVSCVLORVM.}

Prima pars, in qua pracipua Meteorologicos

$$
\text { continentur. }
$$

De $\left\{\begin{array}{l}\text { Cometis. } \\ \text { Lacteo Circulo. }\end{array}\right.$

$$
\}
$$

De $\left\{\begin{array}{l}\text { His, que in } \\ \text { Videlicet. } \\ \text { Plunia. } \\ \text { Grandine. } \\ \text { Nine. } \\ \text { Ventis. } \\ \text { Tonitru. } \\ \text { Fulgure. } \\ \text { Terromotibus. }\end{array}\right.$

De Iride.

De Mari.

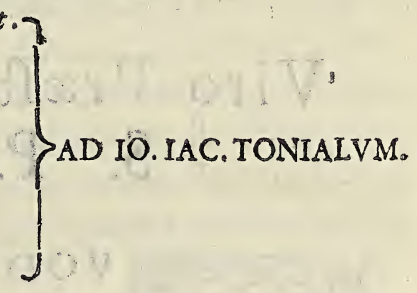

Quod animal oni-?

uerfum ab vnica

anims substantia gubernatur contra Galenum.
AD EPISCOPVM PATAVINVM.

AD FRANCISCVM PATRICIVM .

\section{Secunda pars, in qua, que parua naturalia dici polfunt, tractantur.}

Desfurefpirationis. AD IO. MICHAELIVM.

De Coloribus.

De Saporibus.

De Somno.
AD IO. VINCENTIVM PINELLVM.

AD BENEDICTVM GEORGIVM.

AD FEDERICVM PENDASIVM。

AD HIERONYMVM MERCVRIALEM。 


\section{A N T O N I V S P E R S I V S}

I O A N N I I A C O B O $\begin{array}{lllllll}T & O & N & I & A & L & O\end{array}$

\section{Viro Prxftantifsimo.}
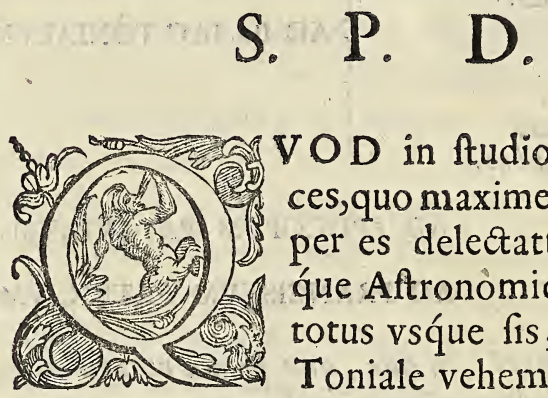

VOD in fudio Mathematices, quo maxime omnium fem per es delectatus, inprimifque Aftronòmic x facultatis, totus vsq́ue fis, laudo te, $\mathrm{mi}$ Toniale vehementer, ac verè virum cenfeo, qui non te otio, quod plerique ifta fortuna, hoc eft opibus abundantes homines faciunt, corrumpi finas; fed, cùm ingenio iudicioque cum paucis fis conferendus, animum tuum optimis artibus perpolitum nobilisfima rerum excelfifsimarum excolis cognitione. Cui tantum detulit Ariftoteles, ut eam vel imperfectam perfecta inferiorum rerum fcientia multo duxerit effe præettantiorem. V tere igitur fortunæ bono dum per florentem xtatem tuam licet, \& viaticum fenectuti para. Col- 
locupleta tuum folidis, atque immortalibus bonis animum:amicitias quoque quòd facis, adiun ge tibi liberalitate hac tua, omnique officiorum genere. qur ego abfte in me expertus non vulgaria, per libenter foleo prædicare. \& quo extaret eorum fignificatio diuturnior, à me tibi nur cupati ut exirent duo hi Telefij noftri libelli de Cometis, \&lacteo circulo vnus, De ijs, qux in aere fiunt alter, libentisfimè curaui: fimul ve häberes occafionem de rebus coeleftibus, coeloq́ue proximis, quo te rapit Aftrorum ftudium, nouam T elefij noftri difputationem alacrius legen di. Cuius tuphilofophiam nagno animo ample xatus maxima cumiudícij, \& ingenij laude tueris. Acliberille quidem, quo de ijs, quę in aere fiunt, differitur, editus ante hac eft, nunc emacu. latior prodit. Alter verò nunc primum publici, iuris efficitur. Vale, \& Perfium tuum ex animo nunquam elabi tuo patiare. Patauio Kalendis Aprilis. $M D \times C$. 


\section{N D E X

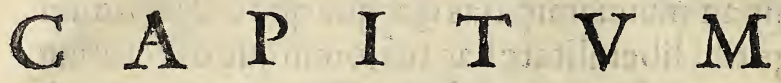 \\ L I B $R$ R I \\ D E C O $\quad M \quad$ E $T$ I $S$. ET LACTEO CIR CVLO.}

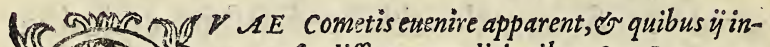

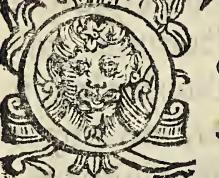
terfe differunt conditionibus.Cap.I.pag.1.a cometem folis lucem eße à saporibus relucentem. Cap. II.

pag.I.b sicometes, qualispofitus est, fit, que cometis eue nire vifa funt, euenire poffe omnia. Cap. III. pas. 2. a

LaEtei circuli conditiones, of quid ip fe fit. Cap. IIII. pag.4.a Cometas ex exbalationibus accenfis fieri Ariftoteli.videtur.

cap. $V$.

pag.5.a

cometas ex exbalationibus accenfis fieri prorfus non poffe. cap. $V I$.

pag.6.a

Qux cometis attribuit Aristoteles loca, or non rectè ea attribut eße. cap. VII.

signum quod cometas reflexione fierinon poffe Ariftoteli indicat, in frmum eße. Cap. VIII.

LaCteum circulum exbalationibus accenfis Ariftoteli fieri vidstur, or ex eisfierinon polfe. Cap. IX.

pag. 12.6 


\section{B ER N A R D I N I TELESII CONSENTINI.}

De Cometis, \& Lacteo circulo.

Que Cometis enenire apparent, \& quibus $\ddot{y}$ inter $\int e f e$ differunt conditionibus. Cap. Primum.

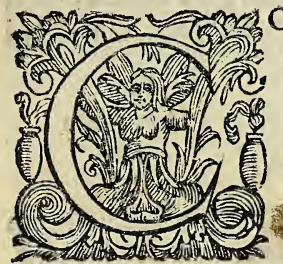

METARVM exortum, confitutionemquè, \& quid omnino Cometx fint inquirentibus, quę ijs ellenire apparent, infpicienda funt omnia, neque enim aliunde, fed ex ijs foltum modus, quo fiunt, \& quid omnino fint, in notefcere poteft. Cometę perraiò fút, ifun a plures interdum fimul heri confeat funt, \& errantium interdum, inerrantiumqque ftellarum quampiam, com $x$ inftar, ambire, unde \& ij, \& reliqux eius generis luces, uel fi diuerfam fortitx fint figuram, nomē adeptx funt. Interdum uero, \& illarum cuipiam barbę, caudęue ritu affigi, itaque barbx caudxue proprijs appellantur nomi nibus, at plerumque certè perfe fieri, nullis fcilicet ftellis hr rere apparent, \& horum figura longè eft diuerfifsima: itaque \& longè ij plurima fortiti funt nomina, eiusq́ue rei finguli, cuius fpetiem referre uidentur: colore etiam, fulgoreq́; fum mopere à fe ipfis difierunt, nam \& albi, \& punicei, \& pallidi etiam, \& magis,minusq́ue fplendidi funt, quin finguli alijs fui partibus magis, minus alijs fulgent. Magnitudine itide maximè interfe differunt. nam Cometes confrectus eit, qui folis magnitudinem æquaret, alius, qui ad terram ufque cœli partem extenderetur, alij parui omnino, \& qui nihil cum illis conferendi fint, \& in alijs eadem perpetuò figura fpeties que, \& magnitudo feruari, In alijs tierò harum quxuis imm m tari uifa eft: $D$ arationis etiam tempus longè diuerfifsimum fortiti funt . alij enim feptem modò diebus, alij Io ngè pluri bus, eft \& qui fex menfibus ftella certè, qua paucis ab hinc an nis in cafsiopex figno confpecta eft, menfibus quindecrm !u 


\section{Bernardini Telefij}

cere confpecta eft. Cur enim qua cometarum more, nihil an cea uifa un quam exoriri, tum $\&$ cometarum more penitus pe riri uifa eft, uel finfuetam fortita fit figuram, non \& ipfa inter eius generis luces ponenda fit? quin \& diuerfis in coli partibus, diuerfisque \& regionibus fieri uidentur; alij enim intra tropicos, alij extra, \& alij funt Iuna fuperiores, alij In colo, \& ipfas omnino apud fellas, quibus appofiti, affixique apparent, diuerfifsimis itidem motibus moueri, \& plerique quidem, qui prafertim fellis affxi uidentur, ipfis cum ftellis, $\&$ cum colo iplo ab oriëte nimirum occidentem uerfus, \& è contra, \& à feptemtrione ad aufrum, \& è contra; quin jjdem diuerfis fimul, incertisqúc itineribus ferri.Sunt $\&$ qui nullo ufquam moueri uif funt motu.

\section{Cometem folis lucem effè à Haporibus relucenten}

$$
\text { cap. Secundum. }
$$

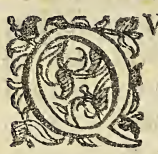

a expofita funt cometis cùm eueniant, utiq; co li partes eas effe, qua perfe quidem non luceant, at qua quempiam ad folem nactre fitum, \& à fole omnino illufratę lunz ritu folis ad nos lucé remictant exiftimare ne liceat, cum alia multa, rum uerò cęli, cometartmq́ue motuum diuerfitas prohibet. itaque aliena à colo res fit oportet, \& qua fupremum ufque ad colum efferri, \& fui quidem natura lucida non fit, atque uel uaporum, qui noftro hoc in ccelo, \& alias in fiammas, \& in fellas accenduntur, qua currere uidentur, ricu, at entis, in quo funt, natura, motuuè accendi queant, uel qua in feipsả collecta ( quod luna forte, \&lactea etiam uia, \& ipfi etiã nofro in colo pafsim faciunt uapores) folis lucem remittat, \& qua fiquidem una fit, continuaque denfior modo, modo ue rò laxior fiat, \& fi multis è partibus, at in fe ipfas collectis có pofita fit, non æquè hac femper in fe ipfis cogantur, fed aliàs magis, mirus aliàs, \& quę utrumuis horum fit fibi ipfi uniuerí, wniformis non fit, \& figuram quāuis fufcipere queat \& qua in fuperbenè fui natura mobilis fit, uaporum nimiru moles ut fir neceffe eft. ijs enim unis rei, que cometes futura eft ineffe oportere uifa funt omnia, entium reliquorum nulli prorfus infunt, ad fupremum fcilicet colum ufque tenuiores, prefercim quiqui func nobis efferri poffunt, \& paulo ro: buftiore. 


\section{De Cometis, \& Lacteo circulo.}

buftiore à calore quauis facto ratione correpti inflammas agi,ut cum alijs inflammis, qux palsim noltro in colo fiunt, tum uerò in ftellis, qux currere uidentur, intueri licet, $8 \mathrm{r}$ in fe ipfos coafi folis lucem, \& ipfum remittere uidentur folë, ut Iris, nubiumq́ue colores omnes, \& ipfi etiam, qui in nubi bus fpectantur, declarant foles rapríras græcis dicti, nä hæc omnia folis lucem effe à nubibus relucentem, $\&$ in commen tarijs de rerum natura, $\&$ in iride amplius faris eft (ut exiftimo) declaratum, \& benè fui natura mobiles, \& à fe ipfis mo tuquouis moueri poffunt, \& moueri uidentur. itaque id mo do inquirendum remanet, num, fcilicet, cometę uapores fint, ab entis, in quo fiunt, natura motuuè accenfi, an à folis luce illuftrati, \& ueluti rapyinıo, Iridesq́ue, \& nubium colores lux cometes. fit tenuibus quideni à uporibus, \&benè in fe ipfos collectis relucens, an ne id quidem, fiquidem (utfequens amplius manifeftabit fermo) uapores, qui eò ufque elati funt, ea tenuitate donati fint oportet, quæ quâtumuis ac cenfa, è proximo tantum uiflis fit, ut quæ quantauis fiat, cö tinua modo fit, uel à fe ipfa etiam, at non magnis diftincta interuallis, cuiufmodi uaporum molem, in fua cometes fit, effe oportet, quauis fui parte, quin punto quouis accenfo un: uerfa fimul accenditur, ftatimó; ac accenfa eft, extinguitur, in fummam fcilicet, acta tenuitatem inuifilis fit, furfumque effertur, neque enim flammæ, qux penitus perire, penitus qú ab fumi uidentur uere pereunt, \& in non ens aguntur; fed, qu dictum elt, ita tenues facte, ut uifum penitus lateant, furfum efferuntur omnes, itaque fi aliorum, qua cometis euenire ui fa funt, quid huiufmodi eas ponere non prohibebit, Comeres folis omnino lux fit à uaporibus in fe ipfos collect is relu cens. age igitur, num huiufmodi fi ponatur, reliqua, quę cometis euenire uifa funt, euenire queant omnia, intueamur.

$$
\begin{aligned}
& \text { Si cometes, qsalis pofitus est, } \text { it, que Cometis enenire wifa, } \\
& \text { funt, euenige poffe omnia. Cap. Terium. }
\end{aligned}
$$

sorometa perrarò apparent, quòd ut tanta uaporum co pia ad quampiam fuperioris coli partem efferatur; qux in fe ipfam colleta folis lucem, $\&$ benè eaz amplam, beneque fplendidam remitrat, diuturno, om nino opus eft tempore, \& plures interdum fimul, \& diueris 


\section{Bernardini Telefij}

in cœli partibus, regionibusq́ue fieri poffunt, \& errantium, in errantiumque ftellarım quampiam ambire interdum, \& cuipiam barbx interdum, caudẹuè inftar affigi, \& nulli inter dum apponi, fed feorfum ab illis omnibus, \& perfe omnino, longeque diuerfifsimis fieri poffunt figuris;quòd uapores $\&$ fuperiore, \& inferiore in colo, \& quauis in utriufque parte, \& figura quauis fibi ipfis coire, \& quam finguli à principio for titi funt,perpetuò eam retinere poflunt, non fcilicet, ueluti \& lun $x$ facies, ita \& cometis figura asfiduè augeatur, imminuaturuè oportet, fed eadem perpetuò feruari poteft, \& feruatur interdum, quòd luna quia fpherica eft, minimeq́ue lu ci peruia,fed undiq́ue dimidia tantum ipfius portio fpectatur, ubiq́ue modo, quę nobis confpicitur eadem, \& à fole illuftratur, portio, ubi ueluti è regione foli expofita eft. Itaque nos ueluti in utriusq́ue medio fumus, ubi uerò in alio ad folem fit fitu; quoniam non quę nobis fpectatur eadem, \& uni uerfa, \& à fole illuftratur, fed ita maior, mino ruè ipfius pars, prout foli luna proximior fiat, remotioruè, utique ipfius facies asfiduè nobis immutetur oportet, \&rexhalatio, quę non ueluti in orbem in fe ipfam collecta, fed in longum, latumq́; extenfa êt, \& folis luce, ueluti \& nubes, quę tenuibus è uaporibus, \& non fummopere infe ipfis denfatis conftant peruia, quin ubi pręfertim fol ei non imminet, nec fubfidet, uniuerfa ab ipfo fpectari, Illuftrariq́ue queat, \& uel fi non uniuerfa, fed altera modo ipfius pars à fole illuftretur, reliquam vniuer fam, folis lux permeat, itaq; \& illuftret, nihil prorfus obftat, \& cometes omnino, quorum altera pars ftellę inftar fplendeat, obfcurior fit altera, huiufmodi ad folem fitum nactos effe, \& rationi maximè congruum eft, \& ipfis penè intueri licet oculis.nam quę maximè fplendet pars, eam folem perpetuò fpectare, reliqua uniuerfa recta in contrariam foli parté protendi apparet, \& non omnes, nec finguli eodem uniuerfo colore,fplédoreque donati apparcnt, quod ueluti noftro hoc in cœlo, ita \& in fuperiore non ęquè in fe ipfos fpiffantur uapores, nam iuxta confpiffation is diuerfitatem, prout uidelicet, magis, minusuè folis lux uaporum fubit molem, \& magis, minusuè ab eius opacitate obfcuratur, ipfius \& relucen tis, \& fubeuntis fpetiem, roburq́ue immutari \& alibi nobis fatis eft (ut exiftimo) declaratum; \& quę noftris à nubibus re, lucet lux, apertifsimè manifeftat, qua fcilicet ab ęquè ijs al- 


\section{De Cometis, \& Lacteo circulo.}

bis relucens, quod non ab $x$ què etiam denfis relucet fummo pere à feipfa $\&$ fpetie, \& robore differens relucet, \& adeò à fe ipfis magnitudine differunt cometę, quòd $\&$ ingens, $\&$ benc̀ exigua uaporum copia in fe ipfam colligi potelt, \& non perpetuò cometarum omnium eadem forma,fpetiesq́ue, \& $\mathrm{ma-}$ gnitudo feruatar, fed harum quęuis interdum immutatur ; quòd \& uaporum moles non xquè perpetuo fibi ipfi coit uni uerfa, fed benè in fe ipfan interdum confpiffatur, interdum uerò laxatur, \& imminuitur etiam, interdum \& diu durare poflint, quòd \& uaporum moles diu eadem feruari poteft; nam uapores mutuoò fefe côprimere fummopere quidem aduerfantur, at mutuò fefe contingere, mutuò fcilicet fefe foue re fummopere appetunt; $\&$ ab ijs, qui afsiduè efferuntur, uel $a b$ alijs alia à cœeli parte aduenientibus longè egerrimè diffolui poflunt. nam fi per fuperum etiam colum uapores, qui eo ufque elati funt, mọentur, tanta certè ipforum copia in unum ut cogatur, à cuius occurfu cometes diffoluatur, ad ip fumqúne ut feratır,perrarò certè eueniat, \& nequaquam cœli, in quo fiunt, more ab oriente occidentem uerfus omnes, fed è contra nonnulli, ex nonnulli etiam a feptemtrione ad allftrum, \& è contra, funt \& qui mxkis, incertisq́ue, \& qui contra,nullis unquam moueriuifi funt motibus, quod benè fui natura mobiles uapores cùm fint, quò ipfis commodius, iucundiusù̀, aut expeditius eft iter, eò moneri poflunt,eoque asfidue mouentur, \& quoniam per ens feruntur, quod longè rapidisfimo, \& nunquam ceffante circumuoluitur motu, \& quod non purum perpetuo uniuerfum, fed cuius itidcm par tes quafíam uaporibus obfeptas effe arbitrarilicet, fi non thno, codemq́uc cometx omnes, nec finguli uno, certoq́ue feruntur itinere, uel fi diftincte horum diuerfitatis caufam intueri non licet, mirari tamen non licet, qui porrò immobiles apparent, proprio ij fortè motu, at enti, in quo fune, contrariam moucntur in partem, Itaque ab illius motu reprefsi, im mobiles remanent, reuoluentium orbium ritu, quos Ariftoteles orbibas, quortum motus inferioribus communicandas non erat, fuppofuit, qui fcilicet, quod eadem, qua fuperiores uelocitate, at contrariam feruntur in partcm, eoque $a b$ illis retrahuntur, quò ipfi progrederentur, nullo prorfus mouêtur motu, uaporum omnino ritu, qui, noftro in ccelo pafsim omnifariam moueri apparent, motibus ${ }_{2} \&$ dubio procul, ijs af 


\section{Bernardini Telefij}

fiduè mouentur, quibus compresfonem uitent, \& libero, pa zenteque fiant in loco; ita, \& qui fuperius ad colum elati süt, quibus ipfi mouentur motibus, uel boni certè cuiufpiam cō fequendi, uel cuiufpiam mali uitandi gratia mouentur. nam fi adeò in amplo, adeoq́; profundo, \& tenui entelongè ęgerrimè loci angultia comprimi polfunt, at tot certè interdum quapiam in parte fieri, quot comprimanturomnino, quòd ad ampliorem certè libenter ferātur locum, exiftimare licet, forte, \& à ftellæ cuiufpiam, uel a cuiufpiam coli partis natu xa alliciuntur; nam fi eadem \& ftellarum omnium, \& cęli uni uerfi natura eft, quia copiofior, quàm colo ftellis ea ineft, \& ę fummopere à fe ipfis magnitudine differunt, \& cœli partes non què à fellis diftant omnes, utique \& ftellarum, \& magis etiam celi partium uires fummopere à fe ipfis differăt oportet, tanta porrò uaporum copia afsiduè è terra eductas, \& ad ccelum elata,nihil tamen, uel terra imminui, uel colum excrefcere apparet unquam, quòd uapores nimis tandem au Çi,nimisque in fe ipfos confpiffati, \& propterea grauioreś quid facti,uel fponte deorfum deuoluuntur, uel à cęli motusi celloque ipfo deturbãtur fortè, $\&$ in aquas tandem coguntur, \& I diluuia non ibi funt, ubi infima he coli portio nimis au\&a, itaque \& nimis eft confpifata, ibi funt, ubi fuperiore in colo ingens uaporum copia collecta eft. It aque quoniam cometa è magna renuium uaporum copia fupero in loco col lecta, fiunt, eaq́ue diffoluta, \& inferiorem ad locum deuoluta pereunt, \& ipfi infe, (quod facum afsiduè tradunt) cometas magnos pręfertim, frequentes q́ue, aut plures, magni uen torum fiatus pręcedunt, comitanturq́ue, \& fubfequuntur; nä ut magnorum etiam principum interitus, bellaque, \& qua bella fubrequuntur mala, pręnuntient, nobis quidem intelligere non licet, nullis apparentibus cometis illa omnia paffim euenire, $\&$ ijs apparentibus, illorum nullum interdum, quin bona omnia fieri, \& non ubi Regum corpora ficciora quid funt, fedubi aliorum regna occupandioccafo faculcafuè fit, bella illos moliri, inferreque intuitis, \& quòd colum qurque temporum conftitutiones graues, pefti-lentesqúc humano generi funt, non Regibus eas magis, quàm hominum uulgui; quin huic, quàm illis magis, ut qui cceli uiribus, iniurijsq́ue minus expofiti fint, graues effe, nocuasq́ue intelligentibus. Ageporò lactei circuli. 


\section{De Comeris, \& Lacteo circulo.}

conditiones, motusque intueamur, \& ex iis quid irfe fit , inquiramus.

\section{Lactei circuli conditiones, \& quid ip fe fot. Cap. 2atrown.}

120 A Aeus circulus haudquaquam Cometarum ritu, nihil pręexiftens oriri, \& certo cöfpeQtus tempo re penitus deficere, \& ipfus interea magnitudo, fpecies, figura, \& fitus parsim immutari, \& proprijs interdum moueri motibus, fed ftellarum more perpetnò lucere, \& eadem ipfius magnitudo, fpeties, fi gura, fitusq́xe feruari, \& fupremo cum cœlo, ftellisq́ue, que ipfí infixę uidentur circumuolui, \& harum fingulę in eadem ipfus parte, in eademq́ue à fe ipfis diftantia, fituqúu permanere apparent, \& earum nullius, nec lunę etiam fpeties ab ip fooccultari, immutariuè, quod unus omnino idemqque ipfe ijfdem, eodemq́ue modo pofitis ftellis diftinctus uniuerfa è terra perpecuò fpectatur, 8 in ijs fupremoque cum collo uno perpetuo,eodemq́ue circüuoluitur motu:huiufmodilacteus circulus cum fit, utique fupremi cceli portio fit neceffe eft, quęuel eandem lunę fortita difpofitionem, lunę ritu folis ad nos remittat lucem, uel paululum quid magis, quàm luna in fe ipfam confpinata perfe unilis fit, lucidaque. Neque enim culus. fi non celi portio, fed ueluti adnentitia res fit, perpetuò ipfus magnitudo, figuraq́ue permaneat, fed utraque immutecur tandem, nec perpetuò lnceat, nifi uel fui natura lucida fit, uel que ab eo relucet lux, a quane nunquam immutetur; \& à fole omnino ea nö uidetur, fed penitus tandem obfcuratur: \& nifi ftellę, que inhętere apparent, uere inhęreant omnes, itaque uno cum ijs eodemǫue mouentur motu, fed rabluna ris cœli aftectio guegdam fit, hand quaquam earum fingula in ijfde ipfias portionibus locatę uniuerfa è terra petpetuò fpedantur, nec (quod uapores eò tenuiores faciút) nhil ftel laram, lunęue licem abdat, immutetur unquam, fed fingule alijs è terris,alijs in ipfius partibus pofitę,quin (quod fuprę mi orbis motum is non adęquat) ijfdem etiam è terris ftella fingulę in alia tandem illius pofitę apparent parte, 2 afsiduè ftelle cuinfpiam, lunęq; lux obfcuretur, im muteturuè, ù nulli dubiumefie gqueat lacteum circulum, quod dicum eft, fu- 


\section{Bernardini Telefij}

premi orbis portionem effe, \& lucem, quæ ex ipfo aduenit, uel propriam ipfius effe, uel ab eo ueluti quopiam à fpeculo relucere, \& à fole cùm illuftretur nequaquam, nequaquam ta men lunæ ritu, non perpetuò uniuerfa ipfius fuperficies, quæ nobis confpicua eft, fed maior afsiduè, minoruè eius portio à fole illuftratur, \& ipfius interdum deficit lux, fed uniuerfa perpetuò fplendet, nihilque eius lux deficit unquam, quod non ut luna, foli fuppofita eft, fed adeò eo fublimior, ut quin perpetuò $a b$ eo ill aftretur, nec terræ, nec lunæ etiã ipfus um bra obftare queat, qux fcilicet priufquam ad eum attollatur, penitus deficit.Ita porrò hanc itidẽ cœli portioné cófpiffatã fuiffe, exiftimandum eft, quòd ut entia, qux uniuerfo à ç̧lo; \& à denfioribus præcipuè eius partibus è terra fiunt, qualia fiunt fieri pofsint, hanc ipfius portionem ita confpiflandam, tantum fcilicet colorem ei indi of ortuit, quin \& cometę, uel fi ( ut uifum eit) ueluti ex accidenti quodam, \& calore cmnino iuxta proprium agente, operanteque ingenium fiunt, in entis tamé cuiufpiam bonum factos effe exiftimare licet: fiquidem longè plurima, quę neceffario, \& (ut diqum efi)ca Jore iuxta proprium agente, operanteque ingenium, in animalium corporibus fiunt in fummum animalis bonum, com modumq́ue fiŭt, \& qui in mari,terraque ingenerantur uapares, neceflariò utrique cùm ingenerentur, \& neceffariò illi cü emergant, fummo emergentes mare afficiunt bono, benè fci licet calidum. itaque \& quòd moueri fummopere appetat, opufque habeat, ac crafsius, corpulentiusque quàm ut à fe ip fo moneri queat, uarijs exagitant motibus, \& per aerem utri q́ue necefiariò (ut alibi declaratum eft) fluentes fummum ei afferunt bonum, motu fcilicet \& ipfum gaudentem, indigen em que, \& à terra frigore ueluti torpidum facium, \& mó tibus coercitum, moueri omnino impotentem, in montef $q$; adigi reformidantem, a fsiduc commouent, afsiduè fcilicet, \&inare, \& aerem ad propriam agunt operationem, qua fummopere oblectantur, \& feruari etiam uidentur entia. At age quoniam Ariftoteles i cometas, \& lacteum etiam circulum ćuaporibus accenfis, \& utrumq́ue in ente fublunari fieri de cernit, ipfus de utroque fententiam exponamus, examinemusque. 


\section{De Cometis, \& Lacteo circulo.}

\section{Cometas ex exhalationibus accenfis fieri Arifotelis videtur. Cap. 2uintum.}

5. Aufam inquirens Arift. cur \& alix famm $x$, \& ftel $\lfloor x$, que profilire uidentur, qux ex eadem qua co meta materia,eodemq́ue quo ij modo qui prixfertim fuperiore fiunt in celo, fieri, idqúte tantū à cometis differre uidentur, quòd citò ille pereunt, ij uerò diu lacent in ccelo appareant, horum omnium (inquit) alioramq́ue multorum principium hoc eft. Củ em terra ui folis incalefcit exhalationem fieri neceffe eft non il lam quidem unam, ac fimplicem ( ut aliqui exittimant), fed duplicem, unä, qua magis uaporfit,alteram, qux magis fpi " ritus, \& uaporem,eam efle qux ex eo humore elt qui intra, \& " fupra terram continetur: qua autem terræ exficcatæ elt fumi " dam, quarum ea qua fpiritus naturam habet, ob calorẽ emi " neat, qux:aitem humidior præpondere fubfidat, obeamq́ue ", caufam id, quod ambit, hoc ornatu, \& ordine difpofitum eft; ", primum quidem fub conuerfione calidum illud, \& ficcum ", eft, quod ignem nominamus, nam quod fumidre omni ex-" cretioni commune eft, nomine uacat, fed quoniam, quod" eiufmodi eft, maximè omnium corporum fuccendi natura", poteft, nominibus hoc modo utamur neceffe eft, infrà hanc" naturam,aer eft: Ac illud quidem animo concipiendum eft, ", hoc quod $\pi \hat{u}_{p}$ ideft ignem ueluti i isérnavuse, hoc eft fuccen-", fionis fomitë, nominamus, circum extremum globi qui ter ", ram ambit, ex tenfum effe, ut fimul, ac leuiter fuerit commo ", tum, ardorem quafi fumus fxpe conficiat. eft enim famma", fpiritus ficci feruor. Q Q igitur ex parte conftitutio eiufmo-" di Idonea maximè fuerit, cum à conuerfione aliquo modo" agitatur, incenditur. fed pro materix, qux incenfioni apta", eft copia ac fitu differêtia exiftit, nam fi in latum , \& longum ", ea materia expanfa fit, ardens fxpè flamma confpicitur, qua-" lis eft ftipulx qux in agris incenditur: $f$ autem in longitudi ", nem folùm diftendatur ea, quæ \& faces, \& caprę, \& ftellæ no" minantur. Tum cometarum conftitutionem explicans, fofi-", tum a nobis (inquit) elt eius mundi, qui circa terram eft, ". Meteo.s. partem primam, qux conuerfioni fubeft, eam omnem exhala $7 . t .42$. tionem effe calidam, \& ficcam, ac eam quidem unà cú aeris 'o

$$
\text { B magna }
$$




\section{Bernardini Telefii.}

25)

oportebat, maximèque opus erat nihil principiú à quo, nec modum omnino explicat Arift, vfquam, quo ignis elementü exhalatioǵue è longè tenuisfima, \& quæ vel non continua, fed quibufdam diftincta interuallis (in huiufmodi enin ftel $1 x$, qux currere uidentur Arif. funt) quauis fui parte, $\&$ pun cto quouis accenfo uniuerfę ob materix ( $v t$ ipfe inquit) ha bilitatem incenditur, itatimq́ue uniuerfa abfumitur, in fummam fcilicet acta tenuitatem inuifilis fit,vt ftellx (quę dicte funt) declarant, adeò denfa, craffaque fiat, ut denfisfimarum rerum ritu à flammis contacta inflammari, \& qux eius porio infammata eft, diu omnino, inuifilemğ'; tenuitatem agi 


\section{De Cometis, \& Lacteo circulo.}

renitatur; itaque adeò diuturnas fufficiat in flammas ; at los cum modo in quo cornetx fiunt declarans à cœli, ftellarum motu exhalacionem denfari innuit, cum (inquit) in infero Tex.4\% loco concretion is principium fuerit, perfe crinita ftella apm " paret, cam uerò exhalatio fub aliqua fteila errahte, uel non er " rante motione concreuerit tum harum aliqua crinita ftella " eficitur.itaque qui ipfum feetati funt non fatis id ab ipfo de " claratım, \& amplius omnino declarandum intelligentes, ibi (inquiunt) exhalatio denfatur, aptaque ad cometë nutriendum fit, vbi exhalatio multa, \& non pura, fed cui uapor commiftus fit in feipfam colligitur, fiquidem uapor quia humidus eft,altera videlicet peripateticis natura igni contrarius eft, eius attioni renititur, itaque non ftatim ab co abfumisur,praterea \& collx inftar exhalationem cogit, agglutinatq́ue, $\&$ non à commifta modo, fed à contigua quidem, at feiuneta omnino humiditate tenuitas, \& ignis omnino elemë tum ob fubiecti aeris humiditatem denfari, peripateticorú nó poftremis videtur:\& alij, quin \& cęli (inquiưt) motus ex halationem denfat, non enim difgregandi folìm, laxandiq́; fed congregandi etiam facultatem motus obtinet ubi qua-m dam naturx ad eft diffofitio, Idque Arift. etiam comprobăt teftimonio, cui fcilicet salor â liquandi, \& cogendi facultate donatus, \& diuerfas nactus rerum difpofitiones iuxta vo tramq́ue agere uidetur: funt \& qui nihil modum quo exhalatio denfetur, inquirentes, fed denfam (ut uidetur) craffam que talem omnino fui natura efle fupponentes ut facile accendi,diuque flammas nutrire queat, itaque modum tātum in quirentes, quo nihil à fole tenuior fiat, fed craffa, denfaque \& diuturnas ad flammas nutriendas apta remaneat ubi (inquiunt) folis lux obliqua, 8 è longinquo exhalationem ferit, nihilab illa tenuior fit, fed denfa, craflaqu manet.

\section{Cometas ex exhalationibus accenfis fieri prorfus non poffe. Cap. Sextum.}

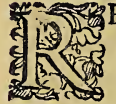

Etè quidem Ariftoteles exhalationem in qua come tes flamma nimirum accendenda eft, benè fplendi dā,beneqúue diuturnä,benè denfam, beneq́ue craffam oportere effe ftatuit: manifeftè enim qux tenui bus in rebus fiunt flammx, neque adeò è longinquo, nec diu

$$
\text { B } 2 \text { om- }
$$


omnino lucent, fimul ac accenfę funt, pereunt, ita fcilicet tenues factæ, vt uifum penitus lateant, furfum efferuntur, vt nö modóflãmas omnes, quæ in exhalation ibus quibusvis fiüt, $\&$ ftellæ ( ut dictum eft) quæ currere uidentur, declarant, fed. hoc noftris etiam inflammis intueri licet, qux tenuibus in rebus, uel incrafsioribus etiam funt : at quibus multa inef tenuitas, qua fcilicet ftatim accenduntur omnes, ftatimque atque accenfr funt, in inuifilem act $x$ tenuitatem, furfumque elatæ, in non ens act apparent . quæuis fcilicet flamma, \& quauis accenfa in re, nullo propemodum ipfa durat temporis momento, fed ftatim perit, ftatim uidelicet adeò tenuis ea,leuisq́ue $a b$ in exiftente fit calore, $v t$ penitus inuifilis fiat, furfumq́ue efferatur, \& quod cium id agit calor, aliam inte-, rea, penitufque ei fimilem, \& e fubiecta educit mole diu. eadem durare videtur:itaque qux in modica accenditur ma, teria, ftatim penitus perit, quòd nimirum materia nulla adeft, è qua flamma alia fiat, quæ in abeuntis illius fuccedat lo cum, quòd diu omnino flamma durct, nó tenuitas, in qua ac cenfa eft,præftat, nec pręftare omnino poteft, ftatim enim(ut dictum eft) fumma ea, $\&$ inuifilis prorfus fit, fed fubiect $x \mathbf{m a}$ terię copia, habilitafque, \& denfitas omnino.rectè itidem $\mathrm{cx}$, halationem, è quà ueluti nutriendus eft cometes, haud quaquam ei, quæ cometis principium uideri poteft, circumponit Arift. ita enim fibi ipf, uniuerfa fi coeat exhalatio, uniuerfa omnino fimul incendatur, itaque neq; uniformis, nee. diuturnus fiet cometes, fed in longum eam oltendit, eiufque, portioné, quẹ fuccenfę, cometifcilicet fubeit, asfiduè ad eú efferriftatuit; at rectè ( $v t$ dictum ent) exhalationi, quę come tes futura eft, difpofitionem, figuramque tribuerit, quę diuturnus, continuufque ut fit Cometes pręftare poffunt. non re etè ( at uidetur) nihil modú nofedocet, quo exhalario, quę inferiore in cœlo quouis à calore, $\&$ à motu quouis accendi videtur, \& quę uel continua fi non fit; (fed cuiufmodi ea Ari ftot. eit, in qua ftellę, quę currere videntur funt) interuallis quibufdam diftincta fit, quantulauis fui portione accenfa fta tim uniuerfa accendatur, fratimque atque accenfa eft, longe tenuifsima, itaque $\&$ inuifilis fiat eadem fuperius elata, \& ra pidifsimo cum cuelo circumuoluta motu, adeò denfa, craffaque fiat,vt (quòd diuturnus ve fit cometes, fiat oportet) à ammis contacta, diu tamen accendi renitatur, \& uel priuf-

quam 
quam accenfa eft, uel accenfa etiam benè lŏgo temporis fpa tio, nihil tenuior fiat:nam non crafsiores, fed tenuiores omnino exhalationes fuperius efferri maximè eft rationi congruum; \& quę à fe ipfis monentur, multoque etiam amplius què à cœlo circumuoluuntur, nequaquam à tenuibus denfa, fed à denfis tenuia fieri ipfi in primis Arift. uidentur, quod comete (inquit) magis extra tropicos quàm intra fiant folis, \& itellar:ın mot ıs caufa eft, qui nó folùm calorem excer T.49. nit, fed quod concretum eft difoluit. \& alibi motionem (in " quit) fecernendi, incendendique aeris facultate prẹditum vi " demus,vt ea etiam quę feruntur liquari fępè confpiciamus, ut non id modo incufandus apertifsimè Arift. uideri queat," " quòd rem, actionemque, quę apertifsimè erat explicanda ue ". luti obiter, \& aliud omnino agens innuat, fed amplitus etiá, quod motui opus attribuit, quod perpetuo is deftruere uide tur, nifi forte eiufmodi fint exhalationes, cuiufmodi quę acalore denfari apparent:rectè enim noftri temporis peripate tici,quoniam calor quędam liquare, \& quędam denfare ui-: detur, eius exemplo motui itidem, \& fecernendi, laxandiq; $\&$ denfandi facultatem attribuunt, Quoniam enim motus non quod res commouet, fed propterea eas laxat, quòd caiorem ijs inexiftentem ueluti excitat einfque anget uires, uti-: que fi res commoueâtur, quę à calore denfari, aptę funt, à mo tu itidem denfari queant, itaq; num exhalationes eamdem quam, qux à calore denfantur difpofitionem fortitæ fint infpiciendum elt: quoniam enim ( ut dictum eft) quædam liquare, \& quædam alia denfare apparet calor, \& naturæ uni contrarias actiones asfignare non licet, utique ne idem perpetuò agat calor, diuerfa rerum difpofitio obftet oportet,ca lor porrò (ut alibi amplius dictum eft) promptius quidem mollia, laxaq́ue, \& ægrius dura, denfaq́ue, at fimilaria omni no qux fant, omnia asfiduè mollire, laxareq́ue, amplius $8 \mathrm{r}$ in fummam tãdem inuifilem tenuitatem agere, \& ea folǹm dêfare apparet, que benè disfimilaria \& magna omnino è craffitie, magnaque è tenuitate penitus fibi ipfis immiftis compofita f:nt, 2 ibi omnino tantum, ubi priufquàm crafsitiem emolliat, laxetóute tenuitatem, cui illa immifta, mollis, laxaq́ue uideri poterat, fummam facit, educitóue omnem, itaq; crasfities fola remanet, \& quæ cffugientem illam ueluti fecta tur, benè etiam in feipfam coaeta, durius concrefcit in ens - 


\section{Bernardini Telefii.}

qualis nimirür cui natura eft, talis apparet:at liquido pateat nullam prorfus nouam craf́sitiem à calore feri vnquam, fed prènexiftentem neluti detegi tenuitate) in qua ueluti late bat, fumma facta, eductaque omni huiurnodi cùm fint qua à calore denfari apparent, exhalationes à motu denfari exiftimare non licetequx fcilicer noitris hammis quibusvis, dü rebus $x$, in quibus factæ funt, adhærent, manifefè tenuio res funt, propterea enim, quod exhalationes promptifsimè faciunt, furfum nö efferantur, fed rebus in quibus factę funt inhęrent, adhuc quod (ut dictum eft) nondum ea tenuitate, itaque nec ea donatx funt, leuitate, qua, ut ab inexiftente calore eueh i posfint, donand $x$ funt, hac fortè ijdem animad uertëtes peripatetici, \&\& modum omnino nullum intuentes, quo exhalationes adeò à motu denfari posfint, ut in adeò diuturnas fufficiant Alammas, Itaque rem omnino quampiä ijs immifcendä effe intelligentes, quę illas \& in anguftius co geret, 2 qux infuper ignis viribus ita aduerfaretur, vt nec ip fa, nec exhalatio, cui immitta eft, adeò citò abfumeretur, uaporem ei admifcent, qui fcilicet, \& folus prętto afficit, \& ad munus utrum que preftandum aptisfimus uifus eft, altera.n. fui natura contrarius, \& humidus omnino cùm fit, optimè peripateticis exhalationes colligare continereq́ue, \& igni reniti poife apparet:quoniam enim ( ut alibi amplius expofi tum eft, \& ipfe pafsim manifeftat fenfus) tenuia quę funt om nia, \& ipf $x$ in primis exhalationes, quin in fe ipfis fififate de fatæq́ue corrumpuntur, $\&$ in aliud aguntur ens, comprę fsionem ita odio habent, itaque auerfantur, vt eã modo, vt amoliantur,uel fiper pofitos montes amoliri nihil pigrefcunt, utique ut in fe ipfis denfentur aglutine quodam colligendę, cogédęque funt, \& naturam utramque eamdem, quam ignis fortitx cùm fint, nifi earum altera in contrariam agatur, uèl $a b$ immifta ea ueluti media fiat, ftatim in flammas agantur omnes, \& qur nullo durent temporis momento:ut enim ipfimet inquiunt, quou is fibi ipfis exhalationes coeant, modo fumus tandem funt, \& promptius omnino quàm noftrorum entium aliud quod vis, \& quàm bellicus etiam, qux in illis quàm qux in hoc fiunt flamm $x$ puluis, \& fulfure, falinitroq; \& carbonibus confectus accendantur, \& promptius etiā quę in illis, quàm quę in hoc fiunt flammæ abfumantur: multo Ariftot. exhalationes, quàm res fingula \& quibus puluis cöficitur, 


\section{De Cometis, \& Lacteo circulo.}

fícitur, \& alia quxvis accendi aptiores, \& multò, etiam tenu iores cùm fint, \& rectè ( ut dictum eft) rem, quæ collæ inftar exhalationes cogat agglutinetóue, \& qux diu igni renitatur exhalationi immifcendam effe intelligentes, non recte (ut videtur) uaporem immifcent, $\&$ uapori exhalationes cóglutinandi, ignique repugnandi uim attribuunt, quibus alia dēfandi, conglutinandique facultates tribuëd $x$ funt, \& qux in fuper denfanda, conglutinandaque funt, craffa omnino corpulentaque utraque, \& iila fefe infuper contigendi fummo teneantur appetitu,oportet itaque qua mutuum contactum prohibent, quantum licet in anguftum cogant, nam tenuia quod ubi conftringuntur fumma (ut dietum eft) moleftia af ficiuntur;fiquidem à quibus côprimuntur amoliri ea nố pof funt quantulumvis præbeant exitum, inde elabuntur, \& alia ipfa coltringere nec poffunt, nec uolunt, comprefsionem (ut dictum eft) exofa, $\&$ in propria feruari amplitudine maximè appetentia,gaudentiaq̣ue Ariftoteles certè terram ne concidat, diffolueturque $a b$ humiditate quapiam continendam effe ftatuens, uel fi aerem primo humidum pofuerat, non $a b$ ipfius tamen, fed ab aqux humiditate contineri oportere de creuit, quod nimirú aeris tenuitati glutinis vis indi non pof fe uifa eft, uapores porrò, qui ex aquis, exhalationibus ijs fcilicet, qui è terra educuntur, \& aerem igni altera natura cōtra rios,\& uapores omninò, atque aerem humidum, exhalationes uerò, ignemque ficcum peripatetici ponentes, itaque ua pores exhalationibus immiftos, nè citò hæ accendantur,abfumanturque obftare, \& ignis omnino elementum à fuppofi ti aeris humiditate denfari ftatuentes, proprias pofitiones, non res ipfas ipfarumque naturam, difpofitionemque intuiti,\& fui ipforum obliti uideri poffunt:nā prxterquamquod (ut alibi amplius expofitum eft) uaporum nulli prorfus, nec ipfe etiam ignis ficcus, fed hic, \& illi humidi omnes, \&r ignis omnino aere, 8 exhalationes uaporibus humidiores peripateticis ponendx funt, fiquidem ignis tenuitas aere, \& exhala tiones uaporibus Arit. tenuiores interdum uidentur, \& tenuitas humiditatis propria, \& humiditas omnino Arift. pofita eft, quoniam uapores, qui fupremum ad acrem, ipfumq; ad ignem elati funt, fi non æquè fibi ipfi omnes, \& aer igni, at ille certè minus tenuis eft, cuius ratio nulla prorfus habenda fit, \& humiditas, ficcitafque nulla agendi,fefe fcilicet, effundendi. 


\section{Bernardini T'Telefii.}

dendi vi donatx Arift uidentur, utique, quin uapores omnes, qui coufque elati funt quacumque è re educt fint, xquè accendi, affumique apti fint, quin fcilicet omnes ftatim ac $\mathrm{ab}$ igne contiguntur, accendantur, ftatimque atque accenfi funt, inuifiles fiant, \& quin ab aeris humiditate, ignis denfari nulla queat ratione, ambigere non licet, proprias itidem pofitiones, non rerum naturam, difpofitionemque intuiti, nec exhalatio humiditate omni deftituta, aridifsimorum lignorum, cinerifque, \& fpongię ritu accendi renitatur uereri peripatetici uidentur.verè enim flamma nulla in crasfitie, dé fitateque fit vnquam, fed uel qux in ijs fieri uidétur, uel quæ in pręinexiftente omnino, uel iamdudum genita tenuitate fiunt omnes, \& quibus nulla ineft, nullaque indi poteft tenui tas, nullx itidem in ijs flammę funt unquam, flamma omnino non aliud eft quicquam, nifi tenuitas fummo donata calore nullā prorf is ullis inexhalationibus crasfitiem, fed omnes tenuifsimas cùm intuentur, nec propterea humiditatem ipfis cùm indant ut accendibiles, fed ut condenfabiles fiant, non fcilicet ut accendi pofsint, fed ut accendi, affumique re nitantur, nequaquam uereri oportebat, ne humiditate $f_{\mathrm{Fo}}$ liatæcrasfisfimarum rerum ritu, \& quę propterea accendi non poffunt, quòd nulla ijs ineit, nullaque ingenerari poteft tenuitas, accendi renitantur,minus etiam uerendum erat, ne exhalatio nimis dêfetur, itaque ob nimiam denfitatem accé di renitatur, ueluè minor quàm oportet, non tanta omnino ipfius copia accendatur, quanta, ut reliquis incendium com municare posfit, accendenda eit:itaque qux in ipfius portio ne quapiam accenfa elt flamma, prius extinguatur, quàm reliqux accendantur: neque enim intelligere licet, qui: longè tenuisfima, longeque calidisfima, $\&$ benè mobilis res, longè calidisfimo, asfiduoque, 8 lōgè rapidisfimo circumuoluta. motu,adeò denfari fuftineat, posfituè,ut ob nimiam denfita tem accendi non posfit, \& adeò denfa facta, fefe tamen in fublimi fuftineat: minus enim fufpicare licet, ne cuius portio leuiter commota accenfa eft, reliqux illi continux à famma contactx nö accendantur uniuerfx exhalationes, præfertim in quibus ftellis qux currere uidentur fiunt, quibus qux fupe rius ad coelum elatæ funt nihil minus calidæe minufuè tenties nihil omnino inflammas agi minus aptr uideri foffunt, \& bellicum puluerem intuentibus, qui, \& ipfe nihil exhalationibus 


\section{De Cometis, \& Laqteo circulo.}

nibus calidior, \& bene craffus peripateticis appareat oportet, quantauis \& illarum, \& huius fit moles, \& quantulauis vtrorunque portio accendatur, ftatim vniuerfam accendi, equè fcilicet igni tenuis exhalatio, \& fi non igneo, at proximo certè, \& qui vel à motu excitus, vel à proximo igne fotus, igneus fiat, donata calore, quin ab igne quantulauis contacta accendatur vniuerfo ambigi non poteft : pręterea vt ad Ariftotilem redeamus tantam afsiduè exhalationis copiam d̀ terra à Sole educi, \&c eductam adeo rapido ad cometam efferri motu, que ftatim inflammas cùm agatur, quæ vix accenf $x$ pereant, flammas tamen adeò diuturnas, \& quæ terram vniuerfam, immenfum quid magnitudine exuperent, nutrire queat, Ariftoteli videri potuiffe fummopere $\mathrm{mi}$ rari licet:nobis quidem, vel fi terra vniuerfa in exhalationem foluatur, eaq́ue ad cometem efferatur omnis, nè noctis quidem vnius fpatio ad adeo vaftam flammam nutriendam fufficere poffe exiftimandum videtur:quoniam enim (ut dictũ eft) flamma quxuis nullo propemodum temporis durat momento, \&xexhalatio adeo accendi apta Ariftotelividetur, vt vel continua qux non eft, fed interuallis quibufdam diftin cta quantulauis fui parte accenfa, nullo temporis momento reliqux accendantur omnes, \& accenfx nullo itidem tempo ris extinguantur momento, fummam fcilicet agantur in tenu itatem, itaque \& inuifiles fiant (ex huiufmodi enim vt di ctuin elt, \& ita omnino ftelle, qux currere videntur Ariftoteli fiunt) vtique vt detur Ariftoteli non dandum omnino, ex halationem, quę cometę veluti appenfa eft, non vniuerfam fimulaccendi, at continuus certè vt fi cometes fingulis tem-poris momentis, \& afsidue omnino ex exhalationis mole ad cometem afferatur oportet qua ( $v$ t dictum eft) terram vniuerfam magnitudine exuperet, quoniã enim fipremas apud. ftellas cometæ fiunt, \& vel harum maximis multo illis apparent maiotes vtiq, immenfum quid terram excendant ofor tet.cometx prxterea qui prefertim fupremo in celo fiunt, fi in exhalationibus accenfis fiunt, modus omnino peripateticis inueniendus eft, quo qux bene quidem tenues, beneq́; in flammam agi aptę, at nondum certè integra ignis natura, nec ea donatæ tenuitate, quę vel accenfa inuifilis fit, è terra ad colum elatx funt ab igneo iam correptx calore in fummam que ab eo, 8 inuifilem prorfus act $x$ tenuitatem è colo ad ter

C ram 


\section{Bernardini Telefij}

ram delabantur, nifi enim id fiat, neceffariò cœlum afsiduè excrefcat, \& afsidue terra imminuatur, vniuerfaq́; tãdemin cœlum agatur, quin \& modis declarandus Aritoteli erat, q:o elemétum, q'ud cęlo fub eit, fuccenfsionis fomes adhuc remanct, \& non diuifam, quin infinito tã tempore accenfum, \& verum in ignem, verafquè actum eft inflammas.quoniam enim adeò accendi actum eft, vt fimul ac leuiter commotum fierit, accendatur, \& fi quidem tale nō fuerit, à fuperiorú corporum motu fieri pofie Ariftot.videtur, \& quocunque omnino modo eius portio talis fit, reliquú vniuerfum fieri poteft, itaq; \& fat tandem oportet, vtiq; infinito tam tempore à' cœlo Ariltoteli circumuolatum, infnito itidem iam tempore accenfum, inflammatumq́; fuerit oportet . Quoniam igitur modis, quo ita denfari, itaq; temperari exhalatio queat, $v t$ diaturnam in fammam fufficiat, reperiri nullus poteft, vti que cometas ex exhalationibus accenfis ficri, ( \& quod Ariftoteli placet) cometem lucem effe in exhalationibus accen fam exiftimare non licet.

Q Oue cometis attribuit Ariftoteles loca, \&r non rectè ea attributaefe. Cap. Septimum.

Primo

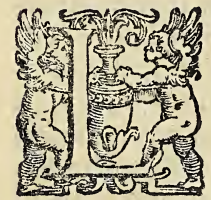

$\mathrm{OCVM}$ porrò, in quo cometę fiunt nos edocens Ariftoteles, \& fiperius ad colum, quod fcilicet diuerfa à fublunaribus natura donatum effe ftatuerat, vapores efferri itaque, neq; cometas in illo fieri poffe fupponens, cum ( inquit) infero in loco concretionis principium fuerit perfe come

„ tes apparer, cum autem exhalatio fab aliqua ftella, feù ", errante, feù inerrante motione concreuerit, tum ha„rum aliqua cometes efficitur : Ipfis enim ftellis comæ " non funt, fed perinde, ac coronx, quæ folem, ac lu"nam ambire, $\&$ ea quamuis locum mutantia, confequi viden"tur, cum fic aer fuerit denfatus, vt hae affectio fub folis curfu ", oriatur: fic coma in ftellis corona locum obtinet; fed hęc qui ", dem ex rellexione talem refert colorem, illic autem eo, qui ap " paret, colore inficiuntur, at cum ad ftellam concretio fita fue", rit, cometes eodem quo fella motu moueri videatur neceffe э) ế:cùm autem feparatin cỏcreuerit, tuin derelinqui videtur. 


\section{De Cometis, \& Lacteo circulo.}

Müdi enim, qui ad terrả pertinet, talis, ef motio.Quod dietú fcilicet, \& cometas omnes fub luna, nullos prorfus fupremo in cclo feri fupponens, \& illorum alios ftellis affixos, \& cum ftellis circumuolui,alios feotum à ftellis fieri, \& circumuolui quidem \& ipfos, ac non eadem, qua ftella velocitate intuens omnes in ente fieri, quod cum cęlo circumioluitur, at alios quod exhalatio à ftella forte concreta, \& veluti ftellę opus ad ftellam quod licet elata, \& quod licet ftella proxima fit fuperiore in loco, \& ignis in omnino elemento, hos vero inferiore in loco, eaque in acris regione, qux \& ipfa fi, quod ignis facit,cęli motum non æquat cum cęlo, \& ipfa tamen circumuoluitur, fieri decernit . Cęterum cur adeò illi à ftellis remoti, ftellis tamen afixi appareant:nullam, vt videtur, rationem af fert Ariftoteles \& euenire id poffe, coronarum exemplo, nos admonet, qux fcilicet, \& ipłæ quàm longifsime à luna, foleq́; cùm abfint, ca tamen ambire apparent, noftri temporis peripatetici propterea, id euenire affirmant, quod ftellæ propinquum cùm fit cometx fpatium, q:10 ab ea abeft, dignof ci nó poteit, \& vel fi fimul cum lteila nö circumuoluatur, fed valde ab ea digrediatur, quoniam è longinquo ip forum diftantiam intuemur, nihil eam percipimus: itaque ftellæ perpetuò coniunctas apparet cometes, \& valdè omnino à nobis rcmota quę funt, vel fi valde etiam à fe ipfis diftent, vbi in eadem $v i-$ fui funt linea, coniuncta videriorizont is exemplo comprobant, qui \& fi quàm longifsimè à terra abfit, ob itineris tamé diftantiam illi coniunctus apparet; fecus autem qui inferiore fit loco, quoniam enim multo quàm ille nobis proximior, multoq́; quàm ille amplius à ftella abeft interuallum, quo ab ea diftat minimè nos latet, \& quantulumuis à fiella digrediatur illico eius digreflum percipimus, ftellæ praterea, in quiunt, lux cum cometis luce, qui in fuperiore fit loco, quia proximior ei eit, facilius, quàm cum inferioris congreditur luce;cometas, fi non omnes, at eos certè qui ftellarum cuipia appofiti apparent, fupremo in cçlo, \& ipfas omnino apud ttel las, quibus affixi videntur, fieri ambigere nó licet,neq; enim Impugna fi fub luna \& ipfi fiant, \& tanto à ftellis diftent fpatic è terris quibufuis, quod pafsim euenire videtur, fellis ijfdem appofiti,affixiq́; appareant, non eamdem omnino vniuerfa è terra vllam ad ftellam, fed aliunde aliam ad ftellas fingulas cbtineant pofitionem, \& cometes qui nuper,ftellaq́; a mplius, que

$$
\text { C } 2 \text { (ut }
$$




\section{Bernardini Telefij}

Ii.2.c.17. (ut dictum eft) paucis ab hinc annis in cafsiopex figno confpecta eft,ille quidem fupra folem, hæc uera fupra Saturnum noftri temporis Mathematicis confpecta elt,minus etiam ne vapores tenuiores præfertim qui funt, eousq́; nobis efferri polsint, quoniam enim Ariftotelis rationes quibus cęlum di uerf $x$ à fublunaribus naturæ effe aftruit fatis (vt videtur) in comentarijs de rerum natura, reiectę funt, $\&$ ens quod terram fupremasq́; inter ftellas medium eft à luna, eademq́; vniuerLib.r.e.3 fum natura conftitutum, \& cuiufmodi ipfo afpectu apparet vnum, idemq́; effe vniuerfum in ijfdem itidem declaratü eft comentarijs, nihilvererilicet, nè qui ad lunam vfque clari funt vapores, ad fupremas ufque ftellas efferri queant, nec

Bafil. Theologorum quorumdam opiniones obftant qui fufi ęris In Hexa- inftar denfum ponunt, fatis h $x$ enim a Bafilio magno reiecte mor. funt, dãnatxq́; in tertia eius homelia, nec tamé,inquit, ipfum firmamentum iuxta vulgatam acceptionem, ex qua videatur ortum habuiffe, aut aqux inglatiem concretx, aut chriftallinæ naturæ fimile, aut folidæ alicuius naturæ, ex ijs igitur nulli fimile firmamentum efle cenfemus:eft enim puerilis, fimpli cifquè profećtò mentis tales de corporibus cęleftibus opinio nes habere, ob id ipfam cœlum, aut ex vno fimplicium corfo rum, \& hoc ex igne, aut ex omnibus miftionem habere non fine maxima ignis parte afferere nobis placet : qui iam $a b$ ipfa diuina fcriptura ita inftituti fumus, vt nihil ultra $e a$ qu $x$ funt conceffa menti noftræ imaginari, cogitarequne concedamus.itaque expofitę tantum Ariftotelis peripateticortim q́ue rationes examinandæremanent : fiquidem quæ Arifoteles fupponere uidetur, ignis eleméturn, fupre maquè aeris f $c r t i o$ à cœli motu, \& eadem illud, qua cœltum uelocitate, hac uerò tardius circumuoluatur, $\&$ comet $x$ uno omnes, eodemque, $\&$ ab oriente omnino occidentem uerfus moteantur motu, nó perperam fortè Ariftoteles è cometarum motuum diuerfitate, diuerfum ijs locum, \&z fuperiorem ijs, qui ftellarum motuú adxquant, inferiorem uerò $\mathrm{ijs}$, qui ab illis relinq:uuntur attri buat : Quoniam uerò ijfdem in comentarijs fatis eft ( ut exiLib.s.c.3. ftimo) declaratum, uti facræ diuinę litteræ teftantur, quòd ter ram inter, lunaq́ue orbem non fibi ipfi tantum fimile, fed fupremo etiam cuelo eadem natura ijfdem donatú eft uiribus, \& infinita hæc tantum, qux intra montium uertices includitur ipfus gortio ab ijs reiecta, \& à præpotente terræ natura debi- 
debilitata,imminutaq́ue, \& veluti torpida fatta, nullo manifefto moueri uidetur motu, reliqua omnis fponte fuis, proprijsq́ue uirib!ıs fimul cum cœlo circumuoluitur, eademq́ue (ut exiltimare licet) uelocitate, \& comctx (ut dietum eft) nó uno, eodemq́ue omnes, \& ab oriente occidentem uerfus, fed pluribus, longeq́ie diuerfifsimis, \& quibus omnino à cœelo moueri non poftunt, mouentur motibus, praterea \& quod fi ignis, fupremaqúue aeris portio, à coelo (ut Ariftoteli placet) circumıoluaturcalidus, tenuisq́ue \& côtinuus omnino igni aer cum fit, vtique, vel vterque fimul cum cœlo circumuoluatur \& vterque cœli motum adxquet, vel fi aerem amplius, at \& ignem omnin o celum praueniat oportet, nam fi, vt peripa teticis placere videtur, qux longius à colo abfunt pigrius ea trahit cœlum, propterea id eueniat oportet, quod circumuol ui repugnant, \& coelum ipforum naturam, viresq́; nō pęnitus exuperat, id verò fi fit, vtique nec fuprema ignis portio penitus coli motum adxquet, fed \& ipfam cœllim præcedat quid, \& vel infenfile id fi fit, at multis certè in reuolutionibus bene magnum,beneq́; Manifeftum fiat,oportet . poftremo \& quod nifi cometx ftellis, quibus affixi apparent uere ijs adhæreant, haudquaquam (quod euenire apparet) quibufuis è terris eamdemq́; ad ftellam eum dem, fed aliunde alium obtineant fitum, nec coronarum exemplo, qux longifsime à fole cùm abfint, e:m tamen ambire apparent, cometas itidem, uel fi adeò à fellis diftent, ijs tamen appofitos uidcri poffe, fatis Ariftoteles declarauit.fiquidē Coronæx, u el Ariftoteli ipfi alię afsidue, atq; alix fiunt, \& certis modo è terris, \& è quibus fpe Etantur, non ę̨dem ex omnibus, fed alix ex alijs fpectantur, at cometes vnus idemq́ue perpetuò, \& unus, idemque omnibus fpectatur è terris, quod (ut dictum eft) nifi uerè ftellx ap pofsitas fit euenire minimè queat, utiq́ue perperam A riftoteles cometas omnes fub luna, \& fuperiore in loco, qui ftellis affixi apparent, reliquos in inferiori fieri decernit: cometas prẹterea qui perfe fiunt, \& à nullis feorfum inferiore tantum in loco, \& qui fub ftellis fiunt, \& ftellis appofiti apparent, in fu periore tantum firri, ut videtur fupponens, incufandus uidetur. Cur enim utrique non utroq; fieri queant in loco,perindeq́ı $\&$ fecus atque Ariftoteli pofitum ent, qui ftellis affixi apparent tardiore, uelociore autem, qui feorfum à feellis fpeQantur, circumuoluantur motu.itaque non rętè è diuerfa co meta: 


\section{Bernardini Telefij}

metarum motuum celeritate, illorum locum uenatur Ariftotcles;at peius certè qui illum fectantur quod cometx adeo à ftellis cism ablint, ijs tamen appofiti appareant, \& illarum cur fum cum non adæquent, adæquare appareant, illad quidem fpatij, quod inter ftellas, comeramq́ue medium eft, brevitati, hoc uerò interualli attribuunt longitudini, quod nos inter cometamáu \&z ftellam medium eft, nă fpatium, quo amplius fuprema aeris, quàn fuprema ignis regio à fellis diftat ad fpa tium quod fupremam inter ignis fuperfitiem, ftellasq́ue medium eft collatam, conferédum omnino, nullius omnino mo menti uideri pote $2, \&$ quantulum is fpatium fit, quod nos, cometamq́ 1 inter, \& hunc, ftellam que intermedium eft, fi quicquam cometx à ftella relinquatur, minime ei iuncus appareat, minus etiam intelligere licet, fuperiorem cometen, propterea fielle unitum, minimè uerò inferioré tuideri, quod illius lux feila luci proximior cùm fit, hic illa ueluti coeat, qui enim immenfo quodam fpatio quæ diftant, luce fibi ipfis iunctẹ uideri queant, at Age quod reliquum eft fignum, quod cometas reflexione non fieri Ariftoteli indicet, \& num rectè Hippocratem incufarit, intueamur.

\section{Signum quod Cometas reflexione fieri non poffe Ariftoteli indivat infirmum effe. Cap. octauum.}

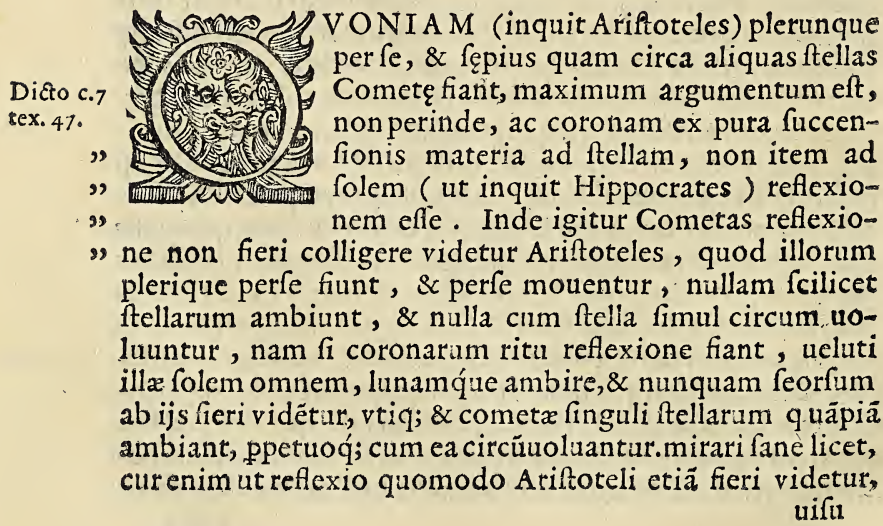


uifu ad nabem, exhalationemó; fublato indeć; ad folë refle xio fiat, non vbi vis exiftat fol recte modo nube ad illum vifis reflecti q 1eat reflexio no fiat, Iris certe refexione, \& in nu be fieri vifa elt quàm longisfimè à fole remota, \& quemuis ad folem nąta fitum, \& lunę portio qux foli,nobisq́; confpicua eft , nibesq́; omnes quemuis ad folem fortiantur fitum ,eius ad nos lacem remittunt omnes, vt non id incufandus Hippo crates fit, quod cometem reflexione ad folem, qué nihil ille ambire, quin qui nullus vbi fpectaturufquam, fieri pofuerit, fed quod ftellam, quam coma ambit nufquam, \& ipfam refle xione fieri,fed perpetuo errantium unam effe, cú quod vifum $a b$ humore ab illa errätium attractum ad folem reflecti pofue rit:nam eodem quo coma modo, \& reflexione omnino ftella itidem fiat oportet, magis autem ftella, quàm coma, barbaq́; fplender, quod exhalationis portio, in qua ftella fit qua reliquis denfior folis lucem puriorem remittit, uel quod ipfa tan tum foli expofita eft, \& unam ad ipfam lux primo, tum ipfa träfuecta,ad reliquas fertur,Itaq; (ut fuperius dictum eft) caur da,barbađ̛́; in oppofitam foli partem perpetuò extếdi vifa eft, $\&$ ut fuperius, \& in iride amplius declaratum eft, qux reflexio ne, \& ueluti in fpeculis fpectantur, non propterea fpectantur, quod vifus ad ea feratur, Indeq́; ad folê reflectatur, quid em ad nubes vfque uifus effundēdus, indeq́; ipfum etiâ ad folem reflectëdus fit, ut folis lucem ad nubes conferat in ijsq́; illam intueatar, qux nullo temporis momento, quaq́; verfus in immenfum effundi, \& à rebus ad quas effura eft omnibus quaq́q; uerfus relucere, \& fpöte fua oculos fubire apparet, fed propte rea fpectantur, quod folis lux ad ea (vt dictum eft) delata ab ijs ad nos relucet, \& à denfis, æqualıbusq́;;,\& albis integra,pu raq́;, (plendida nimirü, albaq́;, quin fol iprénam quia nihil ea fubit, nihil ab eorü obfcuratur opacitate, \& quia nihil ipfam obumbrant, nihil ipfus imminuunt fplendorem, \& quia nullo alieno colorata funt colore nihil illius fedant canciorem, à non denfis verò, inęqualib isḉ; \& \& nó albis ab ijs omnino que fubit, quorüq́; opacitati immifcetur, \& quotum à tumoribus veluti intercipitur, obúbraturớ;, \& à coloribus intingitur, nô integra amplius,paraq́;, fed imminuta fędataớ;,\& vt ad Hippocratem redeamus, id etiă incufandus videtur, quod vifum ab humore à itella attracto ad folem reflecti ponit, nam ne ip fe quidem fol humorem attrahere videtur vllum, fed quem 


\section{Bernardini Telefij}

exuperat in vapores agit, \& ij fponte fua quoq; verfus furfum efferanturà vaporibus, porro in ipfos collectis folis lucem, $\&$ benè fplendidam relucere poffe, in nubibus pafsim intueri licet, quæ nihil interdum minus, quàm cometæ lucidæ fpectantur. Age porrò quod reliquum eft Ariftoteles lacteum circulum conftituentem audiamus, eiusqúue fententiam examinemus.

\section{Lacteum circulum exhalationibus accenfis Ariftoteli fieri videtur; \\ Cap. Nonum.}

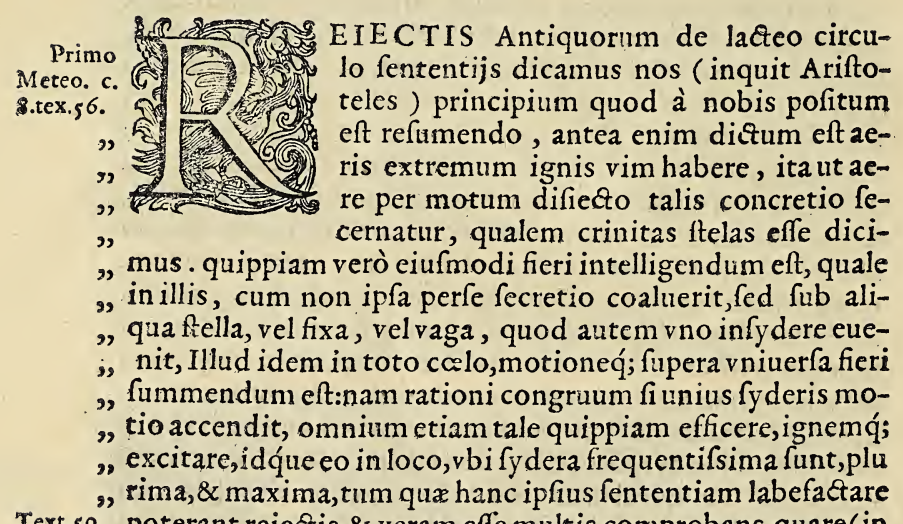

Text.59. poterant reiectis, \& veram effe mult is comprobans, quare(in

" quit) fi caufam cur cometx appareant,vt mediocriter tradi-

" tam amplectimur, de lactis quoque fpetie, eodem modo rem

" habere putandum eft. quxe enim ibi in vno affectio coma eft,

" hanc eaindem in circulo, alio fieri contingit, hacć'; eft,vt (id

"veluti definientes) ita dicamus, maximi circuli qux ex fecre

" tione eff, coma.Ideo(vt diximus) nec multi, nec frepè cometę

") fiunt, propterea quod in hunc locum eiufmodi concretio fe-

"- creta femper fuerit, \& in quoque circuitu continenter fecer-

"natur.fupremo fcilicet aere, qui ignis vim habet à coli motu

" difiecto que in eo talis comcretio facia eft, è quali cometas

* Rellas fieri dictum eit ad locum ftellis fuppofitum, quix 


\section{De Comeris, \& Lateo circulo. I 3}

eo circulo inhwrere apparent cogi omiem, \& ab ipfa xum motu accendi : rationi enin congrum ef fi whius ftellæ motus accendit tot, tantarum tale quidem eficere, ignemq́ue excirare, perpetuunq́ate elfe huac circulum quod einifmodi concretio infta fingulos ftellarum circuitus ex ignis elemento fecernatur, eumdemq́a attrahatur ad locum : Quoniam cometas ex exhalationibus accenfis, cosque, qui fellarum cuippiam appofiti apparent in fublumari ente fieri non pofe, fatis eft (vtexiltimo) declaratum, nihil vtiq́ue examinanda reijciendaq́ue videri poffet Ariftotelis fententia, circulum lactenm ijsdem è rebus, eodemq́ue modo, quo cometas cốlituentis, \& loco in codé collocantis: idq́; modo hunc à cometis differentem ftatuentis, quod non vt, illę ftellę vnius, \& qua breui omnino luceat, fed circuli maximi,amplifsimique $\&$ longe plurimarum felIarum coma fit, \& quę nullo vnquam pereat tépore: quę enim ibi hominem excepere incommoda,eadem omnia, \& multo me hercule ampliora, manifeftioraq́ue excipiunt. itaque uel qui in ipfius verba iurarunt, ipfus poficiones quafuis, vel cux manifeftè rebus ipfis, ipfique repugnant fenfui, quin, \& quę fi bi ipfis penitus contrarię, oppofitęq́; funt, omnes fimul tueri nihil verentur, häc ipfius de lacteo circulo fententiä damnảt, reijciuntque.at vt amplius pofitionis abfurditas innotef $c a t$, illorum quędam amplius, \& fi quid prẹterea circuli laçei con ftitutionem explicans incufandus videtur Ariftoteles intueri nihil grauari oportet.primum quidem mirari licet, exhalatio nem, quę qualis ea eft, quę cometes fit, facta elt, benè fcilicet, denfata elt acre à motu difiecto, à reliqua fecemi, \& lacteú ad circulum vniuerfam efferri, ibiqque à itellarum motu accendi Ariftoteli videtur, potuiffe, nam ut, vt ei detur fiblunare eum à cœli motu difijci,eo difiecto haud quaquam crafsiores, ¿éfioresque ipfus partes à tenuioribus, laxioribusáue feiungi, fepararique, fed in vnum cogi, magisque in fe ipfas vniri omnes, \& fiquidem à fe ipfis feparentur, nequaquam denfiores, grauioresq́ue, fed tenuiores ad lacteum circulam efferri exiftimandum omnino elt, tum \& multo certè amplius tantam exhalationis copiam, \& vna, eademq́ue perpetuo menfura è terra educi poffe, ut (quod dicum ent) ftatim ea cù m accenda tur $_{2} \&$ fimul, ac accenfa eft, abfumatur, \& quę à fole pręcipuè cùm attrahatur, dịcrfifsimè afsiduè viribus; $\&$ in terră agen

D te, 


\section{Bernardini Telefij}

te, cuius difpofitio afsiduè immutatur, longè diueffifsima menfura, $\&$ benè etiam à fe ipfa differens, educatur neceffe eft, in adeo tamen vaftas, perpetuasq́ue, \& vndequaque fibi ip fis vniformes fufficere flammas, nihil vnquam terrę, neque ignis mole immutata, nihil fcilicet terra imminuta, nec igne auto nunguam intelligere licet.

$$
F \perp N \perp S \text {. }
$$




\section{B E R N A R D I N I

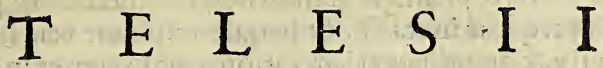 \\ CONSENTINI.}

\section{DE IIS, QVAE IN AERE FIVNT, $\&$ de Terræmotibus.}

2 uivapores pracipue in grandines, plutias, of niues aguntur, quiue in ventos diffunduntur; $\sigma$ modus quo in ea que dicta a unt, illi coguntur, $\checkmark$ quo bi mouentur, inquirendus videridebet. Cap. Primum.

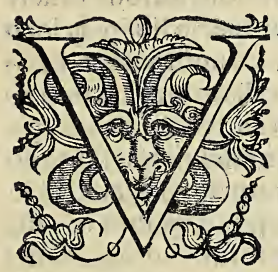

A P O RE S è Terra afsiduè à Sole edu$c i, \&$ exijs in feipfos confpiffatis gran dines, plunias, niuefque côftitui, nihil omninò declarandum videtur, \& omnibus pofitum, plaçitumq́ue, \& quod per fe manifeftum fit:nam \& vapores è Terra oriri, \& in nubes eos, nubesq́; in At neque uentos vapores effe per aerem fluentes dubitare licet, nubes ibi pręcipuè cogi vbi venti fpirant', \& è nubibus eos enafci, \& nubes interdum vniuerfas in eos refolui intuen tibus: fatis etiam per fe patere videtur,eofdem omninò uapo res in grandines, \& aquas, \& niuens cogi,\& per aerem fpirare: fiquidem quibus è nubibus aqua fit, ex ijfdem \& grädo, \& nix fieri, \&r v traque aquę commifta decidere videtur, $\&$ adeò vtra que prōptè,\& negotio nullo in aquã liquefcere confpecta,ea dem penè aqux, ex ijfdem certe vaporibus conftitui videri debet, at vel magis quam aqu $x$ ratio poftulat, in feipfo fpiffatis denfatifque, nel minus.Manifeftè itidem qui fpirant vapo tes, in nubes,è quibus dictx fiunt res, cogi uidêtur: quọniam

D 2 verò 


\section{BernardiniTelefij}

จerò afsiduề quidém è Terris olnnibüs elabuntur vapores, at neq; pluuix, nec grandines, nec niues afsiduè v qquàm fiunt, \& alijs in Terris \& plunia, \& grando frequens, grandisq́;;,perrara in alijs perque minuta fit. Et in quibus fpirant venti, raræ in ijs pluuix, \& grandines etiam rariores, qui vapores in grandi nes, aquas, niues agi, \& qui in uentos diffundi aptiores funt, inquirendum:at multò certè diligentius módus, quo vel ijdê vapores in adeò diuerfas res aguntur, quove in obliquum mo uentur, infpiciendus uideri debet.

2 ui precipuè vapores in nimes, plunias,grandinesg., agus. tur, ov qui per aerem fluunt, ventiǵs apparent.

Cap. Secundum.

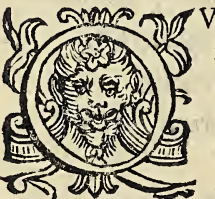

Voniam, ut dictum eft, vel omnium confenfil ac fenfus penè ipfius teltimonio, niues, aquę,grandines è vaporibus funt côcretis, $\&$ in feipfos cöfpifsatis, crafsioribus omni nò factis, fumma donati qui funt tenuitate, inepti omnnnò ad eorū cöftitutioné uideri debent:huiulmodi enim qui funt nec in aperto liberoq́; loco adeò in feipfos confpiffari,at neque ad eò à noftro frigore cópingi poffe videri debent, $v t$ in illorum vllum craffefcant : fiquidem neque aer vllus quantuf goribus fruientibłs quâtumuis, nec tenuifsimi qui funt ven ti,cuiufmodi Boreas ipfe videtur, vel in aquas vnquàm, vel in niues craffefcere apparent: Vapores itaque ex quibus fingula illa fiunt, crafsiufculos effe oportet omnes; at multò certè ma gis qui in grandinem conftringuuntur, qua fcilicet vel afpectu ipfo multò quàm aqua,aut nix crafsior, multoque etiam folidior, è crafsioribus omninò vaporibus compacta videri debet:at contrà qui per aerem fluunt, fpirätq́ue, longè tenuio res; neque enim adeò fint ad motum apti, nec moueantur om ninò, nifi magna donati fint tenuitate, fed immobiles torpeant, \& uel nihil in feipfos impulfi coactiquè, in aquas, aut in niues à nocturno cogantur frigore; veluti qui in rorem, pluuiafquè interdùm, $\&$ in pruinam aguntur. Et manifeftè qua tenuiores funt nubes, in flatus plerunque diffolui apparent; \& vbi rubet Sol, Lunaquè, quod tenuifsimis vaporibus intermedijs euenire Peripateticis êt videtur, vêti gerpetuò füt: at 
vel Ptolomęi teltimonio plauiæ, vbi flauus apparet Sol, qualis per crafsiores fpectari vapores ipfis itidem Perip.videtur.

2uomodo vapares in aquas, \& grandines, o niues Aguntur. Cap. Tertium.

Nam $\mathrm{N}$ aquas porrò craffefcere vapores uel aliud ni

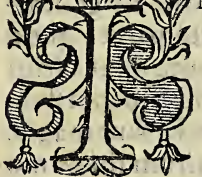
hil pafsi,at in feipfos confpiffati tãtùm, qua cúque id occafione fiat, videri poflunt : fiqui dem dùm in nubes cogútur, quo facto aqua fiunt, nihil omninò aliud pati, nifi in feipfos confpirsari vidétur. Et fi quidê tenuioribus, calidioribufq; partibus fpoliari videantur, at $\&$ ipfum vnius, cófpifsationis, non vlla frigoris opera, quod fcilicet nullü ibi adeftuel in fummo enim calido ambiête pluuię apud nos affid ıè fiınt: \&x pluuius perpetuò ad mótes aer, à quibus qui in eos flaút véti veluti retinétur, \& aliò diffundi prohibétur. $N \tilde{\text { }}$ ad Arabix mötes in lögè ardëtifsimo Sole quotidianæ, vt Pe ripatetici têtătur, $\&$ certis, Itatifq; ferè horis, lógeq; copiofif fim $x, \&$ fummè grẩdes, qux fiut pluuię manifeftè cuentis, qui in eos afsiduè fpirant, fiunt, in feipfos fummè tandê confpiffa tis, $\&$ in aquas coactis. Et fumus quiuis, vel in bene calidis in clafus rebůs, in aquam cogi videtur omnis, vt fi à frigore in aquas cogi vapores interdum videntur, non proptereà perpetuò, vt aqua fiant, frigoris opera opus effe : neque alind omninò, dum in aquas à frigore aguntur, pati ab eo videri debent, at confpiffari tantum. Quod igitur dictum eft pluuiæ è vaporibus in feipfos confpilfacis, efto \& tenuioribus partibus fpoliatis ; at aliud certè pafsis nihil confitutx uideri poffunt: eadem quidem ratione, \& grandines conftitui uideri debent; at è crasfioribus omninò vaporibus, magifGrandique, \& celerius in feipfos denfatis: fiquidem non aliud gran do, quàm aqua bene iu feipfam denfata videri potelt. Et ita omninò vieri inde intelligere licet, quòd magis etiam quàm pluxix, non nifi poft maxima frequentifsimaque tonitrua, poft uehementisfimos nimirum nubium in feipfas concurfus, \& abfque nube nulla omninò fit grando. Nec verò nifi \& vaporum crafsities magna adfit, \& vehementiffima, uelocifsimaq́'te eorum confpiflatio, tandiu in fublimi vapores fefe fuftineant, dium in grandines concrefcant, fed 


\section{Bernardini Telefij}

rel aqua facti, vel res alia intervapores, grandinefq́ue media, decidant omnes. Et grando igitur vt fiat, nulla omninò frigoris opera eft opus ; quin fi adfit frigus, fieri grando omninò nequeat : fiquidem grauiores ab eo facti vapores, non tantam morentur confiffationem, quanta, ut in grandines cogantur,eft opus; fed prius omnino quàm in grandines agantur, decidant. Et nullo omninò frigore ad grandinum conftitutionem opus effe, inde manifeftè patet, quòd vel ubi hyeme fiunt, non nifi in calido ambiente fiunt : frigi dior autem quàm aqua fentitur grando, quòd è uaporibus magis denfatis tenues, calidæque partes extrufr funt magis.

Nix. Nix verò manifeitè frigorís eft opus, quæ nimirùm ibi fit mo do, vbi fummè pollet frigus. Et è vaporibus omninò fieri vi detur, â frigore concretis, gclatifque, \& qui priufquam in aquas cogantur, grauiores facti fint, quàm ut fefe in fublimi fuftinere queant, longè igitur quam aqua, aut grando, candidior nix, longeque leuior, \& qux fi modicum quid fpiffetur, in aquam liquef cit omnis, quòd è uaporibus concret is quidem, fpiffariq́; , iam cxptis, at nondum in aquas coactis, nec ulla fortè tenuitate fpoliatis, conftituta eft .

\section{Cur vapores in obliquum mouentur, or quandiu. cap. Quartum.}

De ventis Verò in ventos diffunduntur, proprio for

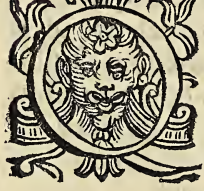
tè motu, fponteque fua in obliquum feruntur; bene enim propria natura mobiles, nec dum aeris nacti tenuitatem, nec ad fuperio rem efferri poffunt locum, nec efferri omninò appetunt. At uel nihil moueri appeten tes à feipfis moueri tamen, impellique uide ripoffunt; quoniam enim teuues fui natura in feipfos fpiffari, deniarique in alienam omninò agi fubftantiam, fummè odio habent, fummeq́ue auerfantur; ubi tanti facti funt, ut locus, in quo continentur plures, aut ampliores eos capere non pofsit ; fuel noui, qui afsiduè è Terra, mariqúc emergunt, eos fubeunt, uel ampliùs ipfi à Sole attenuati ampliore indigcant loco, quacunque omninò occafione propria ibi feruari tenuitate non pofsint; fed comprimantur, inqúue an-. guftius agantur, id ut nitent in obliquum feruntur; \& leui quidem, 
quidem, placidoque motu, fi eo comprefsionem uitatit: Q⿺辶寸 ibi omninò fit, ubi exig aa in aeris parte plures facti funt, quã qui ibi commodè contineri queant; quibus nimirum ne fefe explicent, \& 8 in amplius diffundantur, nihilobftat $: 3$ qui modicum quid à feipfis feiuncti in aperto, liberoque fiunt lo co. Nam ubi aer uniuerfus uaporibus oppletus elt, adeoq́ue ij in feipfos coacti, ut cogi ampliùs non fúftineant, \& uniuet fi fimul ampliores à Sole fiunt, alijque è Terra, mariớue eduCti illos fubeunt, afsiduè nimirum magis vndique comprimuntur, itàque commoti comprefsionem non effugiunt, affid ìè motuni magis concitant, \& rapidifsimo eo tandem, \&w quo qux obitant, omnia amoliantur, feruntur, ut quibus quid uis fuftinendum, moliendumq́ue fit, comprefsionem, ut ui:tent. Et tandiu per aerem fluunt, dum uel apertum, liberúque nancifcantur locum, uel in aquas cogantur, tel etiam longè a motu tenuiores facti , aerisq́ue nacti naturam, $\&$ un $\ddot{x}$ omninò aeri facti nequaquam in inferiore acquiefcant loco'; fed fuperiorem appettant, \& ad fuperiorem ferantur.

Cur vaporeseo motu moucantur, quo moueri videntur. Cap: 2uintum.

NMOPTEREA igitur quotidiani indige-

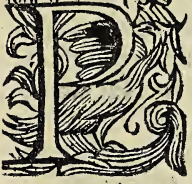
nęq́; qui uideri poffunt uenti , exoriente potifsimum Sole fpirare incipiunt, \& Solem veluti fectantur ; inde fcilicet afsiduè flant, ubi ipfe adeft Sol, quòd vapores amplius a Sole attenuati in contrariam Soli ferantur partem; \& occidente eo ceflant, quòd nihil ampliores facti loco, in quo funt, contef $\mathrm{i}$, nihilinde amouentur. At ubi, quæ in Oceano euenire afferunt, afsiduè qui dem, \& ueluti maris more quafi ftatis, certisq́ue temporibus modo in hanc, in illam modò partem fpirant venti, uel in eundem perpetuò furè : propterea ea euenire uideri poffunt ; quòd longè quidem ex illo plúrimi, aptique in uentos diffundi, afsiduè afcendunt uapores: at neque copia, nec tenui tate ex vniuerfo æquales; fed uel longè modò ex alia eius par te plures, \& in uentos diffundi aptiores, modò uerò ex alia, vel perpetuò ex eadein. Quoniam enim non xquè directus mart eidem perpetuò imminet Sol; nec mare uniuerfum eadem 


\section{Bernardini Telefij}

dem donatum elt profunditate nequaquam in uniuerfo ̨qua Jis t:apo rum copia, nec æquè ij tenues perpetuò: quin uel eo dem in mari a dituerfo Sole, \& in diuerfo mari a Sole eodem cum copia, tum verrò, \& tenuitate differentes uapores fieri vi deri debent: \& a directo quidem Sole, breuique in mari,lon gè quidem plures, at fummè tenues, \& qui ueluti, qui apud nos fummis in eitibus fiunt, nô in obliquum, fed ad fuperiora ferantur: nam \& in fe ipfam, \& a folido, renitenteq́ue maris fundo reflexa lax longè fit robuftisfima. Ab obliquo contra Sole, \& profundiore in mari longè pauciores, longeq́ue craffiores, \&. qui in uentos diffundi inepti uideri pofsint; ut mul ti omnino, aptiq́ue per aerem fluete, in breui quidem mari ab obliquo Sole, in profundiore contrà à direeto,educi exifti mare liceat; \& è parte itaque qua breuius eft mare Sole obliquo facto uentos fpirare. Directo contra inde promptiùs, ubi profundius eft mare;inde omninò afsiduè, unde plures, aptiorefque in obliquum ferri educuntur vapores, \& fatis quidem uapores quò crafsiores funt, eò in niues, aquas, grandines agi; quò uerò tenuiores funt, eò promptius per aerem fluere, manifentatum exiftimo. At fi qua fingulis illis eueniunt, ijs, qux dieta funt, congruant confentiantq́ue omnia; fi fcilicet illorum fingula ibi fieri uideantur, ubi uapores adfunt, qui ad illorum fingulorum conftitutionem apti uifi funt, utique multò id fiat manifeftius;id porrò aperLi.r.e.13. tum fiat, fi qui calor, quali è Terra, qua elabatur in tenuitate, 4. \& 16. inotefcat;uel fatis id itaque in Commentarijs' de Natura con fpectum ampliùs infpicere ne granemur.

\section{2uicalor quali è re, qua elabatur in tenuitate: Mcap. Septimum.}

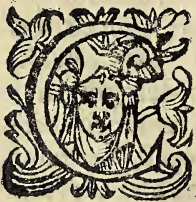

A LOR, qui Terrę à Sole inditur, nequaquam alieno in loco, atque inter contraria immobilis torpere contentus, fed ad cogna. ta entia euolandi , fefeqúue commouendi, propriam fcilicet operandi operationem sümè appetens, res, quibus inditus eft, afsiduè attenuat; tales fcilicet facit, quales euehere, $\&$ in qualibus elabi queat, \& dum utrumque fiat, attenua renunquam cefsat: at utroque peracto, uel fi amplius illa atte- 


\section{De his qux in aere fiunt.}

attenuari pofsint, nihil eas attenuat amplius, fed ftatim euo lat, ut eius non attenuandi, fed è contrarijs abeundi, \& fefe commouendi propofitus finis fit. Qui igitur fummus eft calor, qualis igneus uidetur, è rebus quibufuis ferè fumma ela bitur in tenuitate; quòd nimirum rem, cui infidet, ubi adeo tenuem fecit, ut euehere eam queat, in uapores, $f$. egit : neq; enim crafsius eas euehat calor ullus, nullo ferè temporis mo mento fumma donat tenuitate. At è rebus quibufuis ferè in bene tenui, ut dictum eft, elabens fubiecto, in tenuiore omninò è denfioribus elabitur, crasfioribusq́ue, e quibus uide licet non nifi tenuitati fummæ egreffus patet : \& è quibus fi patêtem egreffum moliri queat robuftus calor, at non ftatim eum nulloq́ue temporis patefaciat momento; diutiùs itaque \& propterea omninò immoratus, quòd elabendi aditus non patet, amplius omninò attenuat : fummus itaque, quod diEtum elt, calor, qualis qui Terris à Sole inditur, perrarò uide ri poteft, ex omnibus ferè, è crasfis certè fumma elabitur in tenuitate. Idem \& languens faccre videtur : ut qui nec paulò grauius onus fuftinere, nec egreflum, uel è laxis, mollibufq̇ue rebus patefacere queat; qui igitur non nifi in fummè te nui elabatur fubiecto. Horum uerò medius non quidem è crasfitie fumma, è qua, ut dictum eft,fumma modò elabatur tenuitas; at \& è liquidis, \& è mollibus itidem rebus crasfiore omninò exilit in fubiecto : qui nimirùm non æquè ftatim, ac fummus attenuare, \& grauius omninò onus, quàm languens euehere, \& quę elabenti obftant robuftius amoliri po teft . Nec uerò ijs, quæ dicta funt, quæ eueniunt diffentire, quin fummè conuenire, congruereq́ue omnia uidentur : è lignis enim igni impofitis tenuisfimus primum elabi videtur fumus; tenuitas nimirum iamdiu à proprio ligni facta calo re, ab eiusq́; crasfitie, ac denfitate retenta egreflum ab exter no ignis calore nacta; nihil dùm amplius lignum exuperante, at modicum quid tantum aperiente: tum crasfior afsiduè fieri fumus; calore fcilicet magis uincente, \& non præexiftenti modò tenuitati egreffum patefaciente, fed aliam infuper ingenerante, nec fummam eam faciente; nondum penitus ligni fubłtantia exuperata, inque igneum calorem acta: at tenuiorem fubinde fumum clarioremq́ue, \& flammam demum; tenuisfimam nimirum, fummeq́ue calidam rem, fummo ligno indito calore:\& löge tenuisfimus aer omnis, ’ 


\section{Bernardini Telefij}

craffa,denfaq́ue eductus Terra ; purus itidem, tenuisq́ue ma rinus, è non fummè quidem craffa, vifcofaq́ue, \& tenaci, fed ex asfidue agitata, commotaq́ue, \& Solis actionem veluti fu giente re : at longè crasfisfimus ex humidisfima,mollisfimaq́ue enatus Terra, multoq́ue è crasfis, ftagnantibusqueaquis magis; quibus fcilicet, nihil Solis actionem vitantibus magnus inditur calor. Nam qux asfiduè fuunt, agitanturq́ue, quoniam Solis vires veluti fubterfugiunt, modicum eæ afiununt calorem : \& proterea ex ijs tenuis enafcitur aer, eoq́ue amplius fi tenues fint, nitidẹque. Tenuis itidem Borealis, montanusqúe aer omnis ab obliquo, languidoq́ue factus, eductusq́ue Sole, at campeftris crasfior omninò, à robuftiore omninò factus calore: fummus itaque, quod dictum eft, $\mathrm{ca}-$ lor, qualis, qui Terræ à Sole inditus, perrarò uideri poteft, non adeo fortè è ualde tenuibus rebus, at ex alijs quibufuis in fumma elabi videtur tenuitate, languidisfimus ex omnibus omninò. Medius verò, qualis qui, vel à robuftisfimo Sole Terræ inditus videri debet, non quidem è crafsis, denfisqúc, at è reliquis Terris omnibus crafsiore omninò elabi videtur in fubiecto. Agè porrò quod reliquum eft, quibus in anni temporibus; à quo nimirum calore, quibusque in Terris grandines, pluuiæque, \& niues fiant, \& uenti fpirent, intueamur,

2uibus in anni cemporibus, quibufque in Terris pluaie, niuefque, o grandines funt, ventique Jpirant, o qui venti quando fereni quandoue plisuij. Cap. Septimum.

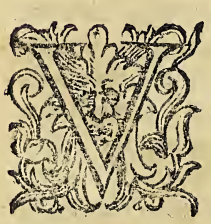

ERE percrebræ quidẽ pluuix,at non valdè diuturna , \& nullis fpirantibus fiunt ventis; Aeftate perrarx, \& qux fiunt, grandiores fiunt: Autumno frequentes veluti \& Vere, at quàm Vere diuturniores, grandioresq́; \& magis etiam fpirantibus ventis; Hyeme frequentiores, 8 z breues, minutxáue, qux per fe, diaturniores vero qua à uentis fiunt, grandioresq́ute. Nities praterea Hyeme in editioribus, frigidioribusq́ue tiüt locis; grandines Vere, Autumnoqque frequentes, grandesq́;;

minus 


\section{Dehis qux in aere fiunt :}

minus Aeftate, \& uel in montanis, frigidisq́ue, uel in humi libus quidem, \& valde humidis, mollibusq́ue Terris; in qui bus omninò \& pluuix, \& niues, \& grandines perpetuò longè crebriores, longeq́ue fiunt copiofiores, \& longè etiam grandiores. In medijs itidem conftitutionibus, magis, quä in fummis xftibus, fummisq́ue frigoribus uenti fpirant, \& editis, denfifve in Terris, atque in mari præcipuè : $\&$ Aufter quidem, Auftroq́ue proximi, Autumno, atque Hyeme plurimum flant, \& pluuij funt; Aeftate autem caliginofi quidẽ, at perrarò in pluuias craffefcunt : Boreas contrà, Boreęque proximi magis Vere, atque Aeftate flant, magisq́ue pluuij funt; Hyeme uerò, fereni plerumque, ipfe prefertim Boreas; alij verò niuofi interdum .

Aquas, Nine qque è crafsis omninò vaporibus, \& Grandines è crafsifsimis conflitui iure vifas fuiffe.

Cap. Octaum.

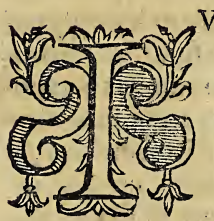

VR E igitur è crấsis omninò taaporibus plì uix fieri vIf $x$ fint; fiquidem Vere, atque Au tumno, \& mollibas, humidisque è Terris h:iufmodi educi uidentur: Boreasq́ue \& Bo rex proximi uenti à proximiore iam facto Sole crafsiores; Aufter uerò Auftroque proximi longè tenuiores fiunt; Aeftate autem longè tenuisfimi uapores : à Sole enim valdè directo, \&zè Ter ra educuntur iamdiu arefacta exficcataq́ue, \& qui ibi in aquas crafefcât modò , ubi plurimi fimul fimmmè in feipfos cô fpiffantur : quod ubi fit, grandiores omninò fiunt pluuix, quales ad Arabix montes in fummè fereno, fummeque calido Cœlo quotidie, \& ftatis penè, certisqúu horis, \& inclinan te omnino Sole fieri Peripatetici afferunt: propterea enim ta les fiunt, quòd vel directus, uel directo proximus Sol tenues quidem inde, \& qui per aerem ftatim fuant, at longè plurimos educit uapores : ij porrò in altifsimos, rectosq́uc adacti montes, neque igitur vlteris progredi, nec in latera diffundi potentes, \& fummè tandem in fejpfos fimul omnes denfa ti , in repentinas, grandesq́ue, \& craflas coguntur pluuias . Qua ratione, \& qux Autumno fiunt, longè quàm Vere gran-

$$
\mathrm{E} 2 \text { diores, }
$$




\section{Bernardini Telefij}

diores, crafsioresq́ue, diuturniores pluuix fiunt : è tenuibus enim quidem vaporibus, at longè pluribus per æftatem om nem collectis, vel ab Auftro, Auftroque proximis uentis, qui plurimi ibi fpirant, minusque, quam per Aeftatem tenues à remotiore iam facti Sole, fiunt. Minutx conrrà, bre uesq́ue, \& tenuiores, qux Hyeme per fe, \& nullis fpirantibus funt uentis; \& minutæ quidem, quòd vt uapores in aquas à frigore agantur, mininè omnes fimul in feipfos ab eo cogan turoportet; fed illorum quocuis $a b$ aliis feorfum $a b$ eo in $a-$ quas craffefcunt : breues autem, tenuioresque, quòd perexigui omninò vapores, perq́ue tenues è conftricta educuntur Terra, afsidueq́ue in aquas coguntur. At quæ à uentis, è ua poribus nimirum aliunde accedentibus fiunt, quoniam è plu ribus, beneque in feipfos confpifsatis, afsidueque acceden tibus uaporibus fiunt, meritò grandiores, diuturnioresque. Et niues itidem iure è crasfioribus, ex ijfdemq́ue omninò va poribus, è quibus aqua fit, fieri; at non in feipfos fpiffatis, fed à frigore gelatis vif $x$ funt : fiquidem nubes exdem in aquas, niuesquue cogi uidentur, \& ibi modò in niues, ubi incre brefcit frigus. Et qui uenti planis, calidisq́ue in locis pluuij funt, niuofi ijdem in montanis, frigidisq́ue fiunt : \& pruina, qux niui eadem uideri debet, è crafsioribus omninò uaporibus à frigore concretis, gelatisq́ue fieri apparet; qux nimi rum in ferenis quidem, \& benò frigidis conftitutionibus, at in mollibus, planiqúue, nulla autem vel in ualde crasfis, uel valde excelfis fit Terris : quoniam enim fereno fit Cœlo, utique è vaporibus, \& ipfa, ut ros, ab hefterno eductis Sole; \& quoniam in planis pracipue, mollibusq́ue Terris, utique nö è tenuisfimis, fed è paulò crasfioribus fieri videri debet: $\mathrm{fi}_{\mathrm{f}} \mathrm{i}-$ quidem \& qui fumma donati funt tenuitate, in niues gelari poffent, utique ir fummis in montibus, multoque mehercu le fieret promptiùs ; in quibus nimirùm frigus, cuius manife ftè, \& nix, \& pruina eft opus, multò fxuit magis:neque enim non in pruinam concrefcant, qui ibi fitunt vapores, quòd, at Arittoteli placet, diffluens ibi aer huiufmodi concretionem

Pruina. diuidat : eadem enim niui pruina Ariftoteli uifa, ijfdemq́ue è uaporibus, è quibus fit nix , conftituta, id modo a feipfis differentibus, quòd pruina è módicis, \& nondum in nubes coactis; nix è multis, \& in nubes confpiffatis : ubicunque fit nix, pruina itidem fieri poffe videri debet. Propterea igitur fummis 


\section{De his qux in aere fiunt.}

fummis in montibus nix plurima, pruina verò fit nulla; quòd è uaporibus illa fit aliunde delatis, hęc uero ex indigenis, \&c è crafis omninò, quales excelfis, praruptisqúce in locis, in quibus lux in feipfam reflecti non poteft, fieri minimè poffunt ; non, fcilicet tenuitas quxuis à noftro frigore gelari poteft, non igitur, vel aer, uel Boreas ipfe gelati videtur unquam, iure itidem grandines è crafsifsimis uaforibus, fummeq́ue in feipfos denfatis fieri uif $x$ funt : huiufmodi enim è mollibus, humidisq́ue Terris, \& Vere pręcipuè,atque Autum no, \& Aeftate etiam editis, frigidisq́ue, \& in fummè humidis fiunt Terris. At neque crasfi tantum dictis in Terris, diAisq́ue in anni conftitutionibus uapores educuntur, fed lon ge etiam plurimi, quot ubi funt, uel fi tenues etiam fint, at fumme in feipfos denfati in grandines craffefcere poffe uide tur; ut quod dictum eft, vel ijdem uapores,at diuerfe pasfi in nitues, aquas, grandinesquue agi videri posfint $: \&$ in niues quidem, fi frigus adfit, à quo $\&$ concrefcant, $\&$ priufquam in aquas confpiffentur, grauiores fiant, quam ut $f f e$ in fublimi fuftinere queant: in aquas verò , nbi nullum adeft frigus, vel quod non eam uaporibus grauitatem indat, à qua priufquam in aquas cogantur, deorfum detrahantur: in grandines auté ibi forte tantum, ubi calor etiam adeft, a quo ueluti leuiores facti vapores, tantifper fe, dum in grandines concrefcant, fuftineant.

\section{2ui per aerem flunn uapores, tenuiores nifos fuiffe. Cap. Nonum.}

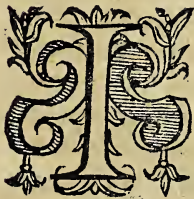

VRE itidem, qui per aerem fluunt, uentiq́ue apparent, tenuiores uifi funt ; fiquidem in fummx crafsis, \& frigidis, editisque in locis omninò, e quibus tenuiores educuntur uapores, prxcipue firare uidentur: in humilibus uerò, humidisq́ue,\& calidis Ter ris, in quibus uapores crafsiores fiunt, nulli omnino, aut perrari:nulla itaque in Aegypto aura unquam. Nulli autem, autperrari indigen $x$ uenti Hyeme atque Aeftate : nam fi tenuiores omnino uapores in obliquum ferri uifi funt, non etiam, \& qui fumma donati funt tenuitate; quales e Terra fumme obftricta, rigenteque, \& fumme arefacta, fumme om nino 


\section{Bernardini Telefij}

nino denfa exalant: qui, fcilicet, nec facile impelli poffunt, \& fuperiorem omnino appetunt locum, ad eumq́: cet, feruntur. Nec uero turbari oportet, quòd in mediis an nis conftitutionibus crasfiufculi itidem vapores educi uifi funt, \& qui in aquas, vel etiam in grandines craffefcant, non qui per aerem uagentur: fiquidem, nec indiuifibiles medij Solis uires, nec uel eadem Terræx fuperícies adeò fimilaris, adeoó; modo eodē Soli expofita, ut eadẽ omninò tenuitate ex ea uapores educi omnes uideri posfint . Et, ut dictum eft, qui eorum in aquas, aut etiam in grandines coguntur, non valde ab ijs, qui per aerem fluunt, difierre, at utrique paululum quid immutati in alteros, agi videntur, \& perpetuò fibi ipfis commifti effe : $\&$ hæ nubis eiufdem partes in uentos, fpiritumq́ue folui, alix uero in aquas cogi, vel Ariftoteli videntur.

2uomodo Tonitrua, Fulgurağ: funt; $\&$ cur fulgura deorfum ferantur, uarius gas; corum fit color, ơuis. Cap. Decimum.

Tonitrua. Anaman ON IT R VA nubibus fieri in feipfas illatis, Fulgura.

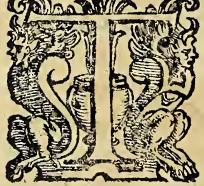
impactisq́; , \& fulgura tenuifsimas illarum partes effe, mutuo conflictu accenfas, extrufasq́ue, nihil declarandum uideri debet : nam, \& omnibus ita utraque fieri uidentur; nec aliud omninò adeft, à quo uel cdi illa, uel hre accendi posfint. Deorfum autem feruntur fnlgura, quòd à fupernis, ut exiftimare licet, nubium partibus detruduntur; qux , fcilicet multò priùs, multoque quàm infern $x$ magis, tenuitate, caloreque omni fpoliat $x$, mi nufqúte à refexa luce calefactæ multò, quàm infernæ priùs, magisq́ue denfantur, ac frigefiunt: $v t$ fi quando nullis omninò fpirantibns uentis tonitrua, fulguraque fieri appareant, proptereà fieri videri posfint, quòd dicto modo denfatis, frigefactifque fupernis nubium partibus, fpiritus, qui infernis ineft, frigefieri fpiffariqúue exhorrens, magno per fe impetu in oppofitam feraturpartem: luceat autem, tantumq́ue edat Differểię frepitum, quòd plurimus in feipfum colligitur, fummeq́ue fulguruas à motu accenditur, \& nub es magna fcindit ui. Differunt por 
rò, \& colore, \& uirium robore inter fe fulgura; $\&$ alia quidem alba videntur, nihilq́; urunt, \& nullum rebus, quas attingunt, permeantve, colorem indunt. Alia uerò rubent, \& qux attingunt, colorant, uruntq́ue ; quòd fummè illa tenuia, fummeque exili prædita funt calore, nihilque in ijs, qux permeant, immorantur:hæc uerò crasfiora cùm fint, \& robuftiore pr $x$ dita funt calore, \& longius in ijs, quę permeant, immorantur.

\section{A quibus, \& quomodo Terremotus fiant. Cap. Vndecimum.}

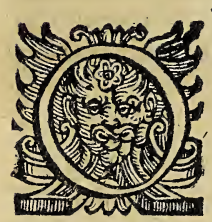

VONIAM verò non in fupremis modo De Terre mollibusq́; Terræ partibus uapores ingene- motibus? rat Sol,fed in profundioribus etiam, \& benè crasfis, denfifq́ue, \& è quibus illi uel fummam nacti tenuitatem elabi nequeant: $u b i$ itaque tanti facti funt, vt Terra ciuitates occuparint omnes, ita vt nec alios, qui asfiduè fiunt, nec illofmet tenuiores iam factos capere ex posfint,am pliore illi indigentes loco, hunc ut fibi faciant, Terram, à qua ueluticoercentur, quàm poffunt uehementisfimè amoliuntur;eo fermè pacto,quo puluis è fulphure, falinitroq́ue confe ctus in ignem actus, \& proptereà amplior factus, quàm vt tor menta in quę adactus eft, cuniculique, quibus inditus eft capere eum posfint, pilas plumbeas quàm longisfimè abigit, $3 t$ ipfa interdum tormenta, \& montes etiam ipfos difrumpit, fummaque in fiblime attollit ui. Quoniam autem vapores in Terre concauis coerciti non ftatim tanti funt, quanti, vt Terram propellant, vel aperiant, fint oportet; non ftatim fibi ex ea egrefam moliuntur, fed diù interdum cum ea ueluti cônflictantur, dum uel plures faeii illam, quod perfapè fieri vifum elt, difrumpant, uel fumma donati tenuitate inde ela bantur:dum certè egreffum moliuntur uariè Terram concuti unt, dimouentq́ue; vnde Terra tremere, \& moueri videtur: frequentes itaque terræmotus in calidis, denfif́que, \& cauernofis funt Terris; in quibus nimirùm uapores plurimi fiunt, \& que capere eos, \& retinere poffunt : illisqúue in anni temporibus, in quibus uapores multi , \& non ualdè tenues fiunt; in fulphureis, fcilicet Terris, \& Vere, atque Autumno; rari Aeftate, atque Hyeme : \& Aeftate quidem, quòd fum- 


\section{BernardiniTelefij}

mè directus Sol, quos facit uapores, fumma eos ftatim donat tenuitate, egreffumq́ue elabentibus ijs aperit. Hyeme verò quòd fummè obliquus perpaucos facit. Fiunt etiam, \& in fummè ficcis, \& in fummè pluuijs conftitutionibus Terræmotus, quòd in vtrifque obftringitur, conitipaturque Terre fuperficies; in illis quidem tenuitate elapfa omni, in his verò plurimis immiftis aquis:fortè,\& multus in vtrifque ingeneratur fpiritus, in fqualloribus quidem, quòd multus Terrx inditus eft calor, in pluuijs uerò, quòd ab aquis frige facta Terre fuperficie internus eius calor in ima omnis fimul recesfit.Agè uerò quoniam longè à nobis diuerfus pluuiarum, grandinum, ventorumq́ue ortum, motumq́ue Arifto teles tradit, eius de fingulis explicetur, examineturqque fententia.

Euaporibushumidis, plunie grandinè que, uentiueròjic cis Ariftoteli funt; \& bumidi quidem ex aquis, ficci uerò हे Terris: at utrique perpetuio firmul educuntur. Cap. Duodecimum.

1. Meteo. $B$ I Terra, inquit Atiftoteles, vi Solis incac.5.

T. 24 .

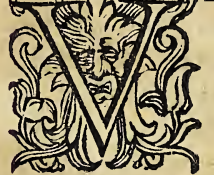
lefcit, exhalationem fieri neceffe eft, non quidem vnam fimplicemq́ue, fed duplicem: vnam, quę magis vapor fit; alteram, quę fpi ritus magis.Et vapor quidem, inquit, ex humore fit, qui in Terra, fupraq́ue Terram continetur ; fpiriths autem ex Terra exficcata, \& ex hoc " ignis, ex illo autem acris elementum conftituitur. Humor "1" porrò Solis radiorum, \& reliqui fuperi caloris efficientia in 8.9. T.6r. vaporem conuerfus, furfum confendit . Cùm verò calor, quicum effertur, defecerit, partim in fuperum locum disfipatus, partim extinctus \& fi quidem in fnblime, \& quò Solis radij non refectuntur, fub latus eft vapor, tùm ex caloris de fectione, tum ex loco rurfus concrefcit; \& ex aere aqua gignitur, quę mox vbi genita eft, rurfus in Terram fertur. Non igitur neque in ualdè fupero loco coguntur nubes, neque iuxta Terram, quòd locus hic radiornm repercusfione incalefcens, uaporum concrectionem diffoluit; ille non magis fit aer, quàm ignis. Pratereà \& à Cœlo circulo actus motu 


\section{De his qux in aere fiunt.}

prohibet, quò minus uapor in aquam concrefcat . Tum gran c.12.T.7 $3_{\sigma}^{\circ}$ dinum conftitutionem explicans; Quoniam, inquit, calo- 29. rem, frigusque fefe vndique coercere, \& comprimere confpi- " cimus; ( qua de caufa fubterranea loca calidis temporibus "x frigida funt, gelidis nerò calida; ) hoc ipfum, 8 in fupero lo " co fieri cenfendum eft. Temporibus itaque calidioribus fri- " gus à calore ambiente introrfum vndique compulfum, inter-" dum quidem aquam ex nube celeriter facit; interdim gran " dinem. Quocircà , \& guttę diebus tepidis multò quàm Hye " me maiores; \& aqux magis impetuof gignuntur : magis au ". tem impetuofre fiunt, cum magis coaceruatx, ma gis autem ", coaceruantus ob denfationis celeritatem. Cùm autem frigus à calore exteriore circumitante introrfim magis com-" ", preffum fierit, mox vbi aquam genuit; conglaciat, efficiturq́ue grando : hoc autem accidit cum gelatio celerior fue ", rit, quàm aqux in infernum locum delatio. Rara igitur, in " ${ }^{2}$. Meted. quit, Hyeme fit grando; \& ubi Hyeme fit minimè pollet fri $c_{4}$. gus : at Vere, atque Aeftate, Autumnoq́ue; \& minus Aefta T. 38. . te, quòd aer ficcior factus eft: nam Vere adhuc eft humidus, " Autumno iam humefcit. Ventorum uerò principium, natu- " ramq́ue nos edocens; Duę inquit, exalationis, funt fpecies, "T una humida, altera ficca: at licet diuerfe fint, non tamen feorfum $a b$ altera educi poteft; nec ficca, inquit, $a b$ fque $h u$ " mida , nec humida abfque ficca ; fed omnia ex eo, quod ex- " cedit, dicuntur. Harum porrò ea, qux maiorem humoris copiam obtinet, aquę pluuię, ut antè diximus, principium eft : ficca autem uentorum omnium principium, \& natura . Et diuerfam omninò pluuiarum, ventorumq́ue effe naturam indeetiam Ariftoteli manifeftari uidetur, quòd anni interdum fummè pluuij funt, interd un verò fummè ficci, fiatuofique; quòd nimiram humidx interdum, interdum verò ficcxexhalationis maior copia afcendit.

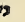




\section{Bernardini Telefij}

Perperam Vapores, quiè Terra educuntur, ficcos Arifto. teli vifos fuiffe; \& ad aquarum conftitutionem frigus allatum. Cap. $X I I I$.

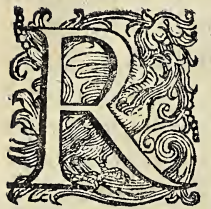

ECTE quidem Ariftoteli non ijdem è Terra, 8 aquis educi videntur vapores; nec qui in aquas, grandinesque coguntur, ijdem per aerem fluere: neque enim vel à Sole eodem vapores ijdem ex adeo diuerfis rebus torum idem omninò corpus, eademq́ue materia uideri pofieri, nec aquarum, grandinumq́ue, \& uenteft. Quin non è Terris omnibus, nec ex omnibus etiam aquis, at neque ex ijfdem ijs à diuerfo Sole uapores eofdem educi videri debuit: non perperam itidem pluuix è vaporibus

Confutaex humidioribus, nenti uerò è ficcioribus eductis rebus fietio fenten ri uidentur. At nec rectè, nec proprias intuito pofitiones: tiz Arift. exalatio utraque, veluti rei, è qua fit, feruans naturam, qua è Terra educitur, ficca : quę verò ex aqua, humida uidetur; neque enim materia, è qua educuntur, fed propria vtriufque natura, propriaque fubftantia fpectanda Ariftoteli erat: \& ló gè tenuisfrma, qux è Terra educitur, confpecta, longè humi disfima; que vero ex aquis longè quàm illa mirus tenuis, $\mathrm{mi}$ nus humida uideri debuit : cui nimirú, ut in dictis amplius expofitum eft Commentarijs, qux tenuia funt, molliaqque, non qux humefaciant, humida videntur; ficca ea tantum, quę craffa funt, duraq́ue, quale neque ex aquis, neque è ter ra educi, ad fuperiora ferri nullum videtur: nullam itaque va poribus vllis ineffe intuito ficcitatem, nulla eorum vlli adijciendaomnino fuit; multoq́ue ijs minus, è quibus venti funt; nihil quidem humefacientibus, \& fummè omnibus tenuibus. At neque ad aquarum, uel ad grandinum, etiam generationem frigus afferendum Ariftoteli ullum, quas ubicunque crasfiufculi uapores in unum coguntur, confpiffanturq́ue, uel in fummè calido ambiente fieri ipfe uidet, \& prę dicat etiam Ariftoteles : nec uerò à proprio nubis frigore, $a b$ ambiente caiore introacto in aquas ea cogi, multoq́ue etiam minus in grandines gelari dixerit ; ipfi enim imprimis AriAtoteli vapores, qui in nubes coguntur, calidi uidenturomnes, \& uideantur neceffe eft à Sole geniti, \& ad fuperiora elati. 


\section{Dehis qux in aerefiunt.}

2ti. Summum certè frigus nubibus ineffe oportebat, quod 2pores in aqui s cogeret, longè Arifoteli frigidifsimas, \& in grandines etiam yelaret, \& temporis id momento, quo è loco, in quo fiunt ad Terram delabuntur . Et per Aeftatem, quàm per Autumnu $\mathrm{m}, \&$ Ver grandines plures, longeque fieri oportebat crafsiores: nam à vehementiore calore magis introagi, vnirique nubis frigıs, \& à ficco compingi magis. Tum ne hyberne quidem pluuix à fummo, vel ab ullo omnino frigore conftitui Ariltoteli poflunt; quòd nimirum aeri ineffe nullum poteft : vt enim neque à reflexis radijs, neque à ftellarum, vel proximi ignis calore calefiat medius aer; pro pria tamen natura fummè Ariltoteli calidus; per fe nubium concretionem difioluere, \& fi quod afcendentibus vaporibus inelt frigus, extinguere videri debct. Non alia certe ratione fupero in loco, quàm apud nos vapores in aquas concrefcere Ariftoteli uideri debuere; non igitur aliud pasfi, at in feipfos coacti tantum.

\section{Non rectè ventorum materiam è terra modo; \& neutram exhalationem feorfum ab altera educi poffc Ariftoteli vifam fuiffe. Cap. $\times 1111$.}

W (1) ribus educens rebus, non rectè illam è fola educit Terra, fiquidem manifente è mari, \& magis forte, quam è Terra, qui per aerem fluunt, vapores educi, \& in mari prætipuè ué ti fpirare uidentur; fluxile fcilicer mare, at crasfitiei,vifcofitatisá́; minimè expers; modica igiturtenui tate fpoliatum in fal concrefcit, ninimeq́ue unquam à Sole vllo ualde adapertum, quòd eius actionem afsidue agitatú commotumq́:le ueluti effugit; tenuioribus modò uaporibus egreffum præbet:tenuis itaque purusq́ue marinus acromnis; $v t$ fiquidem, quod uideri omninò Ariftoreli debuit, tenuiores qui funt vapores, ij promptius in uêtos diffundi uifr funt, non è Terra magis, quàm è mari educi uideri debuere. Et tenuiores omninò vapores qui acrem fpirare Arifoteli vifi funt, inde manifertè intelligere licet, quod qui fpirant, ijdem

$$
F_{2} \text { \& }
$$


\& ignis elementum Ariftoteli conftituunt, longè nimitum tenuifsimum ens; $v t$, quod dictum eft, rectè uentoram mate riam è ficcioribus educens rebus, praue illam è Terra modò educit Ariftoteles. At peius etiam exalationem neutram per $\mathrm{fe}, \& \mathrm{ab}$ altera feorfum, alteram; neque igitur, uel puris ex aquis, uel è non madefacta Terra illam fieri decernit: nam \& aquas quantumuis tenues, liquidasq́ue, vel à fumme lan guente calore in vapores folui; \& è Terra quantumuis arrefa \&a, exficcataq́ue, \&r aquas effluere, \& plantas nutriri , \& aerem educi, \& uentos et 1 am fpirare pafsim intuerilicet; \& è penitus deufta exalationem ipfe educit, à qua falfum, craffumótue fiat mare; $\&$ longe aridifsima ligna, \& è quibus flāma nulla , nullus Peripateticis educi uidetur fumus, lateresáq; \& alia quxuis ab igne imminui, abfumiquue tandem apparent omnia. Que igiturnifi in non ens Ariftoteli abeant, in longe quidem tenuifsimos, \& qui elabentes vifum lateant, at in uapores omnino foluta fint omnia neceffe eft : Ariftoteli certe quò ficcior facta fit Terra, \& humiditate fpoliata omni, eò in ficcam exalationem, atque in ignem promptius inuerti uideri debet; cui nimirum in omnia quidem inuerti videntur omnia, at ea certe facilius, qux fimilia funt, \& co gnata magis : fummè igitur arefa $\varepsilon a$ Terra, magis quàm ma defacta exhalationem emittere, è qua, fcilicet, ut in exhalationem agatur è qua , \& uenti , \& ipfe Ariftoteli ignis conftituitur; frigiditas modo, non \& humiditas itidem extrudenda fit, atque interimenda. Age uerò, \& qux pluuijs, uen tisq́ue eueniunt, que ut videtur, exhalationem, è qua uenti fiunt, fine altera , \& è Terra omnino non madefacta educi non poffe Ariftoteli perfuafere, explicare ne grauemur: forte enim ipfam imprimis uentorum materiam non è Terra magis, quam è mari; \& vel è nihil madefacta Terra, \& folam ip fam, ab eaçue feorfum, qux in aquas concrefcit, educi poffe, $\&$ uentos omnino, pluuias q́ue, quo nobis expofitum ef? modo, non ut Ariftoteli placet, fieri manifeftabunt. 


\section{'2use exhalationem, qua venti funt, feorfum ab alter a; \& \\ ¿ Terra omzinio non madef act a educinon poffe \\ Aristoteliperfuafere. Cap. XV.}

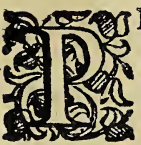

ROPTEREA, inquit Ariftoteles, poft pluuias 2 Mateo. fpirant venti, quòd Terra humefacta veluti exfu- cap.4. dat, ficcæq́ue exhalationis materia fit : nifi enim " aliquis inexiftat humor, exhalationem Terra e- " mittere nequat;veluti neq; ligna fumú, quę nullú " retinent humoré: quin \& eadê caufa eft,vt tí à Septentrioni- " bus, tum à meridie potifsimum venti fpirent: fiquidê Sol hęc " vna loca non peruadit:\& proptereà plurimú aqux in ea defcé ", dit.At vbi aqux copiam Terra excipit, ibi exhalatio plurima, 38 . non aliter ac ex viridibus lignis fumus reddatur neceffe eft: ${ }_{43}^{\text {cap. }}$. ipfa porrò exhalatio ventus eft. Tum Etefix, inquit, poft Sol- ", ftitium , \& canis exortum fpirant; non cùm Sol aut maximè ", propinquus eft, aut maximè remotus : Et inter diù quidem fpirant, noctu autem definunt; cuius rei caufa eft, quòd cùm ", propè adeft antè exficcat, quàm exhalatio oriatur, cum au- ", tem paululum recefferit, moderatus iam calor gignitur, ita vt ", 2qux gelu concretæ colliquefcant:ac Terra tum proprio,tùm "” Solis calore exficcata veluti in fumum, halitumq́ue abeat:no ", Qu autem ceffant; quoniam qua conglaciata funt, ob no-", Qtium frigus definunt liquari: nihil aủt, quod aut gelu côftri ", ctum fit, aut nullam habeat ficcitatem, halitum reddit; fed ", quod humorem cum ficcitate coniunctum obtinet, id cùm "” incalefcit exahalationem mittit. Neque igitur ab Auftro Ete ", fix fpirant, quod vtique oportebat : fiquidem locus ille pro-" ", pter Solis propinquitatem aquas non habet, aut pabulum, ", quod liquefactum Etefias excitet. Et plures, in quit, ab Aqui- ", lone, quàm $\mathrm{ab}$ Auftro fpirant venti, quòd in Borealibus Terris maior, quàm in Auftrinis aquarum, niuiumq́ue copia; quibus in Terram liquefcentibus, maiorem exhalationis copiam oriri neceffe eft. 


\section{Bernardini Telefij}

Nec poft plunias vent os fieri, quod T erra made fact a exhalationem emitat; nec Auftrum, Boreàmque plurimum Spirare, quod à locis oriantur, in quibus p'iunice multe funt, vt Ariflot. placet. Cap.XVI.

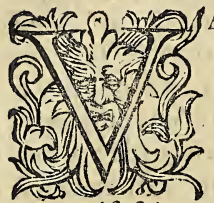

A P O RES, qui per aerem fluunt, ventiq́ue apparent, ijs plerumque commiftos è Terra elabi, qui in plutias craffefcunt, \& nobis dictum elt priùs, \& fieri omninò fenfus, \& ratio manifeftat: \& nubes exdem partim in ventos folui, partim in plunias concrefcere manifeftè apparent. Et è fummè difsimilari, \& valdè profunda,variequ ue Soli expofita Terra, vapores, qui nihil crafsitie,tenuitateq́ue inter fe differant, fieri cxiftimare non licet. At quin qui in flatus diffundütur feorfum ab ijs; qui in aquas, grandinesq́ue concrefcunt, \& hi abfque illis fieri pofsint; id verò videri non debet: liquidem \& fenfus, \& ratio itidem feorfum ab alteris educi alteros manifeftat.Eft enim vbi pluuiæ perraræ, \& nullę omninò annis multis, venti vérò afsidui: \& vbi contrà nulli,aut perrari fpirant venti, pluuię verò, gran dinesq́ue iuges, grandesq́ue. Et fecus omninó, quàm Ariftotelis ratio poftulat; nulli in humidis Terris venti, pluuix verò afsidux:id quod \& aliæx Terræ multx declarant, \& Aegyptus imprimis; qux omnium mollifsima, humidifsimaque ventis omninò caret; at non \& pluuijs itidem, vt videri poffet : quotidianus enim ibi,longeque copiofifsimus ros; craffifsimi nimirum, qui inde educuntur, vapores, \& parùm quid ab aquæ natura dimoti, modica ope, quam à nocturno habët frigore, in aquas craffefcunt.In fummè verò aridis Terris ven ti m lti vehementesq́ue. At vt Terra, qux fummè eft arefacta, exhalationem, qux fluat,emittere inepta videri potuerit, non cer:è proptereà, ceflantibus pluuijs, ftatim venti fieri videri Arittoteli debuere, quòd Terra madefacta exfudet, exha lationemq́ te emittat, quam arefacta nullam edat : neq; enim temporis momento, quo poit pluuias venti fpirant, Terra exhalationem emittere; nec fi tanta, adeoǵue emittatur côfertim, afcendens ca latere nos queat, qux in obliquum acta, veluti nos ferit.E Terra fcilicet, quod minimè fit, fpirare videa- 
tur vëtus, fi exhalatio is fit, quam ibi madefacta emittit Ter$\mathrm{ra}$ : fed proptereà quòd nubium, qux in plunias coguntur, pleræque non è crafsioribns modò vaporibus, è quibus precipuè aq a fit, fed è tenuioribus itidem, \& qui in aquas fpiffari nolint, conftitute funt : hi porrò à crafsioribus feiuncti, \&x dum feiunguntur, impulfi quid, dimotique in obliqutim fluunt, uentiq́; apparent: nec perpetuò id tamen;eft enim ubi in nubeculam coeunt, qux Græcis óuín^n dicitur. Superftare ea mötibus polt plunias, fumi inftar videtur, \& è tenuifsimis nubium partibus, \& qux in aquas craffefcere non potuere, manifeftè conftituta, folasquue eas fupereffe indicans certifsi mum ferenitatis exiftit fignum : rectè itaque infocunda nubes ab Arifotele appellatur. At neque Aufter, Boreasq́ue, fi quidem multus vterque, \& valens videri potuit, proptereà ta lis videri debuit, quòd à locis fpiret, ad qux minimè acced it Sol, \& quę ab afsiduis humefacta pluaijs, exhalationem maximè emittant: omitto enim, quờd Aufter non à polo, fed ab xftiua conuerfione Ariftoteli fpirat; \& quòd nec Boreas ipfe in fubpolari Terra fieri videri debet. Nulli dubium effe poteft fummum Hyeme in fubpolari Terra frigus vigere, \& fum mè obftrictam eam effe, gelatamq́ue omnem:at huiufmodi è Terris nulla omninò exhalatio educi; \&c venti omninò nulli circa Arcum; Hyeme, \& fruientibus frigoribus, cùm maximè viget Boreas, fieri Ariftoteli videntur, quòd exhalatio,ca lore; à quo eleuabatur, extin cto, afcendere nequeat. Quòd fi ventorum quidem materia per Hyemem inde educi Ariltote li non videtur, multò minùs quas in pluuias concrefcat, $\mathrm{e} \mathrm{du-}$ ci videri debet:nam \& ipfi itidem longè hæc, quàm illa craffior videtur. Proptereà igitur multus valensque Aafter, quòd ex amplifsima Terra, \& à robufto edaciturSole; Boreas apud nos quidem, nec multus, nec valens, nifi incipiens interdum, \& aere vaporibus oppleto: afsiduè enim à fubfequente impulfus, inq́: le anguitius actus, qux obitant, \& qux premunt, fumma abigit vi; at non multus ipfe, fummeq́ue tenuis liberum apertumǵue nactus locum, languefcere videtur. Multus itidem apud nos, diuturnusq́;, qui inter Auftum, Fauonium q́ue medius eft, \& Fauonius ipfe è mari, ut uidetur genitus, benè amplo; \& è quo vniilerfo ij precipue exhalant uapores, qui in uen tos diffunduntur. 


\section{Bernardini Telefij}

Ettefias non fubpolaris niuis liquefactione, ut Aristoteli placet, fedèmarioriri. Cap. X $V I I$.

EIVS \& Etefias Ariftoteles è fubpolari edu-

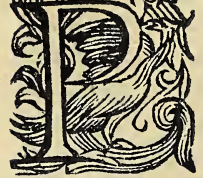
cit niue : fiquidem nec niuem ampliùs ullam poft xitiuam conuerfionem, ubi Etefix fpirare Ariftoteli incipiunt, in Terra effe plures iam menfes afsidnè à Sole illuftrata, calefactaque exiftimare licet : nec fi fit, interdiu, \& eleuato tantùm Sole, fed asfiduè fpirent; nunquam enim ibi Occidens Sol, fed æquè asfiduè lucens, æquè asfiduè niuem liquefaciat. Tum ne ipfi qui-dem, ut opinor, A riftoteli, ijfdem, quibus nix liquefcit ho ris, ijfdemque ferè temporis momentis, exhalationem, in quam acta eft, ad fuperiorem ufque aerem efferri poffe, inde q́ue detrufam ad nos vfque peruenire uideri poteft: oportet autem; paucis enim polt Solis ortum Etefię fpirant horis , \& proptereà noctu non fpirare Ariftoteli videntur, quòd nix noctu non liquefcit. Nequaquam prętereà ab Arcto, fed ab Occidente, è mari nimirùm, \& è mari omninò manifeftè oriri videntur : eft itaque vbi ab Oriente, \& ab Aultro etiam fpirent. Et vere fpirare incipiunt, paucifóue poft Solis ortum horis: Aeftate autem, \& Sole ipfo iam inclinato, noEtuớ;nihil fpirant : quòd Vere, \& elato iam Sole ij, ut dictum eft, educuntur uapores, qui in uentos diffari apti funt. Aeftate autem, Soleq́;;iam inclinato, noctu tenuiores omninò, quàm ut fefe mutuò impellere, $\&$ in obliquum ferri poffint; Aettate quidem, quòd, ut dietum eft, fnmmis agit ui ribus Sol, \& in Terram agit, mareq́ue ipfum crasfius iam factum. Noctu autem, \& Sole nondum elato, uel inclinante iam languidiùs omninò uaporibus egreffum aperiente, tenuisfimi tantú elabuntur, \& pauciores, quàm ut loci anguftia presfi fefe impellere, locoq́ue dimouere opus habeant, liberum prafertim vaporibus nacti aerem. Nullum itaque ut videtur, fignum $a b$ Ariftotele allatum, exhalationem, quæ per aerem fluit, fine altera, \& non nifi ex humefacta Terra educi poffe declarat, 
Non rectè obliqui uaporum motus caufam ab Ariftotele traditamfuife. "Cap. XVIII.

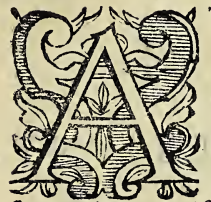

$T$ neque obliqui vaporum motus caufam edocens placere Ariftoteles poteft: fi fiquidem ab vnica circulari aeris vertigine reiecti illi in obliquum ferantur, veluti fumus rotx velociter motx fuppofitus; fi quidem (entilum illis longe tenuisfimus abneget aer, fecum illos Ariftoteli agat vniuerfos, multoq́ue promptiùs, quàm aerem contiguum Cœlum, minimè diuerfa à circumagente illos aere, preditos natura; fed nihil Ariftoteli, aut modicum quid differentes, unicus itaq; fpiret uentus; \& per uniuerfum aerem æquè fluat, non ad fluminım ripas, quàm vbiuis magis : neque in diuerfis aeris regionibus diuerfi. Vel fi non fecum vapores aer trahat, rapiatóue, fed afcendentibus celerrimè circulatus aditum abneget, \& veluti reijciat, hacq́ue, \&r illac difijciat, ęquè in partes omnes difiecti, diffipatique, $x q u e ̀$ in partes fluant omnes, \& per fuperiorem perpetuò aerem; ad Terram certè vfque nunquam delabantur, calidi, tenuesq́ue, \& fuperiora proprio petentes ingenio: $\&$ in editisfimis montibus, in quibus nullos omninò fpirare vinquàm ventos cinis declarat, nihil commotus vnquàm, asfidui illi fiant, vehementisfimiq́ue. Hxc fortè ani maduertens Theophraftus, Ariftotele polthabito, obliqua ventorum motionis caufam, non circulati aeris uertigini, fed duplici exhalationis attribuit naturę ; Commiftę, inquit, inter fe, \& ficca furfum tendente, humida verò deorfum illam trahente, in obliquum feruntur; non rectè, vt videtur, neciluxta proprias pofitiones : compofita enim omnia iuxta pradominantis naturam Peripateticis feruntur.At neque vel fibi ipfis commitx impetu tanto, nec deorfum omninò ad Terram vfque delabantur : vt enim humida fic-cæ æquè leuis non fit, ad fuperiora tamen ferri, \& ipfa videtur; \& nifi in aquas coacta delabi nunquàm.

\section{F. I N I S.}




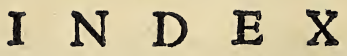 \\ C $A$ P $I \quad T \quad V \quad M$ L I $\quad \mathrm{B} \quad \mathrm{R} \quad \mathrm{I}$. \\ DE HIS QVAE IN AERE FIVNT. $\&$ de Terræmotibus.}

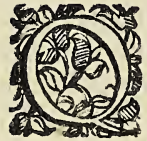

I vapores pracipue in grandines, plunias, of niues aguntur, quiue in ventos diffunduntur; \& modus, quo in ea, que dicta funt, illi coguntur, \& quo bi mouentur, inquirendus videri debet. Cap. I. pag.

$14 . a$.

Qui pr.xcipue vapores in niues, plunias, grandinesque aguntur; \& qui per aerem fluunt, wentique apparent. Cap. I I. pag.

$14 . b$.

Quomodo vapores in aquas, grandines, or niues agentur. Cap. III.

pag. I 5.a.

cur vapores in obliquum mouentur, \& quamdiu. Cap. IIII. pag. pag. 15.6 .

Cur papores eo mots moueantur quo moneri videntur. Cap. $V$. pag.

Qui color, qualiè re, qua elabatur in tenuitate. Cap. VI. pag.

I $6 . b$.

Quibus in anni temporibns, quibufuè in Terris plunie, niwesq́ue, \& grandines funt, bentique spirant; \& qui venti quando fereni, quandouè plunï. Cap. VII. pag. I7.a. Aquas, niussque è crafsis omnino paporibus, es grandines ècraffis fimis constitui iure vifas fuiffe. Cap. VIII. pag. I 8.a. Iure qui per aerem Atunt vapures, tenuiores vifos fuißes.

cap. I $X$. pag.19.a. Quomodotonitrua, fulguraque funt: \& cur fulgura deorfnm ferantur, variusqune eorum fit color, of uis. Cap. X. pag. I g.b. $\mathcal{A}$ quibus, ¿ quomodo Ttrramotus fiant. Cap.XI. pag.20.a. E vaporibus humidis, plunice, grandinesque, venti pero è ficcis Aristoteli funt; ; es bumidi quidem ex aquis, ficciverò è terris: 
at vtrique perpstuó fimul educuntur . Cap. XII. pas.20.b. Perperam vapores, qui è Terra educuntur, ficcos Ariftoteli vifos fuiße; or ad aquarum conftitutionem frigus allatum. Cap.XIII. pag.

2 r.b.

Non rectè pentorum materiam è Terra modo; \& neutram exbalationem feorfum ab altera éinci poffe Arifloteli vifam fuiffe. Cap. XIIII .

pag. $22 . a$. Que exhalation:m, dqua venti fiunt jeorfum ab altera; dis è Terra omnio non mad-facta educi non poße Aristoteli perfuafere. Cap. $X V$.

pag. $23 a$.

Nec post plunias ventos fieri, quod Terra madefacta exbalationem emittat, nec Austrum, Boreamque plurimum fpirare quod à locis oriantur, in quibus pluiva multe funt, ot Arisicteli placet. Cap. $X V I$.

pag. $23 . b$.

Etefias non fub polaris niuis liquefactiona, $v t$ Aristoteli placet, fed àmari oriri. cap. $X V I I$. pag.24.b.

2 Non rectè obliqui saporum motus caufam ab Aristotele traditam fuiffe. Cap. $X V I I I$.

pag. $25 . a$.

$F \quad \lambda I S$. 



\section{BERNARDINI $T$ E I E S I I CONSENTINI.}

\section{Liber $\mathrm{De}$ Iride.}

A $D$ ILLUSTRISSIMVM, of Reuerendiffimum

A L O Y S I V M CORNELIVM Epifcopum Paphienfem, Patauinum defignatum, ac Patricium Venetum. CVMPRIVILEGIO.

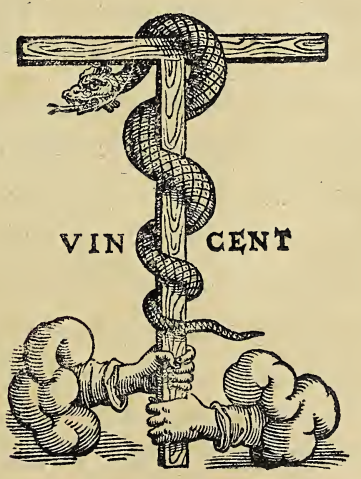

VENETIIS, D. M. XC.

Apud Felicem Valgrifium. 


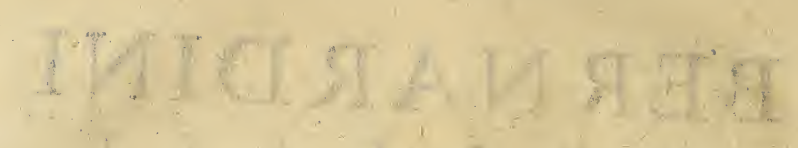

abin 1 in yed I

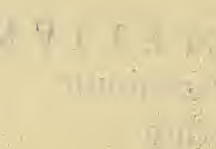

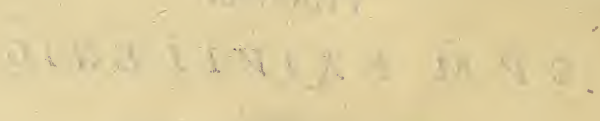

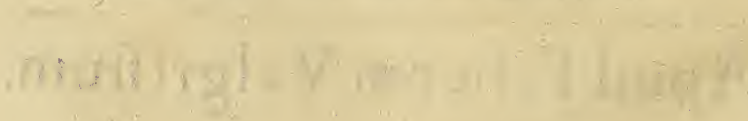




\section{L L VSTR ISSI M O, \\ AC REVERENDISSIMO}

A L O Y S I O

CORNELIO EPISCOPO Paphienfi, $\sigma$ Patauino defgrnato.

\section{Antonius Perfius. S. P. D.}

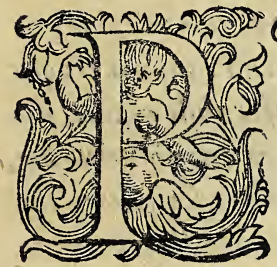

OST nobilemillum vniuerfa terra Cataclyfmum, exquo Noe cum familia Seruatus, bumanum genus re parauit, apud Etbnicos quoque peruulgatum, ac Deucaleonearum undarum nomine à poet is fignificatum friptum fecit Mofes fummi ille Dei frriba, atque interpres, Illuftrisfima ac Reuerendifs. Epifcope, Deum ip um edideffe arcum, feù Iridem pacti indicem, ac faderis interfe, alque humanumgenus conftituti, ut quoties id in colo appareret, toties diuina potentic, benefcïsq́; nobis dininitus collati memoriam renouaret . hoc mi bi, dum eximü PhilufophiBernardini Telefii libellum de Iride in lucem proferre cogitnem animo repetenti cupido inceffit, ut baud it a diffimulis in re fimilitui erga me animi fignificatio extaret, operam dare. Eft igitur a me curatum, ut $\ddot{y}$, inquorum oculos hac Telefiana Iris incurreret, de tuorum in me magnitudine meritorum A 2 breui 
breui bac ad te epifold quogro pacto admonerentur. Namque, vt alia prateream, maximorum femper in loco beneficiorum mibt delatum putabo, gyòd in aliqua apud te gratia vigeam, ac me ipfe in tur rum tibi addictiffimorum numerocenferivelis. Cum enim percrebuerit, te non nifi doctos, probos, ac Japientes wsiros, thi failicet, fimillimos, amare, fouere, atque bornare fotere, cum iu non foicin maiorum fplendore, fummaú; familia nobilitate, verum etiam doctrina, probitatis, as fapientic laude nemini concedas. (Quarum quidem wirtuituring fingulare $\int p e c i m e n$ in adminiftratione Epifcopatus Patauini tibi ab Ampliffmo Cardinali Federico patruo tuo prudent2] fimo uiro delata maximo cü Eccle fra Patauina fructu quotidie exhibes.) Quid mihi proficteci abfe maius, atque optabilius unquam pofJet, quàm ex tua côfuetudine, qua me dignum tua effe uoluit bumanitas ingularis, tan tarum mibi virtutum famain, ac nomen aliquod comparare? Quod igitur opuf culum boc tuo facraium nomini dicarim, id primum boni vt confulas vehementer cu pio; deinde ut tuam in me animi propenfionem, inqua maximamexiffimationis mea partem effe pofitam intelligo, (2uodfacis) tueare te rterum atque iterum rogo, objecrogue. Vale. Patany. 


\section{B E R N A R D I I

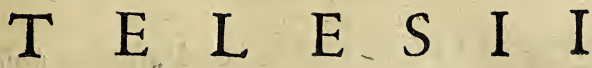 \\ CONSENTINI. \\ lris.}

Que Iridi euenire videntur Arifoteli, o propterea ea euenire, guod Iris reflexiofit. Cap. 1 .

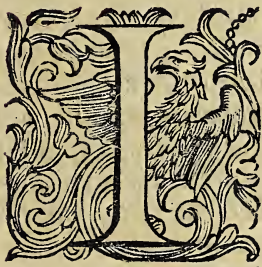

RIDIS (inquit) Ariftoteles, nunquam 3. Meteo. fit circulus, nec fectio femicirculo ma- cap. 2 . ior, \& Occidente, atque Oriente Sole Tex. 8. minimi quidem circuli, fed maxima ", portio, magis autem fublato, circuli, quidem maioris, at minorportio. Et," poft autumni quidem xquinoctium,", diebus breuioribus omni diei hora," exoritur, ltiuis verò diebus per meridiem non fit,nec plures, duobus fimul oriuntur, quarum quamuis vtraque tricolor fit, ", eodemquè colorum genere, ac pari numero interfe congruät ," obfcuriores tamen funt in exteriori, atque ordine contrario, pofiti.Interior enim primum ambitum, qui maximus eft, pu-', niceum habet, minimum verò purpureum: exterior contra, ," minimum quidem puniceum, maximum verò purpureum. " Horum autem omnium caufa eft, quod iris reflexio eft:ac in - ; terdiu quidem Iris oritur, noctu verò à Luna veteres putarüt Text.10. non extitiffe;quod eis accidit propter raritatem: fit namque tametfi rarò. Cuius rei caufa eft quòd colores in tenebris la- " teant, quodq́ ie alia multa concurrere oporteat, eaque omnia ", vna menfis die : nam plenilınio fiat, fi exiftere debet, neceffe" eft : Idque occidente, aut oriente Luna : quare in annis fupra ", quinquaginta,bis tantum in eam incidimus. 


\section{Bernardini Telefij}

2ue, vt Iridern reflexione fieri declaret, Jumit Ariftoteles. Cap. II.

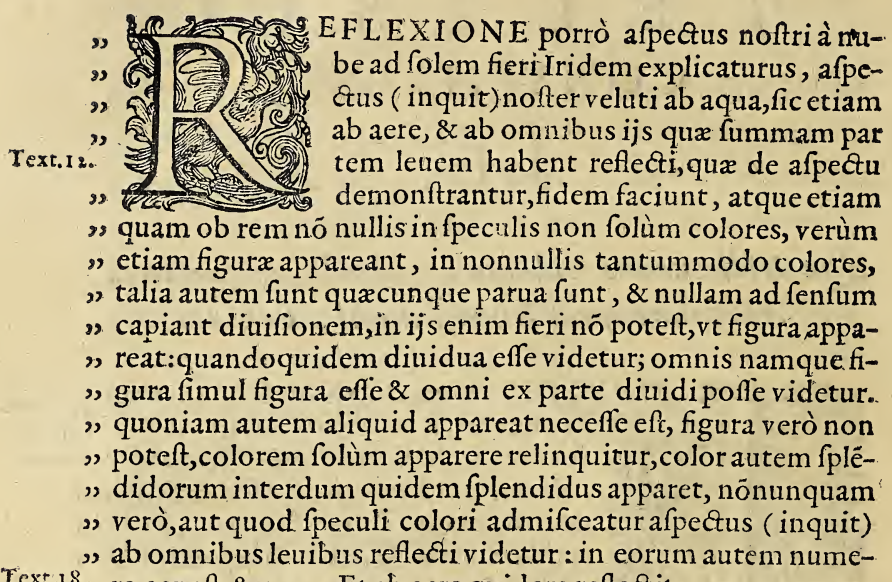

Text.18. ro aer eft, \& aqua. Et ab aere quidem reflectitur cum concre-

" fcere eum contigerit, ab aqua autem maximè reflectitur, \& Text.20" ab ea etiam magis, qux fieri incipit, quàm ab aere.quxq́ue enim partium, ex quibus concretis gutta oritur, magis, quàm " nebula fpeculum fit neceffe eft.

2uomodoiris Ariftoteli fiat, \& a fpecius inbe ad folem reflexionem, omnino effe iridem. Cap. IIII.

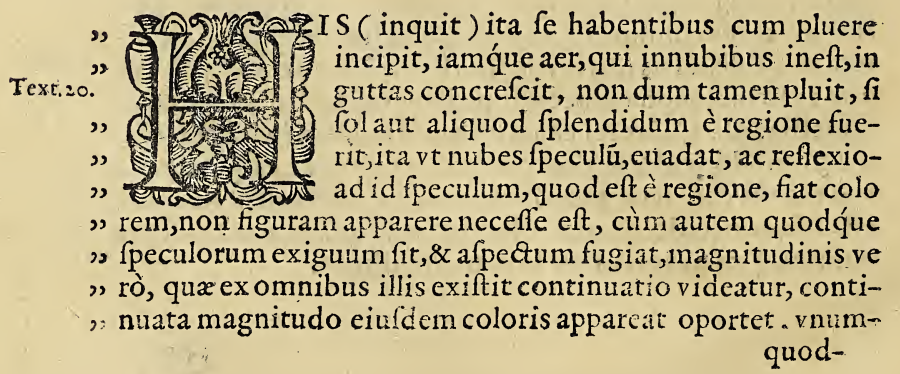


quodqque enim fpeculorum, ei quod cohæret, finum ipfius $\approx$ colorem impertitur . Quoniam igitur hæc poffunt eueni- " re, cum fol, \& nubes hoc modo fe habuerint, nosque" inter ea pofiti fuerimus, ob reflexionem aliquid appare-", bit. at qui \& tam, \& non aliter his habentibus iris exiftere", cernitur. perficuum igitur eft, Iridem afpectus reflexio- " nem iolem uerfus effe.

\section{2 we Iridis colorum differentiam explicaturus, fupponit Ariftoteles. Cap. IIII.}

6. Tridis colorum differentiam explicatu- Text.25.

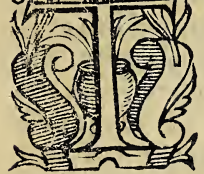
rus,oportet (inquit) quemadmodum di-, ", ctum eft, animo concepiffe, atque pofuiffe, ", primum quidem, id, quod fplendidum eft, in ", nigro, aut per nigrum, colore puniceo appare," re.deinde afpectum longius extenfum lan-", guefcere, $\&$ imminui:Tertio nigrorem, quafinegation em ef-", fe : ob afpectus enim defectum, nigra res apparet.Ideo longin ", qua, nigriora omnia videntur, quòd afpectus ad ea nô perdu-- ", catur; hac igitur de caufa, \& qux remota funt, \& qux in fpe- ", culis videntur, atriora, \& minora, \& leuiora apparent; \& in a- ", quam afpicientibus nubes, atriores videntur, quàm fi in eas ", afpiciatur,idq́; admodum infigniter:nam ex repercuffu afpe-", ctu,exiguo fpectantur.nihil verò Intereft vtrum id, quod cer ", nitur,an afpectus mutetur:; vtroque cnim modo idem flutu- Text.26. rum eft . Adhæc nec illud quidem ignorare debemus, eue- " nire, cum nubes foli-proprior fuerit, in eam quidem infpi- ", cienti, nullo colore infectam uideri, fed effecandidam; in " aqua 'ierò eam ipfam intuenti, aliquem Iridis colorem ha- ", bere; perfpicuum igitur eft, afpect um fractum, quemadmo " dum efficit, ut id, quod atrum eft, propter imbecillitatem ", atrius appareat; ita etiam quod candidum eft, minus candi ” dum, efficere, atque ad nigruma adducere . 


\section{Bernardini Telefij}

Cur tres tantum colores in Iride apparere, eog g, ij quo, Spectantur, ordine, Arifoteli videntur. Cap. $V$.

Text.27.

29

99

3)

9)

99

" xima rerum aliarum pars, ita hi ternario numero terminan-

" tur. Coeterorum verò mutatio fub fenfum non cadit .

"Quocirca \& Iris tricolor apparet, utraque fanè, fed fitu con-

" trario, ac prima quidem extimum ambitum puuiceum ha-

" bet, quòd è maximo ambitu (maximus autem extimus eft)

Text.2 28. copiofisfimus afpectus in Solem reflectatur: is autem, qui fe

" quitur , \& tertius proportione refpondent . quare fi ea, qua

2)

”

ijs Solis coloribus Iris fit, neceffe eft.

Flawus color in Iride, non, vt reliqui ex reflexione, fed expunicei, viridisǵsiuxta fe collocatione,

apparere Ariftoteli videtur.

Cap. $\quad V I$.

Eod. $\mathrm{E} C$ verò quòd puniceum, viridemq́ue in-

S)

99

93

39

)

39

9

")

"

",

,)

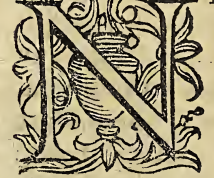
ter flauus interdum fpectatur color,propterea (inquit) tribus plures Iridis colores videri debent:fiquidem flauus, non vt reliqui ex reflexione apparet, fed ex punicei viridisq́ue iuxta fe collocatione exoritur, puniceus videlice t nigriori oppofitus albior videtur, pro puniceo itaque flanis: Id verò huius rei fignum eft, quòd ma ximè pura, finceraqú I ris in nigerrima nube efficitur : tunc enim contingit colorem puniceum magis flauum uideri; ob nubis fcilicet circumftantis nigrorem, quòd puniceum eft album videtur; quandoquidem puniceus, fi ad illa compa" returalbus eft, \& Iride propè terram euanefcente, puniceus color 
color flauus apparet: nebulam enim albam, in qua puniceas " primum apparebat iuxta iridem pofitam coloris flaui imagi $" z$ nem referre : Maximum autem horum inditium iris eft, que Text.29. à luna exoritur, qux prorfus alba apparet, quod euenit, quia on in nube atra , 8 noctu apparet . ergo ut ignis igni additus, "” fic quod nigrum eft, iuxta nigrum pofitum efficit, ut quồd " remiffe album eft, cuiufmodi puniceus color eft, prorfus al- " bum apparet. Quin \& in floribus affectio hæc perfpicuè cer " nitur. nam \& in texturis, \& variorum colorum operibus," alij iuxta alios pofiti colores, fupra quàm dici queat, alij at- " que alij apparent. Cur igitur tricolor arcus fit, hisq́ue dum- " taxat coloribus appareat, dictum eft .

\section{2uam ob caufam exteriores Iridis colores languidiores Ariftoteli appareant, o contrario ordine pofiti. Cap. VII,}

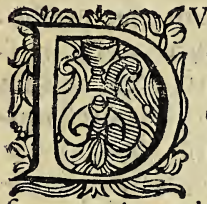

PLEX autem (inquit) apparet Iris, \& ea quę Text.30. côplectitur coloribus languidioribus eft, \& , contrario ordine difpofit is eãdē ob caufam. " $\mathrm{Ob}$ afpectus videlicet, imbecillitaté:quoniä ” enim qux exterior eft, ambitq́ue in remotio , ri fit nube, imbecillior ad eam afpectus pre- ," fertur, $\propto$ languidius inde ad folem reflectitur. Iure igitur ij- ", dem quidem, at languidiores in ea fpectantur colores: \& cō ", trario etiam ordine, fiquidem a minori, atque intimo exte- ", rioris Iridis ambitu, copiofior afpectus, quàm ab alijs ad So " lem reflectitur, quod nimirum nobis, \& primo etiam inte- ", rioris Iridis ambitu proximior exiftit. Puniceus igitur ob ", reflexi ab eo afpectus vigorem alter, qui fequitur viridis, quo ” niam debiliorem afpectum ad folem reflexit, utpotè lon- " gius à nobis diftans , afpectumqque languidiorem , nempè ", longius productum excipiens : extimus denique, qui lon-" " gius adhuc abeft, \& imbecilliorem afpectum excipit purpu- " reus, itaque maior, minorq́ue afpectus, vigor, imbecilli- " tasq́ue in utroque Iride colorum ordinis caufa videtur : fed, aliam vigoris, 1 mbecillitatisque caufam in exteriori, aliam " effe in interiori; in hac enim maior, minorque ambituum " magnitudo, in iila verò maior, minorq́ue afpectus ad nu- , B bem 


\section{Bernardini Teletij}

i" bem diftantia qux validiorem, languidioremq́ue afpectu.

Texr.31, ad Solem efficit reflexionem, tres autem arcus, aut plures " non fiunt, (inquit Arift.) quoniam \& fecundus languidior

" exiftit, ita ut tertia reflexio imbecilla videatur, nec ad So-

" lem perduci queat : Hæc de Iridis conftitutione, deq́ue ip-

" fius coloribus, \& colorum diuerfitate, atque ordine Arift. fuique. Age porro examinentur fingula.

Iridem à reflexa fieri luce, rectè Ariftoteli vifum, at now rectè, nobis, earn inter folemǵ, mediys, co in nube tan-

tum in aquam agicapta fieri poße, pofitum,

nec rectè nigredinem ad eius colores

confrituendos allatam effe.

Cap. VIII.

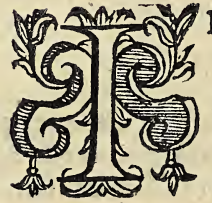

RIDEM Solis luce à nube ad nos reflexa fieri,uel inde tantum declarans Ariftotiles, quod ibi modo fpectetur, ubi ita ad Solem fita fuerit nubes, ut fpeculum effe, $\&$ afpectum noftrum reflectere valeat, alibi, nufquam fatis declaraffe videri poteft, at fi am plius id declarandum uidetur multis manifeftari poteft modis : Quoniam fcilicet temporis fit momento, \& temporis itidem momento ceffat, \& uniuerfa plerumque fimul fit, fimulque uniuerfa aboletur, nihilq́ue nube, in qua fit immutata, at aliam inter eam, folemq́ue media facta , qux nimirum Solis lucem ad eam venientem impediat, non amplius fpectatur, non per fe exiftens res, fed qux appareat tantum, $\&$ à reflexa omnino luce fiat oportet : \& qux in aqua foli expofita, uel in guttis à remis fublatis, vel manu fparfis fit, manifeftè à luce reflexa fit, neque enim in aqua vlla, qux à Sole non illuftratur, Iris fiat ulla, at nullo temporis momen to, fi lux in eam incidat. Quod igitur dictum eft, uel eo vna reflexione Iridem fieri ftatuens Ariftoteles, quod ibi modo fiat, ubi folum fpeculum fit nubes, 3 afpectum noftrum reflectere poteit, probandus omnino videtur, minimè uerò è folis illam regione tantum conftitui decernens; oportere itaque afpectum noftrum medium inter folem, nubemque fieri, \& in eadem omnino linea folem, afpectumq́ue noAtrum, \& Iridis centrum polumaque effe, pasfim enim Iridés intueri 
intueri licet, quas inter, folemq́ue medij nos minimè fumus, \& multas etiam, easque fimul, non decem amplius gradus à fole diftantes antiquioribus afpectas fuiffe memorix proditum eft. \& qux ex aqua foli expofita, vel è guttis à remis fublatis,aut manu fparfis fiút, nequaquàm nobis inter eas, folemó; medijs fiunt, nec quę è ferratili fpectantur vitro, multoq́ue etiam minus, quæ circa lucernam fiunt. Iridis certè colores in nube ut appareant, minimè ita è folis regio ne nubes effe oportet, ut eas inter, folemq́ue medij nos fimus . virg $x$ itaque, ob long $x$ uidelicet nubium partes Iridis intinctx coloribus iuxta folem Ariftoteli etiam confpect $x$ funt . Alijs non hoc tantum, fed coronx itidem integra ni mirum Irides fub ipfo etiam fole, \& inter nos, folemque me dix, non filicet reflexa tantum, \& quocunque modo refle $\mathrm{xa} \mathrm{ab}$ ijs, à quibus reflectirur Irid is coloribus intingi vjdetur lux, fed fubiens etiam, penetransq́uc ab ijs, qux fubit, penetratq́ue, \& pertranfit : ex aqua igituir foli expofita, quę fit iris, eft ubi non à reflexa fiat luce, \& aquam inter folemque media, fed pofquàm, ab aqua pertranfeunte luce, \& qux iridem per ferratile fpectatur vitrum, nequaquàm \& ipfa à refiliente, fed à uitrum permeante fit luce, \& aquam̈ nimiram, $\&$ uitrum permeans lux, $a b$ ipforum nigred ine patitur, afficiturq́ue : \& variè paffa, intinctaq́ue, varijs diltincta apparet co oribus, \& fol ipfe, \& nubes punicex , flauęque, \& purpurex fpectantur; nihiloque minus, qux foli fuppofitæ, \& nos inter, folemq́ue funt medix, quàm quæ foli oppofit $x$, \& nobis fiunt, inter ipfas, folemq́ue medijs, \& refiliens fcilicet à materiæ nigredine (ut dictum eft) \& magis etiam eã permeans ab ipfa inficitur, intingiturq́ue lux : nequaquàm igitur e olis modo regione Iridem conftituens probari poteft Ariftoteles minus etiam in nube modo illam ponens, qux iam in aquam verti coperit. Quid enim non, $\&$ in nihil adhuc verfa fiat, qux in aere crafsiufculo quid facta circa lucernam fieri apparet? \& quæ per fæpè nullis, neque fuccedentibus, neque ceffantibus fit plunijs ? Mirum prxterea fi in guttis fiat, firmam fpectari, ftabilemq́ue Iridem: neque enim in fublimi ftent guttæ, \& non decidant, uel adeo nullo temporis momento, ijs cadentibus, aliz fimiles fiant, 8 in earum fuccedant locum . itaque nulla in Iride immutatio appareat, nec fi decidant, lateant nos.

$$
B \text { 2. Perpe- }
$$




\section{Bernardini Telefij}

Perperan Ariffoteles Iridis colores ternario numero ten minari, of flaum non reflexione, fed puni. cei, viridisǵg iuxta fe collocatione apparere statuit. Cap. $I X$.

O 2 VMMOPERE certè admirari ArifoteF) 20 - 1 Iride colores intueretur, \& quin flauus re1. 25 flexione, \& ipfe veluti reliqui fieri posfit, (5) nihil videret, Iridis colores tres tantum ef5 fe ftatuat, puniceum, uiridem, purpureum; eaq́ue id ratione, quod qux natura conftat ternario pleraque numero continentur; flauum uerò propterea fpectari, quod puniceus viridi, nigriori nimirum oppofitus, albior flauus itaq; ap pareat, pasfim enim Arift. Pithagoreos illiufmodi rationibus utentes contemptui, \& ludibrio etiam habet, \& non prima ipfa corpora, qux in primis fi uera,fit ratio tria effe oportebat, nec aliud quicquam pręter corporis dimenfiones, huiufmddi inclufit numero: tum ( $v t$ amplius in comentario de coloribus expofitum eft) vere flauus, croceusq́ue, eft cuiufmodi qui in Iridis Zona fpectatur,eft, nequaquàm albo is, quam puniceus proximior eft, fed punicei, viridisq́ue mediis, \& manifeftè modicum quid obfcuratus, in viridem tranfit, \& viridisfit, \& luci omnino, albediniqúue punicieum flauo proximiorem effe : in albi folis, ignisque coloris in puniceum, flauumq́; immutatione manifeftè intueri Ariftoteles poterat . fiquidem fol, per longè tenuisfimos, minineque opacos uapores, \& qui in aquas cra fcefcere, nullo queant pacto, à quibus omninò, quam minimum eius albedo fxdatur, puniceus, at per crasfiores, \& qui modicum quid infeipfos confpiffati aqua fiunt, à quibus igitur magis illius candor obfcuratur, flauus apparet. Itaque uel Ptolom i, uel omnium, \& fenfus ipfus teftimonio ferenitatis puniceus fol, flauus uerò pluuiarum prænuncius eft, \& flammæ non in fumma, puraque in quali albę fpectantur, fed in magna quidem, minimumqúue impura accenfx renuirate punicex, in minore uerò, minufuè pura flaux fiunt, \& per huiıfmodi albæ qux funt confpectx, flaux, per illiufmodi verò punicex apparent. Itaque ibi perpetuò candidus fo- 
lis ignisqúue color in puniceum agitur ubi minimum ab immifta, impofitauè nigredine obfcuratut; in flauum uerò, ubi magis . liquido (quod diktum eft) intueri poterat Ariftoteles, luci, eiufque candori puniceum, quàm flauus eft, proximiorem, \& albi omnino, flauique medium effe. Tum in Iride, qux in aqua fit, in crasfiore nimirum, magisque opa$\mathrm{ca}$ re perpetuò ferè flauus fit, \& nullo interdum exiftente puniceo, $\&$ in ea Iridem, quę è ferratili fpectatur uitro, $x$ què ( $\mathrm{vt}$ in eodem expofitum eft Comentario) puniceum à flauo, cro ceoq́ue, \& fub rufo: parum igitur à puniceo disfidente excipi, \& hunc a Ssiduè flauiorem fieri magis, f. à puniceo recede re,\& tandê viridefcere, uideas, ut quafi oculis intueare flauü, croceumq́'; punicei, viridisq́; mediū effe. Signa certe $a b$ Arif. alata flauü magis reflexione, quã punicei, viridisq́; appofitio ne fieri declarăt. ppterea enim vbi in nube nigerrima fit Iris, primus eius ambitus flauus apparet, quoniã quod ambientis color, obfcuritasq́ue apertifsimè manifettat nubes proindeq́ue $\&$ eius nigredo ita in feipfam côfpiffata eft, ut qux ex ea relucet lux, non nifi flaua relucere queat, \& ubi propè terra euanefcit Itis, propterea puniceus eius color in flauum tran fit, quod crasfiore in aere magis lux ob fcuratur.

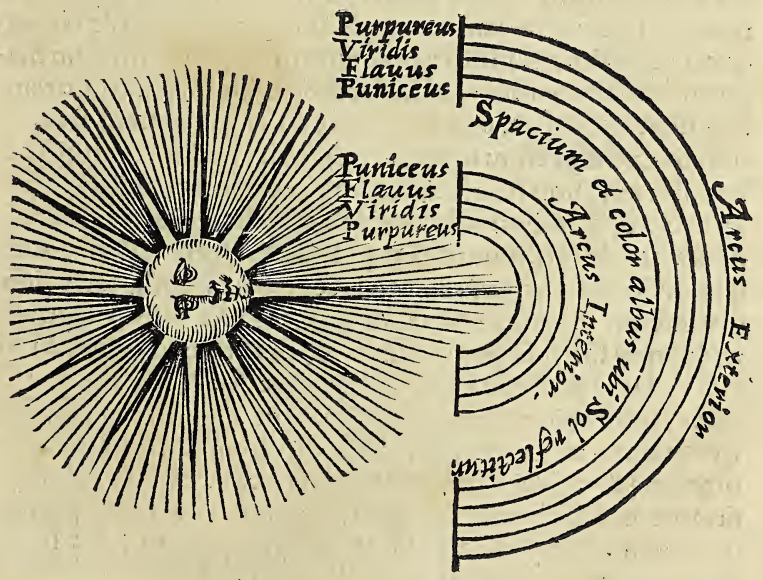

No 


\section{Bernardini Telefij}

xon rectic caufam explicatam Ariftoteli fuiffe, cur fimplio eis Iridis colores, quo spect antur ordine locati fins. nec cur in exteriore languidiores appareant. \& contrario ordine difpofiti.

Cap. $\quad x$.

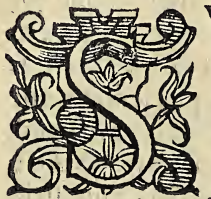

VMMOPERE itidem, multisque modis incufandus videri poteft Ariftoteles, caufam reddens, cur fimplici, atque interiore in Iride prim ${ }^{\circ}$, maximusq́; ambitus puniceus, viridis medius, tertius autem, minimufmus, maximus q́ue purpureus, minimus verò puniceus, $\&$ que purpureus. contra verò in exteriore prilanguidiores appareant omnes. Efto enim non proprijs, verisque, fed perfpectiuorum uti interdum pofitionibus, \& uifum effingere ad res efferri liceat, at ibi id certè tantum liceat, vbi rationes adducuntur, qux vtriq́; conueniant pofitio ni, quales, qux ab Ariftotele ad vtriufque Iridis colorum ordinem explicandum illatę funt,videri non poffunt. fiquidem inde (vt vifum eft) luci proximiores, remotiorefuè colores videri aftruit, quod magis, minufuè uigens afpectus à nube ad folem reflectatur, magis autem, minufuè ille vigeat, quod ad maiorem, minoremuè ambitum, ipfe nimirum magis, minufuè copiofus, uel ad remotiorem, propinquioremque feratur nubem, qux rationes, fi lux ad nubem feratur, indeque ad afpectum noftrum referatur, nullum omninò habent locum, non fcilicet à maiore, vel minore ambitu refle$x$ a lux magis, minufuè lucere, vel infenfile, quid longius producta debilitari , imminuiqúu, \& languefcere videri poteft, qux nullo temporis momento ad extrema omnia ferri, longisfimeque amotas nubes, \& quæ uis alia nihilo fegnius, quàm qua fub ipfo pofita funt fole, iliuftrare videtur, At eò etiam damnandus magis, quòd neque fi ad externa feratur uifus, rectè colorum uarietatis caufam asfignet ad afpectus (vt dictum eft) uigorem, imbecillitatemuè illam referens omnem; \& uigoris, imbecillitatifuè caufam ad maiorem, minoremuè ambitum, magnitudinemq́ue, $\&$ nubis propinquitatem, diftantiamuè, ut ne reflecti quidem, aut frargi $\sigma_{1}: 2 a n: q 1 x$. Igitur quafi per cathetum fpectantur longè fpet- 
tantur exquifitius, \& vbi, quid diligenter intueri volumus; quafi vifum contrah imus, conftringimusq́ue, \& quantum ficet minimum id intuemur, quod nimirum, veluti lux afpeEtusitidem nofter fi ad vifilia feratur per amplius diffufus fpatium debilitetur, imminuaturque, at non (quod Ariftoteli placet) modicum quid progreffus, qui ad longè remotisfimas ftellas nullo temporis defertur momento, nihiloq́ue eas lucidas minufquàm longè proximiores intuetur, \& coloribus ijfdem, nihiloq́ue magis vigentibus nubes fub ipfo pofitas fole, quàm in appofita cœli regione, quos nec valdè etiam albos, fed ad nigrum tendentes, vel longè faltem fpectari oportebat languidiores vifu in refexione tanta fummopere debilitato. Quoniam igitur ad maiorem ( vt dictum eft ) ambitum vifus delatus robuftius inde ad folem reflecti, \& propterea minus decipi videri non poteft, nec modicum illud, \& nullius momenti fpatium, quo exterior iris ab interiore magis diftat protractus adeo debilitari, infirma riq́ue, $\&$ adeo inde infirmius reflecti, \& decipi omnino adeò, ut non languidiores modo, obfcurioresq́ue afpiciat, colores, fed contrario etiam ordine difpofitos, \& pro alijs alios, utique : nec cur interioris Iridis colores eo ordine, exterioris verò contrario difpofiti fint $\&$ languidiores fpectentur, caufam explicans, probari poteft Ariftoteles. Minus etiam contrarijs vtens rationibus, \& qux fefe mutuò impugnent, deftruantq́ue; fiquidem primus Interioris Iridis ambitus punicells, luciq́ue apparet proximior, quod ad maiorem cum copiofior defertur afpectus, proptereaq́ue robuftior ad folem reflectitur, primum itidem exterioris puniceum apparere oportet, \& Ipfum afpectum excipientem copiofiorem, forte \& reliquos omnes interiorem Iridem continentes ambientesq́ue : Tum fi propterea languidiores apparent exterioris Iridis colores, \& extimus illius ambitus a luce magis remotus, quod ad longius fpatium productus afpectus debilitatur, \& infirmior inde refilit; utique \& primum Interioris Iridis ambitum ad nigrum oporteat tendere magis, magis $\mathrm{ab}$ afpectu diftantem. ad quem igitur Imbecillioris Ariftote li deferatur, \& huiufmodi itidem refiliat : neque enim certum, definitumq́ue asfignare queat A riftoteles terminum, ad quem Integer, valensque deferatur afpectus, ad quem $\mathrm{fi}$ progediatur, debilitetur infirmeturq́ue. Tum non vfquequaqque 


\section{Bernardini Telefij}

que æquè à nobis diftans afpectatur Iris, fed $h x c$ ab afpecu noftro, illa longiore diftans fpatio, quàm quo ab exteriore interior. Cuius itaque iuxta Arifotelis dogmata (id quod minimè euenire videtur, fpectari oponebat colores, \& con trario etiam ordine difpofitos. Neque igitur modum Ariftoteles vmquam ex plicet, quod duplex fit iris, nam fi quie foli, vel afpectui noftro propinquiora funt,ea luci proximio ra fpectantur, uno modo fiat Iris, eoq; ordine, quo interior fi lux ad nubes delata ad nos refilit : fiquidem qui continent ambitus foli (ut dictum eft) propinquiores funt, uel quo ex terior fi uifus ad nubes fertur, indeq́ue ad folem reflectitur, \& in longius profectus debilitatur, vt Ariftoteli placet, itaque, \& decipitur.

Incufandus itidem videri potest Aristoteles, caufam cur Spatium, quod inter vtramque iridem eft; album appareat; nibilinquirens: fui verò, quodnon rectè illam explicarunt. Cap. $X 1$.

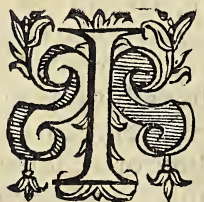

NCVSANDVS Itidem videri poteft Ari ftoteles, caufam curfpatium, quod inter vtramque Iridem eft, non puniceum, fed album appareat, nihil inquirens inquirendú omnino. Suorum itaque plures fummo illam ftudio inquefiuere; at nullus ( vt videtur) fatis attigit ; propterea (inquit Aphrodifeus) fpatium inter duos Irides interceptum puniceum colorem, ut ambitus quibus clauditur non refert, quod non ab omni nubis parte afpectus ad folem, feu lumen folis ad afpectum reflectitur, fed definita funt, certaq́ue reflexionum loca, \& definitum, certumq́ue fplendidi lumen mittentis corporis à fpeculo diftantiä effe oportet. ab ijs igitur fpecul is ita diftãtibus, fitumq́ue certum habentibus arcuum colores reprefentari, minimè verò ab aliis non eundem fitum, eamdemque ad folem nactis diftantiam. Rectè quidem non in omni fitu, fed iucerto tantum, difinitoq́ue Iridem fieri; neque enim ex aqua foli expofita Iris refilit, quocumque illa exponatur modo, \& paululum quid immutato illius fitu, vel aboletur, 
letur, vel longè fit diuerfisfima, \& longè diuerfisfimis, diuerfoque modo intingitur coloribus; at fpatium illud nequaquam in alio ad folem, feu ad afpectum fitu uideri poteft, quàm quos contingit ambitus. Non rectè certè lucidi itidem corporis ad fpeculum diftătiam definitam effe opor terc: fiquidem nullius omnino momenti fpatium exiftit, quo nubes quæuis, quam alia quæuis à fole amplius, minufuè diftant in tanta à nubibus ad folem diftantia, $2 \mathrm{ab}$ omnibus quocunque pofitis loco æquè reflecti uidetır lux : eodé igit colore intinctx nubes qux fub occidente funt fole, $\& t$ qux in oppofita coll parte, non fcilicet uel lux ipfa, uel eius actio huiufmodi apparet, quæ fpatio ullo debilitari ( ut dictum eft) queat.Huiufmodi certè caufas asfignare fatis fi fit, nullo labore, nullaquue moleftia colorum, qui in Iride fpectã tur rationem reddere liceat. omnium longè Ammonius, pro opinio. ximius, \& qui fi in ijs qux ab Arift. didicerat, inque ijs amplius quæ probarat ipfe, paululum quid immoratus foret, veram (reor) protuliffet. propterea (inquit) nullus Irinus co lor illo in fpatio reprefentatur, quod radijs;afpe ctus, feulu- Confuta. minis eò perpendiculares feruntur, qui quoniam robuftisfi- tio. mi funt nubes permeant, nec referuntur. nulla quidem afpe ct us noftri, \& radiorum ab ipfo emanantium mentio erat, Ammonio facienda . nequaquam ad vifilia afterri vifum, fed ad ipfum vifilia introferri omnia ab Arift. edocto, quod fi Arifotelem imitato, perfpectiuos, \& ipfi in hoc fequi in animo erat, nequaquam ad intermedium foatium perpendi culares radios deferri proponendủ erat, fed ad Irid is vtriufque centrum, iuxta perfpectiuorum omnium fententiam; fi quidem perpendiculares reliquis æquè diftent oportet, qui eofdem confpecturi funt colores. Nec verò fi intermedium fpatium Iridis utriufque fit centum, vtraque terram verfus fiat, fed cœlum verfus altera. Sic enim Iris vtraque eodem modo à centro, \& perpendiculari diftat, non fi fub altera conftituatur altera. At neque cur exterioris Iridis colores languidiores appareant, docere nos Ammonius queat, à radijs enim æquê perpendiculari diftantibus §què vigentes co lores fpectentur oportet. Non igitur ad maiorem afpectus noltri vigorem intermedij fpatij albedo referenda erat Ammonio, fed ad lucis, quod fecundo loco facere videtur, \& illud amplius docendi ab eo eramus, cur videlicet qua eò de

C fertur 


\section{Bernardini Telefij}

fertur lux contigua vtraque robuftior exiftit: neque enim perpendicularem eam, directamq́uie pofuiffe fatis fit, fed ma gis explicanda erat res, magisque in aperto ponenda, $\&$ qua nimirum folis parte emanans robuftior fit, quàm ut à nubiú opacitate infici posfit, \& cur itidem qux illi proximæ funt,

3.Refpon continguęque, non ijfdem præditæa apparent viribus, fed indeo Recé teriore exterior languidior, nihil illa (ut dictum eft) à robufiorum. fta diftans magis. Iuniores peripatetici in ijs, qux ab antiquioribus acceperant acquiefcere impotentes, dictarumq́; diuerfitatum rationem reddere defperantes, fi quomodo Ariftoteli placet,Iris utraque a fpectus ad folem reflexione fiat exteriorem minimè eo pacto exoriri contendunt, fed interio ris Iridis imaginem effe, quæ in nube exteriori appareat, à qua ad interiorem Iridem afpectus reflectatur:fpatium igi tur intermedium album videri, quod fpeculi rationem non habeat, in quo Iris interior, ut in fpeculo appareat: duobus enim fpeculis è regione pofitis imago quidem alterius in al tero apparebit, non tamen in fpatio, quod inter utrunq; eft : \& propterea itidem altx languidiores exterioris Iridis colores, quòd à fecunda fiunt, \& debilitata reflexione, una quidem à nube exteriori, in qua exterior Iris apparet ad interio rem Iridem : altera ab interiori ad folem, \& propterea contrario ordine difpofiti, quòd qux in fpeculis fpectantur, quò remotiora, à fpeculis exiftunt eò itidem apparent remotiora; propinquiora, quæ magis propinqua funt . fi quis itaque enfem fpeculum uerfus dirigat eius cufpis que fpecu lo propinquior eft intraillud prima appareat, maximeque propinqua : manubriú tanto intra fpeculum fpatio recedat, quantum extra ab eo remotum eft. Iure igitur puniceum in exeriori Iride primum videri, \& interiori proximus, extremum uerò purpureum, $\&$ maxime remotum, quod maximè

Confuta- ille propinquus, hic remotus fit maximè. At præter quàm sio. quod medium fpatium non aliud, quàm nubes exiftit,eadéq́ue,ut exiftimare licct, plerumque crasfitie, qua, \& contingens ipfum, nubes quæ fpeculum fieri uidetur: in quo igitur interioris, ueræćue Iridis imago uideri debeat,iuxta ea quę fpeculis eueniunt, veluti propinquiores, qui fpeculo funt co lores proximiores apparent, \& remotiores itidem, qui remo tiores : fic \& figurx itidem partes proximiores, qux proximiores, \& remotiores, qux remotiores reprefentant effe op porteat. 
porteat . In exteriori igitur Iride conuexam partem, qua interioris conuexæ, proximæq́; imago eft, propinquam ei,vi deri, remotam uerò concauam, qua concaux interioris ma gis à fpeculo remotæ imago eft, eorum more, quæ in fpeculis fpectantur, non concauam exterioris conucxæ interioris propinquam non alteram omnino (quod euenire videmus) $\mathrm{ab}$ altera contineri . fed alteram oppofitam effe alteri. Peripateticorum itaque nullus cur medium inter utramque Iridem fpatium album fit, vel cur languidiores exterioris Iridis colores, \& contrario ordine collocati fint; nec qux ad Iri dis omnino colores attinet uel Ariftoteles, uel fuorum vllus, fatis explicaffe videri potelt. Age porro quod reliquum eft circularis ipfius figurx, \& diuerfam eius quantitatis caufam asfignantem Atiftotelem audiamus.

Cur circularem fieri Iridem neceffarium Ariftoteli vidsour, \& quomodo talis fiat, \& femicirculi quidem guantitate Oriente, fiuè Occidente Sole, portio verò femicirculo mirsor, fole fu pra boriZontem fublato. Cap. XII.

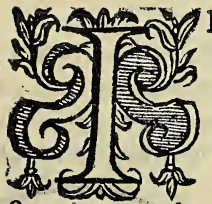

RIDEM circularem fieri oportere, at neque orbem, nec femicirculo maiorem fpectari poffe, \& femicirculum quidem oriente, fiue occidente fole, portionem uerò femicirculo minorem fole ab horizonte fublato, \& propterea (ut videtur) Ariftoteles ftatuit, quod ut Iris huiufmodi appareat, $\&$ unaquaque eius in Zona idem in uniuerfa fpectetur color radiorum fingulorum ab afpectu noftro ad nubem productorum ad fingulos feipfos à nube ad folem reflexos eamdem oportere effe ratio nem fupponit, in conum itaque ad nubes illos ferri, indeć; ad folem reflecti, neceffarium exiftimat, id porrò fieri non poffe, nifi folem inter, Iridemq́ue nobis ita medijs pofitis, ut eadem in linea folis, iridisq́ue centrum, \& afpectus nofter fit, ita porrò fole, nubećue, \& nobis locatis, itaque radiis productis, circularem fieri iridem, at nunquam femicir culo maiorem, orienteq́ue tantum, \& occidente fole femicirculi quantitate, fupra orizontem uerò fublato portiones

C 2 cò 


\section{Bernardini Telefij}

eò afsiduè femicirculo minores, quo fol fupra orizontem ma gis eleuetur, longa illa, \& per obfcura fanè perplexaque demonftratione manifeftare contendit, fuperflue fortè fiquidé (ut fupponit) afpectus noftri radij finguli ad nubem producti in eadem fint ratione ad fingulos fe ipfos ad folem reflexos manifefte in circuli ambitum definere illi uideantur, $8 x$ afpectus nofter, qui ufquequaque in horizontis centro eft, in eadem cum folis, \& iridis centro, poloq́ue linea fit, \& $\mathrm{ma}$ nifefte oriente, atque occidente fole dimidius radiorum tur bo fupra horizontem appareat, femicirculo autem maior fpectari omninò non pofsit, \& quò fupra horizontem fiquidem afpectus nofter ad ea, quæ fub horizonte funt deferri nó pofsit, \&r quo fupra horizontem eleutur fol magis, \& eo portio femicirculo minot appareat, eo enim iridis centrum fub horizontem magis deprimatur, magisque occultetur: minor itaque afsidue fupra horizontem ipfins portio fiat, $\&$. nullo tandem puncto verticis proximo facto, quod nimirum iridis centrum, polusq́ue adeo infra terram recedant, ut nul la prorfus iridis portio fpectari queat. nam qua ditantia fol ab horizonte eleuatur, eadem iridis centrum, polusq́ue, cum in eadem fint recta linea infra illum demittuntur, quod ex defcriptis figuris patere poteft.

Quaildo in folis ortu, aut occafureflexio fit, Dimidia circuli portio à finitore relinquitur, ea Didelicet que Supra terram extat.

Cum fol supra borizontem Sublatus fuerit, Iris apparet minori figura, quadm femicirculi, ac quo magis fublatus fuerit, eo minorem circuli portionem videri.
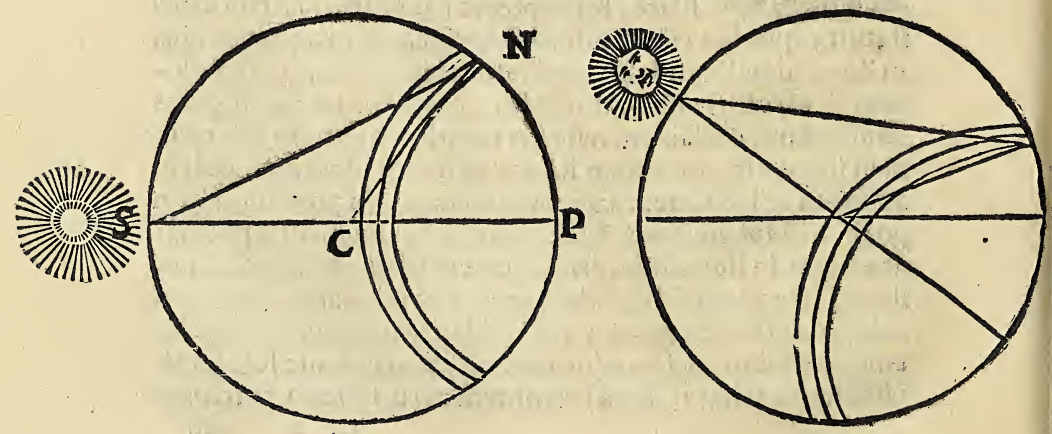

Qua 
Qua diftantia Solabborizonte eleuatur, eadem Iridispolus ac centrum, cum in eadem fint recta linea, infra illum demittuntur . Quare cum ad meridianum afcenderit, minima circuli portio uidetur.

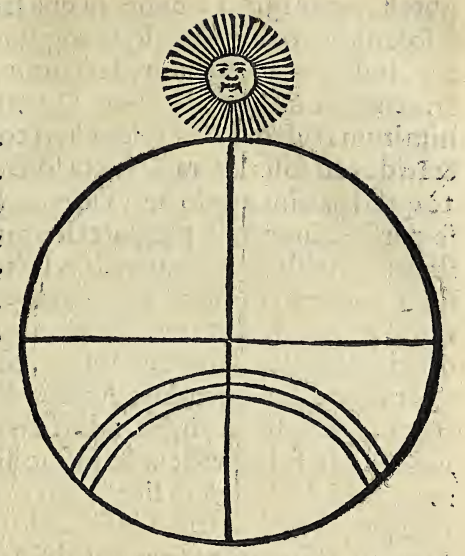

Non recte circularis Iridis figure, nec cur femicirculus oriente, occidenteque fole, minor verò femicirculo fole fublato appareat, caufam ab Ariflotele redditam fuiffe. Cap. XIII.

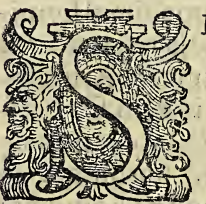

IQVIDEM Irini colores, \& fnis quiq́ue in Zonis in circularibus tantum rebus, \& fi Iris nulla ad folis latera fieri appareat, fed quxcumque, fiat ita è folis regione fiat, vt in eadem cum folis, Iridifq; centro afpectus no fter fit linea : eius Itaque radij finguli ad Iridem producti ad fingulos fe ipfos ad folem reffexos in eaden effe ratione videri posfint, non temerè, nullaqúu ratione, vt Iris qualis apparet, fingulisque eins in Zonis idem fpectetur colorafpectus noftri radios fingulos ad nubem productos ad fingulos feipfos à nube ad folem refexos in eadem effe ratio ne, \& propterea Iridem circularem fieri Ariftoteli decretum videri posfit : Q Qoniam en im reflexione, \& afpectus om nino noftri radijs pasfis Irini fiunt Arifto teli colores, idem vt fpectetur color, modo eodem radios pati oportere videri 


\section{Bernardini Telefij}

poteft . æquè igitur à nube, in qua Iris fit, afpectus nofter, \& à fole nubes Ipfa ad parefq́ue angulos radij ad nubem ferantur, indeq́ue ad folem reflectantur, qux nifi circularis fiat Iris euenire minimè poffunt . Quoniam vérò virgæ oblongæ nimirum Iridem iuxta folem ficri confpecta Ariftoteli funt, \& Irides ad folis latera, \& iuxta folem longè plurimæ (nifi for tè quod pasfim modo fieri videtur, \& quod olim factum fuif fe perfpectiuorum ) peripateticorumq́ue præftantisfimi teftąntur, Ariftotelis temporibus factum numquam fuit, confpici potuere, minimè propterea circularem fieri Iridem, quod ibi modo fiat, vbi afpectus noftri radij ad nubem producti ad fe ipfos à nube ab folem reflexos, in eadem funt omnes ratione decernendum Ariftoteli fuit : neque enim afpectus noftri radij ad virgas, ad Iridesóf; foli propinquas delati, indeq́:ue ad folem reflexi huiufmodi videri poffunt . \& fummè mirari Ariftotelem licet, qui cum à nube affici folis lucem proptereaque Irinis infici coloribus intuitus foret, \& co lores ad vifum intro ferri ftatuiffet, dictam afpectus noftri, radiorum, feù lucis etiam ipfius rationem inquirat, vt qualis à nubibus illa refilit, ad uifum deferatur, non fiquidem ve luti certo fitu, certaq́ue nubis ad folem pofitione, ut ita ei" lux intingatur, opus eft. Sic itidem, ut quo colore intincta à nubibus refilit, talis ad afpectum noftrum deferatur certo opus eft fitu, certaq́ue pofitione, fed qualis à nubibus refle$x a$ eft, talis ad afpectum noftrum deferri modo ad eum poffit, ubicunque is fit defertur, \& ad innumeros fimul homines, veluti qua à fole ipfo emanat, uel ab alijs reflectitur re bus . At multò certe amplius \& mirari, \& damnare Ariftotelem licet,propterea à nubis tantum regione iridem fieri poffe contendentem, quòd iuxta folem ea nubis concretio, que ut iris appareat opus eft, fierinon posfit, fed ftatim aut in pluuias cogatur, aut diffoluatur. Nam fi quod ne hominum quidem vulgus faciat, in eadem nubes, folemq́ue A riftoteles ponat fuperficie,proptereaq́ue nubes, quæ iuxta folem fpe ctantur, foli proximæ, continguæq́ue : quæ uerò in oppofita foli parte locatæ funt remotæ, \& non quomodo funt, vel æquè omninò omnes ab eo diftantes, uelid aliis aliæ proximiores, remotioresuè , quod in tanta à nubium ad folem diftantia nullius fit momenti, non propterea in ijs modo, qua foli oppofitx funt, \& quarum, folisque medij nos fimus, 
\& non uel in omnibus, uel in is faltem, qua ueluti medio modo, \& ueluti ad folis latera locata funt, iridem fieri ftatuendum fuit : neque enim vel ubi fummè imminuta eft fo lis vis, ibi modo ea concretio fieri uideri poteft, nec multo in fuppofitas nubes magis, quàm in oppofitas, aliafuè quafuis agere videtur, nihil omnino fub fole minus quàm è folis regione, \& alibi ubiuis nubes cogi uidentur, fed $x$ que \& eodem ubiq́ue modo, ut fi iriș nulla unquam fub fole, vel adfolis latera, fed omnes è folis tantum regione confpectx fint, non tamen ftatuere liceat propterea ibi fieri tantum, quod ibi tantum ea nubis concretio fiat, qua ut iris conftituatur opus eft . eo itaque magis damnandus, reijciendusque Arifot. qui id ftatuat, fenfui etiam aduerfus contrariusque. neque enim vel fuorum ullus dubitare queat plurimas homini irides iuxta folem confpectas fuiffe. "Aliis certè non fimplices modo irides, fed quatuor fimul, nec de cem amplius à fole gradibus diftantes confpect $x$ funt, $\&$ fub ipfo etiam fole integræ ipfa aliis coronæ nimirum irinis diftinctx coloribus. Quoniam igitur non præterea circularis fieri iris uidetur, quòd folis è regione fiat, \& nobis ita in eius, folisq́ue medio pofitis, ut eadem in linea folis centrü cum afpectu uoftro, Iridisq́ue centrum, \& polo fit, \& uel fub fole ipfo ad eius certe latera pasfim fieri uidetur : nec curmaior femicirculo Iris fieri non appareat, nec cur femicirculi quantitate, oriente, occidenteque fole, minor verò femicirculo fole fupra horizontem fublato fiat, eoque afsidue minori quò fol eleuetur magis, canffa explicata effe videri poteft . ex illis enim hxc tota pendet, \& maiorem femicirculo confpectam fuifle non Senéca modo, fed qui maximè Ariftotelem colit Auerroes teftatur. Cur uerò minoris circuli fectio videtur, vbi dimidia, maioris contra, ubi femicirculo minor apparet, pollicitus quidem Ariftoteles, 22 reddendam omninò,nullam attuliffe uidetur;fui poftea reddere illam tentarunt, \& variis tentarunt uiis, quod nimirum nullus in eam, qua ab illis reddita effet acquicf cere poffet. At horum tamen fententiam in medium afferre, \& num quę ipforum dux facere defperauit, fuorum quifpiam prętiterit intueri ne grauemur.

Senecali. I. natur, quxiti. Anerr. 30 Mereo. Summ.2。 cap. 3. 
Bernardini Telefij

\section{Varie Peripateticorum fententie, cur femicircularis Iris minoris circuli, minor verò femicirculo cir- culi maioris fectio videtur. Cap. XIIII.}

x.Sententia Alex. Piccolo.

2. \$2 minoris circuli portiorem, maioris verò, vbi fe3. 3 micirculo minor fpectatur videri.propterea $\mathrm{Pe}$ ripateticorum nonnullis placet, quod illa in fuperiori, \& putiori fit aere, hæc in terræ proximiori, \& magis crafio, magisq́ue à uaporibus occupato, in quali maiora apparent omnia, tum quod propè terram ubi apparet, minus $a b$ afpectu noftro diftat. Semicirculus autem longius $a b a-$ fpectu abeft, fublimioré enim attingit locum. traditum uerò ett, qux longius cernuntur ea minora, maiora autem, qux

2.Refp.eproximius, aut qua funt videri mole. Alij minorem uideri tiã Alex. famicircularem iridem, quoniam radiorum perfractione, piccolo. non itam reflexione, \& oriente, vel occidente fole in matutino videlicet vel vefpertino fiat aere, in longioreque fupra terram fpatio, in quali minor femper à perpendiculari fit per fractio, proximius uidelicet ad perpendicularem accedunt radij : indenfiore enim per franguntur re : quin $\&$ illud $a l i j$, 3. Refpö. camdem nimirum femper effe iridis cordam, \& æqualem femper, at anbitum ipfum feu arcum deprimi, in fefećue recedere, aut attolli, \& dilatari prout magis, vel minus in fublimi fe artollit foi. femicirculum itaque fieri ubi in horizonte ent fol, at quo magis afcendit arcum fubfidere, \& maio ris circuli fieri arcum, eius corda eadem ufquequaque in ho rizonte permanente : quoniam enim linearum circulum fecantiumq́ue dimidium cum fecar reliquarum omnium maxima eft. Si circuli pottion is corda alterius diameter fit, $\mathrm{fc}-$ micirculus omnino minoris circuli fectio fiat neceffe eft, funt etiam qui idco maioris circuli portionem femicirculo 4. Refpó, minorem videri exiftiment, quod oculus, quo humilior iris fpectatur, eò magis eam diftare, iudicet, idque ob intermedię terræ magnitudinem, iride autem fublata diftantiam צ. Refp5. hanc intelligere nequeat : quam etiam ob caufam orientia Recentio rum. altra, occidentiaque maiora quam medio in cœlo fpectantur: Poltremi, honum nihil probantes, dicendum (inquiüt) portionem 
portionem, que fole fublato apparet, maioris circuli videri, quoniam in aere, nubibusq́ue longuiquioribus cernatur.eas enim, qux propius funt, folis calose folutas effe, aeremq́ue proximiorem fimiliter attenuatum . afpectum igitur, feu fo lis radios è magis loginquo refiecti, itaque turbinem, qui exillis exiftit, longius protendi, ob eamque caufam bafim, qux Iridis faperficies eft, ampliorem habere; fiquidem radij cum recta in turbinem protendantur, quò longius protenduntur, eò magis inter fe diducuntur. Has rationes, cur ubi fublato fole, femicirculo minor apparet, maioris circuli por tio videatur Iris, peripatetici reddunt: Age forro examinen tur fingula .

Peripateticorum nullus rectè caufam explicat, cur vbi femicirculo minor apparet Iris, maioris circuli portio videatur. Cap. $X V$.

ON quidê femicircularis qux fit Iris mino-

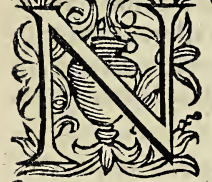
ris circuli portio appareat, quod magis à terra elata eft, itaq́; \& in tenuiore aere, \& longius à nobis fit: ut enim modico illo in Cöfutatio I.Refpon:

if fit aer, ut qux ibi fpectantur, tanto appareant minora nō vniuerfus Iridis femicircnlus, fed cius modo vertex minor appareat; eo enim modo fublimior eft:nam infimis partibus $\&$ ipfa terram attingit : quibus itaque, $\&$ in $x$ què craffo facta. 2ere, \& eqquali à nobis diftans fpatio, nihil anguftior, quin 2mplior fpectetur: mane tantum facta, aut uefperi,tum non unius, eiufdemq́ue circuli, fed duorum omnino portio femicircularis appareat iris, \& minoris quidem eius vertex infimæ uerò partes minoris : Minus etiam admittendi videntur qui minoris circuli fectionem femicircularem Iridē Confuratio 2. fieri afferunt, quòd in aere fit crasfiore, in quali radiorum per fractiones minores à perpendiculari fiunt, nam \& rationibus utuntur, quę incertæe funt, proprijs certè : uerisq́ue corum pofitionibus aduerfantur, contrarixque funt, \& contrarium ijs, qux manifeftè eucniunt, aftruere contendunt. Non

D fcilicet 


\section{BernardiniT elefij}

fcilicer qux uifus radij, fi extra his, \& ad vifilia feratur, pati in ijs illos uerifimile fit, fed qux vifiliū fpeties dum ad uifum feruntur, manifeftè patiuntur, intuenda peripateticis erant . hoc fi factum ijs foret, utiq́ue matutina, uefpertinaque Iris, qux omnino in crafsiore fit aere, amplior confpeeta omnino foret, folem, ftellasq́ue reliquas omnes exorientes, occidentesq́ue per plures nimirum, crafsioresquue confpectas uapores, \& qux per aquam, perq́ue uitrum fpectanConfuta- tur ampliora fpectari omnia intuitis. Nec uerò ij placere pof

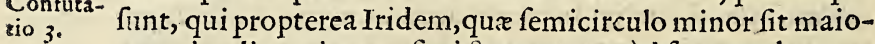
rem circuli portionem fieri ftatuunt, quòd fuper eadem om nino corda irides fiunt; omnes itaque, qux fuper ea femicir culum anguftior, amplior uerò qux portionem femicirculo minorem abfoluit,iris fiat neceffe eft. Semicirculum porrò oriente occidenteq́ue fole perfici, eo autem fublato iridem veluti fubfidere $\&$ in portiones femicirculo minores eo asfiduè definere, quò fol eleuetur magis : quod enim quxritur, fumere videntur, non fiquidem aliud quxritur, nifi cur fubla to fole, femicirculi corda portion is femicirculo minoris cor da fiat: Multis itidem damnandi funt modis, qui maioris cir Confuta- culi portionem ideo femicirculo minorem videri ftatuunt, tio 4 . quòd quò magis humilior fpectatur iris, magis eam diftare iudicat oculus, veluti orientes, occidentesq́ue ftellas diftan tiam ubique ob intermediam terræ magnitudinem intelligens, quàm iride, ftellisq́que fublatis intelligere nequeat. Mitto enim, quod fi uerè qux humiliora funt, ampliora apparent, nequaquam qux femicirculum abfoluit iris uniuerfa ea,qux femicirculo eft minor, uniuerfa anguftior appareat; fed illius uertex modo huius vertice quo, ut dictum eft, folo fublimior eft, haud rectè, qux humiliora funt longius ea ab effe ab oculis iudicare : \& peius etiam qua longius abeffe ij intelligút ampliora ipfis videri peripatetici ftatuút : \& quod utriufque afferunt fignum, minimè id proprium, minimeq́; firmum videri poteft. Nó fcilicet videnti animæ maiora vl$\mathrm{fa}$, minorauè apparent, quòd proximius ea, longiufuè abeffe ipfa diiudicet, fed fingulis eam asfignat magnitudinem, inqua ad ipfam accedunt, \& qua omnino ipfi apparent; fed qux intelligit anima maiora ea ftatuit, quàm videnti confpecta funt. Nec uerò orientes, occidentesq́ue ftellx, propterea quod humiliores funt, itaq́ue longius eas abefie intelligit 
telligit oculus, maiores apparent: fed:quod verè maiores ad videnté aĩam feruntur, \& maiores feruntur, qđearum lux pro lixius per terræ contiguum aerem delata amplior in ea crafitie facta eft, id quod iridi minime euenire poteft : per idem enim fpatium, perque eumdem aerem vtraque fpëctatur,vt fi non verè fit maior, maior omnino non appareat, poftremorum itidem ratio reijcienda \& ipfa eft, qux fcilicet \& magnü quid nubes alias, alijs magis, minusq́, à fole diftare, \& in ijs $m x$. qax fole proximiores funt, eo fublato Iridem fieri non poffe fupponit, quòd à robuftiore iam facto fole magis attenuatæ fint, folutæáue,quàm $v t$ in ijs Iris fieri queat. nam præter quam quod (vt dictum eft) fpatium quo magis, minusque à fole diftant in tanta à nubibus ad folem diftantia, momenti nullius, nulliusq́; omnino videri poteft quantitatis : nequaquam qua fublato fole irides funt, in remotioribus, qux verò oriente illo,occidenteá; in proximioribus, fed omnes inxquè diftantibus fieri videntur. Minimè pręterea, qux foli fuppofitx, \& proximiores omnino videri poffunt, ijs magis attenuari,foluique videntur,quàm qux illi opfofitæ funt, \& quàm longifsimè abeffe apparent : quin eft vbi reliquis aer omnis purusfit, nitidusq́; , is verò cui imminet fol nubibus, caligineq́; oppletus, firmus certè, ftabilisq́, effectus qui eft, longè inconftantifsim $x$ cauf $x, \&$ qux pafsim, fummeǵ; varie tur, afsigandus non eft.Neq; Ariftoteles igitur nec fuorum v1 lus, eorum vlius, qux iridi eueniunt, caufam fatis explicaffe videri poteft. \& quàm longifsimè abfint omnes rectè illam $v t$ explicent, qui lucis naturam penitus non infpexerint.quo niam enim manifeftè iris lux eft à nubibus refiliens, at non integra puraq́; , fed ab ipfis quid paffa ; utiq; cius exortus vt innotefcat, quid fit lux,\& quid à rebus quas attingit, fubitq́; \& à quibus refilit,patiatur, notū fiat oportet.Age igitur, qux de ipfius ingenio, viribusq́́; \& pafsionibus in comen tarijs de rerum natura, $\&$ de coloribus expofita funt, \& ad propofitum negotium fpectant, repetete ne grauemur.

Lib.4.2. 


\section{Bernatdini Telefij}

Lucem ad rubes delatam relucere ab ys, of non albam, puramque, Sed ab carum materia nigredine focdatam, varÿsǵ coloribus coloratam, at direcitam, robuftamque, minus, quàm obliquam, languidamque. Cap. $X V I$.

Lib.4.ac. $V X$ (ut in comentarijs ijfdem expofitum ro. ad Is. eft) robuftius quidem denfam quampiam delata ad rem, \& inqua quod nihil eam fubeat copiofa fiat, at uel benè tenuia permeans entia, proindeque benè exilis pe $a \mathrm{ma}$ nens à fe ipfa ueluti ipfo à fole çuaqua verfus effunditur. itaque fole nondum exorto, \& penitus iam abdito, benè nobis confpicua fit, eoq́'te clarior, quò minus noltro à cœlo abfit fol, quò fcilicet ad illius portionem, qua terris proximior, proindeq́ue $\&$ crafsior fit, $\&$ in qua omnino copiofa fiat, feratur lux. Prẹterea, \& à coloribus, quos attingit vel fi non denfis ij rebus, fed aeri, lacique ad eum reflexa in fint, proindeque non robufti, copiofiq́ue, fed benè exiles beneq́ule languidi fint, intingitur omnibus. Itaque lux aerem viridibus obfitum frondibus, \& panno robuftiore quopiam colorato colore fuperfantem, \& coloratum tranfuecta vitrum, non alba amplius, fed frondium, pannique, \& vitricoloribus colorata in oppofitis fpectatur parietibus:nam non a frondibus, pannoq́ue, fed quod dictum eft,à luce eam intin$\mathrm{gi}$, qux à frondibus, pannoque ad intermedium fuperftantemq́ue relucet aerem. Inde liquido patet, quòd haudquaquam, veluti frondes Intercifa, \& à fe ipfa diuifa, fed continua, nec cuinfmodi fuperficies, $f$ ipfa ad parietem feratur in eo fpectetur linex inftar nullam fortita latitudinem, fed benè ampla in eo fpectatur. Et aquas, nubesq́ue permeans, \& relucens etiam ab ijs, fi paulo profundiores, denfiorefuè fint non albo amplius, qualis, \& lucis, \& illarum vtriusq́ue eft color, fed lógè pluribus, \& omnibus propemodum, qui album, nigrumq́ue intermedij funt, \& ipfo etiam nigro colorata relucet, quòd nimirum penitus eas fubiens, earum materix nigredinem attingit, \& prout maiori, minoriuè eius portioni immifcetur, eò magis, minufuè ab ea exuperatur, ad nigrum 
que agitur, Itaque vbi humile êt mare, album; ubi paulò viride; ; ceruleum vbi amplius: \& nigrum vbi profundifsimü: eo fcilicet magis obfcurata, ad nigrumq́ue acta, quz ab eo re lucet lux, quò ampliori ipfius materix nigredinè immifta elt. Nam materiam nigram efie, $\&$ in ij $f d \mathrm{~cm}, \&$ in proprio am

- plius de coloribus comentario, fat is eft (vt exiftimo ) decla ratum.\& cobuftarum rerum nigredo manifeftè declarat, que nimirum quoniam nec calori, quo clabente tit, \& cuius fpeties manifeftè albedo eft, nec frigori, quod illis inefie exiftimare non licet, attribui potelt, neceffariò materix attribuen da eft.\& mare vniuerfum, nubesqúu albifsimas effe, omnes inquauis illius portione, $\&$ in rebus, inquas hx concrefcunt, in aquis fcilicet, niueque, \& grandine \& nequaquam ullum rerum colorem, fed vnam modo lucem ab ijs reducentem, ab earumq́ue coloribus intinctam nobis fpectari.in marinis itidem aquis, nubibusque liquido intueri licet; vtraq́; enim albifsimx cùm fint oês, nequaquã albx omnes, fed ( vt dictũ eft) lōgè diuerfifsimis coloribus coloratæa apparent, quod ni mirum non ipfarum color, fed lux ab co, at non vno, fed ab inexiftente etiam nigredine Intincta fpectatur:at et $f$ ( $v t$ dictum eft) à materix nigredine intingitur lux, non $x$ que tamé omnis \& quantauis à nigredine, fed languida, à breuifsima, robufta verò,non nifi à benè profunda. Itaque aquam in vitro contentam matutina, vefpertinaq́; lux, quę fcilicet; quod benè obliqua aduenit, nihil reflexa infeipfam colligitur. I taque $a b$ inexiftente aqux nigredine efuperata Irinis coloribus Intingitur omnibus, minimè verò \& meridiana, qux nimirum benè directa infeipfam reflectitur, proindeque copio fa,robuftaquefacta, materix nigredinem penitus efuperat. Itaque nihilab ea fædatur, \& fole ad occafum vergente, affidueque fitum ad nubem immutante, afsidueque minus directam lucem ad nubem emittente, quam albam modo, aut ita poft puniceam, tum, \& purpuream, nigricantemqque intueare. 


\section{Bernardini Telefij}

\section{2uidfit Iris, of quali in nube, of à qualifiat luce. Cap. $X V I I$.}

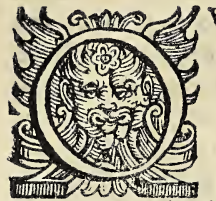

VONIA $M$ id eft lucis ingenium, vt uel fi nubes ea fubeat reluceat, ab ijs tamen nec alba, puraque, fed ab earum materia impurata,eoq́ue id magis, minufuè,prout magis, minufuè profundę, denfxuè hæ fint, vel magis, minufuè directa ipfa robuftior f́cilicet, languidioruè ; ibique modo Iris fit , vbi quxpiam adeft nubes, \& folis lux ad eam defertur, vtique Iridem folis lucem effe à nubibus relucentem, ab carumque materia intinctam, fxdatamq́ue . \& quoniam lux in nubibus relucentem modo intingi vifa eft, benè Infeipfas confpiflatis, \& ibi præcipue fieri Iris videtu $r$, vbi inaquas nubes coguntur, \& directa, be nequè robufta lux, \& nubium, \& aquarum etiam non profundisfimarum nigredincm efuperat, eafque fubiens, \& per means etiam, nihil, aut permodicum quid ab earum nigredine intingi videtur, \& qu $æ$ valdè obliqua, proindeque $\&$ valdè exilis eft, languidaq́ue. Siquidem nubes fubire, \& relucere $a b$ ijs poteft, vifu $m$ certè cömouere minimè poteft. innube omnino benè in fe if fam confpiffatam, \& à luce Iridem fieri exiftimare licet, nec maximè directa, maximèq́ue robufta, nec maximè obliqua, languidaq́ue, fed ab ea quæ harum quafi media fit, \& ab ea fortè, quæ nequaquam à folis parte emanet, qux nubi proximior, earumque, qux nubi expofit $x$ funt, media eft omnium : eam enim nubi directam imminere exiftimare licet; neque ab ijs, quæ maximè ab illa abfunt, maximeque obliquam ad nubem emittunt lu cem, fed ab ijs, qux vtrarumque veluti medix funt:fphericus enim cum fit Sol, afsidueq́ue eius fuperficies immutetur, fingulæ eius partes propriü ad nubium partes quafuis fitum obtineant oportet, eoque fingulas à reliquis magis diuerfum, quò magis ab ijs abfunt, obtineant oportet.Nec uerò fingulas rerum, quæà Sole illuftrantur partes, fingulas à certis folis partibus illuftrari pofuerim vnquam. Quoniam. enim in quantulouis fpecillo, \& è foramine quantulouis vni uerfus confpicitur fol, liquido utique patet, ad quafuis rerum partes, quin puncta ad quxuis uniuerfo 2 fole lucem ac cedere, 
cedere, è quouis fcilicet folis, \& noftrarum etiam flammarum, \& lucis etiam ipfius puncto, qux effulget lux, quaqua verfus in immenfum cum effundatur lux, neceflariò in circumftantis fpatij uniuerfi punctum quoduis uniuerfa feratur oportet. Nec uerò in illud fiat (quod pafsim fieri uidemus ) uniuerfum à fole cœlum, \& loca etiam, 'quæ eius lucem admittunt, $\&$ inquibus flammæ accenduntur illuftrentur uniuerfa. At non propterea fingulis in nubium partibus fingulx, qux ad eas deueniunt, fpectantur luces, fed unam mo do in fingulis ea nimirum quæ reliquas robore exuperat; Itaque reliquas veluti obfcurat, \& inuifiles facit. Nec porrò non ea perpetuò eft, quæ purior eft,fed quæ magis fodata eft:manifeltè enim materix nigredo lucis albedine robuftior elt. Itaque per fummum folis candorem fodata lux quruis adnos adueniens nihil ab illo obfcurari, propriaq́ue fpetie fpoliari; at hanc ille uel fummè exilem, languidamq́ue permeans, huius calore intingi, ad nigrumq́ue agi videtur, \& longè albifsimi, beneque copiofi fluores non nigris modo, fed puniceis, croceisq́ue, \& reliquis coloratis coloribus quantumlifuis impurari, eorumq́a coloribus colorari uidetur : calores nimirum quiuis aibifsimum peraerem fummumq́ue per folis candorem quales funt ad nos feruntar, at folis candor rerum, quas permeat, permeans omnium intingitur coloribus.

\section{Aluce, quam diximus, Iridem fieri, vtriufque eius at duplici smagis colorum ordo, \& vigor decla- rat. Cap. $X V I I I$.}

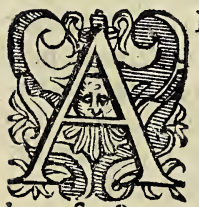

Luce porrò, quam diximus Iridem fieri, non ratio tantum, fed eius colorum ordo apertè quidem in fimplici, at multò etiam in dupli ci amplius manifeftat. Propterea enim vbi duplex fit Iris, non altera alteri contigua fit, proximaq́ue, fed fpatium inter vtramque al bum fpectatur, tum primus vtriufque iridis ambitus inter mediü fpatium contingens, eodem vterq́; colore, \& puniceo co.viridis itidé vtriusq́; medius ambitus, \& purpureus poftre mus. vtraque nimirum iris, prout $\mathrm{ab}$ albo fpatio magis rece- 


\section{Bernardini Telefij.}

dit,magis ad nigrum,obfcurumq́ue, \& $x$ què vtraque,eodem que tendit modo, in eo tätum ab altera differens altera, quòd fuperioris colores paulo, läguidiores apparēt; quod Iris vtraque, \& quòd vtriufquè medium eft fpatium ab vniuerfo quidem fole, at non $a b$ vniuerfo fimul finguli iridis vtrius ̛́; $a m$ bitus, intermediumq́ue fpatium, fed \& hoc, \& finguli illi à certa illuftrantur folis parte, \& inter medium quidem (patiú. à media iridum ambitus, pro vt ab albo fpatio magis recedunt, ita à folis partibus, quę à media magis abfunt, 8 interior quidem iris à folis parte, quę infra eam;Exterior verò ab ea, quę fupra mediam eft, Illuftrari uidetur. Quoniam igitur media folis pars maximè ad oppofitas uubes directa, quę ue rò fummè ab ea abfunt, fnperior quidem ad fuperpofitum ce lum, inferior uerò ad terram directa ad oppofitas folis nube fummè obliqua; harum medię medio fe habent modo, $\&$ eodem utraq́ue:æquè en im utrinǵue incuruetur fol oportet, iure quę ab intermedio fpatio refilit, lux fpectatur. Summè enim directa, fummeq́a ad ipfum robufta delata eft. itaque nihil ab eius nigredine fordata alba relucet, puraque ab utriusq́ue iridis ambitu eò afsiduè impurata magis, magisq́ue ad nigrum tendens, quò ab intermedio fpatio magis remouetur:eo enim afsiduè magis obliqua ad nubes fertur, \& exterioris iridis colores ijdê omnino, qui $\&$ interioris, at paulo lanquidiores; quòd utraque quidem folis pars eundem ad nubem obtinet fitum, at inferior omnino nō fuppofitas modo nubes, fed oppofitas itidem robuftius illuftrare, quę nimi rum \& ipfę immenfo quodam fpatio at fub fole omnino pofitx funt, ùt luci è fuperiori eius parte ad illas adueniête ma gis oblique uideri pofsint. fatis autem \& intermedium fpatium, \& ambitus finguli ampli, latiq́ue; quod fph ęricus quidem, \& immenfus exiftens fol, non ita ftatim incuruatur, ut fpatium nullum in eodem ad nubem fitu, in eademq́ue permaneat pofitione, fed \& media eius pars fatis diu eadem, eädemq́ue ad nubem omnino habet pofitionem, tandiu itaque colore eodem intincta à nube relucet lux, quàmdiu xquè, aut modicum quid magis, minufuè ad eam directa fertur. 
Aqua Solisparte fimplex fit Iris, \& cur quo Spectatur colorum ordine. Cap. XIX.

I P L EX igitur Iris à folis omnino parte, quæ in fra mediam eft facta, uideri poteft; $\propto$ primus, fupremusq́; eius ambitus,propterea puniceus effe, qlux $^{2}$ ad ipfum delata, \& parū ab ipfa declinãs, à parte medix proxima emanâs.fecũdus uerò flauus, ubi is itidem fpectatur, qd à folis parte egreffa lux minus ad nubé, in qua iris fit directa, minusq́; robufta,\& paffa in eo eft magis : neq; enim qui uerè eft flauus, croceusq́; albo (ut dictú eft) quàm puniceus proxi mior eft,fed punicei, uiridisq́; medius, tertius uiridis, quòd à luce factus eft,magis etiã obliqua,\& propterea magis paffa. purpureus poftremus, $q$ đ cuius ipfe opus eft lux à folis parte emanat, qux ad fuppofitas foli nubes benè directa, ad oppofitas ualde obliqua eft, dicto porrò ordine lucem impurari, \& ad ni grum agi,\& in cômentario de coloribus declaratum ui detur;oculis etiam (ut ibi itidê dictú eft ) intueri licet; quos Cap.7or nimirum, fi paulatim conftringas, contrahasq́i,p uniceü primum intuere folem, tum Prafinum, purpureû poftremo, alurgumq́';, eo fcilicet afsidue obfcuriorê, quo eius lux magis occultetur, magisque imminuatur,\& ueluti obfcuretur magis.

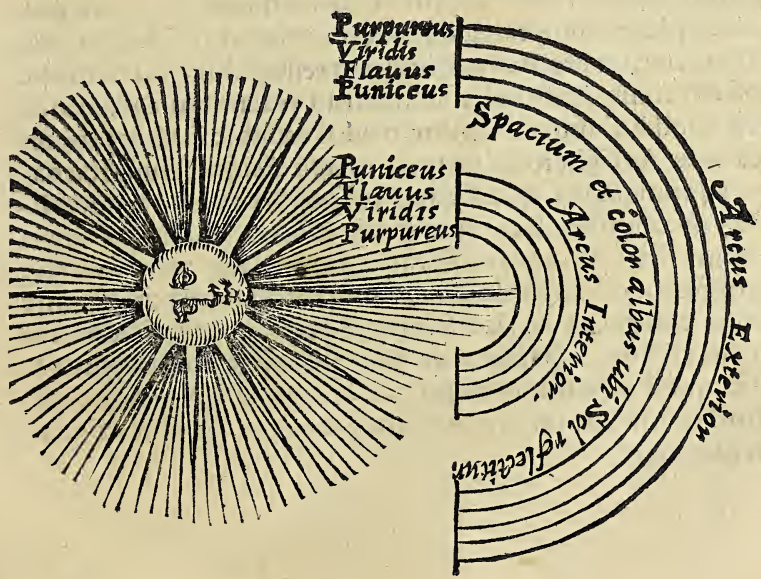

E

Cur 
Cur que à Luna fit Iris, plena ea, ó magis oriente tans. tum, veloccidente, \& languidioribus coloribus; \& cur qua circa Lucerne lucem, \& gattis à remis fublatis fit, purpurea fiat. Cap. $X X$.

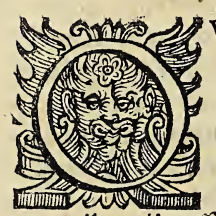

VAE verò à Luna fit Iris, propterea $a b$ vniuerfa ea à fole illuftrata, $\&$ oriente tantum, occidenteuè fieri poffe videtur. quòd languens lunæ lux, non nifi multa facta nubem adeò fubire, ut Irinis coloribus intincta relucere inde queat; \& ab intermedijs infuper vaporibus ijs affecta prius, at neque tamen veracibus vnquã coloribus fpectatur, fed ad album tendentibus.quia fcilicet, vtdictum eft, non à profundioribus nubium partibus, quas nimirum nihil fubit, fed ab ipfarum relucet fuperfitie. Quie contra à Lucernx flamma fit, purpurea videtur, quòd non pur ra, albaq́ue, fed ab immifto fumo obfcurata circumfluum ae rem fubit;nihilque in co copiofior facta, non punicea ab co vigensq́ue, fed purpurea relucet, languidaq́ue, \& qux debilifsimis tantum confpicua fit oculis.neque enim (quod Ariftoteli placet) propterea ijs modo confpicitur, quòd horum vifus celeriter propter debilitatem refectatur, qui nimirum ipfi in primis Ariftoteli nunquam ad videndum egreditur. Sed quod huiufmodi tantum oculos ea fubit lux, \& propterea ortæ Antipheronti propria imago afsiduè confpiciebatur; quoniam lux, quax ( quod in fpeculis pafsim intuerilicet) $a b$ omnium facie eius fpetie efformata, ad oppofitum aerem relucet, ab eoq́; rurfus ad eorum oculos retroflectitur: at quòd longè languidifsimi alios nullos fubire potelt, alijs nullis confpicua fit; laxifsimos Antipherontis oculos fubiens, afsiduè ei fpectabatur. Marina itidem iris purpurea \& ipfa; quòd vaporibus longè crafsioribus fubiens lux, rem am pliori immifceturnigredini, itaq́ue nigro proximior facta ab ea relucet. 
Cur circularis fit Iridis figura, \& cur nulla ant agrè femicirculo maior fit; \& cur fole iuxta borizontem exiftente, Semicircularis ; co verò fublato.minor femicirculo, at maioris circuli portio fit. Cap. $X \mathbb{X} 1$.

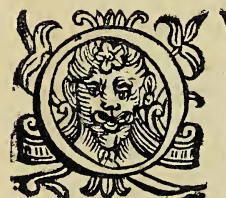

VONIAM igitur qux à media folis parte emanat lux, robuftior vifa eft, quàm vt Irinis coloribus intingi pofsit. Iris fphęrica, qualem effe oportebat folis figuram referentem, fieri non poteft. \& quoniam idem in iride fpectetur color, æquè ad nu bem directa feratur lux oportet. In immenfo quidem, at fphrico fole portio femicirculo maior in eadem ad nubem pofitione defcribi xgrè poteft : nam ad folis partes deueniat benè iam incuruatas, \& retro flexas, \& quix ad alium omnino ad nubem fint fitu. Semicircularis quidem iris conftitui poteft, at non portio femicirculo maior: femicircularis porrò matutina, uefpertinaquue iris, quòd, quoniam à luce conftituenda eft, diu per aerem terris proximum, uaporesq́ue, quibus ille perpetuò obfitus eft, delata, proindeque benè imminuta, obfcurataqúue. \& qux nifi directa ad nubes deueniat, \& in feipfam ab ijs refieEatur, nequaquam uifilis reflectatur. Vtique à folis parte ea emanet oportet, qux recta nubem fpectat, à media nimirum, $\&$ in ea omnino, quòd diu benè Planè uideri poteft, femicirculus conftitui poteft, qui uniuerfus in eodem $2 \mathrm{~d}$ nubem fitu, in eademq́ue fit pofitione, at non ualdè amplius tamen: nimis enim ad folis ueluti latera dilatatus, expanfusqúue ad incuruatas iam, \& retroflexas eius partes feratur. Vt non ad eundem ad nubem fit omnis fitum. Iure igitur femicirculi quidem magnitudine, at parui circuli matutina, uefpertinaq́ue apparet iris; iure itidem meridiana minor quidem femicirculo, at maioris omnino circuli portio ; quòd qux non imprimente, fed in fuperiori, uel inferiori folis parte, à qua precipuè fieri iris uidetur, defcribuntur circulorum portio-

$$
\text { E } 2 \text { nes. }
$$




\section{Bernardini Telefij}

nes. Si ualdè inlongum protrahantur ad incuruatas folis partes. ad aliamque ad nubem factas pofitionem, deueniant, ueluti igitur in amplum aperiendx fint, laxandęque. ut in eodem omnes fint ad nubem fitu, neque ita multo poft finiende omninoterminandęq́ xe. ne in dinerfo ad nubem defcribantur fitu.

$$
\text { F I N I S. }
$$




\section{I $N$ D E X \\ $A \quad P \quad I \quad T \quad V \quad M$ \\ L $\quad I: B \quad R \quad I$. \\ D E I R I D E.}

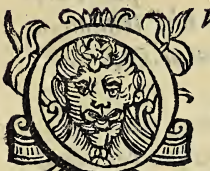

$V \mathscr{A}$ E Iridi euienire videntur Aristoteli of pro pterea ea euenire, quod Iris reflexio fit. Cap. I. pag.3.a

Que vt Iridem reflexione fieri declaret, fumit Arift. Cap. II.

pag. 3.6

\% यas Quomodo Iris. Aristotelifiat, of afpectus nuo b.e ad folem reflexionem omnino effe Iridem. Cap. III.pag.3.b Que Iridis colorum differentiam explicaturus fupponit Ariftoteles. Cap. IIII.

Cur tres tantum colores in Iride apparere, eoque ü quo $\int p e c t a n t u r$ ordine Ariftoteli videntur. Cap. $V$.

pag. 4.6

Flauus color in Iride non ut reliqui ex reflexione, fed ex punicei, piridisque iuxta fe collocatione apparere Ariftoteli videtur: Cap. $V I$.

pag. 4.6

Quam ob caufam exteriores Iridis calores languidiores Arift.appareant, of contrario ordine pofiti. Cap. VII. pag.5.a

Iridem à reflexa fieriluce, rectè Arist. vifum, at non rectè nobis eam inter, folemq́ue medijs, o in nube tantum in aquam agi cepta fieripoffe pofitum, nec recte nigredinem, ad eius colores constituendum allatam eße. Cap. VIII. pag.5.b Perperam Arist. Iridis colore ternario numero terminari, \& $f a-$ uum non reflexione, fed punicei, biridisque iuxta fe collocatione apparere fatuit. Cap. I $X$.

on rectè caufann explicatam Ariftoteli fuiffe, cur fomplicis Iridis colores, quo fpectantur ordine locatifint; nec cur in exteriore languidiores appareant, of contrario ordine difpofiti. cap. $X$.

Incufandum itidem videripotef Arift. causam cur spatium, quod inter stramque Iridem eft, album appareat,nibil inquirens, fui zerøे 


\section{I $N \quad D \quad E \quad X$.}

serò quodnon rettè illain explicarunt. Cap. XI. pag.8.6. Cur circularem fieri Iridem, nec videlicet Arictoteli videtur ; \& quomodo talis fiat, \& femicirculi quidem quantitate oriente, fiue occidente fole; portio uerò femicirculo minor fole fuprà orientem fublato. Cap. XII.

Non-redtè circularis Iridis figura, nec cur Semicirculus oriente, oc cidenteque fole, minorue femicirculo, fole fublato, appareat caufamab Arif.redditam fuiße. Cap. XIII. pag. II.a $\checkmark$ arie peripateticorum fententic, cur femicircularis Iris minoris circuli; minor uerò femicirculo circuli maioris fectio uidetur. Cap. XIIII.

Teripateticorim nullus rectè cainfam explicat cur ubi Semicircu lo minor apparet Iris maioris circuli portio uideatur. Cap. $X V$. pag. $13 . a$

I. ucem ad nubes delatam relucere ab $\ddot{y} s$, Ev non albam, puramque, fed ab earum materie nigredine fadatam, barijśque coloribus coloratam, ac directam robuftamq́ue minufquam obliquam, lan guidamq́ue. Cap. $X V I$.

pag. 14.6

puid fit Iris, of quali in nube, of à quali frat luce. Cap. XVII. pag. 15.6

A luce, quam diximus, Iridem fieri utriusq́ue eius, do duplicis magis calorum ordo, ¿j vigor declarat. Cap. XVIII. pag. 16.a Aqua folis parte fimplex fit Iris, \& cur, quo spectatur colorim or dine. Cap. XIX.

pag. 17:a

Cum que à luna fir Iris, plena ea, \&o magis oriente tantum, pel occidente, of languidioribus coloribus, of cur que circa lucerne lucem, of guttis à remis fublatis fit, purpurea fiat. Cap. $X X$. pag. 17.6

cur circularis fic Iridis figura, ơ cur nulla, aut «grè femicirculo maior fit, \& cur, fole iuxta orizontem exiftente, femicircularis; co uerò Sublato, minor semicirculo, at maioris circuli portio fit. cap. $X X I$. pag. 5.6 




\section{BERNARDINI \\ T E I E $S$ S I I \\ CONSENTINI. \\ Liber}

D E $M A R$ I.

CVMPRIVILEGIO.

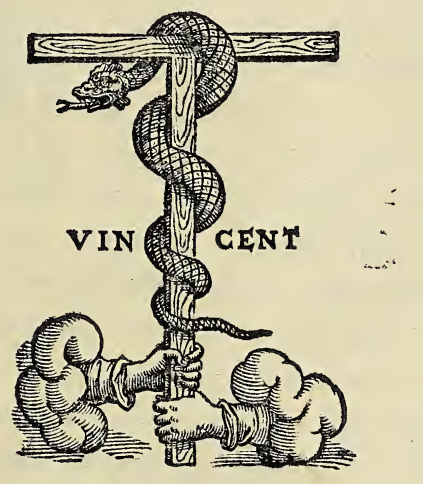

VENETIIS, M. D. XC:

Apud Felicem Valgrifium. 


$$
\begin{aligned}
& \text { WWLOGAWDWH. }
\end{aligned}
$$

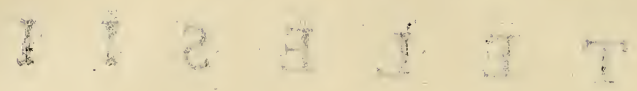

$$
\begin{aligned}
& \text { - } 2 \pi+7 m a \operatorname{lng} \\
& \text { is di } \\
& .1 \text { \& M म C }
\end{aligned}
$$

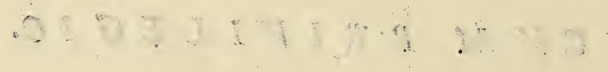

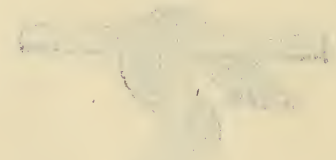

$$
\begin{aligned}
& \because+2-p h y
\end{aligned}
$$

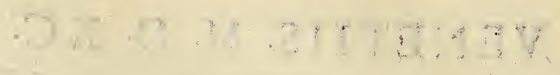

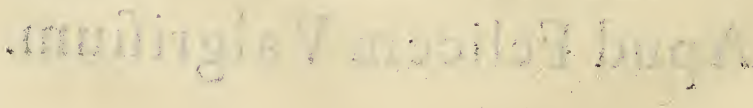




\section{A N T O N I V S P E R S I V S \\ FRANCISCO PATRICIO Platonicx Philofophix}

In Ferrarienfi Gymnafio Profelfori Celeberrimo. S. P. D.

E MINISTI eruditiffime S Patriti, cum Venetijs commo1) raremur, me tibi nouam Tele1 siy Philofophiam, ac Pbilofo51 0 phandi rationem Sapius commenWe deut dare, o te hortari, ut libros eins de natura legeres diligenter. Qnod ubi eft à te faEtum, cùm multa offenderes in ys, qua veluti Demo. critea Delio quopiam natatore indigerent, me identidem tanquam in corum lectione diutius verfatum, ac Telesij familiarem confulebas, Ego igitur libenter, $\mathcal{O}$ obfcura quacunque tibi efJent interpretrabar, or obyjcientium fefe dubitationtm frupulos eximebam, quoad poteram. Ita ad calcr m ulque operiscum legendo perueniffes, tam bonorifice de eo loqut capifii, it ip fum uet rribus philo ophis anteferres. Scripfift quo-

$$
1 \text { a que }
$$


que à me rogatus in eam philo ophiam dubitationes tuas nonnullas, quas ad T elefium tran fmiffi. Ex co candidiffimus philofophus quantitum faceret indicium, baud obfcure fignificauit, cum deinceps (ux fcropta ad tuum fen.fum exigere non fit grauatus. Cum igitur libellum eius de mari ab iplo primum editum, atque aliquibus ex ciufdem fcriptis ad eandem rem pertinentibus auctum, denuo imprimenium curarem, patrem ip $i$, ac patronum nullum Patricio aptiorem inuenire me polfe exifimaui, tuaq́; id'́circo ip/um fidei comendare decreui. $T u$, $f i$ conflanses, in fummi uirs laude, ut te effe mibi, or natura, ¿r confuetudo tua Juadet, buiufce opufculipatro. cinium (ufcipias libenter, ac tuam in co tuendo non vinlgarem eruditionem plaudentibus nmnibus explicabis. Feceris autem mihi pergratum $/ 2$ meis uerbis communem amicum, ac familiarem Francifcum Mutum, $\sigma$ tuum, $\sigma$ Telesï preclarum propugnatorem ingenï, $\sigma$ eruditionis laude ornatiffimurn falut aueris, meoǵ; ipfi nomine dixeris, cum ego ipfius beneficio plerofque ex $\ddot{y} s$, quos iam edo libellos fuerim nactus expeEtare, ut coldemidem ipfemeliores, atque alios cinfdem Auctoris nondum editos nobis eruat alicunde. $V$ ale, as nie mutuo memor e $\{0, P$ atauio. 


\section{B E R N A R D I N I \\ $T$ E $L$ E $S$ I I I \\ CONSENTINI}

De Mari.

Mare non propria natura Sallume efe, ed dulcibus eius

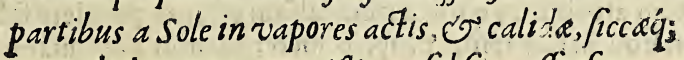

exhalationis commiftione falfum effe fa-

stum, os perpetuò tale fuiffe cAri-

fotelivifum. Cap. 1.

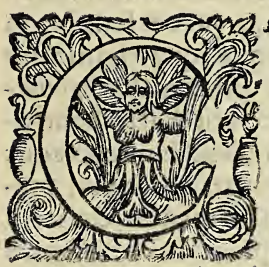

AVSA, inquit, Áriftoteles, quę antiquio res adduxit, vt Mare vniuerfum aquæ principium, \& corpus effe exıftimarét, hre eft: Nam confentaneum videri po 2. Metor teft, quoddam totius aquæ corpus ef- Text, $\sigma_{0}$. fe,quemadmodum, \& aliorum elemen ," torum moles coagmientata eft, \& prin-", cipium, ob copiam, vnde diltributa, mutatur, \& alijs adnifcetur: vt ignis quidem in fupero lo- , co;aeris autem copia in eo, qui eft citra ignem; $r$ erræ corpus ," id, circa quod omnia hxc funt manifelte pofita: ex quo con," ftat eadem ratione, de aqua, \& $x$ neceffario inquirendum. Nul-, lum autem aliud tale collectum corpus, prater maris vafita ", tem, ut cæterorum elementorum, pofitum uidetur. Amnium, enim nec collectũ eft, nec manet, fed ucluti quotidie gigna- ,2, tur, femper confpicitur : Mare sgitur humidorum, \& totius," aqua principium effe, ob hanc dubitationem uifum efi. Cyo, circa \& fumina non tant um in ipfum, fed ex eo fluere aliqui inquiunt: quod enim falfum eft, fi coletur, fieri potabile. ", Huic autem dubitationi dubitatio altera opponitur; quid, tandem caufa, fit cur aqua hac fimulftans, potabilis non fit 


\section{Bernardini Telefij}

"fed falfa; fi quidem totius aquę principium eftr caufa,inquit,

Text.7. maris falfedinis propofrtam dubitazionem foluet, \& efficiet, " ut primam de mari exiftimationem rectè \& neceffariò fuma "mus. tum illam explicans; quoniam, inquit, aqua circa Ter " ram, quemadmodum \& circa eam aeris globus, \& circa hüc, " qui dicitur ignis, obtenditur, Sol autem, hoc modo feratnr, " ob eamq́ise caufam mutatio exiftat, \& ortus, atque interitus; " id quod teauifsimum eft, \& dulcifsimum quotidie eftertur, 3 fecernique, \& in vaporem mutatum fuperiora petere uide" tur; illic a atem rurfus obfrigus concretum iterum defertur, Text. Io. idque natura perpetuò facere (vt anteà dictum elt) in fituit.

"Itaque, inquit, quòd potabile eft, \& dulce, uniuerfum ob leui Texc. 80. tatem attollitur, quod autem falfum eft, prx pondere fubf" dit, non in fuo ipfus proprio loco ; etenim exiftimandum " eft, de hoc recte dubitatum effe;abfurdum nanque eft, nifi ali

" quis aqux, vt ceterorum elementorum, fit locus, atque hanc " effe folutionem: is enim locus, in quo contineri mare cerni" mus,maris non eft, fed potius aquę. Maris autē videtur,pro" ptereà quòd pars falfa fubfidit prępondere, dulcis uerò, ac po " tabilis, ob leuitatem attollitur. Quapropter \& fumina in " eum locum omnia influunt, \& omnis aqua, quę gignitur;in " id enim, quòd maximè cauum eft, talemq́ue terrę locum ma" re obtinet;fed alia pars vniuerfa à sole celeriter attollitur; a" lia relinquitur, ob eam, quę dicta eft, caufam. Hunc ego aque
Text. 10cum effe, \& non maris; \& quamobrem pars potabilis, pre-

"ter eam.quęfluit, occulta eft; alia verò pars maneat; cur itcm

Text. I5. Mare aquę potius fit finis, quam principium, his à nobis tra ditum fit. De eius autem falfedine, \& utrum perpetuò idem

"fit, an non fuerit, nec futurum fit, fed deficiet, dicendum eft: hoc enim modo aliqui fentiunt;omnes quidem genitum ef"fe uidentur fateri, fi quidem \& mundum uniuerfum ; fimul nanque eius ortum faciunt . quare conftat, fi uniuerfum fe" piternum eft, non aliter de mari exiftimandum effe; ijs certè, qui mare generant, eius falfedinis caufa reddi minimè

Text.r 7. poteft. Nam fi illius, qui terram ambibat, \& à Sole fublatus " eft, humoris omnis refiduum, Mare effectum eft; neceffe eft "aqua illa, que in uaporem conuerfa eft, rurfus aduenien"te,cum ęqualis fit multitudo, iterum dulcefcere. Si autem " terra admilta, falfi faporis caufa ponatur, ut qua faporibus nultis predita, in mare à fluminibus deferatur, abfurdum ijs eft, 


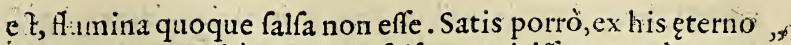
tempore, \& ueluti à principio falfum extitifie mare, demon- ," fratum. At non \& falfedinis itidem caufam fatis explica-" " tam exiftimans Ariftoteles: fi quidem, ut ipfe ait, fi dulcium ", abfceflu partium falfum fiat mare, earum acceflu iterum dul ", cefcere oportet. alienum quippiam, falfum fiat, mini- ," meq́'ıe à fluminibus deferatur, uidendum mari intui-" ", t:is. Qioniam, inquit, pofitum eft, duplicem efle cxhalatio- Text. 2 ro nem, alteram humidam, alteram ficcam: conftat hanc rerum ", huiufinodi principium exiftimandam effe:\& multis quidem Texr.z2. fignis perfpicuum eft eiufmodi faporem, ex commiftione" quapiam exiftere : in corporibus enim quod minimè coctū ", eft, falfum eft, \& amarum: nec aliter fe habet in ijs, que adu- ", rintur; quod enim à calore euictum non fuerit in corporibus excrementum efficitur : in ijs autem quę aduruntur ci- "’ nis. Atque hęc caufa eft cur nonnulli ex aduita Terra mare "' fieri inquiät, quod hoc quidem modo dicere abfurdum eft; " at illud uerum; ex eius fcilicet, generis Terrę falfedinem ma" re accipere poffe; nam, ut in his, que dicta funt;fic etiam in ", uniuerfo, ex ijs, quę nafcuntur, \& natura gignuntur animo" femper concipiendum eft, eius generis Terram, quin $\&$ om-" " nem aride Terræ exhalationem remanere; quale id eft, quod " ex aduftis reftat, ea enim hanc ingentem halituum copiam" fuppeditat: Q ioniam autem inter fe, ut diximus, uaporofa," \& ficca exhalatio admift $x$ funt, cùm in nubem, \& in aquam " illa concreuerit, aliqua femper huius facultatis copia unà có " prehendatur, \& rurfum vnà cum pluuia deorfum feratur ne- ", cefle en.Nec ex ijs tantū, quę dicta funt, perfpicuú eft, in quit, falfitudinem in quadam miltione pofitam effe, verum etiam ex eo, quòd fi quis cereo uafę effecto, eiusq́ue ore talibus re-" bus obturato, ut maris nihil iliabatur, in mare illud pofue-" rit, id quod per cereos parietes ingreditur, aqua dulcis red-" ditur.quod enim terreum elt, \& falfedinem ex admiftione fa" cit,veluti colatü fecernitur. hoc verò \& ponderis caufa eft; \& " crafsitiei. Hæc Ariftoteles de mari, deq́ue eius falfedine, è ", quibus aqux elementum mare pofitum Ariftoteli fuiffe in-" telligere etiam licet at quando Peripateticorum non nullis fecus uidetur; diligentius omninò, qua fuerit illius fententia, infpiciendum eft : nam fi urauis ea fuerit, quin in abfurditates longè maximas Peripatctici incidant effugere

non 


\section{Bernardini Telefij.}

non poffunr, at ut in quibus verè Ariftoteles damnari poffsit nota fiant, inquirenda omninò cius fententia uideri debet.

\section{Mare aqua elementum Aristoteli pofitum effe: Cap. II.}

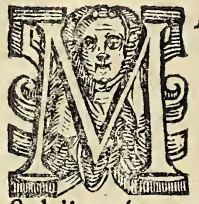

$A R E$ aqux elementum pofitum Ariftoteli ef fe manifeftè, ut uidetur, patet;Antiquorum enim rationem, quæ aqux uniuerfitatem ipfum ftatuit, propterea quod rationi congruum fit, aquarum itidem molem, cuiufmodi aliorum elementorum exiftit, unitam, ftabilemótue oportere effe, prxter morem fuum nihil reijcit, ac ne reijcere quidem teneat, quin admittendam omninò decernere videtur . expofita igitur, dubitatione, qux illorum rationi aduerfari uidebatur, falfedinis, inquit,caufa infpecta dictam dubitationem foluet, reijcietq́ue, \& efficiet, ut primam illorum ratiocinationem, qua mare aqux elementum ftatuebant, rectè neceffario fumamus : nam alteram, qua flumina è mari effuere opinabantur, reijciendam omninò decreuerit Ariftoteles; illud uerò ex eò, quòd falfus maris fapor non eius aqux proprius, naturalifq́'ue : fed ex accidente quo piam factus uidebitur, ac fi diceret, fi quidem propria natura falfum effet mare, rectè dubitatum forct minimè aqux id elementum poni pofle dulcis potabilisq́ue; at quoniam propria falfum factum uidebitur, quòd dulcioribus fui partibus à fole fpoliatum eft, \& calida, ficcaque exhalatio à pluuijs delata illi admifta; nequaquam propterea quòd falfum eft, aquę elementum videri non debet: neque enim quę elementa Ariftoteles ponit, impura ea,alienisqúu rebus com mifta ponere ueretur: quin, uno tantùm igne excxpto, reliqua omnia impura effe decernit. mare igitur non propria natura falfum effe affirmans, \& à quibus falfum fieri queat, fum ma inquirens diligentia; antiquorum omninò rationem cōprobare, \& aqux omnino ipfum elementum ponere videri de bet:at perpetuò illos in fectandi fudio, \& ambitionis omninò ftimulis exagitatus, id illos incufare, quòd non è loco, in quo pofitum eft mare, aqux id effe vniuerfitatem declararint : aqua inquit, quod potabile eft, $\&$ dulce tniuerfum ob 
leuitatem attollitur; quod autem falfum eft prepondere fub- Texto ro. fidit,non in fuo ipfius loco:etenim exiftimandum of de hoc " rectè d:bitatum effe; ( abfurdum nanque eft, nifi aliquis a-- ") qux, vt reliquorum elementorum fit locus) atque hanc effe $\%$ folutionem ; is enim locus, in quo contineri mare cernimus," maris non eft, fed potius aqux; ac fi diceret, commodius ex a- " qux loco, qux aqux fit uniuerfitas intelligi poffe;magis enim " proprium aqux locum, quàm eius uniuerfitati $\mathrm{m}$ fimul colle- $.4 \mathrm{Phy} \mathrm{f}_{\text {. }}$ ctam, effe oportere, rationi congruum fit;propterea enim fortè fimul aqua uniuerfa colligitur, fibiqque omnis coit ; quòd ", uniuerfa in proprio loco effe vult : Ad proprium, inquit Ari-" ftoteles, locum ferri unum quodque ad fuum fimile, \& fuam formam eft ferri; \& fic utique quis exiltimabit, id quod dicebăt antiqui, fimile ad fimile ferri; hoc enim non accidit omni nò, non enim fi quis Terram trăfmittet, \& iuxta Lunam collo cet,ad ipfam ferentur partes:fed ad eundem locú, ubi núc exi ", ftit:ut quod dictú eit, id antiquiores incufandi Ariftoteli videripotuerint, quòd noo è maris loco, fed ex eius magnitudine aqux elementú id ftatuerint:fi quidé elementorü partibus proprius locus magis, quam propria uniuerfitas proprius fit. Nufquã igitur antiquiores damnare, quòd mare aqux elemẽ tú pofuerint, videtur Ariftoteles, fed quòd nó ex eius loco id declararint.Et uel ibi, mare aqux elementum Ariftoteli pofitum effe, qux ftatim fubdit, manifeftifsimè declarant:quafi enim caulam reddens, cur in proprio aqux loco uera aqua a potabilis, qualis fui eft natura, non fit, fed falfa ; à mari, inquit, occupatus eft aqux locus; quoniam, quod in aqua fal fum quidem eft , fubfidit propter grauitatem; dulce autem, $\&$ potabile propter leuitatem furfum ducitur : \& panlò inferius, conftat, inquit, hunc efle aqux locum, \& non maris; \& quam ob rem pars potabilis,pręter eam, qux fluit, occulta fit: funt enim, ac fi diceret, totius quidem, purxáue aqux is eft locus; fed crafsior, grauiorǵue eius pars illum occupauit, quòd tenuiore, leuioreque furfum à Sole acta, ipfa modò re liqua facta eft; $Q$ Quoniam videlicet, aqux elementum, ueluti , \& terræx, aerisq́ue, \& ignis pofitum Ariftoteli erat ; \& in terræ illud fuperficie locatum, multoq́ue terra maius factum \& nullam aliam aquarum molem, cui illud afsignare poffet, prater maris uaftitatem intueri poterat : mare itaque neceffario a gux elementum ponendum intuenti ; modis vtique

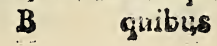




\section{Bernardini Telefij}

quibus poterat omnibus falfum eius faporem, ex accidente quopiam ei ineffe declarandum omnino fuit : qui nimirum fi maris proprius fit, aqux id elementum dulcis, potabilifque ponere prohibeat, id omninò quacunque potuit moliri uidetur ratione. Et aquæigitur, qux ut penitus fimilaris non fit, \& eadem tenuitate, eodemq́ue omnis donata fapore, nullis certè fui partibus æquè mari craffa,minus etiam fal fa ullis aideri poteit; \& $q u x$ à calore quauis expoliata tenuitate, nec craffefcere, nec falfa unquam, quin tenuior afsid tè, d:lciorq́ue fieri uidetur, partes indere nihil ueretur: qux a ten rioribus folis opera feiunctę, adeo craffę, adeoque fint falfr: inditus, ut exiftimare licet, at neceffariò : neque enim aq $ı x$ elementum mare ponere liceat, nifi maris falfedo aqux infit, \& nequaquàm in hoc acquiefcere potens; quo niam enim qux è mari afsiduè educitur tenuitas, in aquam ea rurfus coacta tenuem, dulcemq́ue mari iterum reftituitur: quod itaque fi illius abfceffi craflum, falfumq́ue fiat; eius acceffu tenue iterum fiat, dulceq́ue; Terram illam incoetam, adultam que n:ıfq:ıam quidem confpectam, è terræ latebris er tere nihil reformidat; ex ea ut exhalationum copiả educat, à qua cum plıuis delata, falfum, craffumq́u fiat mare: nihil omninò intentatum relinquendum, incommoda quęuis futtinenda effe exiftimans, modò nec marinx aquxe falfedo propria eius fit; non aliam porrò id ob caufam, nifi ut mare aqux uniuerfitas poni posfir : nifi enim id propofitum Ariftoteli fit, nihil iel ulla maris pafsio, vel alienum ul$l u m$, à quibus falfam id fiat, inquirendum illi erat; quod nimiram propria natura tale effe ftatuere poterat : neque enim quin terra in aquam falfam, amaramq́ue a Sole inuerti queat dub itandum, at non enunciandum Ariftoteli erat, in fal, fulf ır, bitumenq́ 1 , tum \& in ten uifsimos callidifsimosq́; uapores è q uib is ignis elementum conftitui Arifoteli uide tur, in retti afsiduè illam intuenti, prædicantique, ut modismultis Peripateticozum nonnullos mirari liceat, quibis mare aqux elementum non effe declarandum A riftoteli propofitum videtur, qui fcilicet, quem numinis inftar uemerantur Aritotelem, ignauum eum faciunt, inertemq́ue: tum \& itıpid ım etiam, itolidumq́ue : qui nimirum, quod de clarand am propofuerat, declare tnunquam, quin, quod unum ftatiere id poterat fummo id eu ertat itudio : \& quod fi declas 
declaret, uel mundi ei conftructio, \& iple deftruatur mundus, uel uniuerfa eius doctrina diffoluatur:neque enim quod mare aquæ elementum non effe declaret, pręter illius falfedinem allatum eft Arifoteli quicquam; at eam non propriä maris effe, fed ex accident e quopiam, \& alieni omnino çom miltione ei inditam effe contendens, apertè nihil obftare, quin mare aquę uniuerfitas poni pofsit, decernit: tum libens incommoda fubeat, qux minimè omnium fuftinere ipfe ue lit : in proprio nimirum aqua loco alienum ponat ens : \& aquam ipfam ad eum delatam nequaquam ibi feruari, perficiǵue, fed corrumpi ftatuat, deftruique. Tum \& aqux molem,à qua adeo terram excedi ; \& quam eandem iuxta pro- $x$. Metor. priam uniuerfitatem perpetuò feruari oportere decernit, uel cap.3. n'ullam ponat, uel fluuijs eam, lacubusque, qui nullam prorfus Terrę rationem habere uideri poffunt, \& qui afsiduè generari, \& uix geniti corrumpi uidentur, afsignet, oportet. Atvel ipfi ijdem Peripatetici Ariftotelem audientes, in ea terram ab aqua excedi oportere ratione, qua terre portionem, qux ex ea fit, aqua exuperare apparet: \& propterea terræ decuplam aquam effe oportere ratiocinati, anxiè maris fuudum rimantur, \& immenfum illum fub polis effingunt; ut qui nifi mare aquæ elementum ponant, \& immenfim illius faciant fundum, aqua elementum Terra maius oftende- Text. $84^{\circ}$ re minimè queant : uelint igitur nolint aquæ vninerfitatem mare pofitum Ariftoteli fatentur:At alij, \& longè ij quidcm præftantifsimi, mare aqux elementum Ariftoteli pofitum, \& necellario ponendum nihil dubitant, terra longè maius, \& in loco circa terram Arifoteli pofitum. Ipfe certe Ariftoteles propofitam de mari quæftionem abfoluens, manifeftè ", aqux elementum ponit mare : ex his, inquit, qux pofita funt" contat, mare aquarum principium non effe fed finem; Aquę nimirum uniuerfitatem effe, at non quod aq:ı ex eo effuät Sed quòd ad ipfum confuat omnes. id quod \& ignis, \& aeris uniuerfitati enenire Ariftoteli uideatur neceffe eft. Siquidem qui in terra, marive ignis fit, atque aer ad propriam $\mathrm{vm}$ terque uniuerfitatem . at nulla illorum portio ad terrx, marisve ima deferri inde Ariftoteli uideri poteft; ut illorum mo les, non quòd illorum partes inde delabantur, \& ut illorum omnino principium, fed ut finis, \& ad quem ignis, atque aer ubi uis factus confluit omnis, illorum elementum Ati-

B 2 ftcreli 


\section{Bernardini Telefij}

ftoteli ponendum omninò fit. Ingenitum praterea, xternumqque, \& iuxta propriam uniuerfitatem, fpeciemq́; idem perpetuò ponens Ariftoteles mare, ea nimirum mari tribuens, qux elementorum propria funt, manifeftè aqux ipfum ponit elementum.

Mare nec teruium, dulcium ǵ partium abfceffu, nec calide ficcaǵ exhalationis commiftione craffum factum efse, falfumque. Cap.I II.

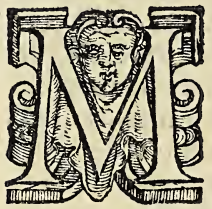

A R E non proptereà craftum effe, falfumque, quòd tenuioribus, dulcioribusq́ue fii partibus à fole fpoliatum fit ; fatis quidem inde intelligere licet, quòd, quae ex illo à fole ed acitur tenuitas, in aquam ea rurfus coacta tenuem, dulcemq́ue iterum illi reftituitur, \& cum fonore mehercule ; Siquidem \& qux è uaporib us è terra ed uctis fit aqua, magna ex parte à fuminibus in mare defertur tandem; quod itaq; fi (ut dictum eit)tenuium, dulciumq́ .e partium abfceffu craf fum fiat, fallimq́' 'ie, earum acceflu iterum tenue fiat,dulceg; \& eò Arittoteli etiam magis, quòd femper crafsi, falfiqúue aliquid omninò fim al extrahi ei uidetur, $\&$ in aquam id cogi tenuem, dulcemq́ue:femper, inquit, falfi pars cum dulci at tollitur, idq 1 te ubi in uaporem abijt, potabile fit; nam non in maris aq :am illum concrefcere, vinum docet, \& humores euaporantes, quorum omnium uapores $\vee$ bi coeüt in aquam craffefcunt omnes: ut non modo dulce fui natura, \& potabile aqux elementum, minimè proptereà falfum fieri queat; $\not$ dulces eius partes à Sole educuntur; fed falfum fui natura fi fit,duicefcat tandem, falfis fui partibus afsiduè eductis , \& dulcem in aquam actis : At multo, vt uidetur,idem priùs, multoğ ie etiam proximiùs, ex aqua manifeftum fit, qux à ca lore in uapores foluitur;n nulla enim illi unquàm à calore quo uis, \& q youis pafia modo craffefcere, uel falfa fieri videtur; fed in uapores agi omnis; nulla intereà crafsitie, nullaq̣; donatafalfedine, quin tenuior afsiduè facta, dulciorq́ue, nullis fcilicet fui partib us crafla aqua, falfa ve; fed bene tenuis uniuer $\{$, duicisứ $a$, \& exiguum gaid à uaporum natura diffidens, 
fidens, maris omninò, uaporumớ; veluti media , in eos dum agitur, nihil intereà ulla fui parte craffefcere, nec falfefcere \& iam potelt, non eam moratà caloris actionem, à qua falfa fie ri queat:prius nimirum in uapores foluta, quàm is ei indatur calor, à q 10 falfa fiat; eo itaque aqux uniuerfitas, quàm fcilicet aq ra omni multò ten uiorem, fimpliciorem q́ é effe oportet, minùs à Sole crafia , minus etiam falfa fiat: minime igitur tenuium, dulciumó; partium abfceffu craflum factum efle, fallum q́; aq ax elementu muideri potêt. At multò etiz̄ minus calida, ficcánue exhalationis commitione; mitto enim quòd nufquàm ea terrx aduftx quantitas, à qua ea exhalationis copia fiat, qux mari uniuerfo falfedinem indere queat, fpectatur, \& quod ad inis, aridisque in terris Ariftote li in primis exhalatio fit longè tenuifsima, \& qux tenuifsimum ignis elementum huiufmodi conitituit : qux igitur fi quidem à pluiijs deferatur, non modò nullam aquis crafsitiem, nullumqúue adijciat pondus; fed multò eas tentriores faciat, levioresque: nulli certè dubium efle potent, quin fi ma ris ualtitati commifta falfedinem indere ei queat, crafsitiēque; lacubus, eas fluuisq́; indat omnibus, \& plauias; quib is cùm deícendit, longè faliffsimas, longeque faciat crafsifsimas; qux, cùm rebus, quas deferunt exceptx omnibus, ucl au tumnales ipf $x$, quibus huiufmodi exhalatio plurima admiIt a effe Ariftoteli uidetur, dulces omninò, tenucsq́ue apparent omnes: Nec verò alieni omninò cuiufpiam committione crafsum, falfumq́ue uideatur mare, quòd qua cius pars ce reum uas fubit, tenuis apparet, dulcisq́ue, ucluti fercolata, iz re omnino exita, qux crafsitiem, falfedinemque indit: $Q$ niam en im maris aqua afsiduè à Sole attenuatur, $\&$ in uapores afsiduè agitur, qux vas fubit, marina cmninò aqua à Sole tenuior, \& propterea dulcior facta uideri poteft, vel qux forte talis à principio facta eft:neq; enim è nö penitus vnifor mi terra, \& à calore nó fnmmo penitus uniforme, nihilć; ; à fe ipfo differếs extractú eft mare, vel fuuialis êt:nec; enim ita marinę ea immifeeri uideri pōt, ut ab ea feparari,feiügiq́; nỏ pớsit.Marinä porrò aquã tenuiorë factā pro dulci falsã fieri, manifeirè pcipias; fi illă in fumú agis, eúq́; in aquã cogas,ma rinä nimirü aquã ampliorē quidê facias, at aliud immutas ni hil;dulcê enim eã facies potabilêǵ;, calore uidelicet per amplius diffufo fpatiü,\& propterea exilıare fąto, läguidioreq́;;

Mare 


\section{BernardiniTelefij}

\section{Mare fui natura falfum effe, \& è terra dulcium aquarum ritu, \& è proprës oriri fontzbus. Cap. : 1111 .}

Lib. 1. Cap.12.

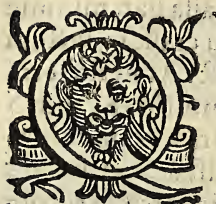

VONIAM igitur nec tenuium, dulciumque partium abfceffu, nec alieni omnino cu iufpiam commiftione falfúm factum effe mare uideri poteft, tale if fum propria natura efle omnino ftatuendum uideri debet; \& dulcium aquarum ritu è terra, \& ipfum à So le educi, firisq̆; \& ipfum è fontibus oriri . Nec uerò gn falfam; tătamq́; in aquam terra à Sole inuerti queat dubitandum:nố alias modò in res, ut dictum eft, agi illam intuentibus, qt: \& tenuitate, $\&$ propria natura longè quàm marina aqua à terra difsident magis, fed ipfum etiam in fal, quod, ut in libris de rerum natura dcclaratum eft, effluere omninò côltitutum videri debet, craffo, falfoq́ue, tenuioribus fui partibus à robuftiore calore fpoliato ; nec, ut in ijfdem amplius expofitum eft commentarijs,ea marinæ aqux exiftit moles, quàm è terra à Sole educi poffe intelligere non liceat; nihilo enim terra amplius mare breuifsimum certè effe uniuerfum ; nec vel Oceanum ipfum unius omninò ftadij altitudinem exæquare, \& à nauigantibus habemus, \& corruleus in uniuerfum eius color declarat, qui mari ineffe apparet, nihil dicto fpatio profundiori;nam ubi panlò altius fit, nigrū ibi fpectarur;obfcurumq́';,\& tale porrò cęrtis modò apparet in locis: at terræ femidiameter quibus breuifsimus uidetur, duo detriginta milia ftadiorum altitudinem exeq!at; alijs longè etiam eft maior:quòd nifi afsiduè è terra enafcatur mare, tot tantisq́; dulcibus aquarum fluxibus afsiduè illabētibus, \& falfis etia fui partibus à Sole in uapores actis, ijsq́ue dulcem in aquam coactis, dulcefeat Ariftoteli tandem; Tum $\&$ deficiat etiam ei tandem è Boreali fublimiore afsiduè effluens terra, neceffe fit.Nec verò quòd maris fontes confpicui non funt, non \& ipfum è fuis fontibus emanare uideri Ariftoteli debet; quid enim, ueluti, 3 lacus omnes, aut eorum pleriq́ue non è fuppo fitis fontibus affluere queat? \& ita omnino effuere fuo demonftrabitur loco. 
Mare aque elementum uideri non poffe, nec Ariforeli videri debuife, nec rectè cauf am ei explicatam effe.

sur tot-illabentibus in Spiritum aquis.

$$
\begin{gathered}
\text { minimè excrefout mare. } \\
\text { Cap. } V
\end{gathered}
$$

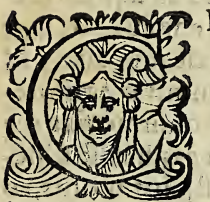

R ASS V M porrò, falfumqúue fui natura exiftens mare, quàm longifsimè abeft,ut aqua uniuerfitas uideri polsit, tenuis dulcisq́; Ari ftotelicertè poni minimè debuit, cui nimirum proptereà mundi conitructio, quam uidemus \& ipfe feruari uidetur mundus, neq; à principio uno ocupari omnia, quod prima illius corpora $x$ qualibus predita funt uiribus, corumq́ue fingulis fua adfunt contraria;qux æquali robore repugnant, obluctanturq́ue;cui igitur timendum fuit, ne altero e frigidis corporibus calido facto, quacunque tale factum fit ratione, à calore tandem occupentur omnia,\& omnia unum fiăt;uel tartarus igitur quifpiam in terrx imis ei effingendus, uel aqua per terram fluens aq $1 x$ elementum ponenda:horum neutrum fi proprix ipfius pofitiones fuftinere poterant: Si quidem mundum fuo arbitratu efingere, conitruereque propofitum homini non erat, dimittendx illix omnes erant; \& nequaquàm quatuor ponen da prima corpora, \& unum ex ijs à fummo frigore, fummaq́; conftitutum humiditate. At neque caufam explicans, cur tot aquarum fluxus afsiduè in mare infuétes nullam maris adijciant magnitudinem, \& nunquam omninò maius fiat mare, laudari Ariftoteles poteft; propterea id euenire ftatués, quod Text. r 8 . in maris illi illapfi uattitate citò arefcant, modice aqux more ", fuper magnam menfam fparfx : eadem, inquit aqux copia,", qux in latitudinem expanfa fit, \& que fimul collecta, nó ẹqua," li tempore reficcatur, fed ufque adeò differt, vt hxc quidem," integrum dië permaneat, altera perinde, ac fi quis aqua cya-" tum fuper magnam menfam effuderit;fimul ac id cogitaneri-", mus, tota euanefcet: id quod fuminibus quoque ufu euenit.", illis enim continenter collectim fluentibus, id quod in ua-", ftum, latumq́ue loeum peruenit, citò femper, ac occultè exic caturj neque enim terrx, vel entis cuiufuis molem ab infufa 


\section{Bernardini Telefij}

2qua augeri dubitare licet;uel fi eius incrementum lateat, nifi fortè \& per exigua aqua infundatur, ftatimque ea inde euaporetur, que fluminibus in mare illabentibus haud quaquam euenire uideri poffunt : magna omninò eorum moles, \& qux afsiduè aucta maris ipfus magnitudinem breui exequa re;nec ftatim ac mari immifcetur, in uapores agi videri poffit; quòd fi etiam fiat, nihilo tamen minus mari molem adijciat: Siquidem uapores è mari ed icti omnes in aquam rurfus coacti, rurfus ei reftituutur,ut nifi in non ens abeant, qua in mare influ int $2 q u x, \&$ hoc Ariftotelici arefcant pacto, id quod nec alijs euenire uidetur, nec placere omnino Ariftoteli potelt;excrefcat ab ipfis tandem \& maius omninò fiat ma re oportet. Ha ud recte igitur Maris naturam explicaffe uidetur Ariftoteles, Age porro, quod reliquum eft, eius motus, eo sumq́ue rationem explicantem audiamus, examinemusque.

\section{2uibus motibus, \& quam ob cuufam moueri mare Arifto. relividetur. Cap. VI.} 2. Metro. tur: ubi uidelicet ob ambientem terram è uafto pelago in paruum colligitur; propterea quòd ultro, citroque frepius libretur; hoc uero in uafto mari perfpicuum non eft ; at fi ob terræ angultias arte loco contineatur,

" libramencum, quod in mari exiguum eft, magnnm illic uidea "tur neceffe eft:Id autem quod intra Herculis columnas conti " net:ur, totum terræ concauitatem, \& fuminum multitudine "Huit:nam Mrotis in Pontum, hic in Aegeum fluit. Qux ve" rò extra hre maria funt, hoc minus perfpicuè faciunt,illic au " tem, \& propter fuminum multitudinem hoc euenit ( plura " enim fitumina in Euxinum, \& Meotidem influnt, quàm in lo" cum eius multiplicem') \& propter modicam altitudinem:Ma "re nanque profundius fubinde cernitur; ac Meotide quidem "Pontus, hoc verò A egeum, Aegeo Siculum, \& omnium pro"fundifsima Sardum, ac Tyrrhenum. Qux autem extra colum 3) nas funt, modicè quidem oblutum profunda funt; fed flatibus ancant:quaf mare in concauo locatum fit: qux explican sespeip.. icorum optimi, duplici, inguiunt, motufluere mare arifetcilvidstur, ho, guj in anguftijs, \& fittis cerni- 
Eur,aitero, quo à Septětrione ad Auftrum vniuerfum defluune ; maria: \& prioris quidem caufam ad maris libramentum re- " fert; quoniam enim inmenfa eft maris moles, \& x qualiter vtrinque pédécns, non in unam partem magis, quam in aliam declinans, vbi in vram moueri incipit, ponderis $x$ qualitate retractum in alteram partem ftatim reuertit:ir:atque ita $f$ erpetuò alternatim. Hæc autem maris agitatio in locis apertis, atque in alto euidens non enffuxam q e confpicum non fa cit; in angut tijs verò cernitur:vel ti lictoribus, qux in angufum exvallitate contrahuntur, motum adi uantibus;fluxus porterioris duas aftert canfas;fuminum nidelicet multitudirem, qux in maria illa Septentrionalia longe plurima, longequ maxima infuunt, à quibus penc̀ expulfa Meots, ontusque in Aegeum infuunt, \& hoc in ea,qux confcquentur. Tum \& terrę Septentrionalis altitudinem, è qua in magis con cauam fluant oportet; quapropter Borealia maria breuiora etiam profundiora, quæ confequuntur, Ariftotcli uidentur, quòd illa in hæc fefe exonerent, ueluti, inquit, in terrx partibus è locis $x$ ditis flumina fluere videntur; fic è totius terræ ," $x$ ditionibus, qux ad Septentrionem fita funt,plurima fixio ,, fit:quapropter ob effufionem profunda illa non funt.loca $\mathrm{F}$ or, rò ad Septentrionem fita excelfa effe, eo declaratur; quòd uc- ,, terum Meteorologicorum multis perfuafum fuit, holē fub ter, ra non ferri, fed circa terram, occultari autem eum, \& noctem, facere,propterea quòd Terra ad Septentriones excelfa fit.

\section{Non redtè Maris motum caufas ab Ariftotele redditas effe. Cap. VII.}

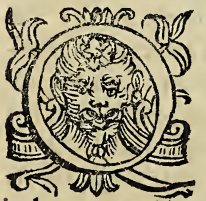

VONI A M libræ more in hanc modò, modò in illam partem inclinäs fluere, refuereq́ue Mare $A$ riftoteli uidetur; videndum omm ninò, num à quibus libra veluti per uices in diuerfas interdum agitur partes, ab ijfdem, $\&$ mare agi pofsit. E libra quidem propterea in hanc modo, modò verò in alteram partem inclinare videri poteft, quòd vtraq; propria natura deorfum fertur; \& quin vtrauis deorfum feratur, à fuppofito aete retineri minimè fo teft; ac ita eft conftructa, vt fi altera delabatur; tollatur, fableueturq́ue altera; vbi igitur æquis v trinque grauatur pöderibus, 


\section{Bernardini Telefij}

ribus, tantifper modò hac, modò illac vergit parte; id verò quòd partes ipfx non à propria tantùm detrahuntur grauita te, fed ab impulfa itidem, quacunque is datas fit ratione. Non fcilicet qux ab externa tantùm deijcitur vi , fed qua a propria modo grauitate detrahitur pars, vel æque grauem al teram, vel etian grauiorem quid talifper attollit, fubleuatọ́; à delapfis nimirum uiribus a'ıcta, \& veluti gratuior facta : at nö diu id tamen: neque enim ulterius fe attolli: \& fublimio-re in loco detineri finit altera; fed ipfa delabitur:nec tandiu id modò, d im xq tè alteri Terræ proxima fiat, fed inferius etiam \& ipfa, velati \& ipfius grailitate à delapfu maiore facta; alteram q́ le tantifper \& ipfa fubleuet, \& tandiu utraque modò in fablimius alteram attollit, ab ea modò attollitur, dum partium delapfus languefcant, \& propria ex tantum decertēt gra iitate.id vbi factum eit, nullam amplius in partem vergit libra, fed immota manet, ne in alteram detrahatur, retenta, coercitaq́ice ab altera:propterea igitur modò hac, alia modò parte interdum libra inclinat, quòd utraque deorfum natura fertur, \& nec in eas diuidi, nec utraque fim al deferri poteft, quin altera delabente, attollitur, fableuaturq́ue altera . $\mathrm{Ho}$ rum n ill $\mathrm{lm}$ mari e.tenirc videri poteit:in proprio enim id lo co,\& in Terræ omninò conca is continetur, fib bique ipfi inni titur vniuer $a m, \&$ ne vlla fai parte inferius delabatur, à feip fo retinetur,coerceturóue:n hilq́;, vt A riftoteli etiam placet, parte ulla, vel alijs fui partibus, uel terra ipfa mag is fublatum cęloǵ̣ne proximius factam, fed uniuerf un fuprema fui fuperficie, æquè ab illo cum Terra diftans, nullam omninò occafio nem habet, car ulla fai parte ufqum inclinet.\& fi id fat, minimè inde $a b$ aliena in contrarium uegentem retrahatur, gra ue, $\&$ benè fuidum, beneq́ te à feipfo diuifibile exiftens; fed quò femel delapfum elt, perpetuó ibi à nulla externa ui impulfum,immotũ Arilt. pręfertim fiat, cui nimirủ prima corpo ra omnia, \& ipfe ctiä ignis in proprio loco immobilia fieri im mobilitate gautdere uidentur.Eoq̣; etiä in ang ıttijs , fretisq̣́; magis; fi fiquidem, ut Arilto. placet, libretur. Mare propterea librari uideri potelt, quòd fluxile cùm fit, fefe eonrinere mini mè q leat:eò itaq te minus libretur, quòd à proximiore continestur terra, 8 lang idifsimè igit ar id fluat, refluatq́ue; fecus, atq de euenire uidetur, nec ulla eius pars eo ordine, eaq; celeritate, qua fuere, reflueregá; uidetur; ut enim libretur M2 
re,temerè certè id fiat, languideq́ue, ut, \& librari ineptifsio mum, \& nel fi libretur, non tamen propterà fuere, refuereǵ uideri pofsit mare: Minus etiam proptereà tumefierinneque enim parte altera attolli, fed vniuerfum fimul bullientis as quz more tumefieri uidetur:nec imaginari omninò licet, à lì bramento in altum euehi mare;neque igitur Ariftoteles ipfe. maris $x$ ftum eius libramento afsignare eft aufus; quin eius in quifitio penitus pratermifia hom ini uidetur:non quidem, ut exiftimare licer, quòd nel maris tumefactio non confpecta, uel eius caufa non inquirenda ei uifa fit, fed, ut fufpicari quis poffet, quòd illam attingere defperarit . At neq; maris motú, q. tò à Septentrione ad Auftrum uniuerfum ferri uidetur, declarans placere poteft Arifto.neque enim Meotis, Pontusqúte in fubfequentia maria afsiduè delabi uideri poflunt, quòd $\mathrm{ex}$ xditioribus locis in magis concaua deferantur: quoniam enim fpęrica eft terra,nec Borealis plaga nec ulla eius pars alia fublimior, uel hum lior uideri poteft: \& fummè Arift.mirari licet, inde Borealis terrx altit.Idinem colligentem, quod antiquioribus Meteorologicis fublimilis uifa fit; $a$ fub qua fefe oscultet nocturnus.Sol, quos longè minus abfurda, \& uera interdum proferentes adeò contemptui, ludibrioqu ha habere ubique ipfe uidetur : Borealis quidem terra nufquam excela apparet; fed humillima uniuerfa, nullis diftincta montibus: plurimi igitur,longeq́ue maximi aquarum fluxus è Meridionalibus locis in Borealia defiuunt maria;talis reor $a b$ uniuer fi conditore conftituta : ut quam directa folis lux calefacere non poteft; unita foueat, collectaque.Neque igitur propterea $b$ :euia fant Borealia maria, quod terra illa fiblimius, fed fi talia funt, propterea funt, quòd languidior minus illam in mare inuertit Sol:\& minus itaque falfa apparent;afsiduè cer tè effuere Ariftoteli uifa;è fontibus, ut dictum eft, manare ui deri debuere;nifi en im è fuppofita terra afsiduèbi mare ema net, deficiat tandem afsiduè effuens, \& fe effundens afsiduè. neque igitur Theologi incufandi Aritoteli erant, mari fontes afsignantes; \& Oceanus breuis uifus nequaquàm in terræ concauo pofitus uideri debuit;neque enim fuppofitus lutus, qui, ut breuis fit Oceanus, fficere Ariftoteli uidetur;aliunde eò importat us terræ illius profunditatem attollere uideri po teft. At neque uentis caret Oceanus, ut Arifoteli uidetur: fed fialibi ufpiam, in eo flant, eft \& ubi idem ferè femper;

C 2 ubi 


\section{Bernardini Telefij}

ubi uerò quafi ftatis, certisq́ue temporibus alter alterum excipit:Iure igitur, ut uidetur, maris, nec naturam, nec eius mo tum, tumefactionisq́ xe caufam explicans Atiftoteles fatis placet, \& utramque nobis amplius inqu rendam exiftimamus, obfcuras uerò tes . quis enim mare fubeat, exortum, \& qux ipfum agitent, tollantq́ue vires intueatur? At diuina tü fi prefulgeat lux, nihil illas intueri defperetur:age itaque, tuo mihi Deus mare illuftra fulgore, ut tuo per me id munere tua que hominibus innotefcat bonitate.

\section{Mare è terra afsiduè, à Sole, at non ex omni tamen fed è pro funda illa educi, ơ cur craßum calidumǵs fa- Itum eft. Cap. VIII.}

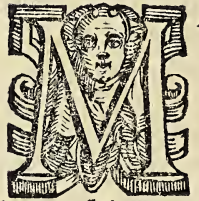

A RE, ueluti aquas reliquas omnes è tetra afsiduè à Sole educi, nel ipfam ut declarat fal:manifente è fuo fluore conflitutum crafficulo, falfoq́ue,tenuioribus fui partibus, uel fpôtè elapfis, uel à Sole eductis; at $\&$ inde ut uidetur, apertifsimè patere poteft, quòd calid um fui natura, molleq́s, s fluidum cum fit, \& à Sole infuper afsid aè in exiftente tenuitate fpolietır, \& magni dulcium aquarum flux is in ipfum influant, defluantque:nultis omninò modis eius \& fpeties, \& natura immutari pofsit, nec fum mis in fqualloribus, \& fub Sole fummè directo, uel ubi à fluminib as quàm longifsimè abett,crafsius, falfusáue;nec fum mis in illunionib ss, \& ixxta maximorum fluminum fluxus ten aius, dilciufve fieri,fed eadem eiufdem cius fpeties, eademq́ te perpetuò apparet natura. Non quidem nifi afsiduè enafcens, $\&$ copia, roboreq́ ue exuperans fui partes immutari jam cœptas in propriam retituat naturam : fed uel uniuerfam in fal concrefcat longè folidifsimum, uel crafsius alibi, faliiısque,tenuius alibi, dulciusque fiat: entium reliquortm omnium, calidorum prxfertim, molliumq́ue, \& propriarım etiam partium more: q!ı feorfum à propria uniuerfitate, uel frigido fub cęlo immutari tandem, è calor certè uel languente in fal agi uidentur. Eterra porrò enafcí uerum mare: at non aquarum reliquarum more pafsim è terris omnibas emanare, perǵue omnes fluere, \& in omnibus 
nibus omnino effe, confpectum, fed certis modò in locis, non ut illa è quauis, \& è fuprema etiam terra, fed ex ima tantùm enafci, \& mole exuperans, copiaue, afsidueḉ; à nouo impulfum in certa uni uerfum loca erupiffe videri de bet. Et multò omninò qux illx crafsius, calidiusqu $x$, non ijfdem in terris, neque à calore eodé, fed è crafsiore omninò terra, \& à languidiore calore, è profundiore nimirum terra educt .m uideri debet : Q oòd fi craflam, denfamq́ue, \& minimè difsimilarem rem à languente quidem, at multò occupatam calore ante oculos ponas; profundã fanè terram in fluorem illam agi tâdem manifeftè intueare crafum, falfumq́ie; paulatim enim,lenteq́ie, \& omnis fimul emollita, nullisq́ue eius partibus in fummam actis tenuitatem, neque ita alijs prias attenuatis, ut è denfa,craffaq́ue te effluere pofsint:quod ubi fit, in crafsiciem, quod reliquam eft, agi interdum apparet, in fluorem, ut dictum eft tandem agi uideatur unicierfa crafsiufculum ill ım quidem, beneq́ te calidum. Q òd fi non tanta in fornacibus agat ignifve, \& in lapidem agat minus difsimilarem, \& magis craftum, magisq́ue uifcofium : cuilis fcilicet,fi quidem partes ullas alijs prius attenuct, nec fummè ten tes faciat, nec egreflum ijs elabentibus aperiat'ır, retent $x$ itaque, $\&$ reliquis non dum in fluorem aets, at emollitis iam agl ttinentur; dum \& ipfx in e:undem aganturfltoré, non in calcem, fed in aquam, \& ipfe agantur crainam, falfamq́; \& amaram. Multo certè in eam amplius protund ior quaett Terra,bcne, ut dictum eft,fimilaris, \& non frpremis fui parti bus magis, nec prius, qux internis à calore emollitus, qui è fupremis terre partibus ad ipfam delatus elt, ipfque inditus, lan guens is quidem, at multus tandem.Et ex hniufmodi om ninò terra marejeduci, aqux ornnes declarant, que è fuprema quidem terra, at craffa, denfaǵ; cuiufmodi Appula apparet, emanet, qu æx filicet crafsiufculx funt omnes, falfxque. At neceffariò crafum, calidumq́; i imis è terris erutum mare, fum mè confultò tale factum uideri poteft; huiufmodi enim exiftens, \& proximas oras calefacere, \& bene tenuis ex huiufmo di par ufque aer educi uidetur: neq; enim crafsiori egreffum prębeat:at tenuè fi fit, minusq́; calidü. cuius itaø; proprius ca lor, \& $a b$ ambientis proprio frigore interimi , fuperariue, \&z è quo qui à Sole inditur, quod terræ euenire non uidetur, facilè elabi queat, fummè, quod ftagnantes aquæ faciunt, adiacentes 


\section{BernardiniTelefij}

eentes terras frigore afficiat, \& v veluti ex ftagnantibus aquis adeò e $x$ illo craflus elabatur aer, ut hominum faltem genus fub eo viuere minimè pofsit, vt nunquam rerum conditoris fapientiam fatis mirari, aut amare bonitatem queas, qui co mundum confruxit pacto, ut quẹ neceffariò etiam fiunt, con fultò, \& meliora omnino, noftrique boni gratia facta videri polsint.

Cur aque marine dulcibus copiofiores, of cur tot illabentio bus in ipfum fluüs,maius noin fiat mare. Cap. IX.

\$:

1 VRE igitur marina aqua adeò dulces copiz 近敦 exuperat, ut nulla illius pars ha videri pof fint;fi quidem fupremx terre partes profundioribus ambitu quidem ampliores videri poffunt, at è dimidio, vt videtur, à mari occupatx minores omnino videri debent.Nec è tanta fortè terræ altitudinis portione aquæ dulces, è quanta falfe fiunt:fiprcma certè terra variè iam à Sole emollita, \& variè eius luci expofit $a, \&$ non $a b$ afsidua ea,nec æquè perpetuò directa calefacta, in longè diuerfifsima entia : quòd fieri apparet, inuerti omninò:\& vel qux in aquas acta eft,nullo ferè temporis momento, in vapores agi ab xitiuo prafertim So le videri poteft. At non \& profunda itidem, ad quam fcilicet nufquam, qui à Sole emanat, fed is modò, qui fupremæ terræ inditus eft, peruenit calor; qui languens quidem, \& idem penè factus illam occupat, \& nihilo fortè per hyemem, quàm per xftarem fegnior:nam fi directus Sol robuftius agit, at robuftius etiam Terram patefaciens ingenito calori aditum aperit magis ; elabendi itaque aditum is nactus, fummeque ad elabédum intentus, minus ad:profunda diffunditur; vnus itaque perpetuò pene profindiori inexiftens terræ calor,bene eam uniformem in unam omnem agit rem. Afsiduè porrò enafcēs, \& maius factum mar e, \& tot auctum afsiduè fluuijs, neque excrefcit unquàm, nec tenuius fit, quòd aqu $x$ hx omnes, \& qua tenuiores à principio fact $x$ fuere ; neque enim vel terra, è qua fit, adeò fimilaris, adeoọ́; idem qui illam inuertit calor,ut in eãdé peniitus aquã agaturomnis;nec ulla eius pars 
alijs tenuior,minusqúue calida fiat. Tum quòd mare à Sole affiduè tenuius fit; non fi quidem in uapores agens ipfum Sol, soa in fuores prius agat, qui marinx aqux, vaporumq́ue elabentium medij videri polsint. Aquæ inquam \& illabentes, \& decidétes, \& qux à principio falfis mift $x$ fact $x$, $\&$ in quas falfre à Sole actre fuere, in terram afsiduè illabuntur:quòd nifi id fiar, nifi fcilicet hoc pacto tenuitas, qua afsiduè Sole fpoliatur, Terra reftituatur;vel deficiat tandem omnis:neque enim pluui $x$ illam feruent, ex illa ęduct $x \&$ ipf $x$, vel adeo arefcat, den faque fiat, ut aqux nulla nulla amplius ex ea tenuitas edı ci pofsit. At neque uniuerfi conftitutio, quam videmus, feruetur, neque unus omninò amplius permanear Mundus; fi quidem Terræ proximus Aer, à Sole à denfifsima itla refilien te iufto plus calefactus, amplificatusq́a ae, pacto nullo loco, in quo eft, contineri queat, nec uelit multò tenuior, multoq́ue amplior factus; fed fuperiora petat; vbi ne fcindatur, ast amplius fiat colum, in fellam fortè coeat, Vacuus certe circa ter ram fiat locus, naturx fummè aduerfum, exofumqque mutuo contactu foueri volenti entia, \& mundum maximè unitum, atque vnum effe; illa ne eueniat tenuitas mari inexiftens in reiram, afsiduè illabens præftat $:$ materiam ijs, qux afsiduè è Terra funt, ingenerandis prabens; diuinitus ita à conditore noftro prouifum, factumqque:ijs viribus donato Sole, eaq́ue à Terra locato diftantia; ijsq́ue moto motibus, vt afsiduè Terza cùm inuertatur, inuerti asfiduè pofsit.

Motum Marinecefjarium fuiße, o à quibus intumefitt,

$$
\text { nioueturǵs. Cap. } X \text {. }
$$

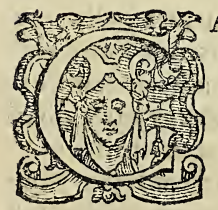

A LIDVM porrò exiftens mare, \& propterea motu, quo feruetur, atque oblectetur indigens, multò ctiam quàm aqux reliquæ amplius, qux ftagnantes, atque immobiles factx corrumpi videntur omnes; Et quo pre tereà folis actionẻ declinet, fugiatọ́tic; nec iufto plus in vapores foluatur. Et per fe moweri impotens, non ea donatum tenuitate, vt ipfum fe commouere queat:ab aliena utique ui fi fer:andum, commo"iendum:ab vniuerfo quidem ccelo pracipuè verò à longè robuRifsimo Sole commoueri, agitariqgue. Conditori placuit noAtso 


\section{Bernardini Telefij}

Itro, non quidem fecum illud rapiente; neque enim fieri id queat; fed vapores, ut dictum eft, in generante; qui fcilicet egreffum molientes, \& egreffu à fuperpofito mari prohibiti; fpiritus more in aqua ab igne ingeniti, attollant ipfum, agitentqúue; propterea enim hx feruent, intumefcunt, atque agitantur:quòd ingenitus fpiritus confertim elabens attollit, $\mathrm{va}$ rieq́ue exagitat non patentem prabentes egrefium; feparati itaq́ue, adapertxq́ue, ut elabenti illi exi tus pateat, non amplius attollintur, fed ftatim refident omnes;nufquàm itaque penitus immobile, \& penitus planú, fed femper agitari quid, \& quid attolli femper apparet mare, veluti qux ebullire incipiunt aquæ; \& Vere, atque Autumno maximè , minimè verò Aeftate, atque Hyeme; quòd, ut in commentarijs de pluuijs ex pofitum eft, Medius Sol plurimos, crafsioresque educit va pores:Robufífsimus, longè ten uifsimos, quales vel è crafsiu fculo egreffum nacifcantur mari : nihil ipfum, quod uidere queas, attollentes, commouentefve:languidifsimus per paucos, \& qui fuperpofitum mare attollere, \& è conftrićto elabi impotentes tam diu retineantur: dum fummè \& ipfi tenues fiant; In plenilunijs itidem in Nouilunijs maximè attolli, intumefcercque videtur mare; in illis quidem, quòd multa à Lu na refiliens lux , multos educit vapores: in his autem, fi Vere in his attollitur mare, quod refrigerato aere fefe colligit,atque unit internus maris calor; \& valens factus plures facit, at que emittit uapores, veluti \& putealis aqua, Borea firante: Minimè in Lunx quadratis, nec multa à Luna refiliente luce, nec in feipfum collecto proprio maris calore; Quin non attollunt modò mare qui elabütur vapores, fed impellunt etiá, atque ad motum incitant, id quod palea aqux fuperpofita de clarat, fi quidem in fuppofitam palex aquam, ita Solis luxà fpeculo afsiduè refiectatur, vt uapores, qui afsiduè fiunt, elabunturque, veluti à tergo paleam feriant, in anteriorem eam partem ferri intueare; $\&$ regredi rurfus, fi ex altera parte dicto modo reflectatur lux : ingenerat fcilicet in aqua fpiritum in eam reflexa lux, isq́ue elabens in alreram partem fuper pofitam aquam,paleamq́ue impellit : non tanti forrò afsiduè ma ri ingeniti vapores, qui ipfum afsiduè attollant, impellantq́; nec perpetuò attolli, nec vndique impelli uidetur mare, fed refidere interdum, quiefcereq́ue: $\&$ in hăc modò refluere partem, hinc modò refluere:ibi nimirum attollitur, indeque im 
pellitur mare; vbi uaporum copia fubeft, at ea elapfa refidet, ibi; neque amplius inde agitur,at qui interea parte in altera vapores facti funt, plures iam facti; $\&$ qui fuperpolitam maris molem attollere queant, egreflium hi molientes,attollunt ip fum, \& elabentes in contrariam incitãt partem; per uiccs itaque attolli, refidereq́ue, \& fluere, ac refluere videtur mare : $8 c$ ut plurimum xquali tempore, \& fex horarum fpatio utrumq́ue:quod nimirú eo in temporis fpatio, tot mari ingenerantur vapores, qui tădiu ipfum attollere, impellereque pofsint. Mira autem maris motus celeritas in anguftijs, fretisq́; appa ret, quòd per apertum fluēs, nibilq́, à fubfequéte vmquam im pulfum, nihil eit quod vfpiam motum concitet: at ubi in anguftius agitur, nec vniuerfum fimul fluere potef, fed vel exigua fui parte tantù , quod remanet fubfequétis furfum impediens, retardansq́; \& propterea ab eo impulfum, ftimulatumq́; motum acceleret, \& præcedēs impellat neceffe eft : At yniuerfum, ut dietum eft, ab elabétibus uaporibus fublatum, impulfumq́; nón æquè uniuerfum attollitur,impelliturớ;, nec xquali têpore utranq́; in partê,Britannicum, \& quod Britannico adiacet mare fummè attolli, \& fex horartm fpatio in terras fluere, totidemq́; refluere videtur.Ide \& Adriaticus finus, at longè quàm Oceanus minus, Ligutti cú Tyrrhcnumó; parum admodum, ut \& fublatum, \& impulfum latere pofsit; Mare iuxtà Aethiopiam, quod Ceneghæx uocatur, quatuor tä tùm horis fluere, octo refluere apparet.Non atque fcilicet pro fundum mare, nec ab xquè reflexa luce, calefactum uniucrfùm non eofdé omne emittit uapores, fed alibi longè plures, crafsiorefve;pauciores alibi,tenuiorefve ; id itaq; fimmè attolli uideri poteft:quod breuius eft, à cuius fcilicet fundo robutior refilit lux : \& inde etiam impelli magis, ubi breuior. eft findus : fortè $\&$ non diuerfa tantum profunditas diuerf $x$ maris tumefactionis, diuerfiá́; motus caufa videri debet, fed diuerfa itidem eius crafsities; neq; enim uel vniuerfa è terra xquè craflum mare educi, uel è diuerfe eo craffo non diuerfos vapores extrahi exiltimare licet, id certè tumefieri magis, $\alpha$ inde mag is incitari uideri debet, ubi plures, crafsiorefve fiunt vapores. At non per uices modò fuere, refuereq́; videtur mare;fed eft vbi fluminis mare perpetioo in unã fuant partê, quod in Adriatico à Naut is obferuatum tradunt, \& in

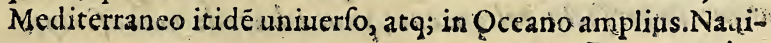

b..........

D gatio 


\section{Bernardini Telefij}

gatio itaq́; ab Hifpania ad infulas Occidêtales, quas Columbus inuenit,uigintı quatuor dierum fpatio conficitur;at con tra ab infulis ad Hifpaniam, eadé propè vfis ventorum ope, non nifi trium, aut quatuor méfum têpore; A quis nimirum -ccurfantibus, $\&$ in contrariam parté fuétibus.Idé \& Lufitanis enenire aiunt, in Indiam, fupcrato Bonx fpei promontorio, orientem verfus nauigantibus, atq; inde redeuntibus : At Mediterraneum, atq; Adriaticum quafi circulo ferri :. Illud enim ab Hellefponto ad Occidétem Solë per tiniuerfam Europx oram ad col.ımnas ufq; Herculeas, \& Gaditanum fretŭ: inde uerò per Africę littora ad A egyptum ufque, \& Syriam ad Orientem Solem: Adriaticum uero dictum forte continuans fluxum,per Ilirię, Dalmatięq ue oram Occidentem uerfus ad intimam ufque finum, in quo Venetix fita funt ; at inde ad Meridiem flaminiam uerfus flecti, ad Apuliam, inde ad Orië té Solem:inde fcilicet ufque quaque mouetur mare, unde plu res, crafsiorefve elabuntur uapores: tales autem, tantiq́; è minus profundo, ut exiftimare licet, mari.Iure igitur ab Hellefponte Occidentem uerfus, è breuioribus, ni mirum Ariftotelis teltimonio, in profundiora vfque quaq; maria, Aquas reliquas nequaquàm impellere videntur, qui ex ipfis elabuntur vapores, quòd in minus calidis, arsidueq́ue fuentibus, \& Solis aftionem ueluti fugientibus longe pauciores funt uapores, \& elabentes nihil aquæ retinentliquidæ, tenuesq́ue:At la cus tamë uidere eft multos, huc modó, modò illac impulfos, at blande, leniterq́ue, ab exiguis vaporibus, nö valtos ipfos, neque in angufum actos ullum,ubi clarior illorum appareat morus, ueluti \& maris.

Tria bec, que fequuntur capita de maris estu, $A$ T elefio quidem or ip a elucubrata funt.9ed tamen ab eodë in prima buinfce libelli editione confulio pratermifja, idǵs ea, at puto, de caufa, quod in bac contemplatione nondum fibi planè $\int_{a-}$ tisfaceret. Erat enim tum in alienis, tum maximè in pro. prïs fententïs iudicandis fanè quam difficilis, at ǵ moro. fus. Itaque nibiledere ille folebat, quod non longa adbibita. difcufsione lentè prius, ac faftidiosè probaffet. Nos tamen, ne ea quidem intercidere, equum putantes, que ip e rudia, atgue imperfecta reliquerat, pauca bec de manufcripto exemplari 
exemplari diligenter excepta, priufquam ea fabi aliquis uindicaret, \&ut fua veridicaret, in calce briug ce libelli ex. cudenda curauimus.

Arifloteles folis vertigini, aly vero diurno lune motui maris aftum, fuxum ǵ: ó refluxum attribunt.

Cap. X. 1 .

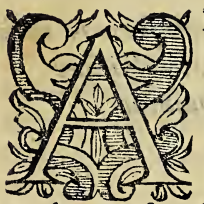

RISTOTELES (fi Plutarcho credimus) Heraclitum, ut videtur, fequutus, à fole eftü fieri exiftimauit; plerofq; enim flatus rua il lum circunflectere vertigine; quibus ingruêtibus, Atlanticumque mare protrudenti- , bus, ipfun intumefcere, atque æeftuare, \& ijs ", tandem ceffantibus, reftum fedari . alij uero, quorum opinio ", noftri temporis hominibus longè, ut dictum eft, probabilior, , quin \& verior videtur, \& qux in libro etiam de elementorum proprietatibus Ariftoteli afcripta legitur, in diurnum lunx 2.Opinio motum xftus caufam referunt: Illum enim hic infequi uidetur, nam ut ille in quartas diuirus eft, iuxta quatuor cœli quar tas, quarum quatuor funt puncta, ortus, occafus, culmen diei, \& noctis, fic fingulis diebus naturalibus mare quater mouetar, bis fluendo, \& bis refluendo; fluendo quidem cum luna ab ortu, atque ad diei culmen afcend it; tefuendo cum à culmine ad occafum defcendit : rurfus cum ab occafu ad noct is culmen afcendit fluendo, ac demum à noct is culmine ad ortum ufque refluëdo. Quòd autem modò maiores, modò minores xttus funt, diuerfos lunx ad folem afpectus caufam effe inq iunt:tunc en im maiorem xftum effe, cum luna quadratum ad folem afpeetum habet, quàm cum folis afpectu magis uacat : rurfis maiorem in coniunctione, \& oppofitione, fed maximam in oppofitione. Praterea cum ab ortu in meridiem,cœlique culmen fertur,maiorem, quàm cum ab occalir verfus medium noetis, fi quidem eius actio maior fit, cum ori tur, quàm cum occidit;quòd mare recta afpiciat. Maiores itidem hyeme, quàm xitate effe, quòd per aquaria figna fol tran. feat, qux lunx uirtitem adimuant:qux antorn maria crafsio-s rem habent aquam, femel tantum, aut bis in menfe eqf tare, quòd non nifi magna tana ui moucri poflint, Tuin faculta-

$$
\text { D } 2 \text { tem, }
$$




\section{Bernardini Tëlefij}

tem, qua luna ita mare exagitat, inquirētes nō àmplius fibi ip fis confentiunt, fed alij influx mom quendam à luna in mare mitti itatuutt, quo mare tume iat, illoque ceffante, aut imminuto,tumorem amittat. Alij influxum ponunt, quo mare ad lunam attollatur, quomodo ferrum ad magnetem, hunc auté influx $\mathrm{tm}$ ad maria occidentalia tantùm mitti, quod in illa duntaxat uim luna obtineat : unde occidentalem lunam, folem orientalem appellant.

\section{Perperam aftus, fluxus g̊, \& refluxus, reliquoruin uero \\ maris motuum, nullam ominino Ariftoteli, fuifque redditam effe caufam, nec reddi omnino poffe. Cap. XI1.}

Cofutatio fententijs Ari.\& Heracliti.

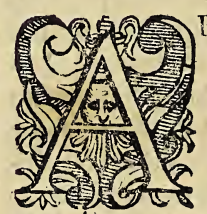

RIS TOTELIS, Heraclitiq; fententia multis (ut videtur) claudicat modis. Primum enim maris ẹltus, \& qui eú infequi uidetur, Aluxus min imè a ventis fieri, uideri poteft $: \mathrm{fi}$ quidem, \& nullis ijs flantibus, \& contrariam fiantibus in partem, fit , \& nufquàm omnino eo ordine, quo mare $x$ ftuat, refidetque.Sed temere ubique fpi rare apparent uenti: tum modus, quo corporeum nullum demitten $\mathrm{Sol}$, fua hat:ıs circumuertat uertigine, longè eft obfcurifsim: $1 s, \&$ q 1 ( ut exittimare licet ) inueniri Peripateti-: cis nunq uàm queat: nam fi ne is quidem, quò fappofitus cœ lo ignis, uniaerfo circumuoluatur à cœlo, din illis omnibus, fummaq te inquifitus diligentia,confpici non potuit; eò hic min'ss vnquam manifeftus fiat, quo uno à fole, eiufque uertigine adeo ab ipfo remotiflat:ıs, nihil (ut uidetur) intermedijs corporibus circumuolutis circumflecti queant, tum fi id agat folis uertigo,flatufque infuper ( ut Ariftoteli placet) At. lanticum protundant, non tamen mare uniuerfum fimul ab illis attollatur, \& per uices fedetur, \& alibi xquali utrumque tempore, alibi uero inæquali, $\&$ magis alibi, alibi minus, \& te mere id, nulloque ordine, fed fecum flatus perpetuo circumflectat fol, quomodo à cœlo uniuerfo fuppofitus ignis circúuolui Ariftoteli uidetur.Itaq; \& mare uniuerfum, certè Adria tici finus minus m:ltò quàm Tyrrhenum, cęteraque, qux illius, Atlanticique intermedia funt maria, qua nihil xfluare, nihilque 
bus impulfum, motum ut fiftat,propriumq́; defluat in locum dicto temporis foatio opus habet.fin verò vbi refluit, non recipit modo fefe, quòd eò effluxerat mare, fed q'od ibi pofitum eft, contrariam fluit in partem. Itaque duplici onnino mouetur motu; \& alteri contrario altero. Propterea æquali tempore flait, fefluitq́ue, quod vbi ita fluit æquali temporis fpatio, ubique æqualis fit uaporum copia, non fimul porrò uniuerfum, fed ueluti per vices altera modo eius pars ętuat, ef funditurq́ ie, modo uerò altera, quòd non uniuerfo in mari perpetuo eadem vaporum copia fit, fed alibi interdum maior, minor alibi : vbi itaque maior interdum facta eft, quauis facta occafione, ubi omnino prius intumuerit, fefeque in alte ram partem effuderit oportet:his uerò dum uiget motus, uel fi iam multi parte in altera ingeniti fint uapores . nihil ex ea erumpunt, non à fipperpofita modo, fed ab afsidue fuperacce dente maris mole opprasfi, reiectique. at verò, ut primum is ceffat, feù languet motus, erumpunt $\&$ ipfi, dictoquè modo mare attollunt, \& in contratiam agunt partem, at non perpetuo xquali v trumque tempore, nec fex omnino horarum fpa tio, fed diutius interdum alterum, \& maiore utrumque minoreuè temporis fpatio, quod,vt dictum eft, non perpetuo eo dem in tempore xqualis fit vaporum copia. Mira autem infretis anguftijsqúue celeritate, qua prefertim, benè quidem in longum, at non in directum, fed velut in obliquum, 8 qua fi in girum extenfas interiacet terras, vtramq; in partem fluit mare, quòd non ei tantum ipfius portioni per tranfeundx anguftix funt, qua in ijs continetur, fed mari uniuerfo, quo ad terras impellitur. ijsq́ue angufijs utrumque contineat adne xas; nihilq́que elonginquo adueniente maris motu (cui fcili cet obfitti non poteft) retardato. quoniam enim quod dictas ad terras delatum eft mare, motum fiftere retrouè, aut alterum in latus ferri $a b$ afsiduè fubfequente mari, $\& a b$ ambien tibus terris prohibetur,vbique ad anguftias uniuerfum confluat, \& quod dictum eft, vniuerfim eas transfluat neceffe eft, at uerò ne uniuerfum fimul tranfire, nec quod remaneat fubfequentium aquarum mole, impulfumque nec reijcere, nec fubftinere cùm pofsit, quod anguftias fubijt, \& quod pracedit omne, quod fubfequentis maris moli, cui vniuerfę anguftix tranfeund $x$ funt, \& cuius motus retardari non potef, locum prabeat mita, ut dictum eft, velocitate fluat oportet, un 


\section{Bernardini Telefij}

de poftremo fluminúritu perpetuo fluere videtur mare, $\mathrm{ma}$ iorem ibi vaporum copiam fieri exiftimandum omnino eft: nam fi ab elabentibus uaporibus quaq́ue verfus mare impelli oportet, at ubi longè plurimi , \& à quibus in fubfequentibus fiunt, fummopere copia exuperantur, eoq́; etiam amplius fi copia infint in terra omnino proxima mari uapores afsiduè educuntur, quòd eam in partem mare effundi nõ poteft , \& ab elato omnino mari , \& ipfa etiam à terra reiectum in alteram perpetıò partem feratur neceffe eft; $\&$ ab elabenti bus omnino uaporibas impelli, \& côtrariam omnino promptius in parté oculis ipfis intueare, fi paleam aqua fupponas, in eamóg, at ueluti palea à tergo folis lucem reflectet, quax fcilicet uapores fuppofita in aqua ingeneret; in cótrariam en im partẽ paleã ferri', $\&$ in eã elatam in alterä retroferri intuebere, fi modo qui dictus eft, ex illa itidem lucem in aquam reflectas, quod dictım porrò eft æftuum, dictorumó'; maris motuum diuerfitatem iuxta elabentium vaporum diuerfitatem fieri, illoram omnium diuerfitas, qua in diuerfo fit ma re,fatis, ut videtur,manifeitat. Propterea enim maximi Galliço in Oceano, \& veneto infinu maris æeftus, fluxusq́; \& reflu xus, quod breui utriusq́; fundo robuita refilit folis, lunæắ; hux, \& magis omnino in illo, q multò cùn amplior fit, in amplius fefe effundat oportet:minimi uero, \& qui æagerrimè cōprehendi queant in Siculo, Sardoq́ue, \& Tyrrheno uniuerfo, quod vel Ariftotelis teltimonio, maria hæc profundifsima fint omnia, \& inqux delata lux vix tandé ad dêfum deferatur, à quo ulterius ferri prohibita vniuerfa, beneq́; in fe ipsã collecta refiliat ; maximè ibidë in plenilunio, quod plurima à lina relucet lux, magni itidê in nouilunijs, quòd aere refrigerato colligit fefe, atque vnit proprius maris calor, itaq; robuftior factus plures facit, emittitá ue vapores, veluti, \& putealis aq 1a, borea fpirante, frigore omnino feuiente, minimi in lunx quadratis, quod nec mult à luna relucet lux, nec fefe colligit maris calor; quod fi ( quod inquiritur) luna exo riente attollitur, ad medium verò cœelum delata refidet, \& oc cidente ea rurfis, \& minus attollitur mare, propterea ea eue-nire exiftimare licet, quod exoriens luna, qnod mare paulò tenuius fact um elt in uapores id agit omne, $8 \mathrm{r}$ uniuerfum pállò lenius facic quoniam uerò non tot afsiduè fiant, quot: maris mole afsiduè attollant, præinexiftentibus uaporibus, 
nihilque vllam in partem fluere appareat, eqfuet, agitcturc; Qui porrò expofitos maris motus in diurnum lunx fer cardines motum referunt, $\&$ influxum omnino à luna in mare Cófutatio fententize emitti decernunt, à quo mare attollatur, vel ad quem ipfum fere mare efferat, uel fi huic illi refponderent:itaque tuna exo riente, \& ad diei culmê afcendente perpetuò marc attolli, effluereque videtur;ad occafum declinante fedari,refluereque; tum rurfus ab occafu ad culmen noct is afcendente, rurfus attolli,effluereque, $\&$ inde ad ortum declināte fedari, refluereque appareat; \& fi motuú omnium diuerfitatis car:fam reÉ è redderent,admittendi tamé non effent, qui fcilicet quod $h$ :mana ratione intelligere non liceat, incorpoream facultatem à luna emitti uolunt, qux nec aquas reliquas, nec ens alivd ul lum commoueat, immifceatue quid mare vniuerfum, vel cuius, lunæq́ue in medio terra ipfa fit, attollat \& tot tantifque exagitet motibus;nihil caufam explicantes, cur luna exoriēte, occidenteque maximè fcilicet obliqua mari facta, mare attollatur, effundaturq́ $x e$, medium vero cœlum tenente, itaque mari directa facta,fedet:ır, deprimaturq́ue. Quoniam ve ro maris motus, ut qui illum obferuarunt referunt, lunæ per cardines motui minimè refpondent, nec refpondere omnino poffunt.Et q oram motuum difcriminum rationem reddunt, nõ rectè, ut uidetur, \& multorum nihil prorfus reddút, \& quàm longifsimè abfunt, reddere ut queant, reijciendi om nino. Non fcilicet perpetuo luna exoriente, mare intumefcere,fefeq; effundere, $\&$ ad diei culmé elata,fedari,refluereque, \& occidente rurfus attolli, fluereque, $\&$ ad not is culmen eve Ea rurfus occidere, refluereque;fed temere, nulloq; certò ma ris têpore \& omnia fieri uidentur. \& dicto ordine fi fiant, nequaquam, quod vt plurimum euenit, fex horarum fpatio mare attollatur effluatque, \& totidem fedetur, refluatque, fed ibi modo, ubi xquinoctialibus fignis fubeft luna, aliàs longè breuiore, diuturnioreue. Tumperperam omnino propterea maiores, minorefuè æfus fieri poffunt, quòd luna magis, minufue à fole illuftretur: iuxta id enim fi illi differant, vtique luna nihil à fole illutrata, quo tempore magni, omnino fiunt æltus, nulli prorfus, aut minimi certè fiant:\& peius etiam propterea occidcnteluna, minus mare attolli, quàm orience, quod oriês rc ctà mare fiectct: nihil enim minus occidens id facit, \& fi cuò luna magis refia mam

D 3 re 


\section{Bernardini Telefij}

re afpiciat,eò id magis attollatur; vtique coli medium ea te nente,magis quàm exoriente mare attollatur, \& fummopere homines mirari licet, qui mare attollendi, agitandique uires à fole lunx aduenire, cum intueantur,ponantque, maris tumefactionis, motuumqúue omnium caufam uni lunx, foli nullam prorfis attribuant : praterea cur in æquinoctijs magis et iă quam hyeme mare attollatur, effundaturque, nec cur maria quxdam perpetuò fluminum ritu unam fluant in partem,ca!'fam reddunt ufquam, \& q quam longifsimè abfunt, red dere ut queant.

Cur maris afus, fluxusǵ, \& refuxus alibi magnus mini-

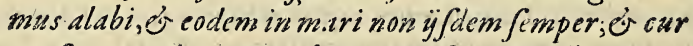
fex, vt plurimum, horarum Spatium illorum uterque, at alibı maior alter; $s$ cur unam alibi perpetuo in partem fuit mare. Cap. $X I I I$.

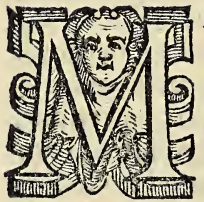

A GNVS porrò, manifeftusq́ue alibi maris xftus, fluxıısq́; , \& refluxus, minimus alibi, at qui rgerrimè depræhendi queat, quod alibi breuius mare eft, profundius alibi, nec eadë vniuerfo fubeft terra,fed dura alij, denfaqúc; alij uerò mollis, laxaq́ue: itaq; ut in ijfdé expolitum eftcomentarijs, non eadem è quouis maris fundo re filit lax, fed benè aliò collecta, beneq́; robufta, exilior ab alio Janguidiorq́ue, qux omnino pauciores ingeneret uapores: \& motus, qui di cti funt, non ijdem perpetuo codē in mari fiút, fed alias maiores, alias verò minores, quod mare quoduis non ab eadem perpetuò, fed afsiduè propemodum à diuerfa Solis, lanxq́; illuftratur luce, \& fex ut plurimum, borarum fpa tio mare intumefcit, ễunditurq́ re ; quod huiufmodi eft ma ris difpofitio, naturaq́; \& cęleftium corporú in ipfum actio,vt dicto temporis fpatio tot in eo generêtur vapores, quot eius. molem amoliri queat, \& quot ne elabantur,diutius ibi retineri nó pofsint.\& fiquidem, quod dictum eft,inde, \& propterea refluit omnino mare, quod ex fefe effunderat, fexitidem horarum fpatio refidet, ex fex fefe recipit mare, quod agitaxum,effufumg̨ue, \& afsid:cè forte ab elabētibus dum vapori- 
è mari elapfis omnibus refidet, fefeq́:ıe colligit mare, \& pluribus itidem factis iterum intumefcit, at $v t$ minus tamen nihil abdita luna,vaporibus auctis, \& gratiore iam facto mare, propterea itidem minimi xftus, fluxusque, \& refluxus in folftitijs, quòd in hyberno quidem maximè obliqua maximèque languens, folis lax perpaucos ingenerat vapores, \& $q u i_{\text {, }}$ quòd neque bene, conftricto iam mari elabi, nec benè tam graue factum, amoliri queat, tamdiu ibi retineat oportet, quoad fummam nacti tenuitatem, vel nihil, vel modicum, quid mare attollentes elabi queant ; in æeltiuo verò, quod plu rimos quidem, at longè tenui ssimos vapores directus educit fol, \& qui nihil propèmodum mare attollentes ex co elabantur à robufto prefertim calore laxiore facto: verè, atque $\mathrm{Au-}$ tumno maximi, quod ( $v t$ in comentario de pluuijs expofitum êt ) medius Sol multos crafsioresq́; ; educit vapores, non xquali porrò tempore mare vniuerfum fluit, refluitq́ue, fed alibi fluit, alibi refluit magis, \& alibi nequaquam per uices fluit, refuit qú fed perpetuò, \& quod dictum eft, fluminis ritu, eamdem perpetuò fertur in partem, quod in non æquè profundo mari non $x$ qualis generatur vaporum copia, fed maior ( $v t$ dictum eft) in magis humili.Itaque qui perpetuò in eo funt fluxus, breuiore omnino in profundiora maria fie ri exiftimare licet. Męothis certè pontusqúue, ̀̀ quibus ad $\mathrm{Ga}$ ditanum vfque fretum fluxus fieri videtur, breuifsimus eft, qux verò confequuntur maria multò funt profundiora, fortè \&x quo pacto Męothis, ponfusque ab influentibus fluminibus in fubfequentia maria expelli A riftoteli videntur, codem ar à fuppofitis aquarum fluxibus à quibus mare conftitui vifum eit. Superior etiam maris, in quod influit impellitur pars, ij certè quia dulcibus nihilo, nihiloq́ue fint pauciores, minores ctiam qui aliundè fit fluxus, quacunque is fiat occafione, d im contrario, \& xquè vehementi obuius fiat, nunquam ceflet,ambigi non poteft.

\section{F I N I S.}




\section{N D E X \\ A \\ $P$ I $T$ \\ $\mathrm{V}$ \\ M \\ $\begin{array}{ll}\text { L I } & \text { B R } \\ \text { De Mari. }\end{array}$}

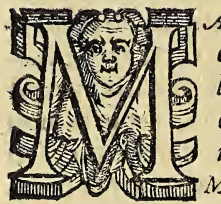

$\mathcal{L} E$ non propria natura falfum $e ß e$, fed dulcibus eius partibus à sole in uapores actis, \&r ca lids, ficca'que exbalationis commistione falfume eße factum, os perpetuò tale fuiffe Aristoteli uifum.

Cap. I.

pag. $3 . a$

cap. 11 .

eße.

Mare nec tenuium, dulciumq́que partium abfceffu,nec calidie ficcaque exbalationis commistione craffum factume efe falfumque .

Cap. I I I.

pag.6.6

Mare fuinatura falfum eße, é è terra dulcium aquarum ritu, $\sigma$ è propirysorivifontibus. cap. IIII. pag.7.b Mare aque elementum wideri non pofe, nec Arifloteli wideri debuiße, nec rectè caufam eius explicatam effe, cur tot illabentibus infpiritum aquis, minimè excrefcat mare. Cap. V. pag.8.a Quibus motibus, \& quam ob caufam mousi mare Ariftoteli uidetur. Cap. $I$. pag. 8.6

Non redtè Maris motuum caufas ab Ariflotele redditas effe: Cap. VI 1 .

pag.9.a

Mare è terra affiduè à Sole, at non ex cmnitamen, fed è profurda illa educi,or cur craßum, calidumq́ue factimeft. cap. VIII. pag. $10 . b$

Cur aque marince dulcibus copiofiores, of cur tot illabentibus inipfum flunysmaiusnon fiat Mare. Cap. IX. pag. I I.b Motum Marineceffarium fuiffe, os à quibus intume fcit, moueturque. Cap. $X$.

Arifloteles folis uertigini, Alü uerò diurno luna motui Maris $v f u \tilde{u}$, fiuxumque, of refluximattribuknt. cap. XI. pag.14.a serperam aftus, fuxusqui, ér refuxus, reliquortm veròmotuum null am 


\section{$\begin{array}{lllll}I & N & D & E & X\end{array}$}

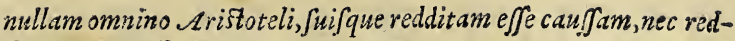
di omnino pofje.

cap. $X I I$. pag. 14.6 cur Maris eftus, fluxusq́ue, of refluxus alibi magnus, minimus alibi, oj codem in mari non ÿdem femper, or cur fex (ut plurimum) borarum spatio illorum uterque, at alibi maior alter, of cur unam alibi perpetuò in partem fuit mare. Cap. $X I I I$. pag. 15.6

\section{F I N I S.}





\section{BERNARDINI $T$ E. L E $S$ S I I C O N S E N T I N I,}

QUOD ANIMCAL VNIVERSVM ab unica Anima Jubfantia gubirnatur,

A DVERSVS GALENVM Liber Vnicus. CVMPRIVILEGIO.

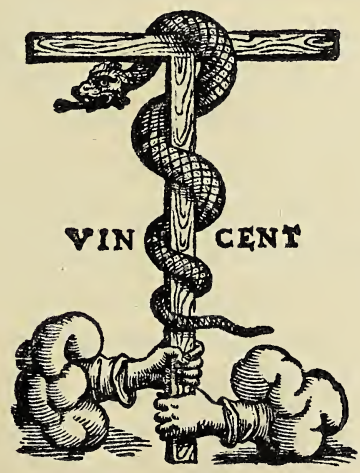

VENETIIS, M. D. XC.

A pud Felicem Valgrifium. 


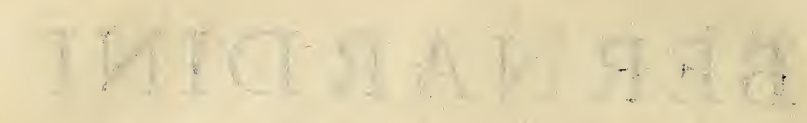

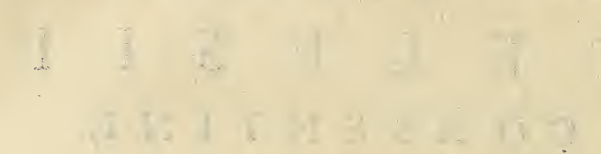

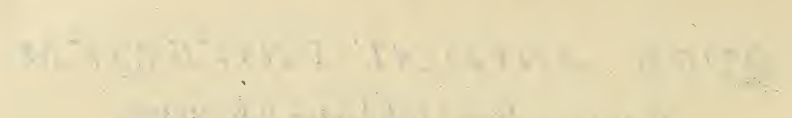

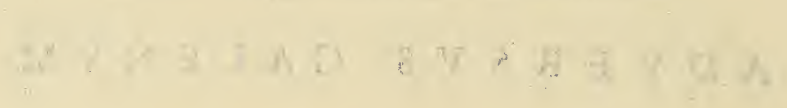
awing and 3

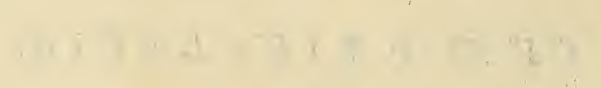
Warition 


\section{P ER I L L V S T R I. A T Q VE OMNI}

DOCTRINAE GENERE Excultifsimo viro,

10. VINCENT1O PINELLO,

Antonius Perfius. S. P. D.

2 V I TLLVS ef non in hac urbefo(1) lum, Sedne in tota quidem Euro-

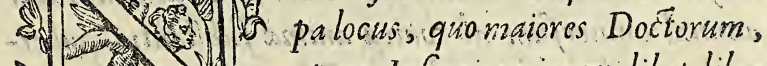
N 1 atgue. Infignium in qualibet libe25 (2) Cusus) frequentiores fint, quàm ad ades tuas, loannes Vincenti Pinelle noftra Decus atatis, atque ornamentum. Confl uunt enim ad te quotidie ex diuer fis orbis regionibus, qui te aut offcï cauffa inuifont, aut de graui aliqua dip putatione con Julant, aut ignotam fibi antea faciem tuam contemplentur. Ita fit, vt cim iffic plures codem tempore conuenerint, nullus fit dies, quo non de quàm digniffimis fcitu rebus Jermones babeantur. Multiq́; , quorum bic fedes eft, ac domicilium, limina ifac tua inprimis terunt. Sic enim alli, ac rectè

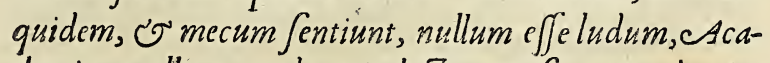
demiam nullam, vnde quis doctiorcm $\int e$, ac prudentiorem abïffe gloriari pofjit. Experior id ego in me ip $\int e$ $\mathcal{A}_{2}$ quctidie, 
quotidie, qui tamdiu frequento ades tuas, neque aliud eft, quo malim bic effe quàm diutiffimè. Quicum enim honeftius, atgue cruditioribus colloguijs diem traducam, ne fingi quidem poteft. Collocuti autem prater ce-

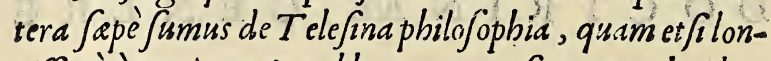
giffimè à peripatetica abborrentem, fic tamen laudas, vt admirandum efe c Auctorem eius ingenuè fatearis. Quapropter amo liberale ingenium tuum, ac te virum omni doctrina politiffimum quamplurimis Doctiffimis vi ris antepono, qui non folum fingulari Sapientia, verùm etiam animi candore, ac probitate incomparabili familiam tuam clariffimam maximis angeas ornamentis. Non oblitus putoes, te difputationes illas à T elefro aduerfus Galenum habitas in eo libro, quo demonftratur animal vniuerfum ab vnica anima fubftantia gubernari, mirificè commendare. Eame igitur pulcherrimi operis à viro laudatiffimo profecta laus de eius libri editione cogitantem admonuit, vt eum fub fulgore tui nominis in bominum aspectum, ac lucem proferrem, vt quem prius habuit laudatorem, eum deinceps patronum fortiretur. Tuum erit nof trum in tui optione iudicium comprobare, ftudiumq́; agnofcere, ac voluntatem in Te fingularem. Vale. Pataü. 


\section{BER N A R I N I \\ $T$ E L E S I I CONSENTINI,}

QVOD ANIMAL VNIVERSVM ab vnica Animæ fubftantia gubernatur,

$$
\text { LIBERVNICVS. }
$$

A quot, qualibufque principÿs, of quibus inuifceribus collocatis, $\mathcal{\sigma}$ quomodo, U que fingulis operantibus homo gubernari, $\mathcal{*}$ cor arteriarum, iecur verò venarum principium effe videtur Galeno. Cap. Primum.

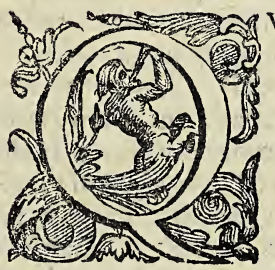

VONIA M non, ve nobis ab vinica ani mæ fubitantia, ¿̀ à fpiritu omnino, qui (vt in commentarijs de rerum natura expofitum eft ) in cerebri ventriculis, $v t$ in principe fede, $\& x$ reliquis in rebus, qux à femine conftitut $x, \&$ cerebro cötinue, fimilisq́ue, albx nimirum, exanguesque funt, inhabitat omnibus, animal quoduis, \& homo etiam ipfe gubernari, eiusq́ue operationes, quafcumque operatur animal, effe omnes corporis, partibus,vt proprijs $v f \mathfrak{x}$ organis, nec arterię, uenæq́ue à cerebro produci; fed homo quidem à tribus diuerfis narura principijs, \& fingulis proprijs inuifceribus, vt in proprijs materijs collocatis, propriasq́ue fingulis operationes, \& propria ædentibus opera, gubernari, \& non propriz fubftantiz porsione, fed facultate tantum à principio miffa. Et cor arteriarum, iecur verò venarum principium effe uidetur Galeno; vel 


\section{Bernardini Telefij}

omnia ita in ijfdem explicata, reiectaque exiftimem commentarijs, vt nihil amplius explicanda reijciendaǵúc videri pofsint:Galeni enim fententiam rationesq́ue exponendas, foluendasque amplius, \& amplius omnino rem vniuerfam aperiendam effe vifum eft . qux fcilicet diligentius infpecta, non animx modò fubftantiam aperiat, ingeniumq́ue (de ea uerò eft fermo, quę è femine educta eft, cuius, corporisq́ue uniuerf, ut in ijfdem amplius expofitum eft commentarijs, que à Deo in homines immittitur fubftantia, forma fit ) fed

7.de placit. magnum quoque, ni fallor, medêdi facultati adiumentum af Hippo. \& ferat.Placet Galeno, Hipocratem (ut uidetur) Platonomq́ue Flato. fequuto, àtribus principijs vitam noftram gubernari,ab vno quidem in cerebro inhabitante, cuius opera for fe quidem imaginatio fit , \& memoria, \& intellectio, cogitatioǵue; in relatione autem ad aliud fenfum partibus, que co pradita funt, impartiri,\& motum infaper uoluntarium ijs, quę eo mo uentur, \& v trumćue neruortm minifterio;itaque à cerebro, ut à proprio principio nernos produci, ut uel ipforum manifeftat fubltantia, neqúc enim alia re ulla à cerebro differunt, nifi, quòd in longiore à cerebro progrefiu, tenuioribus fui partibus elapfis, paulò ficciores, durioresq́ue facti funt . neq́; igitur partes, qux neruis carent, uel fentire, uel moueri ullas, Nec tamen proprix fubftantię portionem, qua fentiant ipfi, \& fefe moueant,partibusq́ue in quas inferuntur, fentiendi, \& fefe mouendi uim apportent, à principio neruis indi vl" lam, fed facultatcm modo, veluti (inquit) illuminatur aer, "non ipfa folis fubitantia per cum delata, at luce tantum ab ipfo emanante : neq́ue igitur neruis omnibus meatus ineffe uidetur Galeno, fed corpulentioribus tantum, fpinali nimirum medullx, ob vehementem uirtutis diftributionem, \& uiforijs dictis. Ab uno porrò principio, \& in cerebro inhabitan te, ut ratiocinemur, fentiamusq́; , \& moueamur, nos habere: " inde (inquit) patet, quod cerebro quouis pacto oblafo de"fipere praueq́ue imaginari, ratiocinariq́ue, \& fenfu, motuq́ue " defticui uidemur.Et ab alio itidem principio, in corde con3. de Hipp. fiftente gubernari nos, proptereaque id itidem nobis indi\& Plato de tum, firmumque factum efle uidetur Galeno; ut quacumóque
cret. ratio iuferit, exequarur, \& libertatis, uictorix, potentie, lmperij,gloriæ, honorisq́ue libidine flagret, \& contemptui haberi, iniuriaćue affici impatiens, pra defiderio illam ulcifcẻ- 


\section{Quod Ani.vniu. ab vnic.Ani.fubft.guber. 4}

di ardeat,ferueatq́g.itaq; irafcibile nuncupetur.Et non jpfum modo cor propriam eius nateriam, propriumq́; fubiectum conitringat, dilatetó'; , fed arterijs idem faciendi facultatem prabeat : eft itaq́ue vbi pulfatoriam appellar Galenus, \& fanguinem infuper in iecinore confectum amplius concoquens, longeq́; robuftiore donans calore, \& per arterias fingulis illum corporis partibus diftribuens, fingularum calorem foueat, itaớ; $\&$ arterias, quarum minifterio id agat à corde pro- " duci.Nam arteriarum cor effe principium, earum (inquit) in corde amplitudo declaret, logè nimirum in eo, quàm in alia qua tis corporis parte ampliores ex eo oriri uideri debent: neq́; enim à minoribus maiora, fed à maioribus minora deriuare exiftimandum eft; \& ab alio omnino principio non in ", cerebro, fed in corde confiftente iniurias, malaq́; omnia reij- " ciëdi,\& fuper excellēdi appetitum, pulfationemọ́; \& proprij caloris conferuationem nos habere : inde (inquit) manifeftum eft, quòd in dictis affectionibus, perturbationibusqúue omnibus cor ualde immutari, eoque oblæfo non eitufmodò, fed arteriarum itidem motns perire, aut. longè diuerfifsimus fieri videtur.

Tertium poifremò in iecinore delitefcens, qux ad nutritionem, generationemq́ue fpectant,præftare omnia, fanguinis fcilicet confectionem, quo fingulx corporis partes nutriuntur, \& è quo amplius concocto, in fememq́ue acto genic ratio fieri appatet; venas itaq́;, quibus utrüque fiat è iecinore produci;nam inde eas enafci, earum itidem, quæ ibi confpicitur,amplitudo declarat. At qui fummus ciborum, potionumq́ue, \& uenereorum appetitus animali ineft principij iecinori inexiftentis effe uidetur Galeno. Neque cnim aliud id appetat,nifi quod ijs, ut propria materia, \& ueluti organis utitur; itaque ipfum precipuè appetitorium appellat Galenus. Et à tertio igitur princrpio in iecinore delitefcente gubernari , ab coq̣ue nutriri, \& generandi facultatem nos habere, inde declarat Galenus; quòd iecinore oblxfo, fi non fu bito, uelati per aliorum lefiones reliqux partes afficiuntur; Temporis tamen proceffu animal nutrimenti inopia langus fcit, \& impallidum mutatur colorem. 


\section{BernardiniTelefij}

Principium, quod Cordi, \& quodiecinori, ineft, ab eo, gused cerebro inexiffit, dinerfum effe; o illorwm wtrumǵs Naturale, hoc uero animale wideturGaleno. Cap. II.

Primo de natur. facult.c.s.

AR RINCIPIVM porrò,quod cordi, \& quod ie(1) cinori, ineft, ab eo, quod cerebro inexitit 1) dinerfum effe, inde declatat Galenus, quòd - 1 hoc qux operatur non femper, fed ubi colli- 1 (1) bitum elt operatur, ut uolintate \& electione operari, \& animale omninò principium effe uideri poisit : illorum uerò utrumq́ue perpetuò,\& quin operetur uel maxime nobis contendentibus continere fefe nequit, ueluti natura non cognofcente numerum, neq́; eligenti operans facultate, quando quidem (inquit) fentire \& mo ueri fecúdum elctionem propria animalium funt, augeri uerò, \& nutriri, plätis etiam communia funt.erunt utiç; priora quidem, anim $x$, polteriora uerò naturx opera; quare animalia iffa, \& ab anima, 3 à natura fimul gubernari dicimus,ftir pes uerò à fola natura;quàmquam ijs etiam animam, llegeta. tricem aliquis attribuete haud in merito porerit, diftingués eam a fenfitrice.Vifcera igitur omnia, quorum actio, operatioq́ue retardari non poteit, nequaquam ab anima, fed à natara gubernari, qux nulla electione, nullaq́ue agens cognitio ne nunquam à propria cefiet operatione; huiufmodi autem nó iecur modo effé, fed cor itidem, cuius nimirú pulfatio nul lo uoluntatis imperio ceffare, uel quicquam immutari queat.

Principiwn cerebroinexiftens ab eo, quod cordi ineft, dixerfum omnino diftinctumque effe, of nulla alterum alterius opera adproprias adendas operationes opus habere videtur
Galeno.
Cap. 111 .

T. of exiftēe, quod cordi ineft, uidetur Galeno,fed pe nitus ab co diftinc:um, feparatumq́; ; \& nihil omrusn $x$ dédas operationes, nulla alteram alterius opera opus habere, 


\section{Quod Ani.vniu, ab vnic. Ani.fubft.guber. 5}

habere, ac ne alterins pafsiones fentire alterum. Dum Ccre-so bro (inquit) oblx fo defipere,praueq́; ratiocinari, \& fenfurom nino motuć; deititui videtur homo;nih il interim vel cordis ", ipfius, vel arteriaram motus pulfatioq́; diminuritur, nec no-", uus omnino in corde fit motus.corde.contra oblafo ipfius, \& , arteriarum motus perit, aut infigniter immutatur, nullo volti-" tario motu:actioneue oblafa quicquam, \& cerebri (inquit) t.de decret. ventriculo non modo vulnerato, uerum etiam compreflo, vt $\mathrm{Hippoc}$. in viuorum animalium anatome fxpe oftendimus, grauifsima fequuntur incömoda, corpuifq; uniuerfurm fenfu, motuq́, ", ac uoce penitus fpoliatur:quò fit, ut fracta capitis offa excifi-" " ri, Iaminam, quam membranx cuftodem appellant, fubijcere " cogamur, ac fi paulò violentius con primamus, hominem fen " fu, fimul ac motu fpoliemus; id uero corde compreffo, accide " re non confueuit; memini enim cum cor veheméter palpitãs ex digitis exiliret, cuidam me permifsiffe, ut fabri forcipe" illad arriperet, neq; tamê fenfum, aut motum, neq́; refpiratio " nis vfum inde deperiffe, folǔqú; arteriarŭ motum, corde ita cô ", preffo, offenfum fuiffe:contra fi cerebro id accidit, arterię quii ", dem confuetum pulfandi tenorem feruant, fenfus uerò, ac mo " tus cum refpirationis uocisq́; ufu fubito intercidunt: ex quo " illud quoq; manifertum euadit , neq́; cerebrum Cordi, neque "' cor cerebro ad propriam actionem indigere. Et alibi ficor (in ${ }_{2}^{3}$.de Hipp. quit ) nudaueris atq; deprefferis, nec uoce, nec refpiratione, \& Plat. denec ulla prorfus voluntaria actione impediri animal cernes: cret.c.

Qıod fi concauitatê thoracis minimè perforaueris, licebit ti " bi uninerfum, ac fimul cor ipfum eximere illæfis voluntarijs" actionibus, id quod in nonnullis facrificijs contingit, in qui- ," bus animalia confpecta funt, corde iam aris impofito, non re " fpirare tantùm, fortiteró;, clamare, fed etiam aufugere, quo- ", usq́; profufione fanguinis commoriätur.cerebrum autem of- ", fibus fi detexeris, aut quemcunq́; ipfius finum comprefferis, ", non cùm duntaxat, ac protinus fpirationis expers e fficies, " fed fenfu etiam omnibusq́; ; arbitrarijs actionibus animal ip- "” fum priuabis.

Porrò tauris, quibus fpinalis medullæ origo iuxta primam "” uertebram diffecatur, refpiratio, \& uox exoluitur, illafo mo : tu cord is \& arteriaram, quòd ipfa pulfandi uis à cercbro non "” defcédat:ut enim pulfatio ipfa motus alterius generis en, fic : etiam principiumalterum non indiget altero. Et alibi cum $"$ 


\section{Bernardini Telefij}

De Hippo. tria uaforü genera Ven $x$ fcilicet, arteriæ, ac nerui cerebro cor cre. 1.2.c.6. cónecităt; fi primú quidē ea in fuperiori ac inferioris ceruicis regione ualidis finiculis exceperis, ne fanguinis profufio ma " gna fequatur, dein autem uinculum medium fecueris, uidebis planè ipfis quidem neruis, qui iuxta arteriam confiftunt, 'incifis, aut intercxptis, minimè mutum reddi animal.pulfu ta "' men arterix particulas, qux fupra uuln :ss, aut uincula funt, "priuari omnes, ijs quæ infra confiftunt, femper eodem modo ") pulfantibus : uenis denió; a at incifis, aut intercxptis, nullam " manifeltè aboleri functionem.unde liquidò conftat neq́; cor " ad pulfatum motum cerebro egere, neq́; cerebrum corde, ut " fentiat animal,\& uoluntarios ædat motus.

\section{Nec neruis,nec arter ̈̈ à proprïs princip ÿs fubftantice} portionem immitti, fed facultatem tantum

$$
\text { preberi. Cap. IIII. }
$$

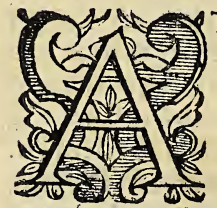

T licet nerui à cerebro producátur, fenfumớ partibus afferendi vim ab illo habeant, $\&$ ar teria itidem à corde deriuent, pulfandique facultate ab eo donentur; nulla tamen proprix fubftantix portio vel ijs, vel illis, à prin-cipijs Galeno inditur, qua fenfum illi, motumq ue partibus apportent, vel hẹ pulfent, fed facultas tantị̆. Veluti (inquit) illuminatur aer non folis fubftantia ad illum delata,fed luce tătùm miffa:quòd inde intelligere licet, quia arterijs, \& neruis incifis, uel etiam valde ligatis, qux ipforum pars à cordis,cerebriq́; continuitate diuifa eft, difiunctaqúue, ftatim motu priwatur.qui fi ab immiffa fubftantia moueren7. de Hipr. tur, à principijs difciancti,\& nulla noua infuente re, à præexi \&. Plar. de- Rente aliquantis permoneri tamen deberent, veluti (inquit) cret.,c.3." fi folidum aliquod corpus in medio illuftrati aeris interpona " $t a r$, ftatim videmus eius fplendorem perire,ceu qui dum im" mutatur euadit lucidus, non autem cum permutatus fuerit: " " fic enim lumen petpetuò feruaret; vel fi ablatum id, quod illu(") minat, effet ; ita \& neruo fecto, quantum fectio à cerebri con "2o tinuitate feparauerit, tantum in infenfibilis ftatim redditur. ", Sed in arterijs etiam eadem natura, qux in neruis cernitur; ' $\leadsto$ diffea $x$ fi quidem, interceptxq́ue funiculo non pulfant, defti 


\section{Quod Ani.vniu.ab vnic.Ani.fubft.guber. $\sigma$}

tut $x$, non eo quòd à corde mittitur, ut eafiftratus putat, fed ", facultate illa, quam ipfarum tunicæ, cordis corpori continux.," inf tentem ab eo femper obtinent.

Aationalis, Irrafcibilisǵg appetitorie fubfantiam, now Spiritum in ventriculis contentum, fed uifceris. cui inheret, temperiem $e$ se, unde colligit Galeno. Cap. V.

a d IOCINALIS porrò, irrafc bilisque, \&

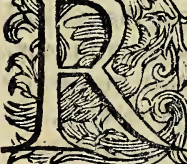
appetitorix fubltantiam vifceris, cui qualibet inheret, temperiem efle inde colligere videtur $\mathrm{Galenus}$ quòd corpore, \& ipfis prafertim uifceribus imm tatis, animæ itidem fubftantia immutari videtur.Cerebro nimirum calidiore, frigidioreue, \& ficciore, humidioreue tacio, anima ipfa perfpicacior, fagaciorq́ ?e, \& magis memor, vel obtufior, hebetiorq́ue, \& ftupidior, minusq́te memor, \& à fri gore hxc, atóue humiditate, à calore illa, atque ficcitate com moderata profertim. Qioniam (inquit) pars anim $x$ carax rationis unà cum corporis temperamento mutatur, corporis illam temperiem effe cenfendum eft, cerebri,nimirum, in quo, collocatur, quod ipfemet paulò ante enuntiarat. Ratiocinan-", di ( inquit) facultas cerebri temperiẹs qurdam eit, \& propte-" rea in diuerfis hominibus, diuerfam effe illam, quod diuerf $x$, funt hominú téperaturæ ; fpiritú verò in cerebri ventriculis, contentü(quod interdum fentire videtur)animam non efle, , inde tandem ratiocinari uidetur. Quoniam (inquit) diuifis, cerebri uentriculis, fenfu, motuque animal deftituitur;at con, iunctis illis paulò poft rurfus fentit, moueturque, dicendum ", eft, in ipfius quidem cerebri corpori animam habitare; pri- , mùm autem eius organum, tum ad uniuerfos animalis fenfis, tum ad motus uoluntarios animalem fpiritum efle; qui ", quidem fi ( quod aliquis exiftimare poffet) animę fabnan-, tia effet, fimul cum eo, dum euacuatur,periret animal, cuius contrarium contingit : nam euacuatus, donec recolligatur, fenfu motuqúu, non vita deftituitur animal. Eadem ratione \& irafcibilem cordis, \& appetitoriam iecinoris temperiem efle declarare videtur Galenus quòd nimirum calidiore, fri-

$$
\text { B.2 gidioreue }
$$




\section{Bernardini Telefij}

gidioreue facto corde, magis, minufue iraficitur, afficiturque animal.

Et calidius, frigidiufue factum iecur longè preftantius, deteriufue concoquit.Cordis (Inquit) temperies irafcibilis anima exitit;iecinoris autem appetitoria :itaque HippocraQund anitem admittens probansq́ue, qui, quibus cubiti vena vehemé $\mathrm{ml}$ mores. tem àdit pulfationem furêtes pronuntiarat, meritò (inquit) c.8. nampranimia in corde caloris abundantia: ftupidos verò " grauesq́ue temperature frigiditas.Hippocrates itaque ( fub", iungit) non irafcibilis modò,appetitoriæq́ue animæ partes, " fed \& cogitatrices uires facultatesq́ue corporis temparatur " adhærere uoluit, eamq́ue omnino fequi.nec fecus Plato ex di ") uerfis Terre habitationibus, ex uario fpú, ex infolationibus, " ac deniq́; ex uarietate nutrimentorum, nô ipforum modò cor " porum, fed animorum etiam diuerfitatê nafci, profitetur, tê" peraméto fcilicet ipfo, quod fubintelligere oportet, interueэ niête. Age porrò examinentur fingula, \& ante omnia num ce" rebri těperies, an fpiritus in illius uentriculis contentus animantium animx fubftantia videri debeat, quod nimirum reEtè confpectum, non magnum modo ad reliquorum intel- lectionem adiumétum afferat, fed reliqgua omnia manifeftet.

Nec cerebritemperiem, nec fubftantiam aliam in cerebro inhabitantem, Cuius vel cercbrum, vel fpiritus organum fit, fedfpiritum in corebrizentriculis coutentum animalium animameffe. Cap. VI.

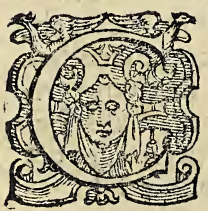

EREB R I temperiem, cerebri nimirum for mam,fubitantianq́'; animæ fubftantiam effe, exiltimare non licet, fiquidem proprix anim $x$ functiones, operationesq́; fenfüs mo tusq́ue videntur, \& uideantur oportet omnibus: \& id itidem, action um fcilicet, opera tionumq́q; \& pafsionum, quas entia ædunt, patiunturá; nullas prorfus, à fola illorum ędifforma formamque pati folam, fed omnes à compofito ædi, \& compofitím pati omnes, communes nimirum, formæ effe, materix q; qux fcilicet fibi ipfis coeunt, ita ynum fiunt, ut quod magis unum 


\section{Quod Ani.vniu.ab vnic.Ani.fubft guber. 7}

fit, nullım prorfus inuenire liceat;nihîl prorfus ( ut àlibi amplius expofitum eft) in ex ijs côpofito reperiri queat, quod vel fola forma vel materia fit folaj, vel non utrumq́; frmuliatiiman itaq; animalium corporis formam enuntiäs A rintotiles; operationes, quas operatur animal, nullas anima folitis, fed compofiti efie enuntiat omnes, \& ipfum etiam difcere; $\&$ intelligere ipfum; fenfus igitur, qui in animali fieri; motusq́ue, qui ab eo ædi videntur, pacto nullo, cerebri formæ afsignari poflunt: Quonia quam enim functiones, operationesćj; entis formæ naturæq́; attribuantur, quarú penitus expers ipfun eft ens? Nec verò quod cerebri temperiæ immutata an ima itidem immutatur ingenium, proptereà cerebritemperiem, nataram q́; animam effe, exiftimandum Galeno fuit .nam $8 c$ nibil ea immutata; fed paulò crafsiore infpirato aere, $\mathrm{Crafsio}^{-}$ ribusq́; è ventriculo, ventreq́; ad cerebri uentriculos fublatís vaporibus, qui cerebri corpus non fubeunt, $\&$ à quibus nihil prorfus ipfum pati queat cerebrum, non modo fentiendi, intelligédiq́; facultas fummopere immutatur, fed animaluni uerfum,nulloq́; interdum temporis niomento; \& cerebro ni-z hil prorfurs iblixfo, exitio datur, diuenfa porrò intemperie di-? uerfa fit fentiendi intelligendiq́; uis, quòd, ut in ijfdem am $\rightarrow$ plius expofitum eft commētarijs, ex ijfdem, è quibus reliqux corporis partes, \& ipfum conftitutum eft cerebrum, humorin bus edìctus fpiritus ipfi itidé, ueluti \& cerebrü, diuerfus fit, diuerfisqú; fentiendi, intelligendiq́; donatur uiribus ; \& uel non ex ijfdem quibus cerebrum confectus rebus, at in cerebro contentus, ab eius onnino immutetur tiribus. Age verò quoniam fummopere (ut uidetur) de animx fubftantia anceps Galenus non perpetuò animæ temperié illam effe enuntiat, fed eft, vbi cerebro quidem inhabitantem fubftantiam, at à fpiritu aliam, \& cuius fpiritus, vel ipfum etiam cerebrum organú fit, id infuper intueri ne grauemur:fi quid en im aliud, anim $x$ certè fubftantia, quxquàm diligentifsime infpiciatur, digna eft. Q roniam (inquit Galenus) cerebro ad ventricitlos vsq́; diuifo, \& fenfu deftituitur.

At animal \& motu, ventriculis poftea coniunctis, \& fpiritu " recollecto rurfus, \& fentit, \& mouetur, dicendum eft in cere-," bri corpore animam inhabitare, primum autem eius organú,, cùm ad vniuerfos fenfus, tum ad motus voluntarios anima- ", lem fpiritum effe; \& haud ita multò poft, Animalis inquit, ,

fpiritus 


\section{Bernardini Telefij}

is fpiritus in cerebro confiftit, non tanquam anim $x$ fubftantia,

"fed veluti primum organum in cerebro inhabitãtis, qualifcú-

" que ea fit, fubltantix:alibi, non fpiritus, fed cerebrum ipfim

\% in cerebro inhabitantis animæ organum, \& princeps fen-

Lod "fas, \& initium omninò à quò in feforra omnia communis fen tiendi facultas influat, videtur. Alteratur (inquit) fenfus in9 ftrumentum:dignotio autem ipfius alterationis fit ex una fa" cultate omnibus fenforijs commini, qux à principio influit, "Cęterŭ, initium ipforum fiue cồem fenfum, fiue princeps fen" forium nuncupare voles, nihil intererit. atq; hoc prior difpu" tatio cerebrum efse iudicanit, à quo omnes particula fen" fum, \& motim obtinent, quod nimirum qua partibus fenfuim, motumq́'; afferunnt, nerui à cerebro exoriuntur emnes. " quoniam (inquit) nerui è cerebro \& mêbranis ambientibus " contrahuntur, per eam ipforum partem, qua è cerebro oritur, fenfus membris omnibus, motusq́; fappeditatur: Alibi ftupidưm inuitus, atq́; immobile cerebrum, non fentiendi or ganum pronuntiat Galenus, fed à natura factum, ut fenfus organis uim fentiẻdi largiatur, Animam, qıx neruis, eorumq́; minifterio reliquis corporis partibus fentiendi uim largitur omnibus, nifi fupida fubitantia donari eam placeat, in cerebri corpore inhabitare exiftimandum Galeno non fuit : qui nimirum cerebro modo quouis contrectato, \& incifo etiam nullum animali dolorem, fenfum fieri nullum, nullasq́; corporis partes fenfu diftitui, aut motu intuitus eft;minus etiam fpiritum in ventriculis contentum, animx in cerebro quouis in habitantis modo organum effe: fr quidem ( quod in cerebro dila niata ea, compreffaq́; euenire non videtur) fpiritu in uentriculis incifo, comprefiouè, immori an imal videtur. ne $\rightarrow$ ? q́ie enim animx organo magis, quam ipfa offenfa, oblxfáq; anima, doleat, deficiató; animal.Ineptifsimum itidem, at cô traria ratione cerebrum quod fentientis, motitraq́; anima or ganum videri queat, uel quod ratione omnino ulla fentiendi,fefeǵ; mouendi uim partibus fuggerat, non fi quidem immaginari licet ab organo, aut ullo omnino à medio facultatem ullam alijs apportari pofse, qux non ipfi prius indatur, $\&$ qua caret omnino ipfum. Quoniam igitur nec fubftantia in cerebro inhabitans, nec cerebri temperies, aut cerebrum, ipf.m animæ fubftantia uideri poteft, \& cerebro omnino ineffe uidetur Galeno, fuper eft, ut fpititus uideatur in illius con-

tentis 


\section{Quod Ani.vniu.abvnic.Ani.fublt.guber. 8}

teritus uentriculis, quo in oculos illapfo humoribusq́; immi- 7. de Hipp. fto fentientes eos tieri, \& cui ex oculis egreffo uidendi munus ipfe afsignat Galenus. Vt nunquàm fatis hominem mira- , ri queas, qui animæ fubftantiam, fedemq; præoculis quum ha beret, alibi utramq́; inquirat. quin quàm liquido intuitus fe "Eod.c.7. mel foret, non perpetuo illam uideat; fi (inquit) de animæ,, fubftantia aliquid pron untiare oporteat, alterutrum neceffa- ," rio dicemus, aut hunc effe ueluti lucidü, æthereúq; corpus,,$p i$, ritum nimirum, in uentriculis contentum, qui Incidus, xthe-, , - rensq́;; Galeno effe uidetur, aut incorpoream, inquit, fubftan- , ,tiam, cuius primum uehiculum hoc ipfum corpus fit:\& alibi rpinali (inquit) medull $x$ confpicuus ineft porus ad vehemëtem uirtutis diftributionem. Propterea fcilicet bene latus meatus in fpinali factus effe videtir Galeno, quòd fubftantix fenfum, motumq́; partibus diftribuentis,iplius nimirum ani $m x$, magna illi copia indenda fuit, eam porrò aliam à fpiritu in uentriculis contento, exiltimare haud quaquam licet . ex eadem enim cerebri fub?tantia, fpinalis conftituta,ijfdemq́; obuolitta tunicis, \& eadem omnino cerebro cum fit, cundẽ, quem in fuis cerebrum continet cauitatibus, fpiritum, \& illum fua incauitate continere, neceffario exiftimandum eft. Vt nifi ratio obftet, qux fpiritum animæ fubltantiam non effe perf lafit Galeno, animæ is fubltantia omnino ponendus fit.age igitur examinetur \& ipfa.

Rationem, que fpiritum in uentriculis contentum, anime Jubftantiam non efJe, declarasit Galeno inamem eßse. Cap. VII. cret.c.5. , 


\section{BernardiniTelefij}

in reliquis contentz ventriculis ab ambientis uiribus offenfx, \& a magno omnino, infuetoq́; perterrefaetamalo, non modò ex adapertis illis, non euolant, fed veluti malum inde illatum axerfarx, quàm longifsimè licet in de alfugeant, itaqne reliquos in uentriculos : forte $\&$ non fatis ibi in tuto effe exiftimantes, in fpinalis fefe omnes retrahuut cauitatem: ad illas porrò reliquis è corporis partibus fpiritu reuocato omni fenfu er omnes, motuǵ; deftituuntur; at uentriculis (ipfe inquit Galenus) conıuncuis, fingulisq́; f fpiritus portioni bus proprias in fedes regrefsis, rurfus fentit, moueturó; animal, itaque anim $x$ fubifantiam fpiritum efse liquido patet, quocùm fcilicet, \& fen fus, \& motus, \& ipfa recidit uita, \& qno cùm \& fenfas, \& motus, \& ipfá redit uita;nô cerebri tem peries, quo nih il prorfus offenfe, interdum interire animal, \& fummopere interdum oblafo, uiuere videtur. Quoniam igitur qua uia, ne firitum anima fubftantiam poneret, Galenú reiccit ratio, infirmifsima eft, \& uel imprimis animam, illum effe declarat ; \& ea infuper ille natura, eaǵue donatus eft difpofitione, quibus, cui fumma motus ædendi exquifitifsimaç; fentiendi uis, præcipux fcilicet animx operationes, fun Etionesớ; afsignand $x$ funt, donatam effe opertet fubitantiă; fummo nimirum calore, fummaque donatus eft tenuitate; qui igitur ad motus quos uis $\nsim$ dendos promptifsimus fit, $\mathbb{R}$ qui, uel a languidifsimis rerum uiribus immutari, \& vel angu ftifsimos neruofi generis poros fubire, inquam ijs in habitare, \& per eos, ut libet, meare queat, ad ia omnino omnia, qux operari, præftareque anima uidetur, operanda praftandaque aptifsimus cum fit fpiritus, quin anim $x$ is fubftantia , \& ipfa omnino fit anima, nulli dubium efse poteft at age quoniam non quod nobis pofitum eft, propterea fentientes, mobilesq́ue videri neruos, quòd fubftâtia, qux fentit, motusqúne adit, \& fpiritus omnino portio quadam ijs infit, fed factiltate quadam à principio immifsa huiufmodi fieri Galcno placet:rationes, qux id ut poneret, illum impulere, explicentur, examinenturqque. 


\section{Quod Ani.vniu.ab vnic.Ani.fuḅtt.guber. 9}

Sentiendi, fefegs Commouendl facultatem partibus ner. ui Galeno afferunt, non fubftantice portione, fed facultate tantum à principio indi.

$$
\text { ta. Cap. VIII. }
$$

Nre and VOD ad facultatem, qux à cerebro defcen- Lib.\%. de

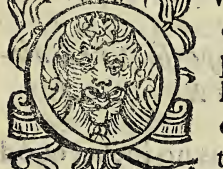
dit fpectat, nö licet nobis (inquit Galenus) Hipp.\& Pl. promptè firmare, anquemadmodum ex fo dec. cap. 4 . prompte affirmare, anquemadmodum ex fo De Sympt. lari fplendore qualitas quædam profecta in ca.r. cap.5. omnem aeris ambientis partem diffemina-, tur,ipfa folis fubftantia fuo loco permanen-" , te;fic etiam ex cerebro uirtus quxdam per neruos influat; an, potius fpiritus fubftantia ad fentientes ufque, \& fe fe mouen- , tes partes proficifcatur,aut aliqua ex parte in neruos incidés ", ita ipfos immutet, wt eorumalteratio in mobilia membra di, ftribuatur, cuiufmodi quippiam fieri in neruo viforio contin git. Siquidem per viforios neruos, qui ab anterioribus cere-, bri ventriculis oriuntur, \& manifeftè concaui funt, fplendi-, dus fpiritus ad oculos fertur, id quod ex ipfa ftructura intel + , ligere licet:\& praterea, quòd vno quidem oculo claufo, dila $\rightarrow$, tefcat alterius pupilla, ftatim autem eo aperto, rurfus in natu ralem magnitudinem redeat.Verum enim vero minime quidem arbitror néruis omnibus meatus ineffe, fed ijs tantum, qui corpulentiores funt, quemadmodum eft proceffus ille fpinalis medullæ ad vehementem virtutis difributionem . Propterea igitur non à proprix fubftantix, \& à fpiritus omniho portione, fed á facultate quadam, ab animali principio in neruos immifla fentiendi, fefequè mouendi facultate donari, eos exiftimat Galenus; quòd meatus per quos in eos fpiritus influat, neruis ineffe non intuetur : tum prætereaque neruo incifo, tuel fortiter ligato, qur ultra incifionem, uinculúuè exiftit pars, ftatim ftupida fit, Immobilisque : quòd fi fpiCap.3. ritis infit, haud quaquam multo fiat temporis momento, fed tantifper faltem, \&otandiu omnino, quamdiu, quin fuxerat fpiritus durat, \& fentiat, 8 moneatur. Velhti (inquit) fi foli $\rightarrow$, dum aliquod corpus in illuftrato aere ponatur, ftatim uide-" ", mus, quod aeris infra et, obfourari, ceu qui dum immutatur, ", euadatlucidus, non autem cùm permutatus fuerit in femel accepta mutatione perfeuerans: fic enim lumen perpetuò re-

C maneret, 


\section{Bernardini Telefij}

maneret, uel fi ablatum id, quod illuminat, effet: ita \& neruo fecto, ligatoue, quantum fectio, vinculumuè à cercbri continuitate feparauerit, tantum is infentiens redditur. Et in arterijs etiam, eademq́ue in neruis cernitur tiatura fiquidé diffect $x$,interceptæuè funiculo, non pulfant, facultate fcilicet if la, quam ipfarum tunicæ cotdis corporis continua influentem ab eo femper obtinent, deftituta.

Rationes, qua fpiritum neruis non imefepergafire Galeno, inaneseffe. Cap. IX.

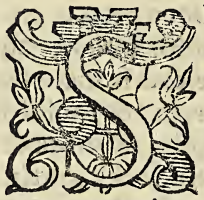

PIR IT V M neruis reliquis no inefie, quòd non,ut in fpinali medulla \& in uiforijs, fic \& in reliquis meatus confpiciatur, exiftimandum Galeno non fuit, qui fcilicet, nullum $v f$ quam in hominum cute rorum intuitus, res ex ea effluere uiderit, multoq́ue fpiritus eft muntis tenuis, \& fi fpinalis medull $x$,viforiorumó;, tum \& neruorum reliquorum ufum, quem pulcherrimè intuitus fuerat, veluti ante oculos pofuiffet : Reliquis itidem in neruis cauitates, in quibus fpiritus inhabitet, inefie intuitus itidem foret. Quoniam enim !pinalis medullę, viforiorumque non idé quod neruorum reliquorum munus effe Galeno eft uifum, ut fcilicet partibus, qub xs infixi funt,fentiendi,fefeque commouendi facuitatem afferant; quin ipfi ut illarum pafsiones percipiant, \& quibus oportet, commoueant illas motibus. Sed fpinalis quidem medullæ ut neruis, qui ex ea producuntur, fentiendi,fefeque commouendi virtutem, facultatemq́; diftribucret, fpiritum fcilicet contineret, qui illis omnibus diliribui pofiet;neque enim alia è fpinalis cauitatc uirtus, fa cuitas uè influat. Sed fpiritus modò, qui in ea contineretur, fi quidem nihil prorfus in ea intuitis unquam, \& non frultra, fed quempiam in vfum, quampiam fcilicet ad rem continendam conftructam effè neceffario intelligentibus; quin longè tenuifsima fubftantia, \& qux ftatim ex adaperta ea euolet, omnemque lateat fenfum; quin idem omnino fpiritus, qui in cerebri ventriculis, quibus continua ea ef, quin quibus annu merari ea potef, in ea itidem contineatur, ambigere non licet.Viforiorúu verò, ut per eos fpiritus in humores effundatur, iे quo fentientes ij fiant, tum \& qui ex oculis Caleno egreffus, 


\section{Quod Ani.vniti.ab vnic.Ani.fubt.guber. to}

aereque in alterato, \& in propriam acto naturam, vel longè re motifsimas intueatur res. Vtiq́que fui ipfus, prepriarináque pofitionum memori Galeno neruis, corumq́ue portionibus quibus uis, qux partibus fentiendi, fefeque moucndi factiltatem afferre Galeno videntur; jjsćue imprimis gu è fpinali medulla producuntur, in quos feilicet ex eius cauitate fentié di, fefeq́ue monendi uirtutem infuere afferit, porcs in effe, in quibus qui fentit, motusq́ue ædit fpiritus infit, intelligčdum omnino fuit;neq; enim alia (ut distum eft)res in neruos è fpi nali productos immitti potef ; nifi qui in ca in habitat fpiritus;nec aliam oculorum humoribus, 8 oculis ipfis, fartibus verò reliquis aliam fenciendi vim fubfantiam afer zxin:mare licet; itaque itermodò per fpinalem med llam, viforiosq́:te proprias ad fedes, propriaque ad munera firitui faciendum cùm fit : reliquis verò in neruis, \& externarum tcrú vires percipiendx, \& tum nerui ipi, tum vero \& partes, quibus afixi funt flectend $x$, intendendxq́ue omnino commouendx funt motibus, quod factum ef, faciendum omnino vi deri potuit Galeno, unum nimirum bencóne cin amplum \& in eorum medio; imuiforijs, Spinalique medulla neatum conftruendum:per quem feilicet fibi ipî v nitus, collectusq́; $\&$ nullis ufque ab angultijs reicetus iucundum, com ncdumque, \& tutum iter faciat fpiritus: reliquos veiò longè anguftif fimis poris, \& nihil in externis quam in internis partilus mi nus diftinguendos fuife, quin quod factum itidem uidetnr, neruos fingulos è longe pluribus, longeque fubtilifsim is ner uulis in fe ipfos collectis, complicat isque componendos, \& fingulos anguftifsimis perforandos fuiffe poris: bene enim fi bi ipfi in ijs collectus, vnitusque, \& nihil rerum, quibus ineft crafsitic reluctante, nihilq̨; externarú rerü actiones reijciēte,

Facilius promptiusqúue, ut libet, illas fleciat, \& exquifitius eas percipiat. Nam quod dicum eft, neruos fingulos primis è neruulis in feipfos collectis, conplicatisq́ue compoftos effe, inde liquido patet, quòd finguli veluti inminutifsima fila fcind i poftunt. Itaque uel fi nulli reliquis in neruis po ri Galeno confpecti fint, haud quaquam propterea nullem in cos,fpiritum influere exifimandum fuit; Minus etiam quod incifis ijs, vel fortiter ligatis, confricisćue, cur ultra incifio nem, uinculumó; ipforum funt portiones, fenfu, motúq; deAtitui uidentur, Quoniam enim ( vinin ijfem expofitun efk

$$
\text { C } 2 \mathrm{com}-
$$




\section{Bernardini Telefij}

commentarijs) propterea fpiritus portionum, qux partibus infunt pafsiones, unituchtation cerebri ventriculis refócéti, itaque 2 animali percipitintur, quod huic ille continuę funt, cóque omnino modo, quallarum quxuis immutationes, motusq́ue fiunt, \& inter nedijs omnibus, \& ipfitandem com municantur uniuerfitati, quo qui aqux aerisque portione in dunturmotus, vniuerf ij aquæ vniuerfoq́ue communicătur axri. Vtique quãtauis fpiritus copia nerui portioni, quam vel incifio, vel vinculü à cerebro feparaucrit, infit, \& quaduis ea patiatur pafsiones, nihil eas magis fpiritus vniuerfitas patiatur, percipiatque, quam inciforum ferpcntum pars altera alterius mala:\& nos ipfi corporis partium pafsiones, quibus nullus ineft fpiritus. Immobiles itidem diatæ neruorum partes fiunt, quod nulla forte fpiritus portiones à fe ipfis proprijsq́ue viribus res, quibus infunt commouent, fed quos fin gulæ ædunt motus uniuerfitatis arbitrio, \& ipfa ab vniuerfita te commotx eos $x$ dunt omnes : at ut qui uaforum quorundam fibris inexiftit fpiritus, cui fcilicet ( ut ibi itidem expofitum eft) non alij xdédi funt motus, fed ex alià modo fibrarum parte in aliam eundum, motus nimirum €̨dendiss, quem quantulufuis fpiritus proprijs viribus $x$ dere queat, $8 x$ quem nullo uniuerfitatis decreto, nihilque ea commota per fe ipfum \& iucunda moleftauè à re, cuius nullus uniuerfitati fiat fenfus, $x$ dere uelit, $x$ datq́ue, non cert $x$ \& quos neruis inexiftens ędit, a quibus magnæ corporis partes, fummaquie interdum commoueri uidentur arte, \& qui manifefte à voluntatis imperio ab vnituerfitatis nimirum pendent decretis, \& ipfos $\mathrm{ab}$ ijs in exiftente fpiritu iuxta proprium arbitrium, proprijsque operante uiribus, ædi exiftimare licet:ut enim fingule ip fius portiones fingulis corporis partibus inexiftentes, quos edere uidentur motus, per fe, nullaque uniuerfitat is ope ęden di potentes uideri queant, non ccrte $\&$ fciētes uideripoffunt: neque enim cognitio intelligentiaq́ue, quam fubftantix, quæ partes commouet, inefle uidemus, fpiritus portioni cuivis, fed principi modò attribui poteft, \& manifefte huiufmodi: partium motus vniuerfitatis imperio, \& ip fainfuper uniuerf tate commota, funt. Si quidem ( $v t$ in ijfdem expofitumeft commentaris) quos ipfa illis ædendos decernit motus, ftatim eos illis inexiftens ędit fpiritus, fummè interdum graues dolori ficosçue, \& à quibus abitinendum decernit:uel fi cos ædens 
x dês fpiritıı voluptate fumına aficiatur, vel fumma exolua * tir moleftia, abltinet abijs tamen. Et portioni cuius paulò ro bultiorem, operofioremuè xdenti motum, reliqux omnes in feruire, \& quam poffunt opem ferre apparent, ita fcilicet prin cipe imperante. Vt fi è quibus neruorum portionibus ad cerebri ventriculos præclufa eft uia, nullis cæ moueri apparent motibus. Non propterea id euenire fatuédum eft, quod fubftantia, facultasue, a qua commouebantur, nulla ijs inexiftat amplius; fed quòd ab uniuerfitate feiunct $x$ funt, cuius arbitrio, atque ope res, quibus inditæ erant, commouebant:quin uel fi proprijs uiribus, quibus ineft, partes commonere queat fpiritus, incifo, colligatoue neruo nihil eas cómoueat tamé; fiquidem quod hominibus fingulis proprio à cętu feparatis euenit, a fe ipfo, \& à propria feiunctus uniuerfitate fummopere turbetur, \& ueluti exanimetur, itaque $\&$ torpidus fiat oportct. In firm $x$ igitur rationes; qux Galeno perfuafere, nö propteraa fentire, moneriq́ue neruos, qnod animæ fubftantia ijs inexiftat, fed quòd facultas modò quadam indatur, at non qux fpiritum ipfum inefle declarare poterant, \& qux declararunt interdum. Age porro explicentur \& ipfa.

\section{2ue Jpiritum neruis ineffe Galeno declarare pote- rant. Cap. $X$.}

3. 2 T E T E quidem Galeno ftupidi fui natura, 31 atq́; immobiles, \& qua fentiendi, fefeq́; mcuendi facultate nerui donati videntur, re quapiam à cerebro in eos immiffa donari ui détur;fi quidem, in fomnum delapfo anima li, qui uaporibus è ventriculo ad cerebrum fublatis præcipuè fit; \& fpinalis medullx cauitate humoribus oppleta, rei nimirum, quæ è cerebro in ner uos infuens fentiendi ijs, fefeq́; mouendi vim affert, præclu fa uia, quales fuifunt natura, ftupidi funt, immobilesq́ue. At vero quòdeadem prorfus cerebro fubftantia donati, ijfdemque obuolati tunicis, nihil omnino aliud à cerebro differre ipfi itidem videntur, nifi quòd in longiori ab illo progrefla, te nuioribus fui partibus elapfis ficciores facti funt durioresó;; cuius modi vbi ipfum fit cerebrum, quæ in eo refidet fubftan tia, nihil deterius fentire, intelligereqúu, nihil ad motus ęden dos fegnior Galeno fieri videtur. Vtique non facultate à cerebri 


\section{BernardiniTelefij}

rebri naturā, 2 ipfo omnino à cerebro in neruos immifla fen tientes eos fieri, mobilesq́ue intelligendum Galeno fuit:fed à fubftantia in cerebro quidem contenta, at quàm longifsimè à cerebro diuerfa, \& à fpiritu omnino in illius inhabitan te ventriculis; rem aliam nullam cerebro illis, uè in effe, $\&$ in illos omnino, qui fomnum faciüt, itaq́; ftuporem animali, rorporemq́; inferunt, uapores illabi, \& f piritum intuito bene calidum, beneq́; tenuem, ea nimirum natura,eaq́; donatum difpofitione, qua fubftantiam, cui neruis fentiendi, fefeq́ue mouendi ius afferenda eft. Quin cui neruorum, partiumque, quibus infixi ij fant, pafsiones percipiend $x, \&$ ipf $x$ comouen dx funt partes, donatam effe oportet. qui igitur uel anguftiffimos neruorum poros fubire, fummaq́; per eos uelocitate fer ri, \& ut libet fecum illos fectere, tendereq́; queat, \& quin ab externarü rerum uiribus, \& uel ipfis à vaporibus fummopere turbetur,immuteturq́; \& velleuif́sima, quę patitur, ttatim per cipiat omnia qui ad functiones'omnino muneraq́;, quę neruo fum gen is, eiue inexiftens fubftätia pręftare,obireq́; uidetur, preftanda,aboundaq́; omnia, aptifsimus videri poteft:\& quo poftremo oculorim humoribus immifto fenticntes eos lieri, \& à quo ex oculis egreffo acrem, qui nos remotifsimasq́; inter res medius elt, propria natura, \& fentiendi omnino, ui7. de placi- dendiq́ue vi donari enunciat uniuerfum. fpiritus (inquit Ga tis Hipp. \& lenus ) per uiforium neruum illapfus oculorum humorsbus
Pl.t.c. immifcetur, ut tota cor im fubftantia fentiens fiat, \& reliquis

" igitur corporis partibus, ut \& ipfe fentientes fiant, fpiritus

" omnino eli immifcendus; tum uifio (inquit) haud quaquam

" rerum imaginibus ad inexiftentem oculo fpiritum delatis tie

" ri potelt; nō fi quidem montis magnitudo quanta exiftit per

" oculi pupillam introferri, fed quod fpiritus per uiforios ner-

" uos in oculos delatus, ex ijs exiliens, \& ambientē aercm in al

: terans, \& ueliti conuerberans ipfum fibiafsimilat, \& per ip-

"fum ad coloratum corpus extenditur, fi animal externas re-

" motafque res ut intucatur, percipiatque, ad eas vfque effunde

" dis eft fpiritus, \& fpiritui omnino contingenda ex funt, uti-

" q́ise \& proximarü uires ut percipiar, côtingatur, ab ijs oportet.nequze enim qur in animali fentit fubftantia, uelut in iltis c partibus, multifue compofita eft è fubftantigs, \& guarun fanguliz fiagula percipiant res, fed una omnino omnes eadem q́ le percepir ratione, \& cc ntingens omnino eas, ab earumq ; 


\section{Quod Ani.vniu. ab vnic.Ani.fubrt.guber. 12}

paffa, immutataquè uiribus, id uero \& omnibus vifum eft, \& neceflarium omnino eft. Qun \& neruorum portionum, in quas feil à unculis, feu ab intufo humore ad cerebrum praclufa eft uia, ftupiditas, torporquè non incorporea facultate, fed corporea fib?antia, \& f piritu omnino è cerebro in neruos ettufo, fentientes, mobilefquè eos fieri, declarare Galeno poterat fi quidem denfiores factos neruos, ijfquè inexiltentes humores, qui fcilicet nihilo neris minus permeabiles ui deri polfunt, fi non fatim illa fubeat, at fubeat omnino tande natutarum agentium more, qua incorforex quòd funt, magis in fe ipfas conftrictas, denfafquè res ferius quidem ęgriufq:xe, at fubeunt eas tandem omnes : inde etiam intelligere Galenus poterat, non facultate à cerebro emilfa uim neruis indi, qua fentientes fant, mobilefquè, fed anima in cercbro inhabitantis, \& fpiritus omnino portionem ad illos aduenire, eāquè \& fentire, \& neruos, partefquè, quibus ij infsxi funt, commouere: quòd quæ facultate agunt proprijs conditionib!s omnibus, ijfquè imprimis, quas ennttant in qux agunt, donant, \& nullo prope modum temporis momento, qux fimi li natura,fimilique donata funt difnofitione. Icaquè fol atquè ignis, qui facultatc emiffa Caleno agunt, qux ab iffis nó valde difsident, ftatim calida omnia, licidaque faciunr, 8 in folem ignemquè agunt : quin \& qux contrarijs naturis, contrarijsquè donata funt difpofitionibus, ijs illa panlatim cxusnt, proprij fquè afficiunt, $\&$ indunt eas tandem omues, qua fcili. cet facultate agere, \& facultatem emittere nidentur, non acultas ab ijs alia ulla, fed propria natura, propriaquè cmanat fubtantia; itaq; qux ea exuperat præinexifente uatura, eiuf què condition ibus eiectis, fe fe ijs, propriafque conditicnes indit omnes. Vt nifi qux in cerebro inhabitat fubfantia alia rum naturarum, quæ facultate \& ipfæ Galeno emittunt, nulli prorfus fimilis fit, fed diuerfa ab ijs omnibus agat racione, neruis ea omnibus fentien di, fefcquè mouendi, non facultatê, qua fpoliari queant; fed naturam indat tandem. qua enim uno à cerebro illi differunt, nihil ićprorfus ( ut dictum ent) obftat.Quin fi non ftatim, at breui omnino neruos fubire, fe feque ijs penitus indire queat, cerebri itidem ftupiditas, immobilitasque non modò, quod alibi dicum en, fentientem, motiuamquè animam ipfius temperiem non efse, fed \& nulla omnino à fubftantia in cerebri corporc inhabitante, faculta- 


\section{Bernardini Telefij}

tem in neruos immitti, qua fentientes, mobilefquè fiant; fed propterea tales uideri, quòd à quibus rerŭ uiribus nerui ijfquè proximæ corporis partes immutantur; ijs itidem inexiftens immutatur fpiritus; \& commotus is \& neruis, \& quibus affixi ij funt, commouet partes . cui enim dubium efse po teft, quin fi fubfrantia in cerebri corpore inhabitans facultatem in neruos immittat, qua fentiētes, mobilefquè fiant, mul tò illam prius, multòquè robuftiorem ipfum immittant in cerebrum? propterea igitur neruorum pafsiones quxuis fatim animali percipiuntur, at cerebri malorum, nullus prorfus animali fit fenfus, guod quæ neruos oblxdunt rerum uires, eadem \& neruis inexiftentem offendunt fpiritum, min ime uerò \& qua cerebrum eadem, \& fpiritum in ipfius contẽtum uentriculis, qua fcilicet ne ad fpiritum ufquè ferantur, ipfum què attingant fpiritum, à cerebri corpulentia, profunditatequè reiciuntur, \& propterea nullam fe fe commonendi cerebrum obtinet facultatem;nerui uerò fumma ea donati apparent; quod non ut neruis, fic \& cerebro propterea inditus eft fpiritus, ut feorfum à reliquis corporis partibus uarijs illud commoueat motibus, fed ut in eo refidens portionum omnium pafsiones, necefsitatefquè percipiat, \& quibus ijs jllarum occurrëdum eft motibus, ijs illas commoueri præcipiat, fortè \& commoueat, ij s i pra commota, munera omnino motufquè ut $æ \mathrm{dat}$, quos fibi ipfi vnitus, nullamq́ue propriæ fedis partem fecum fectans pulcherimè ædere queat.Poftumò \& mouentis lafsitudo, eius nimirum immutatio, qux pau!o uehementiores, diuturniorefquè motus confequitur apertif fimè Galeno declarare poterat, non facultatem à cerebri corpore, naturauè in neruos immitti, qua fentientes ipfi fiant, mobilefquè;fed ex illius uentriculis fpiritum in ipfos illabi, $\&$ fentientes cos uideri, mobilefquè; quòd ijs inexiftens fpiri tus externarum rerum uires percipiat, 2 commoneat eos, fi quidem qux facultate emifsa agunt fubftantię, nihil eæ unquam quòd illam emictăt, dcfatigari, debilitariuè;aut immi nui uidentur, nec pofsunt om nino:qui cnim ab actione, quã natura ędmnt, \& quę ipfarum propria eft, defatigentur, debilitenturquè, aut qui imminuantur, nullam unquam fui portio nem emitrcntes ? Itaquè calorem afsiduè, luccmquè cmittcns fol, nihil propterca cefatigari, debilitariuè, aut imminui uidetur.idem nerò \&r noftro eucniat igni, nifi inexiftens $c$ : 


\section{Quod Ani.vniu.ab vnic. Ani.fubft.guber. 13}

lor, quam ipfius portionem tenuifsimam, proin deq́ue leuiffimam, inuifilemq; fecit, fecum afsidic̀ cfierat.

Naturx nimirum (vt alibi amplius deciaratum e $\mathrm{t}$ ) quę nô fui portione quapiam, fed facialtate emifia agcre uidentur Galeno, eo praditre ingenio, ijsq́; donatz funt uiribus, ut nihil ipf $x$ unquàm è proprio decendentes fubiecto, nihilq́; in in eo imminutx unquam, proprias tamen facultates, propriasque uires perpetuò, inceffanterq́ue effundant, \& qua ijs attingunt, ijs illa donent omnia.Itaq; quoniam à paulo uche mentioribus, diuturnioribusue motibus non defatigari tantum debilitarine , fed imminui etiam, \& deficere tandem, qux mouet fubftantia videtur, non facultatem cam, fed fui portionem in neruos immittere, exiftimandum omnino eft, \& propterea defatigari, quòd motus xdens, non fe ipfam modo, fed circum politas fecum veetat corporis partes; \& imminui deficereque tandem, quod è concalefactis, a dapertisque partibus afsiduè elabitur. Itaque liquido patet fentiendi, fefeq́ue mouendi uim, qua nerui donati uidentur, hand quaquam à facultate ijs indi à cerebro, eiusuè natura eman $\vec{z}$ te, fed à fpiritu omnino ex illius uentriculis in neruos illapfo, quinquæ nerui fentire, \& quos ædere uidétur motus, haud quaquam neruos, féd ijs inexiftentem fpiritum fentire, xdereque omnes: Vt nunquam fatis Galenum mirari liceat, qui adeo manifeftam rem, \& quam apertifsimè interdum intuitus erat, nô perpetuò eam infpcxerit. At age rationes examinentur, qux tres homini inefie animas \& fubftantia, \& loco, re ipfis feparatas, differentesq́ue, eæq́ ıe ante alias, qux fubftantias cordi, iecinorique infidentes non animales, fed natus rales effe Galeno perfuafere.

Perperam Galenus operationes, quas nulla animal operari videtur electione, non anima, fed natura afsi. gnandas decernit. Cap. XI.

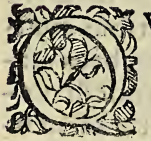

V A NDOQVIDEM fentire, \& moneri fecundum electionem propria animalinm funt (inquit r.de natur. Galenus) augeri verò, \& nutriri p!antis etiam cô faculs. c.r. (1) muniajerunt utique piora quidem an im $x$, pofte"
riora vero natura ipfiss opera : quare animalia fimul $3 a b "$

$$
\text { D anima, }
$$




\section{Bernardini Telefij}

anima, \& à natura gubernari dicimus; ftirpes verò à fola natu ra,quamquam his etiam animam uegetatricem aliquis attri buere haud immerito poterit, diftinguens eam à fenfitrice. Propterea igitur, ut videtur, non ab anima modo, à fentiente nimirum, cognofcenteque fubltantia, fed à natura itidem à bruta nimirum, cognitionisque omnis experte fubltantia animal gubernari,ftatuit Galenus : quòd an ma quia fentien di,dignofcendique facultate donata eft, \& fenfi cognitioneque operatur, quas operationes, \& quos ædit motus electione, \& ibi omnino eos ædit, fîtitq́ue, ubi ædendos, fiftendofque intelligit, collibitumuè eft : quin \& operandi, mouendique modum immutat, vbi immutandum intelligit, collibitumue eft, \& operationum, motuamq́ue, quos çdit, nullus ipfam latet; operationum a:tem, motuumqúe, quos animal $æ$ dit, longè plarimi nullo animæ imperio fieri, fiftue; nulla omnino ab eius volantate pendere immutariuè, quin nullo cum animalis fenfu fieri uidentur . quos igitur ab alia adi fubtantia exiftimand:m fit, qæa brita fui natura, \& qué in af Im operetar, ignara, prorfus nulla operetur intermifsione: Vn fcilicet, ut uidetur animæ fentiendi, motus ucrò $x$ dendi,nihil nature quam anime minus facultatem attribuẽs, idqú modo in ijs ædéndis ab altera differre alteram fupponens, quòd anima, ubi collibitum eft, eos fiftit; natura verò nulla cos edit intermifsione, rerum naturæ, \& fibi ipfi difcors aduerfusá te uideri poteft Galenus, 1lli quidem, quod ( ut in ijfdem expofitum elt commentarijs) fubltantiarum à quibu's res confitutæ funt omnes, una modò fentiendi uis communis veriqúue, motus verò ædendi uni modò calori tributa eft, nec qnaliuis, fed longè tenuifsimo, leuifsimoque inexiftenti fubiecto.Itaq; ea modò à fe ipfis moueri uidentur entia,quę fumma donata funt tenuitate, reliqua verò omnia, qux paulo corpulentiora facta funt, cuiufmodi uifcera, resqúc alię funt, quę à proprijs naturis moueri uidentur, in mobilia fui natura funt omnia, \& ab alia inexiftente mouentu fubftantia, fi bi uerò ipfi, quòd motum, fenfumque, quos animæ modò in cerebro refidenti afsignarat, \& quos ijs modó partibus communica ri uiderat, enuntiaratq́ue, inquas, qux à cerebro $\mathrm{cma-}$ nant res, \& nerui cmnino, quibus fcilicet, illam fentiê di motusquè ædendi facultatem Galeno indit, immittuntur, reliquas, quas nulla fubit neruofa portio, uel quos fubit quidems 


\section{Quod Ani.vniu.ab vnic.Ani.fubft.guber. 14}

at incommodo quopiam affectx, illa ind non poteft,prorfus ," ftupidas immobilesquè effe, fieriuè uiderat, enuntiaratquè; " cordis utrumquè, $\&$ iecinoris naturis $\&$ ipfi omnino cordi, fique attribuit iecinori, id enim agit operationes utrique atattribuens, qux fenfu, cognitioneque, 8 motu infuper conficiend $x$ funt ; \& cordi feorfum fui ipfius, arteriarumq́ue omnium dilatationem afsignans, côftrictionemq́ue, quam fummopere afsiduè variari, itaque perpetuò prout,pręfens pofuit ufus, ipfe omnium pulcherrimè infpexerat Galenus:cui enim dubium effe poteft, quin fenfu, cognitioneque operetur, qux operandi modum afsiduè,itaque perpetuo immutat fubftan tia,prout ad fui ipfius bonum, conferuationemque immutan dus is eft? Nec propterea propria pofitio deferenda Galeno erat, quòd operationum cuiufmodi ab anima alix fentiente, Imperanteque $x$ duntur immutanturque, alix uerò nihil pror fus ab eius voluntate pendere, $\&$ nullo cum animalis fenfu fie ri uidentpr, fed in illa omnino perpetuò perfiftendum, quæ ni mirum ipfo pofita erat à fenfu;tum modus inquirendus, quo animx illæ omnes cum fint, \& anima omnino illas æedat omnes,nihil tamen animali percipiuntur, nihilq́ue ab eius uolú tate pendere uidentur. \& paulo diligétius inquifitus $G$ aleno is fi foret, quo partium fingularum pafsiones, immntationes que animali percipiuntur, \& qux operationes, quiquè motus à voluntatis imperio pendent, ille itidem confpectus foret. Quoniam enim qux corporis partium, ijfque inexiftentium fpiritus portionum pafsiones eius uniuerfitati in cerebri uentriculis refidenti non commnnicantur, nihil eas perci pit animal, itaque profundioribus foporibus, qui (vt alibi ex pofitum eft) multis crafsifquè uaporibus ad cerebri uentricu los fiblatis, fpirituque in ijs exuperandis occupato, detentoquè fiunt : quin \& in uigilia etiam, at fpiritu intentifsimè Lib. de fen no.c.7.8. quid cogitante, nihil uel graues partium palsiones percipit animal, \& ne grauifsimas quidem in apoplexia, qux vel omnium confenfu fpinalis medullæ cauitate humoribus oppleta, uia nimirum à neruis, qui omnes prope modum ex illa exoriuntur ad cerebri uétriculos præclufa fit. Et portionum reliquarum pafsiones, immutationesq́ue vniuerfitati ut comminicentur intermedio fpiritui communicandx onnino funt uniuerfo:neq; enim nifi ad illam perueniant, ijs ipfa immutari poteft, \& nifi in intermedio eæ fiunt, nulla in uniuer-

$$
\text { D } 2 \text { fitate }
$$




\section{Bernardini Telefij}

fitate fieri poffunt ratione. itaque exiftimare licet non quasuis fpiritus portionum immutationes, motusquè uniuerfitati communicari, fed motuum ritu, qui riuulis à cómuni qua-? piam aquarum uniuerfitate effltentibus in duntur, tiehenetes modò illa ad uniuerfitatem peruenire, in eaq; fieri, langui dos verò nihil proffus uniuerfitati communicari, qui nimirü languidiores afsiduè facti, priusquam ad illam perueniāt, de ficiunt prorfus; \& 'ita omnino etenire, afsidua, qux à fpiritu uaforum fibris inexiftente fuccorum attractio, retentioquè, \& expulfio fit, apertifsimè declarat . qux fcilicet quia fenfum omnino omnes conf́equntur, fpiritu omnino quid paffo, im mutatoque, fiant oportet, \& nullo plerumque cum animalis funt fenfu; propterea fcilicet, quod quæ à languidifsimis inexiftentium fuccorum uiribus, afsiduè in fpiritu fit immutatio, quia exilis ea eft, languidaquè, priufquam aduniuerfitatem perueniat, deficit prorfus, at fi à robuftioribus fuccorum uiribus robuftius fpiritus immutetur, eius immutatio, paffioque haud quaquam animal latet. Quioniam omnino eas modo fpiritus portionum immutationes, motufque percipit animal, quę uniuerfitati in cerebro refidenti comminicantur, ijque modò uniterfitati communicantur, qui intermedio fpiritui communicantur unituerfo, uehementes nimirum modò, languidiores verò, \& qui adipfam ufque non perueniunt uniuerfitatem, nihil ei communicantur; itaque \& animali penitus ignoti funt, at quin vel is portioni; in qua fiant, ignoti erunt, \& quin res ea, à quibus fiunt uel attrahat nil amoliatur, ambigere non licet : fi quidem longè exquifitifsimo fenfu preditam fubftantiam uel leuisfimas fui ipfius pafsiones nihil fentire, \& longè ad motus quosuis $x-$ dendos promptifsimam, organifque, quibus qualibet attrahere, expellereque queat, donatam omnibus, qux oblectant nõ attrahere, \& molefta qux funt, nó expellere exiftimare nó licet, cofque modò portionum motus uniuerfitat is imperio ædi ab eiufque pendere arbitrio exiftimare cùm liceat, quibus ijs portionum necefsitatibus occurritur, qux ipfi innotuere uniuerfitati : qui uerò boni cuiufpiam attrahểi, maliue reijciendi gratia $æ$ duntur, cuius nullus uniuerfitati factus eft fenfus, quos (ut dictum eft ) portiones fingula fpöte fua redunt, quod languidiores funt, quàm ut ad uniuerfitatem perueniât, vel huiufmodi enim res attrahi, repelliuè poffunt,

$$
\text { à qui:- }
$$




\section{Quod Ani.vniu.ab vnic.Ani.fubft.guber. 15}

à quibus qux in fpiritu fit immutatio, penitus uniuerfitatem lateat, ij nihil magis uniuerfitati innotefcere uideri cum pof fint, quàm qui ab inciforum ferpentum parte, quæ à capite fe iücta elt, ædi uidentur.hæc inquàm omnia ita cum fe habeăt, utiq; \& cordis pulfatio, \& uafarú omnio attractio, expulfioq́ue, operationes omnino quæuis fenfu modo ex, motuque conficiantur,uel fi nullo uniuerfitatis imperio $æ$ di, nullaq́ue ab cius voluntate pendere, \& nullo etiam cum animalis fenfu fieri uidentur, eidem tamen fubftantix, qux iuxtà uoluntatis imperium operari videtur Galeno, \& fpiritui omnino attribuend $x$ funt, cuius ( ut alibi expofitum eft) fenfus, qui in animali fit, motusq́; eî́ omnis. Nam cordis pulfationem, vaforumq́ue omnium attactiones, expulfationesq́; à fentien te, cognofcenteque, fieri fubftantia, ấsidua illius, harumque diuerfitas apertifsimè manifeftat, qux fcilicet temere nunquàm, fed perpetuò prout vfus poftulat, fieri uidetur. Itaque prauus omnino canon, quò animales à naturalibus operatio nibus diiudicandas precipit Galenus. Et fi quifpiam ponendus eft,non is à motus perennitate, intermifsioneque ; cur enim quæ motus ædendi facultatem fortita ef fubftantia, $\grave{a}$ quibus feruari,oblectariq́ue, vel à moleftia quapiam liberari fe fentit, non perpetuo eos $x$ dat? fed fi quidem non folo à motu, ab eius certe diuerfitate fumendus eft, \& quæ illarum motu confici videntur, \& non codem perpetuò, fed tali alsiduè facto, quali quod propofitum eft opus, optimo confici queat, animæ ommino afsignandæ funt omnes. At age quan do uel operationum, quas uniuerfitati ignotas effe, fufpicari non licet, non nullę inuitis nobis æduntur, easque fiftendi, quę eas ędit fubfãtia,impotens omnino ef.Itaq; nō ab anima ędi fufpicari licet, qux fcilicet uolens operari uidetur, eligenfque, \& vbi coliibitum eft,operationem fiftendi potēs apparet, illarum earumq́ue prẹterea, quę naturales uidentur Galeno diligentius, quàm homini factum uidetur, quafdam intueri ne grauemur. forte enim fibi in his difcordem Galenum, qui fcilicetbrutæ, turpidæq; naturæ operationes afsignet, qux manifeftè à bene fentiente, beneque mobili fubftã tia.huiufmodi enim fit oportet; quę uifcera, nafaque, quibus inexiftit, commouet, $x$ duntur, $\&$ in illis id efle fpiritus ingenium intuebimur: vt uel fi ( quæ fieri \& ijfdem in commentarijs declaratum eft, $\&$ in operationibus, quẹ exponentur multis 


\section{Bernardini Telefij}

multis manifeftimum fiet) partium fingularum pafsiones quęuis uniuerfitati innotefcant, motus nimirum, qui in ijs inexiftentibus portionibus ab alienis naturis fiunt ad uniuerfitatem perueniant omnes, \& quos illæ ędunt motus, uni uerfitatis arbitrio eos ędant omnes; quin operationum tamen motuumque, quos ipfa ædendos decernit, \& ipfa omnio $æ$ dit vniuerfitas, , perpetuò $æ d a t$, continere fe fe minime queat.

operationum, que nullo à voluntatis Imperio pendent, multas anime afsignari pojfe of afsignandas omninoeffe. Cap. XII.

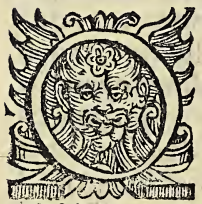
PER A TIONVM, quas nulla electione, quin quas inuiti operari int erdum, $\&$ à quibus ceffandi impotentes videmur, multas animæ afsignari poffe, $\&$ afsignandas omni no effe, ipfa imprimis declarat cogitatio, if nifettè, quæ non vult, quin quæ fummopere auerfatur, exhorretó́; , \& vel vbi eorum cogitatio nullum ipfi aftert bonum, quin cogitet, retinerefe fe anima minimè poteft: Minus ctiä ne quæ inquitere, reminifciuè propofuit, eousq́ue inquirat, dum inuenerit:

Præterea \& motus, quos vel bo no quopiã rerum fucceffu ex hilarata, vel malo triftata, aut ab imminente periculo perterrefacta, vel ob acceptam iniuriam, commiltumuè peccatum indignata, affecta omnino $x$ dit, quos, quia corporis eos immutationes côfequuntur, quix $\&$ in ipfús confilium, quòd latere velit, uel pufillam eam digeneremq́ue, \& uilem, aut furiofam interdum declarant, quæ magna generofaque, \& prudens fui eft natura, videri maximè appetit, maximeq́ue contendit, libentifsime non $x$ dat. Nam in letitia, iracundiaq́ue, \& verecundia propterea externas corporis partes calidiores fieri, rubicundioresq́ue, quòd fpiritus in eas efiufus fit omnis, fanguinemáq; fuppofitis arterijs,uenisḉ; inexifentem in eas egerit:in meltitia contra metuque, frigidas, pailidasque, quòd fpiritus ex ijs in internas recefferit, fanguinemq́a in eas egcrit, fuo fatis declarabitur loco. Qux certe in timore 


\section{Quod Ani.vniu.ab vnic.Ani.fubft.guber. I 6}

euenifit, propterea euenire, quòd fpiritus (vt dictum eft) nec verò naturalis, cognitionisq́; omnis expers, fed animalis, $\&$ ipfa omnino anima in internas recedat partes, vel ipfe teftatur Galenus. Pertimorem (inquit) fanguis, \& fpiritus fe $f e$ introrecipiunt, quò fit ut algeant partes in fuperficix pofitx,adeoq; interdum vehementer, ut non nulli rigore quoq́; corripiant:ur; tufsis itidem, \& fternutatio, rifusq́, nihilà voluntatis imperio pendent, fed in inuitis nobis, repugnantibusq́; fiunt, \& illas animx cùm propterea ( ut exiftimare licet ) afsignet Galenus, quòd moleftarum rerum expulfiones cùm fint, fentienti omnino, mobilique attribuendx funt fubltätia, Vtiq; \& rifus motus omnino quidem, \& ipfe cum fit, $\&$ ab anima $x$ ditus fentiente quid, intelligenteuè, anim $x$ \& ipfe ipfi itidem aísignandus elt Galen ; fe fe fcilicet conferuandi proindeque, \& oblectandi fummo cum fpiritus teneatur defiderio, \& fui ipfius cormpticnem, proindeque $\& 2$ dolorem fimmopere cum exhorreat:quin res, à quibus cofer uatur, proindeque, co uoluprate aficitur, in quirat, procuretque; \& quin aduenientes profpiciens, exhylaretur, \& præfentes, appofitafq; amplexecur, attrabatgue.nec quin à quibus moleltia fe affici, proindeq́; \& corrumpi fentit, odio cas habeat, \& accedentibus perterritus triftetur, nec quia quibus li cet perpetuò amoliatur modis, cohibere fe fe poteft, neluti neque nos homines quin adueniëtes ictus reijciamus, \& uel à quibus nihil feriri nos timemus, oculos occludamus. Quoniam igitur operationum, cux yel Galeno ipfi ab anima $x \mathrm{di}$ videntur, multas inuita interdum operatur, eafque fiftendi impotens elt: haud certe, que à uoluntatis imperio pende re non uidétur, non anim $x$ fed, uel qux cognitione quadam, \& quodam $x$ di uidentur motu, natur $x$ afsignandas decernit Galenus. 


\section{Bernardini Telefii}

Operationum, que naturales videntur $G$ aleno, multas anime afsignandas eßse, quod alio afsidue, atque alio, coǵsperpetuo aduntur modo, quo propofitum opus optimè conficitur. Cap. XIII.

VIN \& modus, ratioque, qua operationum
multx, qux naturales Galeno uidentur,con
ficiuntur, animales eas effe, manifeftè de-
clarat.
Natura (inquit Calenus) quod cogni"retur nulla edoceri poteft confuetudine. Rectè fanè;namqux

93 operandi modum rationemq́ue immutant, propterea immu rent, quod propofitum opus ut cöficiat, alia fibi operandum intelligunt ratione. Qux igitur in uentriculo cibos concoquit fubftantia naturalis ea uideri nó poteit. Q ioniam enim uel maxime alienos, maximeq́; contrarios cibos, \& qui nihil in principio exuperentur, quin qui moleftia fumma, fummo q́ue ventriculum afficiant malò, fxpius affumptos cöcoquit eos tandem, probumq́que agit in fuccum; utique operandi, có coquendiq; modum ea immutet, proindeq; cognitione, atq; electione operetur oportet : neq; enim propterea, ut Galeno placet, familiares tandem ventriculo illi fiunt, quod $\&$ ipfi in uentriculum agunt, \& ventriculum fibi ipfis fimilem reddüt; id enim ut agant, fibi tanciem, quò magis egerint, eò humanum in nutrimentum minus agantur. Pefsima certè qux uis uiuêdi ratio,cur in optimam fí repente mutetur,magno mutetur incommodo, quod fieri Galeno imprimis uidetur, nul la prorfus caufa afsignari queat, fi uentriculus à naturali regatur facultate, qua fcilicet nec operationem, nec operandi modum commutare no:uit, at nullo innotefcat labore, fi ab anima, à fentiente uidelicet, cognofcenteq́ue, \& eligente fub ftantia, \& quę proprias operationes,propriofq; motus immu tare queat, gubernetur. Experta nimirum anima ad cibi huius concoctionem, calorem hunc uel non fufficere, uel nimium effe, copiofior ipfa in uentriculum confuit, copiofioremq́ue 


\section{Quod Ani. vniu.ab vnic. Ani.fubft.guber. 17}

remq́ue adducit calorem, \& uehementius uafa commonet, uel languidius \& minor ipfa eft: \& ubi minore, \& diuturnio re opus eft calore, quali opus eft, co ubiq; utitur, nihiloquàm peritifsimus coquus minus:tandiuq́; concoquendi,operan randiq; ratione anima immutat, quousq́; modum inueniat, quo prauam uiuendi ratiouem corrigat, quæ fi repente mutetur, magno mutetur incommodo; ad diuerfas enim illas diuerfi motus, diuerfiq; operandi modi neceffarij funt. Pran dium fcilicet liberalius fumptum concoquere affuctus fpiritus, prandio affumpto, plurimus in uentriculum conuolat, ve hementiusq́; uafa commouet, omnes omnino rectè illud ut concoquat, uires affert, intenditq́;;, at non modica affumpta cœna, \& quä labore modico exuperare affuetus; fit copiof $f-$ fimus fortè per id temporis in iecinoris, reliquasq́; illapfus inuenas, ut cibos non pulcherrimè in uentriculo concottos in probum inuertat fanguinem;prauam hanc uiuendi rationem repente fi commutes multis magnisq́; commutes incō modis: nam \& modicum prandium à calore magno ( neque enim minor quàm folet confluat, aut languidius uafa agitabit fpiritus ) plus iufto concoquetur, minimeq; in chilum, fed crafsiorem agetur in rem : magnam contra conam non fatis exuperet, neq; enim copiofior quàm folet, ftatim accedet, negligens que per id temporis operari aflietus eft;repéte itaque immutata uiuendi ratio fummopere, paulatim ni hiloblrdit, nam modicum incommodum fubftinere licet, magnum non fic; imminutam nimirum ujuendi rationem fentiens fpiritus, paulatim \& ipfe motus, operan diq́, immutat modicum, poteft autem, \& fummè mobilis, \& fumma (ut dictum eft) cognitione, \& longe uarijs donatus organis, mi nime uerò \& naturalis fubtantia fupida, immobilisq́ue, \& organ is carens, fed idem femper, codem q; agit modo, \& mo tus $x$ dendi potens fi fit, ijfdem perpetuo commoueatur mo tibus. Nam (quod dictum eft) ubi quod propofitú eft opus, cxpto motu abfolui non potet, alijs id ipfum moliri, \& in morborum crifibus, pręterea \&r in cãtibus manifefte intueri licet; manifefte enim in illis qux moleftiam inferunt, uarijs modis, uarijfq; amoliri tentar uijs, prudentifsimi Imperatoris ritu, qui ubi inftituto aliquo modo hoftes profligare non poteft, alia, atquè alia id tentat ratione; $\&$ in his ubi qua lis ædendus eft fonus, $æ$ di non uidetur, manifeftè mufculos 


\section{Bernardini Telefij}

ad uocë efformandä paratos mille cômouet modis,nec alijs, ató; alijs commouere ceflat unquã, donec \& moueat, quo, qualis propofitis eft, $x$ datur fomnus. Q oniam igitur opera tiones, quafcumque fere operatur animal, pafsim uariari, af fidueque tales $x \mathrm{~d} i$, quales pręfens pofsit vfus, videntur, haud quaquàm naturali facultàti, fed fpiritus omnino, \& ipfius om nino uniuerfitati. neque enim quæ laringis fibris, mufculifg; ineft portio, fonos percipit .

\section{Praterea of quod organorim funt minifterio. Cap. XIIII.}

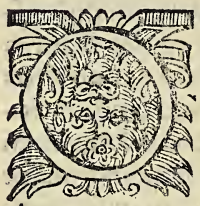

RGANA praterea, quorum minifterio qux in animali fiunt, operationes fiunt omnes, fatis Galeno declarare poterant ab anima eas $x$ di omnes.nam qua neraoram (qui animx facultatú uehicula uifi Galeno funt) minifterio non fiunt, fibrarum funt minifte rio,qux nernorum ueluti propagines, portionefque, \& neruo rum ritu partibus, quibus immifcentur, fenticn di,fefeq́ue có mouendi facultatem afferre vifix funt : \& quæ uel fi à neruis produci vifx non forent, animx tamen organa Galeno poné $\mathrm{d} x$ forent, vi fcera ijs, uafaq́ue omnia, \& longè quidem varijs intertexta, earım que hác minifterio attrahere, retinereque, tum \& expellere oinnium optimè intuito, \& nequaguàm temere, eodemq́ue femper operantibus modò, fed eorum unis interdum, reliquis quiefcentibus omnibus, pluribus uerò interdum, interduin verò \& omnibus fimul, \& iuxta prafentem perpetuo ufum: Itaque quoniam (vt dictum eft) qux in animali operationes, \& qui motus neruorum ope ra non fiunt, fibrarum ofera fiŭt,\& fibræ nihil quan nerui mi nus à fubftantia gubernari uidentur fumma pradita cognitione, utique animalis operationes, motifque omnes, ani$m x$ afsignandos effe liquido fatet: $\&$ ucl $u$ na hac ratione ani mal uniuerfum ab unica animæ fubftantia gubernari, fatis declaratum uideri poffet : at magis id ut manifeftum, \& res omnino uniuerfa magis in aperto ut ponatur, vifcerum, uaforumq́ue aliquorum operationes, motusq́; , \& modum, quo operantur, infpicere ne grauemur. 


\section{Quod Ani.vniu. ab vnic.Ani.fubft.guber. 18}

Pentriculi appetentiam omnem attratsionem, alterationem, \& expulfionem non naturalibus facultatibus, fed anime afsignandas eße. Cap. XV.

SO ELIQVAE quidem uentriculi facultates, (I) operationesq́ite naturales Galeno uidentur

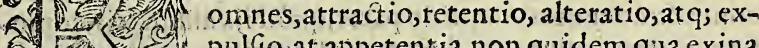
3. pulfo; at appetentia,non quidem qua exina nitus \& ipfe, ut ven nia repleri appetit, itaguie \& attrahit, hanc fis quidem nat rralem in omnibus enuntiat Galenus, fi qux fu-m etonis ferfun infequi udetar, animalis omnino uidetur; qux nimir am fenfam fequitur, ab ipfa feilicet admonita tan dem coactaq́ le re. Primum (inquit) Symptoma inanitio ett," fecundum inanitarum partium naturalis appetentià, hanc fe. quitur peruenas, qux in uentriculum porriguntur, factio;pofremo animalis appetentia omnitm ultimá; fi proptetea appetentia ultima animalis uidetur Galeno, quo fuctionis feguitur fenfum prima itidem animalis uideri debuit, qua nimirum fenfun \& ipfa fequitur : neque enim fuctionis magis quàm inanitionis, ant uifcerum modo parsionum fenfus anima eft omnis, fed pasfionum omnium fenfus $\approx$ què eit animę omnis, \& fpiritus omnino, qui (ut diCum eit) uafis, eorumqú inexiftens fibris, ubi fcuros, quib is maximè oblectatur fuppofitis uaforum partibus non ineffe, contiguis, reliquisq́x we eos, attrahit, \& eijcit etiam, rbi ab eorú prauitate obladi, ucl à nimia copia comprimife fentit. tum modam, quo attractio fiat nos edocensiGalenus, ," ab anima eum fieri pulcherrime declarat. Ventriculus ( in quit ) morfu ftimulatus, cibos appetit, ad eosq́ue excipien-", dos attrahend ofque ad os fertur, adeoque interdum anidè, ", \& impetu tanto, ut penè in os yoracium animalium uenter ", omnis confluat, exceptos rectis, tranfuerfisqúu cefophagi ifis bris attrahit ; Recte fanè. Animx igitur opus attraçio, qux fcilicet mouentis opera, \& in fentientis, appetétifque firgra tiam. Q in \& alteratio, concocioque, nel fi non ab uno ipfius uentric slo, arterijsque $\&$ uenis ei intertext is inhabitantis,

E 2 fed 
fed à fanguinis infuper illis inexiftentis, proximorüq́ ; tuifces rum conficitur calore, non propterea ucl ventricalit, uel dieta rum reram natura, fed ipfius ontino fpiritus opus ponenda eft:nam \& qux artifices cum organorum aliorum, tum ignis ope conficiut opera,non organorum, fed ip fortum opera funt artifcmm : neque:enin res tantum, que concoquenda funt in uentriculum confert fpiritus, fed proprijs etiam eas tiribus, \& vehementiore arteriatum, venarumg; motu magna ex parte conco quit. Ex fpiritui ornnino demandatam efie ciborum concoctionem inde liquido patet, quòd ijs aftumptis, copiofior in tentricuitum confluit,copiofioremq́tue perpetuò adda cit fanguinem, 2 arterias trehementius commouet; $\&$ vbi val de imminutus eft uifcertum calor, itaque nifi amplius fuperveniat auxilitu, non fatis cibi concoquantur;longè illa omnia fpiritus operatur amplius, maior feilicet eius copia exter nis è partibus in uentricultrm illabitur, maioremóue fanguinis portionem fectumin illum agit, \& vehementius intertextas arterias, thenasqúue commouet, itaque albent illa', fritgentque, \& pulfas ieehementiores fiunt: ptatereà \& quòd vbi poft afitimptos cibos, intentè quid cogitamas, uel paulo vehementiores'xdimus motus, ubi fcilicet à uentriculo aúoca tur fpiritus, cibi-minus belle concoquuntur. Expulfionem po fireniò \&' ipfam; non naturx fed anima, non ftupidx nimirü, torpidẹ́que, fed fentientis, mobilisq́ue fubftantia effe optss, iffe itidem pulcherriniè nos docêt Galenús.fi quid (ip fe in quit (Galen:ts) prater naturam, \& moleftũ in afperis arterijs,

" uel in naribus fentitur,ad id expellêdum infurgitianima, nec nifr eijciat, ceffat unquam; cur enim non \& qua uentriculum " molettia afficiunt, ab anima \& $\mathrm{ipfa}$, fed a natura eijcienda funt? cum prafertim non ut arterix, naresq́ue minttifsimis tantum fibris exiguaù nerui portione, exili nimirum fentie di facultate, fe $d$ infignibus neruis, fentiendiq́ue ui longè $c x-$ quifitifsima vētrinculns donatus fit. grauifsima igitur Symptomata cordis morfis difficilis, atq; abolita refpiratio, epi lepfia, atque infania, \& animzo omnino deliquia ê uentriculi afectionibus enenire folent, \& fibrarum minifterio cum eifciat, expellatque: Quin \& fingultus, qui ibi fit, ubi c̀ úentriculi corpore crafus eijciendus eft flatus, $\mathrm{ab}$ anima itidem fit: itaque horribili quopiam confpecio, aat etiam immaginato ftatim is ceffat, fpiritu fcilicet, \& igfa omnino uniuerfitate 


\section{Quod Ani.vni.ab vnic.Ani.fubft.guber. Is}

maius ad malum uitandum, maioremque ad operationem opefandani conuerfa.

Veficam non a naturali facultate, fed ab anima gubernari Galeño exiflimandum fuiffe, \& à Spiritus

omnino uniuerfitate gubernari. Cap. $X V I$.

G1 ON IN AEquoque excretionem ipfi in primis 19 Galeno non a naturali facultate, $\mathrm{fed}$ ab ani(1) 3 (5) mà omnino fieri intelligendú fuit.Ne conti I.ib. 5. de viu part. 10. 1 15 nua (inquit ipfe) fat urinæ excretio fibra- " (10 20 rumipfius vieficę varietas præftat obliqua- " 1. (1) rum pręcipuè,cùm enim omnes intendit,vn " dique circa ea, qux continet vehementer aftringitur, donec " fupra modum referta,grauetur pondere. vibi uero excretioni $\%$ accingitur, cęteras quidem fibras laxat, folas autem intendit ", tranfuerfas. Et mufculi excrementi vefica fupfetias ferunt, is , quidem, qui ad meatum urinarum eft ipfius principium, quo ; ueficx annectitur, laxans: tenfi verò omnes abdominis mu- , fculi,ut intropropellant, ueficam \& comprimant: côtractuf- ," que poftremo undiq; ille idem, qui circa collum eft, premếque foras id locij; quod in meatum fubierit, atque ipfam denique excretionem accelerans :. Vefsic $x$ nimirum fibris, \& mufculis uefsicam contingentibus inexiftens fpiritus, $\mathrm{vbi}$ uel ab vrinx acrimonia mordetur, vel ab onere grauatur eijcere eam agreditur; primum itaque mufculım; quo aeficę os clauferat, relaxat; tum \& reliquas etiam fibras, quibus omnibus intenfis uelut in orbem coacta, \& occlufa undiq; urinam retinebat, folasquue intendit tranfuerfass; fibras uidelicet, qui bus ueficam ueluti in orbem cogebat rimittens, folucnsq́; in longum eam extendit, \& tranfiuerfas fortius intendens, cö ftringesq́ue, \& ita in anguftum eam agés abdominifque mufculis intro propellês nullum omnino urinæ relinquens locú, eam uniuerfam exprimit, \& mufculum poftremo, qui circa ue ficr collú eft, côtrahens, comprimenfq; quod urinę in m eatu fubeft, expellit omne, unituerfamque accelerat excretionem. Adeò uarium, multiplexque excernendę urinx opus, ad eo concinne; \& fibrarum, mufculorum que opera,ac minifte- 


\section{Bcrnardini Telefij}

rio æditum uniuerfum nequaquàm à multis, ij fque naturalibus, fenfus nimirum, cognitionifq; expertibus facultatibus, fed ab una omnino, eademque $x$ datur fubitantia oportet, $\&$ qux fenfu funmo, fummaq́ue prędita fit cognitione, 8 mufcul is fibrifque inexiftat omnibus, \& has, ut libet intendendi,remittendique, $\&$ illos relaxandi contrahendique potens fit;à fpiritı nimirum:nec verò à fingulis ipfrus portionibus proprio arbitrio, fed iuxta uniuerfitatis operantibus imperium, \& ab ipfa omnino commotis uniuerfitate. neque enim fi qux adeò diuerfis, adeoque à fe ipfis diftinctis rebus fpiritus infunt portiones, nỏ ab uniuerfitatis imperio pendeant, $\&$ non ipfa omnino moueantur ab uniuerfitate, fed à fe ipfis fingulx, \& proprio operentur arbitrio, quin opus, quod tam varia fingularum operatione, \& fimul ab omnibus ędita con ficiendum eft,rectè confici queat, intelligere licet.

\section{Preterea ópudendum. Cap. $X V I I$.}

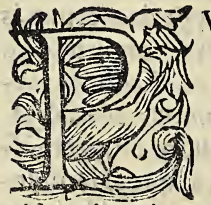

VDENDV M quoque (liceat enim quando huc delati fumus)\& pudendum non ut re liqux corporis partes, idem perpetuò fpecta tur,fed vbi ad opus, quod in ipfo xdendum eft; qux ipfum gubernat animæ portio inftruit,adeo immutatur,taleç; fit, ut non pre xittentis animãtis pars, fed veluti aliud animal fe:i, Ariftote li appareat, \& operationé quę in eo ędenda eft, oper ãs, \& abfoluens, præcipuè voluptate aliarum omnium, quibus alijs in partibus, alijsq́ue in operationibus longe maxima; $\&$ tanta afficitur, ut reliquis corpore is partibus derelictis, confluat uniuerfa, vniuerfa fimul,vt ea fruatur, itaque reliquis in par: tibus fummopere läguet. Quod omnino fubtātia, qux fingu las corporis partes gubernat, maximè infignes, maximèque manifeftas in pudendo edit operationes,proindeq; in eo pre cipuè manifeftam illã fieri, rationi congruum eft . fi in eo ipfam quàm diligentifsimè intueamur incufandi non fumus, nam fi diligens eius infpectio, \& prolixus de co fermo ingernuo uiro turpis eit; non certe \& philofopho fub?tantiam, cui fingularum corroris partium operationes renm afsignande fint, inquirenti, exponentiq; turpem eum effe exifimamas. ipfum inquam, pudendum, non à iecinoris natura,à qua gu-

bernand:um 


\section{Quod Ani.vniu.ab vnic. Ani.fubft.guber. 20}

betnandum Galeno eféneculla prorfus à natutali facultate, fed à fịiritis quidem portionibus, uafis, quę pudendü fúbetine, infidentibus, at non propriò fed uniuerfitatis arbitrio, \& ab uniueritate commotis gubernari,liquido patet. Quoniam en im uel omnitum confenfa, uel ipfius penè fenfus teftimoiro, farg !nis, fiatusq́ 1e infuxu intumefcit, attolliturque, ad provtium nimiram opus accingitur, \& à folo murlieris confpect $q u i n$ à fola venereotum imaginatione, à rebus nimirum atcollitur, qux uec natiram ullam, ullamuè naturalem facultatem habent, nec ipfas etiam fpiritus portiones pudendo eiufque uafis inexiitentes, fed ipfam modò mo uere queant uniuerfitatem, utique portionum quidem opera, at non proprio, fed uniuerfitatis operantibus arbitrio, \& ab ipfa omnino commotis uniuerfitate, pudendum ad proprium exercendam opıs parari,liquidò patet. Quoniä enim (ut in ijfdem expofitim eft commentarijs) ut portiones ab ijs qux unizerfitas fentit intelligitur ad motus, qui corum gratia $æ$ dendi funt, aguntur, cos omnino ut $x$ dant motus, qios $x$ dendos vniuerfitas decernit, $\mathrm{vel}$ ab ipfa commouendę fant uniuerfitate, uel eorum quux ipfa fentit, inteiligitque fenfis ipfis intellectioque communicanda, \& peritia infiperholuntafq; illos ædendi, uidenda, \& qui vniuerfitatis decreta portionibus innotefcant, motuumq; $x$ dendorum peritia, voluntafq; ijs indatur, lögè æger rimè imaginari licet;atqui quibus uniuerfitas mouetur, ijfdem \& contingux moueantur portiones in commota aqux, aerifque porione quä tulauis apertifsimè intueri licet, quæ fcilicet non precedentem in aeris portionem, quam ipfa contingit impellit, ijfdecque, quibus ipfam monetur, cōmouret motibus, fed quę huic veluti à latere, \& qux his veluti à tergo funt quòd fingula ne contiguarum contactu priuentur, veluti fugienter eas, codêque, quo fugiunt confectantur motu. Vtique quos uninerita tis arbitrio portiones $x$ dunt motus, ab illa ijs moueri exiftimandum omnino eft . cur enim fi tantula aeris portio circuifluum aerem quibus ipfa mouetur, nullo temporis momento commouet omnibus, \& languidiores ij quidem afsicha fiunt: at nunquàm certè immutantur, vt foni, qui uel omniü confenfu motus funt aeri inditi, \& ad animam vfque delati , animxq; ipfi inditi declarant omnes : cur \& contiguas vniuerfitatis portiones ijfdem, quibus ipfa mouetur moti- 


\section{BernardiniTelefij}

bus commoueri exiftimare non liceat ? cum prxfertim fpiri tus longè quàm aer tenuior, longeque ad motum promptior fit, $\&$ qui ab vniuerfitate commouend us eft, in ang ultifsimo \& à bene renitentibus ob fapto rebus coerceatur loco.itaq; nequaquàm, quod aeri licet, quò uniuerfitatis impulfum declinet, veluti in latera moueri, proindeq́ te à feipfo feparari queat, quod ubi fit motus itidem ueluti difsipatur, non idé omnino permanet, \& ut unde digrefsi fumus redeamus, non ibi tantum portiones uenis arterijfque, qux pudendum, fubeunt infidentes in pudendum uniuerfitas impellit ubi ipfa uenerea imaginat ur, uenereaque appetit, fed uel vbi à uaporibus opprefla, eorumq; concoctioni tota intenta, nihil fenti re,nihilq; imaginari videtur, \& ubi omnino propterea pudé dum ad excernendum femen infurgere uidetur, quod fpiritus feminarijs vafis, teftibufq; \& altitibus inexiffês, à nimia illius copia opprefsus, vel ab acrimonia ftimulatus, fummopere illud excerni appetit . non fi quidem fanguinem is, flatumq; in pudendum agit, fed qui venis arterij $\mathrm{fq}$; infidet, \& illius huic moleftia, appetitufq; ut innotefcat tandem, prius omnino uniuerfitati, à qua uterq; tueluti à communi principio derituat, communicetur oportet, \& ab ea portionibus indatur, à quibus fanguis in pudendum agendus eft.Ipfis porrò à fpiritus portionibus, quarum opera manifeftè intumefcit pudendum, à fe ipfis operantibus id gubernari, exiftima re cum non liceat, quam lógifsime abeft, ut a iecinoris natu $\mathrm{ra}, 8 \mathrm{c}$ facultate $a \mathrm{~b}$ ea emanãte, id tumefieri exiftimare liceaț. cui nimirum fentiens, imaginanfq; fubftantia, cuius motu manifeftè gubernatur, nec cognitionem ullam, nec ullam prorfus vafa commouendi facultatem indere poteft. feminis itidem emisfio nalla bruta, immobiliq; à natura, fed à bene fentiente, beneq; mobili fubriantia, \& à fpiritu omnino uafis inclufo, in quibus continetur, \& per qua effuit femen, infidente, \& conftringẽdi ea potente, pudendum gubernari manifeftifsimè declarat : neq; enim bene uifcofum, beneq; corpulentum femé cum fit, à rebus in quibus continețur effluat, erectumq; in pudendum afcendat, \& ex en effluens, bene in . longum, \& fublime etiam efferatur, nifi \& ipfum eadem, qua fanguis ratione è uafis $\mathrm{ab}$ inexiftente fpirituconftrictis ex* primatur, eijciaturq;, tanta porrò eijciturui: ut, qued dién eft, bene in longum, furfumq́; efferatur, quòd noluptate qua fpiritus 


\section{Quod Ani.vniu. ab vnic.Ani.fubft.guber. 2 I}

Ipiritus uafis, per qux effuit, infidens, afficitur, reliqux porziones, \& ipfa etiam uniuerfitas boni appetēs eadem in uafa confluit omnis, \& proximiu's ab illa contingi appetens, \& ue luti fugiens illud infectans valentifsimz, libens intendit. proindeq; \& $\nabla$ afa conit tingit, ijfq; inexiltens eiaculatur femen, \& partes interea reliqux fenfus motufq; auctore deltizutæ, ueluti demortux apparent.

\section{spfum itidem cor, atque arterias, \& has, earum gi, \& cor. dis fibras, ligamentaǵs à cerebro dedudci Galeno vifasfuiffe. Cap. XVIII.}

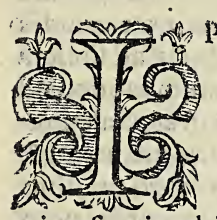

PSVM itidem cor,arteriaq́ue, \& fibra,ligamentaque, à quibus ill $: d, \ll$ hæ dilatari, con Atrigique uidentur, manifelte non à cordis tcmperie, facultateque in co delitefcente, ex eoque in illa effufa, fed à fpiritus portionibus illorum fingulis infidentibus, \& rniuerfitatis arbitrio dilatātur,\& manifeftè arterix, earumque $\&$ cord is fibrę non à corde, fed à cerebro deriuât. \& fum mopere Galenum mirari licet, qui vtrumque intuitus non fit.cordis (inqnit Galenus) Caro eit dura, $\&$ agrè patibilis, Levfu parmultiplicibufque fibris confiata, quo nomine à mufculo dif- c.8. fert, fi quidem mu fculis unum modo ineft fibrarum genus, , rectarum fcilicct, aut tranfierfarum; utrafque autcm cor, \& " pręter eas etiam obliquas fortitur, duritie, contentione, \& $\mathrm{pa}$ " tiendi difficultate plurimum ab alijs ommibus difierentes," ob actionis continuitatem, \& vehementiam, inqua femper " cor ipfum uerfacur:porto finguli mufculi, fingulos habent ac" fimplicet motus, $\&$ ob id multiplici fibrarum uarietate non ", égent, quemadmodum cor, vétriculus, matrix, \& uefica utra- " que quippe horum fingula rectis quidem fibris attrahunt, ", externunt trafuerfis, retinent auten fimul omnibus coope- " rantibus;quorum omnium actiones in corde ipfo, vel iam " iam ab animali reunlfo ac pulfante adhuc, vel detecto peran " teriorem regionem pectoris contemplari licebit. Nam cum " rectis fanè fibris contrahentibus fe, reliquis autem deductis, " \& laxis contractior fanè fuerit facta longitudo, laxior ucrò ." unjuerfa ipfus latitudo, hoc ftatim videbis cor totú dilata-" 


\section{BernardiniTelefij}

9

)

tum omne fibrarum genus habuit cor, ut facile dilatetur quả do quod nature fuę accómodatum eft, trahere appetita; frin gitur uero undique quando ijs, quæ traxerit frui tempeftiuú fuerit: contrahitur denique quando fuperfuis excernendis accingitur;arterijs fingulis fibrx à neruis diductx ad focieta tem coherent per quas fit mutuus non actionum modo, fed affectum confenfus; Nunquam igitur fat is mirari Galenum queas, qui cum arterias fibrafque omnes, ex femine, ueluti $\&$ cerebrum, neruofque conftitutas efle; \& a cerebro omnino diduci, \& cor earú opera dilatari,conftringique; cordis uero carnem ueluti, \& iecinoris è fanguine conftitutam, \& quam longifsime $a b$ arteriarum, fibrarumque natura difsidentem, fenfufque per fe, \& motus pulcherrimè in tueretur, enútiaretque;arterias tamen à corde produci contendat, \& cordis, arteriarumque motum, \& cordis ipfus temperiei, non eidem fubfantiæ feu facultati afsignat, cui particularum aliarum omnium, mufculorumq; motus, neruorum, fibrarumque ope ra æditus, af signandus uifus ei eft, fubftantięnimirum, feu fa cultati à cerebro em ananti.

Qiòd igitur dictum eft, fimmopere mirari Galenum licet, qui cornon à fe ipfo, fed à fibris ligamentifque, ipfi quidem intertextis rebus, aut quę nullam ipfi, fed fummam cere bro cognitionem tribuat, \& quæ non fimul omnes nec codem mouentur motu, at ibi omnino.fingulx itaque mouentur ubi, \& uti, quod conficiëdam eft opus, rectè cófici queat, moueri fingulis oporteat:ita omnino, ut unum, eundemque omnes fcopum habere uel ab una omnes, eademque moueri fubstantia exiftimandum omnino fit; pulcherrime intuitus cum fit earum motus, non fubltantix in cerebro refidenti, cui fentiendi, incolligendiggue, \& motus $x$ dendi facultatem inefle 


\section{Quod Ani.vniu.ab vnic. Ani.fubft.guber. 22}

ineffe confpexerat, fed brutæ, torpidęque cordis naturx attri buat.qui inquam fpiritum in cerebri uentriculis contineri, \& ex ijs in oculos, \& ex ijs foras ad res quafuis intuendas exilire, \& ex oculorum altero in alterum nullo temporis cōuolare momento, \& in finalis medulle meatum copiofifsimum influere ob uehementem ( $u$ t ipfe inquit) uirtutis diftributionem, ut fcilicet neruis, qui longè plurimi ex illa exo riuntur fentiendi, motufque redédi uim indat:ipfe nimirum in omnes illapfus eorum omnium, partiumq́ue, quibus infixi funt pafsiones fentiat.\& quibus commouendx ex funt, ijs ipfe commotus commoueat motibus.nam nifi id fiat, quam fpiritus ijs uirtutem infundere queat, à quo nihil ipforū natura difpofitioq; cum immutetur, è ftupidis, immobilibufq; fentientes fiant, mobilefq;. Et qui digito, cui iamdiu fentié di mouendiq; facultas penitus, \& propterea omnino adēpta fuerat,, ei f pinalis medulla portioni, è qua qui illă apporta bat neruus exoritur, humore illita. proindeq; nerui poro obftructo nullus fpirituié, eũ fubeúdi patebat aditus, medicamen to, à quo humor in fatum ageretur ibi appofito, ftatim digi to illă reftituit.Hæc inquã intuitus operatufq; Calenus cum fit,fummopere mirari licet cordis arteriarúq; fibras, \& illius ligamêta nô à fingulis inexiftéte fpiritus portione, \& omnibus uninerfitat is arbitrio operātibus intếdi, remittiq;,proin deque cor arteriafque ab ea dilatari, conftringique intuitum non fuiffe. Qưin fí nullus è cerebri uentriculis tullú in neruú fpiritus influere itaq; neque ijs inefle uifus Galeno foret. fen fum omnê omnéć,; qui quauis in corporis parte fit motus, re tum præfentia è cerebro emanătium, \& quæ, eadernque, qua cerebrü natura donatæ funt, fieri intuito, \& à fubftantia omnino in cerebro inhabitante partium fingularum communicari, earumque omnitum iudicium, \& intellectionem omnino omnem in illo fieri intelligenti, utique fubftantia huiufmodi vétriculis indenda, \& ex ijs in res, qux cerebro cogna$t x$, \& fentiendi, motufque $x$ dendi facultate donatæ funt, effundenda Galeno erat . neque enim quos illx, \& arterix prxfertim earumque, $\&$ cordis fibræ ligamentaque, $x$ dunt motus,ipfarum, cordifgue, \& minus etiain facultati ab eo emananti attribuere licet.fi quidem ( ut in ij fdem expofitum eft commentarijs ) c̀ quatuor naturis, è quibus fibi ipfis commiftis antiquioribus omnibus, \&x ipfiumprimis Galeno on-

$$
\text { F } 2 \text { nia }
$$




\section{Bernardini Telefii}

nia conflitui uifa funt;motus uni tẩtum calori tribui poteft, $\&$ is non cuiuis inexiftenti fubiecto, fed ei modò, quod in fummam ipfe egerit tenuitatem, quod fcilicet adeo leue fece rit, vt nullo fecum euehat labore, moueri uidetur, minus tenui inditus rei vel fummus fi fit, quòd eius oneri impareft, veluti torpet.id verò vel ipfis intueri licet in flammis, quẹ fci licet dum non in eam actx funt tenuitatum, fi nulli firmo inhreant, ad terram dilabuntur omnes, tandiuque ibi iacent, dum longè leuifsimas, proindeq́ue $\&$ inuiles inexiftens fecerit calor; tum fecum eas efferat. neque enim qux perire uidenturflammx, in non ens agi; Sed quod dictum eft, pati, operariq; exiftimandum omnino eft. Itaque ac flammas qui dem, priufquam adeò tenues fiant, vt vifum omnem lateant, ab inexiftente calore attolli pofie intuito Galeno: \& nequaquam frigori, humiditatique, \& ficcitati, naturis nimirum commintis penitus immobilibus, ad motus $x$ dendos, oneraque attollendi robuftiorem fieri exiftimare cum liceret, vtique, quod dictú eft, calidifsima,tenuifsimaq; quæpiã fubftātia fibris, ligamétifq; Galeno indenda fuit, à qua quibus afsi duè moueri uidetur, mouerentur motibus; vel fi arteria à cor de ad cerebrum fublata funiculo alligata, fuperior eius pars, quę à corde veluti feiuncta eft, nō amplius pulfat, nã non perperam quidem, propterea non amplius illam pulfare Galeno vifum eft. quòd rei cuipiam inde aduenienti, a qua pulfus fiat, prxclufa eft via . at verò quia quæ à corde ad cerebrum afcendunt arterix, non omnes cerebri ventriculos attingunt, $v t$ ijs inexiftentem fpiritum ex illis primò ill apfum fuife exi ftimandum fit.\& non ipfo à corde, fed alijs ex arterijs quæ à cerebro, ijsq́ue ipfius ad natx funt partibus, qux ventriculis proximiores fortè funt, uel inquas è vent riculis aditus fpiritui patet. non magis arteriarum pulfationem ceflare, quòd $f_{2}$ cultati à corde emananti, quam quòd motui, qui ab v niuerfi tate in cerebriventriculis refidente porticnibus art $\epsilon$ rias pul fantibus uidetur, præclufa eft via. Quin ff ff iritus arterijs inexiltens fponte fua eas attollat, à propria vniter fitate fuperatus pulfare omnino ceffet quòd ab ea feiunctus fu mopere turbatur, fummopereque perterre fit. itaque veluti torpidus fit. Tum, vt detur Galeno,arterix partc $m$ à corde feiunctam propterea non amplius pulfare, quod rei cuipiam à corde aduenienti, qux vt pulfaret, præftabat, aditus obftructusfit, non propterea 
propterea à facultate à corde ijs indita, eas expandi exiftims re licuit Galeno:nam neque peritus incorporę rei in arteria quã fubibat modicum quid conftrictã nō pateat aditus, verè arteriarú molē ab illa attolli pofle intelligere licet.Itaq; fi qă̌ rei cuipiam à corde in arterias infuenti praclufa via pullatio ceffat, \& fangais modo res alia nulia protf $u$, à corde in eas influit exiftimare forte liceat, propterea arterias afsiduè $a b$ inexiftente fpiritu amplificari, quòd à nouo, qui afsiduè in eas illabitur, fanguine, afsidue comprimitur fpiritus;molettia nimirum afficitur, itaque eam vt declinet arteriam in amplius expandit, proindeq; vi billud non fit, neque ipfe eas expandit amplius. Minus etiam quòd arteria in corde, \& ve$n x$ in iecinore longè amplifsime fuectantur, à zorde lllas, \& has à iecinore exoriri fatiendum Galeno fuit. quid nifi utræque inde enafcantur, vbi maximx funt, nec planta ratio, nec naturx feruetur ordo: non fi quidem ( $v t$ in ijfdem amplius declaratum elt commentarijs ) nequaquam riuorum, qui è communi quapiam aquæ vniucrfitate effluunt, ramorum ve ritu, qui è communi enafcuntur trunco, quos fi nô eò afsi duè minores, quò longius à communi recedunt principio, at nufquam certè ampliores fieri rationi congruum eft. Sic \& vena arteriaque, ¿ res aliz, qure è femine fiunt, vel fi ce rebro portiones reliqux omnes annexx funt, eiufque moles ita fingulas excedat, vt veluti communis omnium uniuerfitas, eo veluti omnium parens principiumque videri pofsit, nequaquam è conftituto iā illo effluxife, fed \& ipfum, $\alpha$ illas omnes è femine in vterum coniecto, ab eog; uniuerfo fimal \& compreffo, \& liquefacto, proptereaque in diuerfas diffufo partes, fimul omnes conftitutas effe, prouideque ibi fingulas maiores fieri potuiffe \& factas omnino effe, vbi maiores fieri oportuit exiftimandum omnino eft. Minus etiam, propterea non aliarum corporis partium ritu ab anina in cerebro in ha bitante, indeque in cordis tunicam, fibrasgule illap fa, fed a propria ipfius natura dilatari, conitringique ponendum Gale no fuit. quòd cercbro oblafo reliqux corporis partes (fi quidem reliquis id euenit omnibus) fenfu motuque deftituuntur, at cor arterix que moueri non ceffant; nam ( $v$ talibi dictum eft) quoniam cordis, proindeque eius tunicx fibrarumque praterea, \& arteriarum dilatátio, conftrictio, qux fummo pere ad vitæ conferuationem neceffaria eft; itaque prouidendum 


\section{Bernardini Telefij}

dendum fuit, ne fi quando incommodo quopiam detenta uniuerfitas nouum in illas fpiritum immittere, motumque prx inexiftenti indere non poffet; non propterea is illas dilatandi, conitringendiq; impotens êfét. longè illis copiofior, quam reliqnis in vafis inditus eft fpiritus, \& quantus wihil amplius ab vinierfitate auctus commotus uè à fe ipfo aliquandiu qux amoliènda, \& qux amplexanda, \& qui omnino motus $æ$ dendi ei funt, $x$ dere poffet, $\&$ ne breui deficeret, è rebus, quibus ineft elapfus, carnofiores ex fact $x$ funt denfioresque. \& forte ea cerebri offenfione, non adeò turbata eft vniuerfitas, vt earum etiam ipfius Portionum, quibus pracipuum demandatum eft munus, obliuio eam coeperit. At vnde digrefsi fumus redeamus, \& qux amplius cor ab anima in cerebro refidente gubernari Galeno declarare poterant, explicentur.

\section{Que amplius ab anima in cerebro cor gubernari Galeno declarare poterant. Cap. $\quad x I X$.}

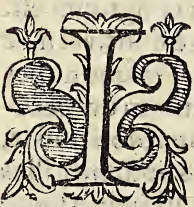

NDE etiam patcrc Galeno poterat âbani$\mathrm{ma}$ in cerebro refidente dilatari, cónffing $\mathrm{i}-$ que cor, quod corde nithil aftecto, at cerebro tantum, maxima fit in pulfibus alteratio, \& deficere etian vidêtur interdum:nă Galeno hoc differre ab animalibus natufalia organa uidentur; quod ijs cognata actionis uis infit; animalibus verò à principio, veluti lumen à fole, ipfa defluat, quare folis " (inquit) partibus, qux fentiéndi \& fefe mouendi vim habet " (qua fcilicet ab anima omnes regi videntur Galeno) accidit "vtipfis, nequaquam interdum affectis, eorim nihilominus " actio exoluatur, id quod naturalibus minime euenire folet.

" Quoties enin harum actio lx ditur, ip fa fanè primô afficiuntur. in apoplexia igitur deficere vifus cord is motus, animę at tribuendus omnino erat: $\&$ inde etiam amplius, quod maximè ad vitx conferuationem neceflaria pulfatio, 8 mille afsidne modis varianda cum fit:ijfque ufque quaque quibus varianda eft, cùm varietur mo dis, nequa qua in brutex eam fưbftantix demandatam fuiffe exiftimandum fuit. Fure (inquit " Galenus ) refpiratio animx demandata eft, fubftantix nimirum, 


\section{Quod Ani.vniu.ab vnic.Ani.fubrt.guber. 24}

rum, fummè cognofcenti, fummèque vigilanti;quippe qua,fi ,, paulul um priuetur animal, aut non ita refpiret, ut vfus poftu- ," lat, intereat illico : itaq; neque in fom is ceflat ab opere hoc", anima tanquam maximè neceflario, neque alia re occupata " vlla muneris huius obliuifcitur, quod fi ipfa vel maxima co- ," gitatione impedita vel perturbata, \& veluti morbo corrupta, ", vt in delirio, paululum id pretermiferit; fatim maiore cona- ", tu aggreditur, quod intermifsione eft deperditum, refpiratio " nis magnitudine refarcire fudens, adeo operation intenta," ent, fine qua perdurare animal nullum temporis fpatium pof-, fet.Rectè fanè omnia, \& pulfandi igitur munus fubftantię om nino demandatum fit oportet fummo fenfu, fummaque præditx cognitione, \& fumme vigilanti, mobilique nihilo quam refpiratio eft ad animalis vitam conferuandam minus neceffarium, \& in quo eden do nec cognitione, nec folicitudine opus fit minore, quod nimirum fi paululum quod intermitta tur, illico vel ipfius Galeni teftimonio intereat animal, quippe quod naturalem Galeno uitalemque calorem proximius etiam, quam refpiratio ventilat, refrigeratóue, $\&$ fuligines in fuper explodit, à quibus fuffocetur vitalis calor, \& ipfum denique generat animalem fpiritum. Itaque neque in fummis intermittitur, \& quin afsidux id $x$ dat, re nulla impedire poteft, qux pulfat fubfantia: quod fi quádo uel timore, uel mor bo aliquo impedita, corruptaque paulatim quid ceffat, aut nó ita valenter, vt,y fus poftulat, pulfare queat : fi quidem magnitudine, quod intermifsione deperditum elt, refarcire non po teft, celeritate, \& frequentia fupplet : vt in inflammationum pulfibus, alij fque multis uidere eft nihil etiam minus concin ne, minufque ad prefentem vium comode quam refpiratio, pulfatio $x$ di, milleque $\&$ ipfa (vt dictum eft) variariuidetur modis, \& ijs femper, quos præfens ufus poftulat: Galeno hæc fupra alios nota omnes, pulfandi munus nihil minus quam re fpirandianimæ commiflum effe demonftrare poterant. 


\section{Bernardini Telefij}

\section{Vel difcrimina, qua inter refpirationem, pulfationem go effe caleno videntur, pulfationem ab anima feri declarare. Cap. $X X$.}

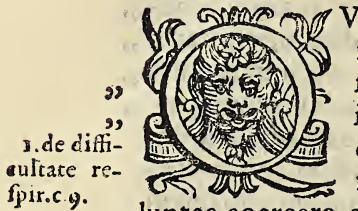

VIN vel difcrimina, qua inter refpirationem, pulfationemq́; effe uidentur Galeno, fi quæ qualiaq́ue Galeno uidentur, funt, \& ipfam pulfationem ab anima fieri declarãt. differt à refpiratione pulfus (inquit Galenus) quod illam, crm opus animale fit, voluntas coercere, ac proinde in varias fpecies mutare pofsit, poteft, quare circa inflamatas partes dolor vehemens ob arteriarum motum moritur, quodin noftra manu non ef motum uel magnitudine minorem uel uelocitate tardiorem facere. At thorax, fi inflamatus fit, \& ad motum cogatur tardius multoquam oportet, dilatabitur, ac proinde difficili cum refpiratione animal indifcrimen fuffocationis producet. cxterum ne fuffocetur, denfiores actiones xdit, non am plius tantam ceffans, quantum folebat, quum fecindum naturam haberet : quamobrem neceffe tunc eft, totam refpirationem paruam, tardam, \& dêfam, multoqúe fanề minorem, quàm par eft fieri, non autem ita multò tardiorem, fiquidé dolor non adeò grauiter ob motis uelocitatem, ficuti ob magnitudinem dilatationis thoracem uexat: Eximium itaque(inquit) quid ad inxqualitatis generationem refpiratio habebit, prater pulfuüm rationem, dum uidelicet à fola ani mali facultate proficifcitur, partim uerò à complexu ipfius cum doloribns. Quoniam fcilicet ab anima fit refpiratio, \& fub uoluntat is imperio eft, ubi cum dolore fit, ut minore co fiat cohibetur, multisque mutatur modis, at non pulfus quo uis cum dolore factus, uel ceffat unquàm, uel immutatur om nino quicquam; fummopere etiam id nobis contendétibus q'od nimirum à facultate fit qux nullum dominium, nullú volitatis agnofcit imperium. Propterea igitur animale opus refpiratio, pulfatio uero naturale uidetur Galeno, quod illä \& cohibere, \& modis multis uariare foffumus, at pulfationem, nec cocrcere un quam nec ullo tariare licet pacto.fum- 


\section{Quod Ani.vniu.ab vnic.Ani.fubft.guber. 25}

mopere quidé mirari Galenum licet, fiquidem pulfatio, vel ipfius teftimonio, ubi cum dolore fit, eadem fermè ratione, qua refpiratio \& omittitur, \& uariatur : cum dolore autem fit, ubi arteriæ fibręque in inflamatas tumefactasque impinguntur partes, in quibus fcilicet $\&$ ipfe eft, \& qui ipfis in exiftit, fpiritus comprimatur, neceffe eft:eo itaq́ue amplius ubi qux inflämatx funt partes, multis, magnis qque abundant arrerijs:precipux igitur, in peripneumonorum pulfu multifor mis ineft inæqualitas, quòd multæ pulmoni, magnæq́ue infunt arterix.Quxcunqúue certè de refpirationis in $x$ qualitate Galeno dicta funt, de inæqualitate etiam, quę infla matorum peripneumonorúq; pulfibus teftimonio Galeni fit, dici poffunt omnia. Quoniam enim in huiufmodi affectibus dolore afficitur, dum pulfat anima, nequaquam crebro \& celeriter, $\&$ vehementer, fed raro, \& tardè, \& languidè pulfat, tum quia huiufmodi pulfatione ufus non expletur, \& animal in pe riculum adducitur, ne fuffocetur, crebrius pulfat, celeriusq́ue \& uehementius;rurfus quia fic pulfans dolet, iterum \& celeritatem, \& crebritatem, \& robur aliquando plus, aliquando minus remittit; Quid enim faciat mifera, \& confilij inops, quę neque actionem fiftere ob fuffocationis periculum, nec reperire aliquando doloris medelam potelt? tum immoderatã ( inquit) faccre fpiritus attractionem, rurfusque immo- , dicam quietem eius eft, qui nec quando defiftere $a b$ actione," oporteat nonit, nec quando rurfus incipere, fed in utroque" menfuram egreditur ob conuenientis ignorationem.Cü igi, tur refpiratio animale opus fit, defipiētes auté habeant oblæ- „, fam rationé, tú circa actiones, tú circa ipfarú interititia obli-, ", uifiores fiüt. Rationalis igitur quę pulfar fubftátia; quę nimi ”, rum menfura ( vr dictum eft) fumma, fummaq́ue v titur arte, $\&$ modis mille pulfationem uariat, femperque ad pręfentem commodi ufum; quòd fi metu aliquo turbetur, uel ira, metuque fimul iunctis, neque equaliter, neque ordine pulfat, q.nimirú fpectra Galeno, \& phãtafmata aliquädo plus,aliquã dominus à naturalibus, proprijfq; reuocát operationibus; \& quocúq; turbetur anima affectu, turbatur \& pulfatio.Agè ueroquò res magis aperiatur, magif́,; manifeltetur, Galenú, qui pulfus in fingulis animę affectionibus, varijsq́;morbis \& in ua rijs fiāt animalis dipofitionibus, docētē audiamus.in eorum enim diuerfitate quę eos ædit fubfátia, cófpicua fiat oportet.

$$
\text { G Tu! }
$$




\section{Bernardini Telefij}

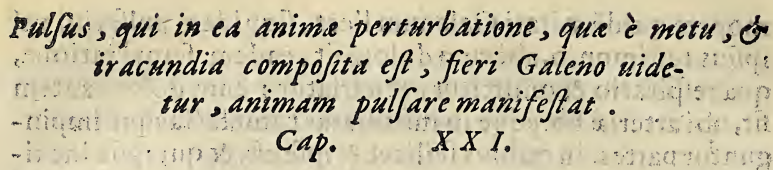

2, de cauf:

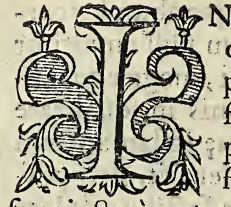

Nea animę perturbatione (inquit Galenus) quę ex timore \& iracundia uindicteque appetitu compofita eft,vbi fcilicet ad vindicta fertur anima : \& eodem tempore renocatur propter metum, ne maius malum accipiat; fluctuat itaque à vindictę cupiditate impul pulfu.

fa, reiecta à metu: in hoc (inquit) certamine atque agonia inordinatus fit pulfus, turbatusq́ue \& inequalis, \& iure quidem, cùm non tantùm a diuerfis fed natura contrarijs turbetur caufis. itaque ob uindictę cupiditatem alti, magni, celeres, vehementes; quia uero maior eft timor mali accipiendi,

2. de caứ. quâm fpes inferendi, parui, humiles, languidi, 8 tardi fiunt: pulf.c.rquare inuicem utrique pro caufę prepollentis natura uariari uidentur, ac excellit quidem modó i ra, modò metus, Quin ipfe (inquit) timor uehemens exiftens inęquales efficit pul fus, idque non ufa, fed facultate oblęfa:Recte fanè.eadem igi tur, quę rei indignitate commota uindictam appetit, molitur que, \& qux periculi magnitudinem metitur, \& impendens pręuidet malum, fubftantiam, quam quis rationalem effe ne get ? eadem \& pulfat: nifi enim eadem rationalis pulfatoria exiftat, nequaquam uel uindictam illa moliente, uel imminens malum reformidante, inæqualiter, inordinateque ipfa pulfet. Quin \& cum quadam etiam uibratione in huiufmo" di (inquit ) animẹ perturbatione fit pulfus : valdè nimirum " turbatis varieque exagitatus \&x ueluti infipiens factus fpiri "tus non ordine, neque furfum omnino attollit arterias, fed nondum bene ijs elatis, non in altum amplius, fed ueluti in Jongum fertur. Alti porrò, magni, celeres, \& uehementes pulfus in uindict $x$ cupiditate fiunt, quòd illatam iniuriam ferre impotens, \& uindictam moliens, penè ut inferens fpiritus uniucrfitas uindictam in vniuerfum fefe effundit corpus, pro indeque $\&$ in cor,arteriafque longè influit plurimus; $\&$ ueluti furens vehementer eas commouet.iure igitur alti , magni, celeres, wehementesq́u fiunt pulfus, $\&$ fanguine à vehemen- 


\section{Quod Ani.vniu.ab vnic.Ani.fubft.guber. 26}

tiore motu concalefacto , accenfoque tales omnino ędend funt : Iure itidem humiles, parui,tardi, languidique eodem in affectu fiunt.fi quidem ab imminente malo perterrefactus fpiritus, quam licet portionum partem reuocat.vel ffonté fua illę eam mittunt. exiguas itaque in arterijs factus, $x$ grè eas attollit humiliter nimirum, \& tarde pulfat láguidequie; $\&$ magna, calidioreq́ue fanguinis portione intrò à recedente fpiritu acta,non alia opus eft pulfatione.

\section{Itidern \& pulfus, qui in triftitia, latitiag fiunt. Cap. $\quad X X I 1$.}

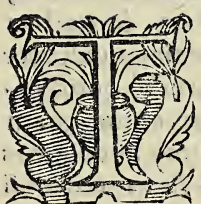

RISTITIAE pulfus paruus eft (inquit 4 decaufo Galenus ) \& läguidus, \& tardus, rarufque:le pulr. $^{\text {pard }}$ titię autem magnus, tardus', os rarus eft pul " fus.pulfans igitur facultas animalis Galeno" fit oportet, cui nimirum naturales nunquä à " neceffarijs operibus vacare ; \& torpere nun-" quam, aut negligenter effe uidentur. At que (inquit) fub uo-" luntatis poteftatem cadunt, hẹ, fępe ubi uoluntas ipfa circa alias actiones detenta fuerit,negligentius perficiuntur. Qui porro in timore fit, non quidem inordınatus, at in reliquis, ei, qui in timorefit, quàm fimillimus, quòd malum paftus fpiritus, non, quod futurum pauens facit, trcpidat, \& ueluti viam inquirens, qua id declinet, huc illuc agitur. ac eodem certè modo affigitur deijciturque, ut $f \in f e$ mutuo vt foletur, fubleuetáue fefe, quantum licet, colligit. In lętitia aut $m$ pro pterea magnus ęditur pulfus, quòd $\mathrm{f} e \mathrm{fe}$ bonis affuentê often tandi, \& quibus licet motibus oblectädi appetens in uniucr fum corpus, proindeque in uniuerfas cffund itur arterias, at bląndo temperatoqne motu. itaque partim concalefacto fan guine;non celer etiam creberque; aut uehemens edendus eft pulfus, fola enim magnitudo vfum fupplet. Quòd fi diuturni (inquit) fuerint affectus, aut uehementes, pulfus omni-" bus fuccedunt, qiales uiribus diffolutis:cum nimiru $\mathrm{mf}$ acul" tatem difoluant chenes.rationalem fcilicet, qua bonum in-" tuita, expectanfre ixtatur, triftatur malum rafia paffuratè, irafcitur iniuria afecta, \&und detam parat:at malum reformidans, malum noninfert, fedrefugit, \& utrum que intert. , 


\section{Bernardini Telefij}

dum fimul. In immodica porrò latitia fpiritus uires diffoluuntur, q iòd bona, magnaque uniuerfitatis portione in oculos, atque in os, aliafque externas in partes, in quibus nullus $x$ ditur motus, eifufa, in cerebri uentriculis minor fortè facta eft, quàm ut, quod afsiduè facit : ad portiones, quibus corporis partes commouendx funt, quampiam fui partem mittete quear, \& bono rum, qux euenere, contempla* tioni tota intenta, parum qux obeunḍa funt munera, obire curat, \& fpiritus omnino, qui externas in partes effluxit, $\grave{e}$ concalefactis ijs quapiam afsidue elabitur pars. In nimia cô tra triftitia, timoreque, quòd paffo à malo deiectus, \& ab imminente deterritus infuper, \& hominum, \& malorum etiam qux euenere, e:tenturaque uidentur, confpectum ex horrens, intus fefe abdit uniuerfus: itaque in partibus, in quibus motus ædendi funt, minor in omnibus fit, quam ut ualenter eàs commonere queat, \& ubique torpet.In ira uerò quòd nimis exagitatur, nimifque accenditur, \& magis etiam, quam in letitia elabitur. Itaque quoniam iuxta an:m $x$ affectiones pulfus afsiduè immutantur, talefque cmnes fiunt, quales fi fpiritus portiones iuxta uniuerfit atis arbitrium, \& ipfa omnino pulfet uninerfitas, fieri oporteat.vtique non brut $x$ cordis nature, fed fpiritui omnino, eiq; atq; ipfius portioni, que bono rerum ficcefsa latatur, malo triftatur, \& qux contemptui habita indignatur, $\&$ imminentia mala frauidit, exhor retque, qux ratiocinatur omnino.

\section{Itidem, ópulfus, qui varÿs in morbis, viiryj que funt in} anmalisdifpofitionibus. Cap, $X X 111$.

4. de canfis pulf.c.6.

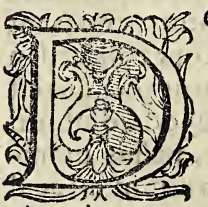

OLOR, inquit Galenus, qui quidem uariat pulfus (uariat autem ingens, aut quòd prin cipes o ccupar partes, quemadmodum $\&$ in flammatio, ) fi paruus fit, atque incipiens, pulfum x'dit maiorem, uehementiorem,celeriorem, \& crebriorem; auctus ucrò iam, admodumque ualidus ut etiam uitale robur offeridat, mino $\mathrm{rem}$, lang iidio rem, celerem, atque crebrim : $\&$ quo diuturnior fit a it uehemétior, hoc illortm quodque increfcit mas gis : qui uerò iam facultat $\mathrm{cm}$ diffoluit, in rcmifsiorcm, 80 paruitan- 


\section{Quod Ani.vni.ab vnic. Ani.fubft.guber. 27}

paruitatem;ementitaque celeritatis fpeciem; atque ingen- ," tem crebritatem commutat : fi quidem facultas ut in omni,, moleftia, ita \& in doloribus ad reijciédum id, quod infeftat, ", fefe accingere folet. quare in magnitudinem, \& celeritatem," vehementiamque pulfus permutat. qux fi in eò nihil profi-, ciat, ueluti ex inani labore uis eius, atque contentio opprimitur, ac fic pulfus in remifsionem recidunt. Non igitur bru ta cordis natura, nec naturalis facultas ulla, qux fcilicet ne proprias quidem pafsiones $G$ aleno percipiat; nec operationem uariand i modum teneat vllum, \& quę nec arterias mouens, nec ab alieno dolore debilitetur, deficiatque unquam; fed fubftantia pulfat fummo fenfu, fummaque cognitione, \& fumma fefe, circumpofitafque mouendi pradita facultate; \& qux uniuerfo inexiftens corpori, ab ijs, quæ partibus malum inferunt, moleftia afficiatur \& ipfa, \& propterea magnis in doloribus vbi fcilicet quapiam in parte ualde ipfe euexatur, \& magni, rehementes, celores, crebrigue: funt pulfus, quòd ut, qux portionem in ea refidentem offendunt, amoliatur, maiorem quam folet fui portionem immittit uniuerfitas. \& vehementius celeriufque , \& crebrius pulfat, \& dum integrx ad funt uires, eò asfiduè magis, quò magis oblxdatur . ut enim dictum eft, non alia operatione ulla, fed uafa modo, refque, in quibus moleftia afficitur, commouens, agitanfque ; qux molefta fune amoliri poteft fpiritus, \& motu omnino amolitur omnia. qux amoliri non poffunt funditus diffoluenfque diu porrò cum noxijs rebus conflictatus, \& à vehementi arteriarum commotione defatigatus, tandem, \& ècommotis concalefactifque partibus elapfus, prouideque $\alpha$ im minutus fpiritus, nec magnos, nec uchementes $x$ dere poteft pulfus : at moleftia amoliendi defiderio accenfus celeres, quales poteft, $x$ dit, \& fi tales incidant ualde iam defeffo, imminutoque, crebros faltem: quibus fcilicet licet modis, \& qua licet ux, qux molelta funt, afsiduè amolitur.Inflamationis in- Eod.c.7. quit, pulfus omnis ueluti ferrans.ut alia arterie pars attolli, , minime uerò \& alize uidentur. habet etiam uibrationis ali-", quid hic pulfus, \& celer quidam ef, creberque, nec tamen , perpetuò magnus. Nifi nimius propriarum pofitionü amor, detinuiffet, rebus, qux manifeftè eas demoliuntur, \& quas ipfe pulcherrime intuitus erat, uel uno hoc in pulfu, non à cordis 


\section{BernardiniTelefij}

cordis nat:ara, nec a facultate ab ea arterijs indita,fed ab ani ma in cerebro refidente, \& à quapiam ipfius portione in eas immiffo, at ipfis omnino arbitrio operante; eas expandi intuitus omnino foret Galenus. Quoniam enim eadem prorfus, qua thorax, arterix itidem partibus inflammatis dilatari, videntur prouidentia,nunquam fcilicet dilatari cef fant.at quod fi tumefact is in partibus xquè dilatêtur uniuer $f x$, grauis ibi fentiatur dolor, non $x q u e$ unixerfa dilatantur, fed ibi magis, ubi nihil aut partm tumefacta eft pars. nihil uerò aut exiguum quid elata ea elt . itaque in terrx modum alia parte attollitur arteria, alia non. \& dum attollitur; dum, fcilicet in tumefactas adigitur partes graui inexiftens fubftantia aficitur dolore, ntique quod dictum eft, fubftantiam ijs ineffe, cui comprefsiò fummopere molefta eflet, gra uisque. \& non proprio ipfam arbitrio, fed alterius iuffu pulfa re intelligere poterat Galenus:neque enim fi facultas à corde indita pulfet, palfandi modum immutet unquam. nullam enim immutandi occafionem, perit iam uè habens nulla incorporea cú fit à cōpreffa arteria moleftia affecta. \& nulla donata cognitione. Minus etiam, fi non ab vna omnes vnituerfitate, fed a fe ipfis fingulæ fpiritıs portiones atterias, quibus infident, dilatent, quibus arteriarum dilatatio nullum infert malım, parte alia magis, minus alia dilatêt. Nec(quod partibus inflammatis facere Galeno videntur) iaculorü more, manu emifforum atterix omncs, fed ex modo; qua infämatis infunt partibus, vibrare appareant:ijs enim modò inexiftens fpiritus attollere eas reformi đäs veluti longum agat. at age velfi in pulfu, qui parte quauis inflammata fit, arterias â fpiritus portionibus in ipfis inhabitantibus ab uniuerfitate cómotis expandi fatis cófpectum eft, quoniam digna res eft, que faltidio etiam quouis infpiciatur, in eo etian, qui pamone inflammato fit. cum in reliquis, qui varijs in norbis, varijsque in aminalis diffofitionibus fitt, intueri nè grauemini. Pulfus (inquit Calenus ) qui pulmone inf am mato fit, \& v vo in pulfu, \& in collectiua, quam dicunt, in $x$ qualis eft, nam in vno quidem ictu interpellatus, vindecunque bis feriēs, in collectiua autê cũ alias fortit̄ differentias, tum mo dò̀ intermittens, modò intercurrens. Spiritus igitur arrerijs ine xiftens, \& vnituerfitatis arbitrio pulfat. propterea enimnon: ordine, nequeiqualiter pulfat, quod tumefactum in pulmo- 


\section{Quod Ani.vniu.ab vnic. Ani.fubtt.guber. 28}

nem illas adigens comprimitur, ita comprefsionem vitatis quantum licet dilatare iutermittit. Lathargicornm (inquit) 4. dc cauf: pulfus, peripneumon icorú pulfui fimillimus, idq; modo dif- pulf.ca. I 3 . ferens, quòd minus inæqualis, $\&$ intermittens potius, quam " intercurrens, dicrotufque interdum fit, vndofus v fquequa in: $\%$ altis fit foperibus . manifeitè igitur non cordis natura facul-" " tafuè ab eo emanans, quod fcilicet nihil prorfus paflum eft." fed fubltantia in cerebro inhabitans pulfat. qux ab immiftis " vaporibus oppreffa. \& horum concoctioni tota intenta non rectè;atque ordine pulfat, Idem fortè \& amplius phrenetico rum manifeftat pulfus, qui uimirum fummopere variari, immutarique videtur, corde nihil oblælo, at vel tenui meninge, fi Galeno credimus, vel fepto tranfuerfo anima rebus ofteris, \& fentiendi, motusquie ædédi facultate donatis, quibus quá túuis pafsis, nihil cordis actio Galeno immutaturnihil à cerebro, animalique dependens principio.\&verò fi non ab ani ma in cerebro refidente, fed à propria natura moueatur cor, quiduis illa, illiufque organis pafsis, nihil tamé huius immu tetur motus . vt enim fibra cerebro cor connectent, uniantque, non ptopterea quod Galeno amplius placet, mutuus fiat actionum, pasfionumque confenfus.qui enim naruralis facul tas animæ pasfiones perciniat, actionesuè, vel è contra;

Phreneticorum (inquit) pilf is nonnih l vndofi habet, \& fabtremere interim tibi uidebitur, interim etiam pracifus" cim conuulfione quadam: in menies etiam innequalitatis in " pofitu genus infigniter in illo aliquando apparcre, immo to-," tam fubinde arteriam fua fede deferta attolli confpicias po- " tius cum vibratione ebullientem. quam more pulfus difen-" " tam, pari modo detractam potius quam contras am . manife" ftè igiturqod dictum eft non cordis natua, facultas ve ab ea arterijs indita, fed fpiritus ijs inexiftens, \& ab iofa commo tus vniuerfitate pulfat. propterea enim huinfmodi fiunt pulfus, quòd ab immiftis exhalationibus exagitaca, perterrefaEtaque, \& infipiens omnin facta unicerfitas inordinatisfimo, \& diuerfo commouetur motu; \& motum, cuos anfpicatur nullú abfoluit, fed ftatim ab omnibus ceflat, alljsq́; moue ri aggreditur, \& arterias aridiores factasà propria dimouet fe de.\& fyncopi (inquit) imminente, crebrior fic pulfus, \& fub, tremere etiä videtur, \& hoc perperuò phrenetici pulfus hént, " vt cum quadam motus conuulfione éorum motus abrumpa-, 


\section{Bernardini Telefij.}

9) turnon paulatim definet, quid nimirum ab aduetante, ve ss dictum eft, exhalatione perturbata \& imminuta omnino uni " uerritas, quibus poteft modis fibi opé affertr. \& crebtius pulfans, quam licet fibi parat euaporationem, fcilicet qua precipuè nutritur,copiofiorem è plexu retiformi educit, 8 malo omnino quouis oppreflus f́piritus frequentiore id amoliri tentat motu. \& imm inutum effe phreneticorum fpiritum, fa tis ipfius manifeftat motus. propterea enim non paulatim de

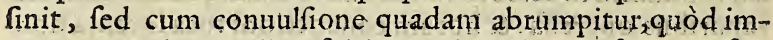
potens arterias attollere fpiritus nolés etiam ceffat ut nô fpi-

" titus uoluntate definere fed eo inuito abrumpi uideatur mo

"tus.ijs, inquit Galenus, qui animæ deliquium patiuntur fi uehemens fuerit ea difpofitio, pulfus inæquales fiunt, intercidể tefque. animalis igitur non naturalis cordis actio ponenda Galeno eft. cui nimirum naturalia:ab alijs affici non placet. ut munere non fungantur fuo, fed ea tantum qua à uoluntatis imperio pendent. Inæquales porrò, intercidentefq; in anir $m \mathfrak{x}$ deliquio fiunt pulfus. qui enim $\cos æ$ dit fpiritus. ad eam uidelicet portionem plurimus conuolauit. qua magna quapiam moleftia afficitur, id quod eam infert, ut amoliatur:qui

" igitur in arteriarum fibris reliqu us factus eft exiguus, \& ue-

"luti exanimatus, nec arterias ualenter dilatat, nec eas

Eod, 5. 17\% dilatandi ordinem feruat.Conuulforum (inquit)arerix mo tus ad modum chord $x$ eft, furfum, dcorfumque agitatx in $x$ qualis,idque minimè certis têforibus: Animale igitur opus pulfatio. fiquidem motus qui in conuulfis fiunt, prater uolü tis quidem imperium, at ab anima omnino Galeno xdūtur. $\mathrm{Ab}$ eadem porrò à qua illi, \& ipfa facta fubftantia illorum itidem ritu prater ordinem, praterque inftitutum, $\&$ in $x$ qualiter, nec certis temporibus fiat oportet. Et ab eadem omnino, " aqua \& conuulfio. pulfationem itidem. fieri Ypiritus uniuerfi

" tate inde manifeftè intelligere licet. quod illam nô fubfequi

- tur modò, fed præcedit etiam. Vbi (inquit Galenus) quod conuulfionis eft, ad utranque arteria tendi apparet.ftatim ho mo conuulfione corripitur.quòd nimirum priusq́ue reliquis in partibus is vniuerfitatis motus manifeftus fiat, in arterijs manifeftatur; Paraclitorum (inquit) pulfus inordinatus elt intermittenfque. non igitur facultas à corde arterijs indita,

Eod.ca.18. Fed fpiritus earum fibris inexiftens, \& ab vniuerfitate commotus pulfat. Quoniam, fcilicet nel Galeni teftimonio, propterea 


\section{Quod Ani.vniu.ab vnic.Ani.fubft.guber. 29}

prerea paralytici fenfu, motuque deftituuntur, quod neruis humore quopiam in fufis, obftructisque facultati à cerebro emananti,nullus eos fubeundi patet aditus. fubftantia o mni no quę in cerebro refidet, motufque $x$ dendi facultatem partibus Galeno indit, oblæfa paraly fis fit: $\&$ pulfus in ea inordinati, intermittentefque fiunt, utique non à facultate à cordis natura arterijs indita; quæ quantumuis animali principio ob $1 x f o$, nihil Galeno oblædi, nihil propriam actionem immuta re Galeno videtur;fed ab illa eadem fubltantia,à qua reliqux exangues albæque res commouentur,arterias itidem cómo- Eod.ca.2\% ueri, exiftimãdum omnino eft. Nihil etiam minus eorum id declarat pulfus, qui veratrum fumpfere;propterea enim inxqualis, inordinatufque $\&$ ipfe eft, dum contuelluntur præfertim, \& dum uomunt, quòd veratro eijciendo intenta uniuerfitas, munerum reliquorum obliuifcitur prenè omnium. itaque nec ordine, nec æqualiter pulfat . veluti neque in ijs qui fyncopa corripiuatur, \& qui cổelluntur, \& qui fingultiunt.in his enim rei, qux firitus portionem ventriculi inexiftêtem diuexat, expulfioni intenta vniuerfitas: in illis verò, vel ipfa malo quopiam affecta in tus, vel fibrarum meatibus obftructis, quos ipfa ædit,tales ad portiones in fibris contentas perueniunt. Mulieribus ibidem hy ctericis corruptis difpofition ibus proptera paruus atq; ob fcurus fit pulfus, feu quòd fpiritus vniuerfitas rebus, qux por tionem utero inexiftentem moleftia afficiunt amoliendis in tenta, occupataque : cos tantum diligenter ftrenuèque $x$ dit motus, quibus illæ amoliêdæ funt:reliquos lāguidè:feu quòd maiorem fui portionem in uterum immifit; ut qux fpiritum ibi diuexant, eijciat, exuperetue \& horum alterü fieri, \& fubftantiam omnino, quæ fentit, intelligitque \& motus $x$ dit,pul fare, inde intelligere licet, quòd qux utcro laborant, difficili etiam laborant refpiratione, \& ftupidæ funt, immobilefque, \& anima deficiunt, \& non nullis brachia etiam contrahütur. in eorum itidem pulfu, qui experge fiunt, non à cordis natura facultatem ab ca arterijs indita, fed a fpiritu om nino earú fibris inexiftente, $8 x$ ab uniuerfitate foto, commotoque, pulfus fieri, liquidò intueri licet.Quoniam enim non corde eius ue ui fed cercbro animalique principio, quod in cercbro refidet; quid pafio, fomnum fieri uidetur Galeno, nequaguā fi illa pulfet fomno cefiante pulfus maiores, uehementiores, ce- 


\section{Bernardini Telefij}

leriores, crebriorefq; , \& cum quadam etiam uibratione fiãt. nam ut fxpe dictum eft,cerebro, fubttantiaque in eo refiden: te,à qua fentiendi,motufque ædendi neruofo generi indi ui detur Galeno quiduis pafta nihil cordis, arteriarumque, qua fcilicet à corde emanant, \& à facultate ab eo indita mouentur,immutari uidetur Galeno.Tales porfò animali fomno ex cito fiunt pulfus: quòd fpiritus uniuerfitas ram diu in uaporum concoctione occupata, \& propterea nó fatis interea mo tibus, qui portionibus æedendifunt,uacans; illis tandem exu peratis, \& bene ipfa refecta, non diligentius modè omnes có mouet, eafque imprimis, quibus pulfandi demandatum eft munus, fed fui etiam partem quampiam auxilio illis mittit. itaque in amplius, \& $x$ uehementius, celeriufque, $\&$ crebrius ar terias expandit, \& in longum etiam agit;quod adueniës progredienfque fpiritus, ueluti fecum illas trahit . Poftremò \& pulfus qui fpiritu immin to aliind nihil animali paffo longè fiequentifsimi Galeno fieri uidentur, nó cordis naturam facultatemuè $a b$ ea arterijs indita, fed fpiritus portionem arterijs inexiftentem, $\&$ ab uniuerfitate commotam, pulfare aper tifsimè manifeltant.nam fi nihil illa cerebri pafsiones fentire, nec ullo cerebri malo propriam actionem immutare, uifa eft:longius etiam ab elt, ut fpiritus imminutionem fentiat. nec fi fentiat, \& laboranti opem ferre uelit, frequentioriarteriarú mota id fieri intelligat.propterea igitur fpiritu imminu to frequentiores fiút pulfus, quod vt dictum elt, fpritus quidem portiones arterijs inexiftentes, at vniuerfitatis arbitrio, \& ab ipfa omnino commotę vniuerfitate pulfant.ea autem, \& fui ipfius defectum, \& ab eilaporatione, quę è plexa retiformi educitur, refici fe fentiēs, copiofius ut reficiatur frequentius illas, proindeque \& reliquas omnes commouet, inexiftentemque ex agitat fanguinem:ita enim copiofiorem educiteuaporationem. Neq; eft quòd reliquorum pulfum uarietates enarrentur, in fingulis non a cordis natura, fed ab anima in cerebro refidente eos $x$ di declaretur, quofcunque intueare, quauis in corporis animæue difpofitione ædantur, manifefte $a b$ anima eos $æ$ di intueare . \& eorü, qua fingulis eneniüt fi ab anima ędant, caufam uel ipfís intueare oculis, atnö fi cot: dis naturx afsignentur: Nec quò modò fiant, neque corú uarietatis caufa innotefcere queat unquam. Quoniã uero corde vulnerato, ftatim interit animal; itaque cordi, ut propria: mate- 


\section{Quod Ani.vniu. ab vnic.Ani.fubft.guber. 30}

materix, proprioq; fubiecto, vitalis (ut inquiunt) anima in fidere,videripoffet. Agèvel non ad modum forte proprio in loco caufam, cur huiufmodi cordis offenfiunem fubita confequitur mors, intueamur.

\section{Corde vulnerato fatim animal interÿt, non quod cor ip fum vite fit fons, fed quod qui eius tunic fibrisǵspiritus inexiftit, vulneratur. Cap. $X X \perp \backslash 11$.}

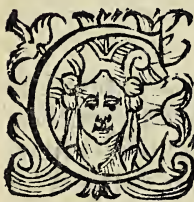

OR DE vulnerato, non propterea animal in terire, quòd cordi,ut proprix materiæ, proprioque fubiècto uitalis infidat anima,itaq; veluti uitæ fons cor fit;\& inde manifentè intelligere licet , quod Galeni (ut distum eft) teftimonio corde exempto, arifque impofito uictimę non null $x, \&$ clamauere fortiter, \& longius ctiă au fugere. \& ferpentis corde exempto, integros, \& diffectos nihi lo magis parte, cui cor ineft, quam altera aliquandiu uiuere, mouerique pafsim intueri licet . Præterea, \& quòd uentriculo, mufculifque faucijs lōgè plurimis nihilo minus promptè quàm corde ipfo unlnerato, præfens confequitur mors. Propterea igitur ( $u t$ alibi amplius expofitum eft) integris interdum membris abfcifsis, fuper uiuit animal, cordeq́, ipfo exêpto non ftatim interit, at illorum mufculis, \& hoc uel tantillum faucio nullo commoritur temporis mométo. Quod mo dico fpiritus incomodo illorum ytrumque fieri potelt, \& fit interdum. At cor mufculique uulnerari non poffunt, quin illius itidem tunica qua plurimo fpiritu plena illud obtegit, nec hi quin nerui è quibus magna ex parte compofiti funt ${ }^{\circ}$. Itaq́ue \& tunicę, \& is inexiftens vulneretur fpiritus, qui quod non uitæ fons, fed uita ipfa, ipfumq́ue eft animal; Vbicunque multus ipfe grauiteruè oblxditur, ftatim interit. animal itaque manifeftarū partiú nulla prorfus oblæfa, at fpiritu abaere infpirato affecto, \& à præfente, uel imminente etiã malo perterrefacto, itaq; nimis in fe ipfum confricto, uel à bono quo piam exhylarato, nimifque diffufo, ftátim animal con:moritur. Praterea \& quòd corde interdum penitus iam arefacto penè, \& penitus cófumpto, diu tamể furcruiuere vidétur homines: id uero \& omnibus ethicis enenire exiftimare licer,

$$
\text { H } 2 \text { dum }
$$




\section{Bernardini Telefii}

dum certè Romano uiro diuturno morbo abfumpto nuflun: prorfus inuentum eft cor, fed cius tantùm tunicas quod nimi rum non quamcumque cardis corruptionem mors confequi tur,fed magnam modò, $\& \tau$ quanta reliquis etiam in uifceribus facta animal perdat. At unde digrefsi fumus redeamus.

Animalis operationes omnes una ab anima adi, \& animal vniuerfum una ab ea gubernari, in ijs, que anima affectabomini eueniunt, infpiciendum eße. Cap. $X X V$.

NONIAM operationum, qux naturx imprimis fubftantix nimirum nulla agenti co gnitione afsignari poffe Galeno uif funt, ab anima à fubftantia nimirum partium fin gularum necefsitates cognofcente, $8 \mathrm{r}$ modum infuper, quo ijs prouidendum fit, intelligente $x$ di, \& 2 dendas omnino effe, fatis eft ( ut exiftmo ) confpectum : Et operationum, quæ animali æduntur nullx prorfus fruftra, temereuè, fed quempiam fingulx in $v$ fum, eaque omnino ratione, qua quod expetitur bonum, ut comparetur, \& qua quod amoliendum eft malum, ut reijciatur, quæ omnino propofitum ut opus rectè conficiatur, $x$ dend $x$ funt, $x$ di apparent: $\&$ vna excepta concoctione, qua à uifcerum quidem natura conficitur. at molient is omnino, \& qux concoquenda funt comportantis, adducentisque ope $r a, \&$ qux infuper fi quidem iniecinore ab una eius natura ab folui poteft ; in corde certè, ventriculoq́ue $\&$ venis atterijfque haud multò magis à proprio ipforum proximorumque vifcerum calore, quàm a fpiritu cóficitur, illa omnia commo nēte, agitanteque, operationes reliqux omnes rerum neceffariarum actractio, noxiarumq́ue expulfio, \& fuccorum alijs à partibus in alias tranflatio motu conficiuntur omnes; quin omnes à fubltantia in cerebro refidente, $\&$ cui fentiendi, intelligendique, \& partes commouendi facultatem afsignat Galenus, minus etiam quin confulto ipfa eas ędat omnes am bigere licet;vel fi quædam ueluti ex accidente , \& cafu quodam conficere uidetur,modum fcilicet, quo conficiëda funt, non fatis intelligens.at qua conficienda funt, conficiens ra: tione, 


\section{Quod Ani.vniu.ab vnic. Ani.fubft.guber. 3 I}

tione, ut ubi qnapiam in parte ab acribus inexiftentibus ua poribus diuexatur, eamque confricans moleftia fe exoluit;ne que enim pruritum ab inexiftétibus uaporibus fieri, nec partibus confricat is elapfuros eos intelligit. itaque, quod dictú eft, non confultò, fed ueluti ex accidente, quod propofitum eftopas conficere uideri poteft. Nam fi illorum neutrum diftinctè intelligit, at proptereà omnino partes confricat, dilaceratq;,quod res quę in ijs ipfam diuexant, amoliendas, \& non alia róne nifi partibus adapertis expelli poffe intelligit . Itaq; expofitis in operationibus animal ab unica animæ fub ftátia gubernari in fpexiffe cótēti, in immutationibus itidé, quę anima affecta cú in fingulis corporis partibus, tú in fingulis propèmodú animę operationibus fiüt, id intueri ne gra uemur:illę enim vel imprimis nú uno à fpiritu in cerebri quỉ dé uétriculis, ut in principe fede refidéte, ut per corpus uniuerfum diffufo, an à cordis itidem iecinorifq; natura animal gubernetur, manifeftent oportet : fi fcilicet, qux in iracundia,metuque (neque enim ambigi poteft, quin fubftantix cui uindictx malique inferendi cupiditas, eidem, \& pœn $\approx$ malique patiendi metus afsignandus fit ) \& qux ea in latitia, eaque in triftitia, que ijs affluentibus, vel deficientibus bonis, que cordis natura appetere uidetur Galeno, \& cordis omnino natura indignata, vindictamque moliente, uel fupplitium, malumque exhorrefcente, \& dictorum bonorum acceffu exhylarata, uel à contrarijs malis afficta (detur enim in prefentia Galeno dictis à rebus cordis naturam affici poffe, quod \& ipfum fieri non poffe, fuo apertifsimo declarabitur loco) ita fingulas corpo ris partes, animęque ope rationes mutari oportere, prout in fingulis dictorum affectuum immutari apparent, uifum fir, it aque immutationum omnium caufam intueri liceat, haud perperam Galeno uifum fit animal non ab una fubftantia in cerebro inhabitan. te gubernari, fed fentire modò, intelligereque, \& motus $x$ de re,at nequaquam affici : Non ipfam fcilicet illatas ingiurias vulcifci, honoremque \& fuper excellentiam appetere, minus etiam dedecora,malaque reformidare, neque illis fuccedentibus lętari, aut his oppreffam triftari, fed hęc omnia cordis naturæ effe.Itaque quę in fingulis affectionibus homini euenire apparent, intueamur. 


\section{Bernardini Telefij}

20u in iracundia, Verecundiaǵ, homini eueniunt, animal uno à Spiritu gubernari declarant, \& vericundiam candem iracundie effe. Cap. $X X V I$.

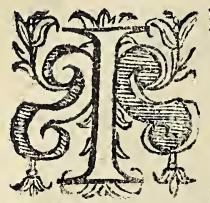

RACVNDIA efferuefcente cor quidem fummopere immutari, longè nimirum calidius fieri, longeq́ue \& veheurentius, \& crebrius pulfare, at ipfo nô folú, fed relique corporis partes omnes multo calidiores ru bicúdioresq́ue \& multo etiam robuftiores, \& ad motum prōptiores, \& oculi grandiores turbulentique, $3 x$ veluti malum minitätes ( $\&$ fi Theophaftro credinus) eft è quibus fiammę effuere, atque quęfentit, intelligitque fub ftantia minus fentire, deteriufque intelligere nidetur. $\mathrm{Hxc}$ qui cord is natura indignata, vindictęque libidine accenfa euenire queant, intclligere non licet:efto enim vindistam il la moliente, vehementius pulfat, \& calidius fiat cor, itaque copiofiorem calidiorcm que in partes effundat fanguinem, \& proptcrea ex magis incalefcant, rubicundioresque fiant, non certe robultiores, \& ad motum promptiores fient, quin languidiores, minufque ad motum prompta.ita enim in febribus, in quibus calidifsimum fit cor, vehementifsimeá; \& creberrimè pulfat, perpetuò euenire uidetur: robuftiores, \& ad motum promptiores ut fiant partes, haud quaquam co piofior, calidiorque à corde in arterias fanguis immittédus, \& ab ijs in partes apportandus, fed in neruos, quorum opera motus fit omnis, qux ipfos flectit, intenditque fubftantia co piofior, motusq́; æadendi appetentior influat oportet : minus etiam quouis calore affecto corde, \& quallis pulfante vi, qui tanta in oculis immutatio fiat, quorum fcilicet humores, in quibus immutatio fit omnis, nulla fubit arteria, \& ni hil Galeno cercbri natura, \& fubitantia omnino, qux fentit, intelligitque, cordis naturx labores, affectionefque cum percipiat, nihil omnino quantumuis ea affecta, \& quouis modo cor commouente minus fentiat, deteriufque intelligat;at ue rò fi iracundia, vindictrq; appetitus fpiritui afsignetur, qui hẹc eueniant omnia,ipfis intueamuroculis. Illatum nimirum malum, illatamque iniuriam propulfandi, puniendique 


\section{Quod Ani.vniu.ab vnic. Anirfubft.guber. 32}

fummo fpiritus flagrans defiderio, quiefcere,fefeque in propria fede continere non poteft, fed uind ičã moliës, paranfq; fefe inde quafcumq; in partes, $\&$ in externas præfertim, qux fcilicet robuftus cómouédx funt, effundit. itaq; grädiores calidioreq; , \& rubicúdiores fiunt omnes : ut enim dictú, qui uenis arterijsq́; ineft fpiritus, ijs inexiltentē fanguinem quo cüq; ipfe fertur,fecú agit, ut in cordis tunicas, fibrafq; \&arte rias ipfosq́; in oculos logè plurimus delatus, \& ubique ueluti frcens vehementius illas omnes commouet, oculorumque humores exagitat, turbatque:itaque non pacati illi amplius, fereniq́ue, fed maris ritu fummopere à ventis exagitati,turbulenti apparent, \& ueluti minabundi, \&uni intentus vindicta, quas externis à rebus patitur pafsiones parum fentit;minus etiam qux olim percepit, cum ijs qux.modò fentit, conferre poteit.in verecundia itidem multò quidem omnia lexiora, at eadem omnino, qux in iracundia euenire appa rent:eadem enim omnino iracundix uerecund ia elt:hoc tan tum interiecto difcrimine, quòd in iracundia ab alijs offenfus fpiritus, ab alijfque iniuria atfectus in alios indignatur? in verecundia attem à fe ipfo offenfus, \& à fe ipfo iniuria affectus in fe ipfum indignatur. Neque enim propterea in uerecundia rubore afficimur, ut Galeno uideri peteft, quòd à principio timens anima fefe intrò recipit, mox rem minimè r.formidandam animaduerfa, \& fefe decrptam indignata maiore adexterna ui, multoǵ; re greditur copiofior:nö fi qui déleuia modò peccâtes, \& quæ nobis ipfis ignofcere pofsimus, erubefcimus, fed mala fumma, fummaque committentes fcelera: \& qux non timenda modò iudicet fpiritus, fed maximè auerfetur, exhorreatque: fed propterea indignatur, quod operationem operatum fe intelligit haud quaquam ip fus fubitantia propriam, \& à qua maximè corr mpi, deftrui q́ue, 8 in aliam longè ignobiliorem fubtantiam agi, guia atum fe fentit? eoq́ue etiam amplius fi peccans, \& fe ipfum deturpans, corrumpenfque ab alijs deprehendarur, à quibus nimirum omnibus adi vult, fuppicićue, \& diuinus omnino, qualis fui natura eft, haberi, fe igitur peccantem ex ofus, non deceptum, \& in fe ipfum peccantem, feq́ue iffim iniuria afficientem, corrumpentem q; indignatus, non quidem adeo uehementes, at eofdem omnino, quos in alios ira tus, alijfque infeftatus edit fpiritus motus. Neque igitur è

rimore, 


\section{Bernardini Telefij}

timore, \& iracundia (ut Galeno placet) compofita videtur rerecundia, fed iracundię omnino eadem, hoc modo (ut dictum eft) differens, quòd in uerecundia non in alios, at in fe ipfum irafcitur, indignaturque fpiritus, in reliquis eadem prorfus eft . itaque ubi commifsi fceleris dedecorifuè confcius, \& fe ipfum prautum percipiens, degeneremaque exitio det,penitufque perdat fpiritus.

\section{Praterea of qua in timore. Cap. $X X Y \perp 1$.}

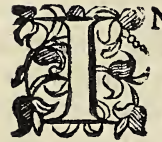

N timore contra, partes albę omnes, frigidęque, \& fummopere ad motum fegnes fiunt, quin $\&$ tremore interdum; eft uerò ubi \& horrore etia rigoreque corripiantur,\& non modo intelligen di uis penitus deprauatur, maioraque omnia, \& terribiliora apparēt, fed fentiëdi etiā facultas corrúpitur, imminuiturque. Hæc itidê fi cordis natura timeat, qui enteniant, intueri non licet; efto enim perterrefacta ea mints quam oportet, \& nullo ipfum arteriasq́ue dilatet conftringatq́ue ordine : itaque non tãtum, nec adeo calidum fangui nem in eas immittat, non certè quod ut partes è rubris,calidifque albę fiant, frigidęqúu fiant oportet, quam in illas immiferat, ex externis illarum partibus in internas agit. Minus etiam ad motum ędendum languidiores fiant partes.

Nec tremore, horrorevè, aut rigore corripiantur, fi quidcm uel Galeno mouendi uis non à cordis natura, fed a fubftantia partibus inditur in cerebro inhabitante, quę cordis natu rę affectiones, pafsionesq́ue nihil fentire uidetur Galeno, \& tremor, horrorque \& rigor motus omnino cùm fint omnes, mouentis fubftantię uitio eueniant oportet; minus etiam fentiendi, intelligendiq́ue uis Galeno deprauetur: $A t$ fi que fentit intelligitq́ue, \& mouet eadem, \& timeat fubftantia; qui illa omnia eueniant, nullo intueamur labore. PerterrefaQta nimirum, \& ueluti exanimata princeps ipfius fortio mutuo fefe ut foueat, \& ueluti confoletur,quàm maximè poteft fefe in unú colligit, \& imminéti intēta malo nihil pręteritas pafsiones recolit, nihil etiampręfentes percipit: huius porrò moleftiam portiones reliqux percipientes rroprijs fingulę muneribus,proprijq; relictis fedibus, ad eâ conuolāt omnes, militum, ciuiumque ritu graui quopiam ipforum Duci,

Principique, 


\section{Quod Ani. vniu.ab vnic. Ani.fubat.guber. 33}

Principique, \& fibi etiam ipfis imminente periculo; Itaque fanguine internas in partes acto, externx frigidæ fiunt, albeq́ue, \& qui reliquus in ijs factus eft fpiritus, uix earum fublti nens onus.Si quidem eas attollere, non certè ualenter commouere poteft, eft vbi \& ponderi cedat:itaque tremore corri piunturfurfum à fpiritu elata, $\&$ deorfum à proprio onere de traetx, quin \& ubi vehemens fit timor, horrere ctiam, rigereque videntur . quod trepidante fpiritus vniuerfitate, \& qux motu, confilijque inopia confiftere nequeúte, \& nequaquam vno, certoque, fed alio afsiduè, atq; alio commota notu, ipfius itidem portiones qux partibus inexiftunt, \& quæ vniuer fitatis motus fectari omnino uidentur,ijfdé \& ipfa exagitan tur motibus, horrore nimirum, rigoreq; correptę apparent, \& oculi minimi, triftefque funt, fpiritus nimirum abfeeffu, $\mathrm{cu}-$ ius acceffu, \& grandes, $\&$ hylares fiunt, pauloq́ue minus fpiri tu malum immaginante, quàm expectante, \& veluti intuente, hæc omnia eueniunt.nam languidioribus quidem, at ijfdem omnino, quibus fentiens imaginans fpiritus commoue tur motibus, itaq; nauigationis memores, naufea afficimur.

\section{Itidem \& que in maroribus. Cap. $X X V I I I$.}

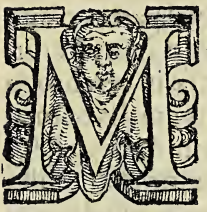

INVS etiam qux in mœroribus immutationes fieri uidentur, qui cordis natura malo rerum fucceffu triltata euenire queant in telligere licet, minus enim omnia, ac eadem omnino, qux malum quippiam expectantibus, eadem \& parsis id euenire apparent:par tes, fcilicet omnes alb $x$, frigid $x$ q́ue, \& oculi in primis minimi,triftesq́ue fiunt; Et fentiendi, intelligendique, \& motus $æ$ dendi vis, fi non prorfus perit, fummopere cer tè imminuitur. nam ut cord is natura triftata languidius pulfet,minoremque fanguinis copiam in partes effundat, nô cer tè vt dictum eft, ftatim ex pallidæ fiant, frigidæćue. Minus etiam qua à fubftantia in cerebro inhabitante fe fe commoue di,fentiendique Galeno donantur facultate, minore ca done tur. Et oculi, in quos nihil prorfus à cordis natura, \& ipfo à corde innittitur, nihilo minores, minufque fiant fplendidi. $Q u x$ ce rtè ratiocinatur fubftantia nihilo fegnius, nihilque ratiocinetur Galeno peius cordis natura; \& corde ipfo fum- 


\section{BernardiniTelefij.}

mopere oblxfo, quam nihil prorfus paffo. Ac fi qux fentit, intelligitque, \& partes commouet fubftantia,eadem \& malo re rum fucceffu triftetur, modus, quò illa euenient, nihil omnino inquirēdus eft; fummo, fcilicet fui natura gloriofus fpiritus, mifer, hnmilifque uideri non fubltinet: it aque (quod $\mathrm{ma}$ lo quopiam opprefsi pafsim homines faciunt) quàm maxime poteft colligit fe fe,penitufq; abdit, \& munerum oblitus omnium, nec præfentium rerum uires fentit, nec remotarum naturas intelligit . Nullamq́que operari operationem, \& uoluptate omnino nulla affici unlt:ut qui eo effe modo, feruarique non uult, nec appetit.in lætitia contraria, in eaque imprimis; quę bonis, quorum appetitu cord is natura Galeno fagrat, ho mo aficitur, oculi quidem ampliores, at vniuerfum omnino os cìm grandius, tùm fplendidius, \& reliqux corporis partes calidiores, rubicundioresq́xe, \& eas commouendi ius, fi moderata fit lætitia, augeri; at fentiendi intelligendique imminui uidetur. Hx itidem immutationes qui fiant, fi cordis natura latitia aficitur, intueri non licet:Vt enim exhylaratum cor ualidius pulfet,maioremq́ue fanguinis copiam in partes effundat, non fratim certè grandiores ea, calidiorefque $\&$ ru bicundiores fiant:nec oculorum magnitudo,aut fplendor ul lum capiat incrementum:In quos nimirum nihil prorfus (ut dictum elt) à corde immittitur, nihil etiam vel partes cómo uendi, uel fentiendi, intelligendiq́ ue uis Galeno immutetur; cui fcilicet (ut fape dictum eft) nihil fubftantix in cerebro in habitanti, cui illam omnem attribuit Galenus cord is naturæ affectiones, nec contra communicari uidentur. At uerò fi fpi ritus lætetur, quomodò immutationes illæ omnes fiāt, nullo innotefcat labore; gloriofus ni mirum fui natura ( vt dictum eft) fpiritus bonis vbi affluit, quibus præfertim donatus alijs fiper excellere videtur, haud quaquam fe fe abdit, fed quam maxim 2 fieri poteft, fe fe oftentat, itaque $\&$ in reliquas exter nas partes omnes, \& in oculos præcipuè, in quibus pręcipuè confpicuus fit, fe fe effundit, minimeq́ue torpet unquam: fed ubique uel ti lafciuit;itaque ampliores quidem oculi, at uniuerfum omnino os amplius fit, fplendidiusque, \& blando in oculis fpuritus commotus motu, ueluti pacem in ijs,bonaq́; omnia pollicetur, \& partes reliquæ omnis in calefcunt, \& rubefcunt infuper, qux præfertim arterijs, uenifque abundant, \& moderate fi latetur, moderateqúc in yartes fe fe effundat 


\section{Quod Ani.vniu.ab vnic.Ani.fubf.guber. 34}

fpiritus, promptius eas, robuftiusq́; commo!let. nam (ut fuo amplius declarabitur loco) ubi nimis, tantusq́ue omnino ex tremas in partes effunditur fpiritus, ut qui reliquas in cercbri uentriculis fit, proprià munera non tecte obire queat , \& fpiritus omnino non belle fibi ipfi unitus remaneat, fed veluti à fe ipfo iungatur:Vbique exoluitur ipfus uis, \& ext inguitur interdum uniuerf $\mathrm{s}$, fentiendi certè, intelligendique facultas, uel moderata in latitia imminui uidetar: in bonis, enim quę effiuxere contemplandis, fruendisq́; intentus f piritus, qux patitur, non fatis fentit, minus etiam qux olim paffus eft, recolit. Quniam igitur fi cordis natura afficiatur, modus, quo, qux in iracundia,mctu, triftitia, latitiaque homini eueniunt, fiant, confpiciendus omnino reperiri poteft nullus: at manife?tifsimus fit, fi qux fentit, intelligit que, \& motus ædit fubftantia, ea itidem afficiatur, quin ab vna ea quas animal operatur operationes, ædantur omnes, \& uniuerfum omnino animal gubernetur Galeno in primis ambigere non licet.

Anime itidem defectum, deliquiorumg caufam innotefcere non poße, ja a pluribus naturalibus facultatibus; at manifeft am effe, fi corpus uniuerfum ab vric a anime fubstantia gubernetur. Cap. $X X I X$.

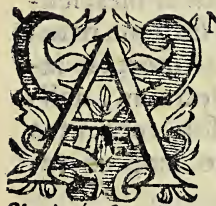
N I M AE itidem defectum, deliquiorumq́ue caufa nunquam innotefcat, fi diuerfę corpo ris partes à fingulis naturalibus gubernentur facultatibus:at in promptu, apertoq́; eafit, \& una eadéǵ; omniú, fi illæ omnes ab vni ca regãtur anima, in uniuerfis neruis delata fibrisq́; fuerit. itaq; operępretiú, quibus, \& in quibus animæ perturbationibus quibufq; in corporis affectionibus, \& euenire ea foleăt, \& qux ipfis accidunt, tü ipforú intueri caufam, ut in ijs etiã ueritas elucefcat. fenes præcipue (inquit Galenus) \& natıra imbecilli magna affecti triftitia, \& latitia itide Glav.c.14. magna,animo defecerunt, qui autē robufto funt corfore, ex ” immodicis euacuationibus idem patiuntur. Iamverò fi ab- "

$$
\text { I } 2 \text { fceftus }
$$




\section{Bernardini Telefij}

„, fceffus quifpiam rumpatur,vires vehementer ledit. Actum „pracipiè cum tnateria tota fimal ad uentriculum, uel ipfus os, aut ad thoracem defuxerit; quod fi quando etiam nos ab "fceflus fecantes (inquit) totam fimul emittere pus uolueri"Inus, animi defectum fubfequi eft neceffarium. Nec uerò la", borantibus aqua intercutem, tota fimul humiditas (quam"uis ea praternaturam fit) fine noxa uacuari poteft. Sed \& "tum quoque neceflum eft, hominem animo deficere, $8 x$ dolo"rum etiam uehementia, difolutiones accidunt. Quin \& ner", uus percuffus, \& mal gna in articulis ulcera , \& immoderata "quxdam frigiditas caliditafuè : Præterea \& infignis crudi, tas, obitructioǵue, aut inflammatio alicuius prxcipux partis, aut os uentriculi male affectum, aut improbx euacuationes, \& ob alia itidem multa , neluti ob fudoris copiam, ob uteri fuffocationem, quin, \& ob grumos vocatos, non cos folum, qui in vefica, fed multò illos magis, qui in inteftinis uentriculoque atque thorace non nunquam continêtur, Animi defectio, \& color pallidus fequi folet. Pulfus uero paruus, obfcurus, \& frequens apparet, laboransq́ue ipfe cum anxietate refoluitur, \& in omnibus (inquit) qui animi deliquium patiuntur, fi uehemens fuerit ea difpofitio, pulfus funt inæquales, intercidentesq́ue. Affecuum horum omnium ea vna communisq́ue exiftit caufa, \& nimirum fpiritus portionis omnis, \& ipfa etiam uniuerfitas conuolauit, ubi labor, vbi dolor, ut fibi ipfi ibi laboranti opem ferat, \& infeftantia, noxiaque inde explodat, expellatquue. Reliqux igitur corporis partes vitx omnes, fenfusq́ue, \& motus auctore deftitutr, quales fui funt natura immobiles fact $x$, concidunt, \& ueluti demortux iacent; \& dicta quidem caufa communis defectuum, deliquiorumque omnium effe uidetur. Et qua fola contentos quiefcere liceat; at fingulorum tamen ratio feorfum exponatur. 


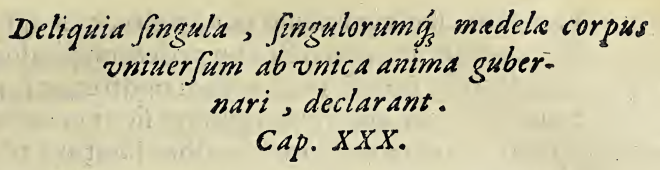

Ges $\mathrm{x}$ in modicis euacuationibus fequuntur ani

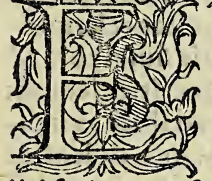
mæ deliquia, fi quidem qux quauis è corpo ris parte eijciuntur,fpiritus ea omnia, \& pro pterea omnino eijcit, quod grauia ei funt, moleftaque, \& vbi qux diuexatur fpiritus portio, qux eam infeftant, fola ipfa ammoliri fat is non eft, proprijs reliqux fedibus, proprijsq́ue defertió muneribus, ei opem afferunt omnes.Itaque modo reliqua in ijs facta, quanta nec ipfarum molem dimouere, fubftinereuè, nec quafuis externarum rerum aciiones, fed uehementes modò fentire queat, Immobiles, ftupidẹque apparent. Iure igitur qui ob immodicas enacuationes deficiunt, frigidam eos fpargere, mandat Cialenus, tùm $\$$ ipforum aures comprehendere, 3 ventriculi os perfricare, compellereque, ut uomant, ftomacum digito, uel pennx immifsione irritando, ac deniq́ue manus, pedesq́ue colligare, qux fcilicet eò tendunt omnia, ut fpiritum inde anocêt, quò connolauit omnis . auocatur autem, ubi alijs in partibus diuexatur, affligiturq́ue, id fiquidem ( ut frpè dictum eft ) fpiritus ingenium eft, ut ubi noxium quid moleftumá; fentit, eò nullo conuolet temporis momento; fibi ipfi ibi laboranti opem ferens. proptereaque, dum ftomachus digito, vel pennx immifsione irritatur, uomitus confequitur. neq́ue enim qui ftomacho inexiftit tantum, ad id, quod moleftiam infert amoliendum infurgit fpiritus, idq́ae vt eijciat, ftomachum conftringit, fed qui ventriculo ineft, omnis. Nam \& id (vt dictum eft) fpiritus eft ingenium, vt ibi, qux eius portio infeftatar, quod infeftat amoliri per fe non poteft, contigux proximæque opem afferant, \& ipfa vniuerfitas, fi vniuerfitatis opus eft ope. Tùm non qux uis. fibrx pars per fe vel intendi vel remitti poffe apparet; fed que dam modo earum principia, paltes reliqux principiorum omnino motum confequi uidentur: (vt ex ijs qux in ijfdem expofita funt commentarijs patere exiftimo) non ftomacho 


\section{Bernardini Telefij}

neceffiment hominem anima deficere, quax fcilicet ut a moliantur, diuturna fpiritus uniuerfi, opus eft opera, ea non tota fimul amolienda funt; diu enim cum noxijs rebus confliEtatıs, diuq́ie, \& ab ijs, \& à fe ipfo compreffus pęnitus tandem deficiat, pęnitusquue pereat. itaque non diu exercendus, fed ab opere reuocandus, \& nequaquam dolorificis rebus,fed fuauifsimis odoribus, fiquidem, \& id itidem eft fpiritus ingenium, ut non ad noxia modò expellenda, fed ad fuauifsima itidem fruenda, amplcctendaq́ue conuolat uniuerfus, En itaq̛́; ubi odoribus naribus appofitis curātur deli quia. cor enim fuauitate illectus ea ut perfruatur uel quibufuis alijs omifsis uniuerfus ad uniuerfitatēe, $\&$ ad cerebri uêtri culos, in quibus fit odor cónolat, unde mox uniuerfo reftitui tur corpori, eò uidelicet ( ut dictum eft) modo in internis perpetno firitus operatur, quo $\&$ in externis, $\&$ fpiritus fingulx, quò finguli eorum coctus, quorum quiuis, fi eius pars malo quopiam opprimatur ad id amolicndum confluit uniuerfus. At fi ingens interea aliqua uoluptas propofita fit, quodque imminet malum fummum non fit, \& quod cætui uniuerfo, vel eius parti exitium non inferant, Jaborantis molęia neglecta, ad uoluptatem perfruédam confuit uniierfus. 


\section{Quod Ani.vniu.ab vnic. Ani.fublt guber. 36}

uerfus. Ex dolorum itidem vehementia diffolutiones (in- Eod. quit)accid unt:ubi fcilicet dolor, ubi uidelicet alienum quid " moleftım q fpiritum torquet, eó aduolat uninerfus, ut quod » infeltat eijciat, idque vel ex humorum confexu, qui illuc fit " intelligere licet. Quin \& neruus (inquit) percuffus, \& mu- " fculi caput, malignaque in articulis ulcera deliquium animẹ inducunt iurè fanè. nam fi partibus offenfis quibufuis ad Glaus. promptifsime ad eas uniuerfus conuolat fpiritus, ut portioni neruis ijs immitis inexiltenti opem ferat, fed fcilicet earum mala attingunt, co percufio neruo mufculique capite ad utrunque conuolat promptius, quod utriufque malum proximius fpiritus attingit, \& quorum quidem unoque confricto inexiftens comprimitur fpiritus . \& fi ad mala amolienda, qux uis eo ad maligniora. Iure ctiam immoderata frigiditas, quæ nimirum quancumq; corporis par tem corripit, eam, eique inexifte ntem fpiritum in angufum agit, comprimitque: itaque haud quaquam, qui ad eam con fluxit fpiritus inde anocandus, fed prainexiftenti locus amplificandus, calefacienda fcilicet atque aperienda particu$1 a, \&$ igne, \& frictione, \& cibis, \& medicamentis calidis . Nimia etiam caliditas, fi quid aliud animẹ deliquium inducit, corpore uidelicet uniuerfo, neruifque \& fibris calefa$c t i s$, atque adapertis minimeque egrelíum fpiritui ab negantibus, tenuiori prefertim facto, euolat is, atque clabitur, itaque \& exoluitur nimis tandem imminurus. Hos frigida fpargendos, \& refrigerandos, flabellandosq́ue mandat Galenus ut fcilicet fpiritus intro agatur, \& corpus omne confringatur, itaque elabanti exitus occludatur.obntructio præ terea, $\&$ inflammatio. Vbi fcilicet aliena res quampiam ilia-" bütur in parté, quia \& ipfa, \& ijs, qux ipfi infunt neru of $x$ por tiones, \& fpiritus amplius, qui in his continetur, comprimitur, qui reliquis inexiftit partibus, ad illam confluit omnis, ut qux ibi ipfum ditexant, amoliatur. Inde itaç auocetur,alibi itidem affigendus eft, cruciandusq́ae; artus fcilicet fortiter per fricandi, diligandiq́ue.fequitur, \& animæ deliquiú ob fudoris copiam; iure me herculx; quo enim à malo, feu folid $x$ corporis partes, feu humores in uafis contenti liquantur, ab eodem \& fpiritus portio, quam illi attingunt, diuexatur, itaque reliqux ad eam confaunt omnes, opem laboranti ut ferant. his porrò haud quaquam manus; pedesq́ue 


\section{Bernardini Telefii}

pedesq́ue alligare oportet. Neque ad uomitum pronocare, quippe quibus non vnam in partem confluxit fpiritus, è qua Eod. ad reliquas, \& ad principium reuocandus fit: fed corpus qui
bufcumque licet modis refrigerand um eft, ut perfrigeratū,

" confrictumque non amplius liquefcat. At qui (inquit) ex

" plenitudine exoluuntur, qui propterea exoluuntur, quòd

" ad partem plenitudine oppreffum fpiritus confluxit omnis,

" malum inde amoliturus: horum (inquit) perfricandi,\& de-

" ligandi, \& calefaciendi etiam funt artus, ad ipfos nimirum fpiritus reuocandus; quòd fit, dum qui reliquus factus eft, moleftia afficitur, \& aduenienti , opemque afferenti aditus patefit .

2 Qure ex matrice laborant, atque exoluuntur, harum artus perfricare oportet, ac deligare, [piritus nimirum, qui uniuer fus ad laboranté uterum conuolauit, ad partes reuocandus, quòd ( ut fepæ dictum eft) fieri uidetur, dum qui in illis reliquus factus eft, moleftia \& ipfe afficitur. At quibus ute-

Eod. "rus furfum \& ad latus reuellit inguinibus \& coxis cucurbitulx applicand $x, \&$ naribus quidem ea, qux fodifsimum ha

" bent odorem, matricibus autem odorata, eaque medicamenta, qux laxare, calefacereque poffunt. $\mathrm{E}$ fuperioribus fcilicet partibus uterus detrıdendus, \& ad propriam fedem reuocandus, fpiritus nimirum, inferioribus inexittens partibus cruciandus, ut ad illas uniuerfus delabatur fibi ipfi in illis laboranti opem ferens, \& ad uteri amplius locum odoris fuauitate eò illectus, \& foeditate è fuperiore depulfus loco ; proprix nimirum conferuationis fummè appetens fpiritus, \& eadem omnino ratione, codemque in internis, q'10 $\&$ in externis operans fenfu, \& qux fouent ipfum oblactantque, quod fuauifsimi odores vel imprimis faciunt, promptè fectatur, \& qux fummopere oblędunt, \& abfque proprį̧ falutis periculo uitare poteft : cuius modi tetri funt odores, libens ea uitat : nam à quibus exitium tandem reformidat, 8 uitare non licet ad internitionem vfque cum ijs depugnat. Qiod fatis reor in dictorum deliquiorum omnium, ac multò etiam clarius in eorum curatione intueri potuit Galenus, quę ob triftitiam, aut gaudium, aut timorem proueniunt, alıt iram, quę nimirum omnia fuauifsimis odoribus, \& vomitu itidem oblectante nimirum, \& cruciante re curari ipfe precipit: odorum uidelicet fuanitate allectus fpiritus, affectionis 
fectionis etiam, qua occupabatur, oblitus, non amplius, quibus in ea commouebatur commo tetur motibus. Nam fcilicet fe fe amplius colligit, contrahitque nec diffundit, difsipatque, q:iin ad propriam fefe reducit difpofitionem . \& nimis confrictus fi fit, ectiam in fe ipfam coactus, confpiffatufque, fe fe ueluti explicat, diffundi tue, at colligit $\mathrm{fe} f \mathrm{f}$, nimis diffufus nimifque difsipatus fi fit.

\section{Idem \& mors, que dolorem, \& qua anima confequitur per. turbationes. Cap. $X X X I$.}

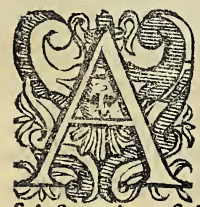

T non deficere tantùm, fed mori etiam (in- ;, quit Galenus ) contingit ob uehementem ", dolorem, aut timorem grauem, \& ob im- ", menfam itidem lętitiam. Quibus enim uita", le robur infirmum eft, animę uero affectio-" ", nes nes, ob imperitiam fortes, ijs facile anime, , fubftantia refoluitur, atque horum aliqui etiam ob męftitiã perire : at uir magnanimus ob nullam animę perturbationem fuccumbit unquam. Rectè fanè: quoniam enim quę in dolore fiunt deliquia, propterea fiunt, quòd quapiam fpiritus portione grauiter offenfa, relique omnes ad eam confluent, quę eam affigunt res ut amoliatur.Idque dum agit, \& ab illarum uiribus oblęditur, \& anguftum in locum confluxus uniuerfus fummoperè comprimitur, quod (ut dictum eft ) maxime fpiritui moleftum eft, \& letrale prorfus, utiq́ue grauis, diuturnusq́ue vbi fit dolor, ubi fcilicet diu multima; à contrarijs præpotentibusq́; diuexatur uiribus, \& diu, multumq́ue comprimitur, pęnitus tandem corrumpatur oportet. fi quidem id fpiritus eft ingenium, ut ad res, à quibus qualuis in corporis parte malo fe affici fentit, amoliendas cô fluat uniuerfus, \& corrumpi potius fubftine at, quàm non exuperatis, eiectisq́ue illis, inde decedat.ita omnino (ut ali bi dictum eft ) fingulorum hominum fpiritus, ueluti finguli hominum catus, \& ipfí omnino operãtur homines. Et quod qux in timore mœftitiaque deliquia fiunt, propterea fiunt, quòd fingulę fpiritus portiones uniuerfitatem, turbatam, afflictamque, \& fe fe contrahentem fentientes, (ciuium, vt dictum eft,militumó́; ritu, qui Principem, Ducemque magno quopiam communique malo oppreffum intuiti, ad eum cô$\mathrm{k}$ fluunt 


\section{Bernardini Telefij}

fluunt omnes, fefeque ei agglomerant, mutua ut ope feruentur omnes ) proprijs fingula fedibus, proprijfque derelictis muneribus principem ad fedem,principemáue conflunt ad portionem, ubi nulla id fit menfura : adeò tandem comprimitur fpiritus, ut fpiritus, ut uaporum fortè ritu anguftas in res coactorum, in aliud cogatur ens. Et amplius promptiufque malum expectans, quàm pafius id. Nam quibus adueniê tibus conferuari poffe defperat fpiritus:ea ubi aduenere, exitiumq́ue non intulere, minusq́ne imminentia exhorreat oportet:itaq́ue plurima perpeffus, uiuere fubflinet, at que appetit etiam, quæ nihil expertus, æquè, \& magis fortè, quàm fui ipfus exhorreat interitum. ob latitiam uerò quod bono quopiam rerum euentu elatus, \& ueluti ebrius factus geftit, lafciuitq́uc; $\&$ fe fe oftētandi cupidifsimns, ad externas uniuerfus effunditur partes, itaq́ue (ut alibi dictum eft) non oculi modò longè in latitia grandiores, longeq́; fplendidiores, fed os etiam uniuerfum amplius fit, nitidiufque, \& nullum fefe ad illos effundendi faciens finem : comprimitur in illis tandem, fnffocaturq́ue, fortè \& uictoris exercitus more diuerfas in partes, \& ratione nulla, nullaque effluens menfu$\mathrm{ra}$, non unus remanet amplius, fed ueluti in diuerfas diuiditur portiones, \& fingulas à reliquis omnibus, omnesq́ue ab uniuerfitate principióque, quò afsiduè opus habere, \& $\dot{a}$ quo afsidue pendere uidentur, feiunctas, difclufafque, qux igitur fummopere turbatæ, perterrefactæq́ue omnes, quàm maxime poffunt fefe colligunt,itaq; \& comprimunt, corrumpuntqúue, longe certè is tenuifsimus, fenfuque præditus longè exquifitifsimo quid uis à propria natura, à propriàuè dimotus difpofitione quid uis omnino paffus, immutatufuè fpiritus nullo interijt temporis momento. Promptius porrò in lætitia, quàm in mæroribus corrumpiturfpiritus;fi quidé promptius libentiufque effundit fefe, quam cótrahit, bonifque à rebus efferri fefe, quàm à malis deprimi finit, \& nō qui libet;neque enim \& generofus qui elt, fublimifque, qui ipfe modò ne impuretur, cætera quæuis negligit, itaque à nullo rerum fucceffu agitatus, commotusqúue nec nimis contringi,nec dilatari poteft nimis. 


\section{Quod Ani.vniu.ab vnic. Ani.fubft.guber. 38}

Corporis partium, actionumg, confenfus animal vniuer. fum ab vnica anime fubftautia gubernari declarat. Cap $X X X 11$.

ARTIVM poftremó omnium,earumq; ope

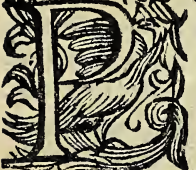
rationum, pafsionumq́ue côfenfus, animal haud quaquam à pluribus, cognitionisq́ue $8 c$ motus expertibus naturis, fed $a b$ una omnino fubftantia, \& fentiente ea,intelligenteq́; \& partes commouendi potéte gubernari eas omnes; quin quas ex fingulæ operationes, quofque $æ$ dere uidentur motus fingulis ipfam inexiftentem eos ædere, omnes manifeftè declarant;nam fi partes fingulx proprijs gubernen turà naturis, vt proprias ex percipiant necefsitates, ijsq; pro uideant, reliquis certè operantibus, laborantibusq́ue, nullam unquam offerant opem, nec quas in fui ipfius nutrimentum, bonumq́ue conficiunt res, vel ab alijs confectas affumpfere, alijs communicent ullis, nihil earum necefsitates percipien tef, nihilque earum operationes, fibi ipfis commodas, neceffariasque intelligentes, fecus ac facere uidentur; f fquidē qua uis operante, ita fe fe reliqux ad illius minifterium accommodant omnes:itaque illi omnes iuferuiunt, ut omnes ad illius vnius vfum factx uideri queant. Et fingulx quos in fe ipfis continent fuccos, vel fi fummopere ijs opus habeant ob lectenturq́ue, libentifsime alij cōmunicant omnibus:propte reà nimirum, quod partes omnes ab unica, ead omq́ue gubernätur fubutâtia, quin omnibus ipfa ut proprijs inexiftês orga nis, quas illę ędere vident operationes, ipfa eas ædit oēs.Ita que quia huius portio corporis parti ineft, qua quod propo fitum eft opus, optimè confici vniuerfitas decreuit, eo modo operatur, portiones reliqux reliquis inexiftentes partibus, il li inferuiunt omnes, \& quam pofsunt ferunt opcm, \& propte rea proprios fuccos, propriaq́ue opera ueluti mut tò fibi ipfis communicant partes, quòd ab vna omnes, cademque gubernantur, nutriunturq; fubftanti2.\& plutibus fimnl noxijs à re bus moleftia affectis partibus, fi quapiam fræter cateas affi gatur, nullus aliarum.Scd huins modò doloris animali fit fen fus, quòd qux illis omnibus inexiltit fubftantia, \& cuius, qui in animali fit ${ }_{2}$ fenfus eit omnis; eam in partem cöfluxit vni-

$$
\text { k } 2 \text { uerfa, }
$$




\section{Bernardini Telefij}

uerfa, in qua torqueri ferentit maxime, itaq; exigua in religs facta, nihilque fe ipfam in ijs comprimés, nec cú infeftätibus depugnans rebus, \& longè omnino in illa diuexata uehemen tius, nullum in ijs fentit dolorem. Et propterea una modò par te vehementer afflicta, reliqux languent omnes, quod ab una omnes, eademq́ue gubernantur fubftantia: itaque uehementer ea in quapiam diuexata, in eamq́ue confluxa omnis, langueat in reliquis oportet. Et propterea plures fimul, \&r diligéter omnes operationes operari non poffumus, quod una, eademq́; cùm fit, qux illas omnes operatur fubftantia, pluribus ea fimul intenta effe non poteft: fingulx certe fi partes a proprijs gubernentur naturis fenfus præfertim plerifque, \& cognitionis expertibus, adeò à fe ipfis diuerfe illæcum fint, \& fingulx non proprijs tantum, fed reliquarum fortè omnium operationibus conferuandę fint, operibusq́ue, quarum omni no nullæ propria opera, \& qux ad propriam faluteu neceflaria funt, conficienda, parandaq́ue fatis cum fint, fed fingula aliarum omnium ope afsiduè opus cùm habeant, ambigere non liceat, quin breui omnino corrumpantut omnes, earum nullis reliquarum necefsitates percipientibus, nuliisque pro priam falutem ab aliarum falute pendere intelligentibus, nul lis cmnino ullam alijs opem ferentibus, ut nifi rationes obftent, quæ Hippocrati, Platonique, \&x cos fequuto Galeno aliam in homine fubfantiam ratiocinari, aliam verò irafci, $\&$ aliam appetere, perfuaferút, liquidò pateat, animal uniuerfum ab unica animæ fubtantia gubernari. Age itaq; explicentur, examinenturque $\&$ ip $\{$.

Sentiendi, ratiocinandi, movendig, ,tùn du irafcendi,pulfars dique preterea, di nutriendi,generandique utm à diwergs, homines babere principys.

¿̀ quibus colligit Galenus.

Cap. $X X X I I I$.

s. de Hipp. anoz \& Plat.decret.c.7.

ว)

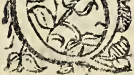
brutorum initar promptè ad repletionem ferimur, nihil conducat ne, an obfit confiderantes atate uerò pronecti, ne bibimus quidem omni-

" no, ubi perfuafum habucrimus, expotu noxam fubfequutu: 


\section{Quod Ani.vniu. ab vnic. Ani.fubft.guber. 39}

ram:frepe minus edimus, fi \& hic copia obfutura eft, inte- , rim aquam bibimus, uinnm concupifcentes;rationis autem ", expertes homines fimiles infantibus, atq́ue feris, neque tē-", pus expectant,n eq́ue quátitatem qualitatemuè corporis in ", fpicere fuftinent. Vrique manifeftum eft homines non à fo-" ", la rationali fubftantia gubernari, fed ab alia itidem, quę,quo", niam qux ratio auerfatur, concupifcit, ad eaque fruenda", homines allicit, appetitoria dicitur, $\&$ manifefte à ratione, diuerfa eft : manifelte enim ratio ei aduerfatur, ab ijsq́ue ad ;" quę appetitoria hominis allicit, retrahit illa, importunamo; ; appetitorix commotionem continct : \& pugna frequenter, utriufque inter fe oboritur, que enicenter duplicem efie in ", nobis naturam facultatum inter fe disfidentium declarat: fi ", enim ueluti in pueris una in effet appetitoria;nihil fanè pro-", hiberet ijs, quę appetimus intempeftiue nos frui, quemad-, modum etiam fi fola inefiet rationalis, nullum effet ncgotiü ," firientem non bibere, aut exurientem non effe . Neáue fobrius, neque contipens, qui non bibit, nominaretur ficuti " nec qui non uadit, nifi uelit. fitientis itaque nolentis aute" bibere, anima una quidem facultate, aut parte, potmin con- ", cupifcit : Altera uerò alia fugit, auerfaturque fiquidem uni ", atque eidem arripere aliquid, fugereque non licet. Et quo-", niam infuper ubiratio appetentiam ultrò fequitur, pugna", nulla in anima oriri uidetur, fed uniuerfa fibi ipfi concors ," ifs, quęappetit fruitur; $w$ bi verò appetitoriæ rationalis aduer ", -fatur, rational emque in uita ad fruendum appctitoria tra- ", hit; fummè homo irafci, ind ignariq́ue uidetur:liquido iti- ", dem conftat, iraf cibilem ab appetitoria diuerfam effe homi", nibusque inditam, ut rationi fubferuiat auxiliaturq́ue, per- ", inde ac uenatori canis, contra tertiam anime fpetiem: qua-, ", re (inquit) ubi ultrò ratio appetentiam fequitur, iracun-", dia rationem confequitur: ubi autem appetentięaduera-, tur, renititurque ratio, iracundia à ratione ftat, eique opem," fert, pręcipue cum ratio ipfa uel intus, uel extrinfecus iniu- ", ria fe affici \& ui compelli autumat. Si quidem autumare fe ", iniuria affici rationabilis eft facultatis; eam autem ulcifci ", animofe proprium exiftit . Vbi igitur appetitoria facultas," immoderate ad aliquod irruens inuitan rationem co fe-, cum attraxerit, irafcibilis cōtra illam rationi fuppetias fert. ", At ubi à nullo fe iniuria affici putat ratio minime iracúdia ", efieruefcit, 


\section{Bernardini Telefij}

, efferuefcit, \& fi quàm maximi tunc corpus puniatur algere " ab aliquo, nel famefcere, uel fitire coactum, unde liquet ira" cundiam naturali ftatu præditam, opiniones rationis fequi, " fieri tamen quandoquue poteft, ut hęc quoq́ue prauè affecta, " immorigera rationi moueatur:Quod autem, 8 iracnndia i " ratione diuerfa fit, hinc (inquit) docet Plato, quòd pueri, " perinde ac ferę maxime iracúdiexiftẽtes, ratione careāt.eodé " fiquidem modò pueri, quò \& ętate prouecti irafcuntur, hoc " interiecto difcrimine, quòd hi in multis iracun diam $\mathbf{r a -}$ " tione continent, quem admodum paftor aliquis ge nerofum " canem ferocius proximos infilientem ${ }^{*}$; in pueris autem, $n$ :hil huiufmodi accidit, quemadmodum neque in beftijs, quòd in illis quidem, nondum, in his uerò numquam, ratio anim $x$ impetus inhibeat.

Num que irafcitur, of que animal nutrit, generatque intelligenti, mouentique eadem, anillarum ab hac diuerfa, \& altera cordis, iecinoris altera temperiesfit, notum ut fiat, conditiones, quibus illarum utramque donatam eße oportet, inquirendas effe. Cap. $X X X I 111$.

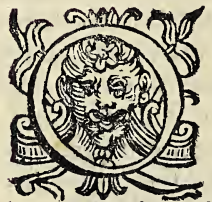

VAE in homine fentit, intelligitque, \& motus adit fubftantia, \& fpiritus omnino, qui in cerebri uentriculis, ut in maximè propria, ac principe fede continetur, at \& reliquis cerebro fimilibus rebus omnibus: itaq́ue \& omnibus inexiftit corporis partibus, num is itidem irafcatur, indigneturque, \& illatas iniurias ulcifcendi, \& libertatis, uictorix, potentix, imperij, glorix, honorisq́ue flagret libidine; Præterea \& animal nutriat, generetq́ue, \& cibos, venereaq́ue appetat, an brutx cordis temperies iracundia, uindietróue, \& illorum omnium, ciborum uero uenereorumq́ue appetitus iecinoris natura af fignandus fit, notum ut fiat. Vtique conditiones, quibus que indignatur, uindictamq́ue, \& honores appetit ( liceat enim corum omnium, que cordis temperies Galeno appetit loco, unum ponere honorem, nam qux eorum honori idem 


\section{Quod Ani.vniu. ab vnic.Ani.fubft.gubcr. 40}

non funt, honoris gratia, \& propterea omninò præcipuè appetuntur, quod honorem pariunt) præterea \& quibus, cui animal nutriendi generandique, \& cibos, uenereaque appetendi facultas afsignanda eft, donatam effe oportet, infpiciend omnino funt.Nam fi ex omnes fpiritui in effe appareant, fruftra, temereque alia cordi quæ irafcatur, uindictamq́ue, $\&$ honorem, iecinori alia qux nutriat, generetque, $\&$ cibos uenereaque appetat, indatur, fubftantia. Cur enim operationes, quæ quoniam unum, cundemq́ue omnes habent fcopum, \& quæ unius omnino omnes animalis conferuationis gratia $x$ dendær funt, at non perpetuò fimul omnes, fed fuo fingulx ædendx funt tempore, \& alieno $x$ ditæ, fummum animali infetunt malum, uel uni omnino, eidemque omnes afsigandæ funt fubftantię;uel fi quidem pluribus, \& quarum certè fingulæ aliarum omnium necefsitates, laboresque percipiant, \& opem fi liceat fibi ipfis mutuo ferant omnes, id fi non liceat, nihil certè ( quod vel Galeno facere uidentur ) fecum ipfi pugnent, \& feipfas operantes mutuò turbent, impediantque, cur inquam diuerfa quidem que funt operationes, at qux unius eiufdemque rei xduntur gratia, \& quæ non omnes fimul, \& ueluti per uices, minimeque eadem femper menfura $x$ dend $x$ funt, uni fi fubftantix \& fummo fenfu, fummaq; pręditæ cognitione, \& quæ fingulis ineft corporis partibus, eafque, ut libet, comouendi obtinet facultatem, rectè afsignari poffunt, diuerforum eæ uifcerum naturis afsignentur, \& quarum fingulx diuerfo ab alijs præditæ fint ingenio, \& proprijs fingulæ gaudentes ope rationibus, ijfque intentæ unis, nihil aliarum necefsitates, laboresq́ue percipiant. At eò certe minus f fi qux cordis, iecinorisq́ue natura operari appetẹreque videtur Galeno, ea operandi,appetendique prorfus impotens utraque, non fcilicet eo ingenio, ijsq́ue donata appareat conditionibus, qui bus qux irafcitur, uindi\&amq́ue, \& honorem, \& quę nutrit, generatque, \& cibos venereaq́ue appetit, donanda fit. At ve rò quòd ę ut innotefcant, qux ad iracundiã hominem agüt, \& quæ eam fedant. Et uindict $x$ honorifque, præterea, \& ciborum, uenereorumque appetitus fit, manifefum fit, oportet.Age ea primum inguirantur. 


\section{Bernardini Telefij}

Conditionibus, quibus, qua irafcitur, uindict am $q_{3}$, \& bono. rem appetit, donatam effe oportet fubftantiam, $p i$ -

ritum omnibus, cordis uerò naturam nullis prorfus donatam effe. Cap. $X X X V$.

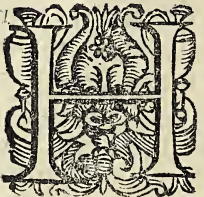

OMO quoduis perpeffus malum, triftitia quidem afficitur, mættitiaque. at fin non ob contemptum, fed iure, uel cafu quopiam il latum intelligat, quantumuis graue id fit, moleftumq́ue, nihil omnino indignatur, ni hilq; à quo illatum eft, punire appecit:at uel leuifsimo accepto incommodo, fi iniuria illatum id iudicet, qui nullo prorfus, at comptemptui habitus, excandefcit, eoque fui contemptorem punire flagrat defiderio, ut quouis cum periculo, \& malo etiam quouis puniendum decertat, ita que laborum, qui propterea fufcipiendi periculorũqú; quę fub eunda funt, magnitudinem nihil ærtimans, ad puniendum eü ruit, \& nifi puniat, nifi fcilicet eo fe nlhil deteriore declaret, quiefcit nunquam. At verò fi qui malum intulit fuplex fuppli cium deprecetur, vel uon contemptu, fed cafu quopiam, \& $\mathrm{à}$ nolente omnino, nihilqúue ipfum contemnente, \& nihil propterea fe fe efferente, fuperbienteque, fed commifum errorë ingemifcente illatum, fe omnino nihil ipfo præftantiorem, quin deteriotem prxdicet, oftentetq́ue, iram deponit omnê,, nullumq́ue ei amplius molitur malum, quin benefacere etia appetit;non malum porrò paffus, fed contemptus homo cùm irafcatur, uindi\&amq́ue moliatur, $\&$ in honore habitus latetur, \& à quò maló afiéctus eft, bęnefacere etiam ei appetat, liquido patet, uindictr appetitum, non rei alterius, fed unius omnino honoris appetitum effe.At neq́ue(quod dictum eft) quin reliquarum rerum, qua cordis natura appetere uidetur Galeno, appetitus, nō aliorum \& ipfe bonorum, fed vnius honoris appetitus fit, ambigere licet.fiquidem qux illarŭ idem honori non funt, propterea precipuè appetuntur, quòd hono rem pariunt:nam \& qux cōtemptum propulfant honorem ea pariunt; fubftantix, qux irafcitur,uindictamque, $\&$ honorem appetit, huiufmodi ingenium cùm fit, ut fcilicet non malum ea aliud, fed vnum exhorreat contemprum, nec bonum aliud ullum, 


\section{Quod Ani.vniu. ab vnic.Ani.fubft.gubcr. 4 I}

ullum, fed vnum expetant honorem, illumque ut propulfet, \&hoc ut potiatur, nihil malum aliud quoduis pati, \& bona quxuis, \& fe etiam ipfam proijcere reformidet: Vtique quod Galeno imprimis placet, malum à contemptu, \& reliqua bona ab honore dignofcere, diiudicareque queat, rationalis om nino fit oportet. Et nobilis infuper fui natura, generofaque: propterea enim contemptui, uilifquc haberi adeò exhorret, tantoqne honorem appetit opere, utfui contemptores vel fui ipfus exitio, exitio punire velit; \& à quibus in honore habetur, uel fummis ab ijs affecta malis, benefacere etiam ijs appetat, \& quouis fui ipfius incōmodo procuret.quò d à quibus vilis habetur, ueluti uilis fieri, corrumpi nimirum, in corumque animalium agi fubftantiam, quorum ritu ab illis tractatur, \& à quibus in honore habetur, à quibus nimirum, ut nobilis, generofaque excolitur, veluti in propria ab ijs conferua ri uidetur natura. Non fcilicet ibi modo ( $v t$ alibi amplius expofitum eit) corrumpitur humana fubftantia, ubi exitio da tur, fed nihilo fortè minus, peius certè, ubi qua fua origine in digna funt,vel operatur, vel patitur, veluti enim in aliam \& ignobiliorem tranfit fubftantiam. Prætera \& appctendi, \&z cum corpus uniuerfum, tùm fingulas eius partes commonen di potens ut fit oportet, qux irafcitur, uindictamque molitur fubftantia;neque enim nifi appetere queat, uindictam ea, honoremq́ue appetat; quin neque irafcitur, indigneturq́ue unquam; propterea enim irafcitur, indignaturq́ue, quòd ijs priuatur bonis, qux magnifacit, \& qux fummopere appetit. Et propterea ipfius iuditium, imperiumq́ue partium confequitur motus, quòd in ipfius is eft poteftate. Nam fi fubftantia alia partes moueri decernat, appetat uè, alia eas moueat, quò vel ubi magno mouend ex funt labore, adeo hæc illi promptè obtemperet, intelligere nō licet; nec Galenus id explicet vmquam:fubltantia, cui iracundię,contemptusq́ue odium,\&. honoris appetitus, \& illius omnino propulfandi,puniend iq́q; \& hunc comparandi facultas tributa eft, huiufmodi conditionibus donatam effe cum oporteat, haud quaquam cordis naturx afsignanda videri poteft, qux nimirum non rationis modò,fed fenfits etiam, itaque $\&$ animalis appetitus expers. Et cor quidem,arteriasq́ue dilatandi, conftringédiq́ue, \& alia rum corporis partium nullam prorfus commouendi potens Galeno vifa eft vfquam : qux igitur aliud prorfus nihil Gale- 


\section{Bernardini Telefij}

no operari queat, nifi quòd operari uidetur, fanguinem, fcilicet à iecinore confectum tenuiorem, calidioremque facere, \& multum omnino in co fpiritum ingenerare, $z$ fi quid appe tete queat, id tantum appetat, quod etiam Galcno appetere uidentur, quæ non ab anima, fed à natura reguntur, ić nimirum modò,à quo fouetur, conferuaturq́ue, $\&$ id modo odio habeat à quo corrumpitur, deftruiturque, quæ nihil ipfam im mutant, quin quæ nihil prorfus agunt, ac ne exiftunt quidem ipfa, fed intelligentis animæ ueluti cogitationes quęda funt, cordis temperies, ut appetere, auerfariuè a at fyercipere omni no pofsit quàm longif́simè $\mathrm{ab}$ eft.

Nullis itidem iecinoris naturam, quibus, qua animalnu-

trit, gencratque, \& cibos, venereaque appetit, donan da eft, donatam efle; at fpiritum donatum effe omnibus. Cap. $X X X V Z$.

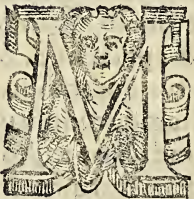

INVS etiam, qux animal nutrit, generatq; $\&$ cibes, vencreaque appetit, alia a fubftantia in cerebro inhabitante facienda, \& iecinori, ut proprio fubiecto indenda Galeno fuit:fiquidem conditionibus, quibus, cui hu iufmodioperandre funt, appetęndeque operationes, donatam efie oportet fabfantiam, iecinoris natura nallis prorfus donata eft : rerum fcilicet vires fentiendi, \& pafsiones, motusqu ue quibus ab illis affecta eft, commotaque commemorandi, recolendique, \&rappetendi eas, odioque habendi, praterea, \& fingulas corporis partes commouendi, uafaque omnia, ut libet, dilatandi, confringédique facultate predita eft, \& corporivniuerfo, fingulisq́ue inexifit cius partibus;quoniam enim cui proprium quippiä mun ${ }_{2}$, propriumque commiftum eft opus, operationes itidem, quibus id abfoluendum ef, uel fi plures ex fint, operandi facultatem tributam; carum vero, quæ nihil proprium, fed alienum pertinent ad opus, prorfus impotentem factam effe, nif rerum omnium conditorem Deum incrtix incufare veli mus, poncrim ompino eft; my dufque (vt dictum eft) quo fubtantix, qua cerebro, cordi, iecinorique, ut proprio fingulę infident fubiceto, mutuam fibi opem ferant, \& fingulęalias 


\section{Quod Ani.vniu.ab vnic.Ani.fubft.guber. 42}

ad proprias quidem impellant operationes, at quæe, nó quod ipfis, fed quod alijs demandatum eft opus, conficiant, repcriri nullus potelt. Itaque id fingulis munus, idque mociò dema datum effe opus, exiltimandum ef, quod proprijs facultatibus, proprijsáue conficere poffunt uiribus:itaque fubltanti६, cui animal nutrien di,generandique demâdatum eft munus, operationes, quibus vtrumque conficiendnm eft opus, oferandi omnes, facultatem tribitam effe receffario exiftimandam eft.te cibi illi primum magnaque interdum comparandifunt indufria: $\&$ in os ij ingerendi, in cocuc ueluti molien di, \& in minutifsima frultula redigendi. nam paulo corpulen tiores aflumpti longè egrius concoquuntur, cortm que interea uires percipienda, dignofecndrocue, \& fenfus, cui ab ijs factus eft,memoria retinędus.nifi cnim ille percipiantur, res interdum affumi queant, cux non módo ab animalium calore exuperari, in eorumque nutrimentum inucrti nequeãe, fed qux fummopere ea oblæćluit, \& penitus ctiam perdant; \& ni fi pafsionis, qua ab ijs facta eft, memoria feructur, farius abijfdē moleftia maloq́; afficiantur: tū in uentriculım, uêtrẹć; detrudendi, tandiuq; in illo retinendi dum in chilum, bene fcilicet tenuem, beneq́ue albam agantur in rem:in hoc verò, tum tenuifsima eius portio, \& qua à iecinoris calore exuperari, $\&$ in fanguinem agi queat, emulgatur uniuerfa, $\&$ in iccur importetur, \& quod in eo confecus fanguis è ualde dum difs imilari re, \& à non robuftifsimo confectus calore, non vniuerfus corporis partium nutricationi commotus fieri potuit, fed alia eius portio nimis, minus alia quam oportcbat calida, tenuisquie, vel horum altera facta eft, it aque ijs cmnibus probum in fanguinem, qux acta eft, expurganda $\&$, in pro

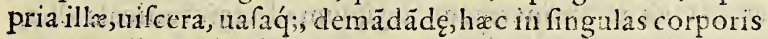
partes, nihiloq; in fuperiores, quã in inferiores fegnius cöportäda, \& quę in feminaria uafa, teftesq́; delata eff, in femen ibi acta, fomineum in uterum, ueluti eiaculanda. Et cum ciborum portio cuius crafsities in uentriculo, uentrećue exuperari non potuit, tum praui, qui in iecinore facti fuit fucci, expellèdi, eijciendique. Qhoniam inquam, animal, ut nutriatur, operationes hę omnes, \& ut femen in uterum conicetrm in fętum agatur, alię longe plurimę ędendx funt, \& ad quas operandas haud quaquam minore fentiendi, motufaue ædendi facultate opus eft. Vtique fubftantic, cui animal iu-

$$
\text { L } 2 \text { triendi, }
$$




\section{Bernardini Telefij}

triendi,generandiq́ue demandatum eft munus, rerum vires percipiendi,dignofcendiqüe, ne præfentium modò, agêtium q́ue, fed retnotarum, earamque, quę nihil nunc agunt, at olim egere, intelligendi nimirum, \& quarum actio iucúda uifa eft, appetendi eas, amplexandique, alias odio habendi, reijciendique, \&x cum uniuerfum fimul corpus, tum fingulas eius par tes feorfum ab alijscommouendi,uafaque omnia, ut libet dilatandi, contringendique facultate prędita fit, uniuerfoque inexiftat corpori fummè eft neceffarium:qui enim nifi fenfu, \& lógè eo exquifitifsimo donata fit,proprias ciborum percipiat uires, aut qui nifi pafsionis, qua ab ijs affecta eft,memoria remãferit, corum ullos uel appetat, uel auerfetur: $\&$ nifi un de ij comparandi fint, intelligat, \& fingularum corporis partium minifterio ad comparandos eos,aflumendosq́ue uti fin gulas nimirum, ut opus eit, commouere,flectereq́; queat, qui illos comparet, affumetque, \& conterat.Et nifi uafa omnia, ut libet dilatand $i$, conftringendique potens fit, qui cibos, confe ctosq́ue ex ijs fuccos, uel attrahat, uel retineat, uel expellat:\& nifi fingulis corporis partibus inexıftat, qui fingularum paffiones necefsitatesq́ue percipiat:fingulasqúue, ut libet, cōmoueat : Itaque ( quod dictum eft) qux animal nutrit, generat que fub?tanria, non alia ab ea quę in cerebro inhabitat, faciẻ da, \& iecinori,vt proprix materię idenda; uel ipfi enim Galeno conditionibus, facultatibusq́u e, quibus, cui nutriendi ge nerandique afsignandum eft munus, omnibus illa, hæc nullis prorfus donata elt. Nam fi nullam illa fui portionem in partes mittere, at proprias certè, \& fentiendi omnino, mouendi que facultates omnibus communicare uifa eft. Iecinoris verò natura non intelligendi modo, fed ne fentiendi quidem facultatem Galeno obtinet:nam quę ipfum obtegit tunicula alba, exanguifque cum fit, è fernine confecta, \& à cerebro emanare nô iecinoris pars uideri Galeno debet, ut uidetur omnino, \& quouis illa, iecinorisóque natura, donata fi fit fenfu, quoniam uoluptatis, quam in ciborū affumptione, thenerifque vfu, in pręcipuis nimirum nutritorię generatiuęque fubftantię operationibus animal percipit, nullus prorfus illi fit fenfus, nutriendi,generandique munus illi afsignatum effe exiftimare non licet; Et in propria omn is contenta materia, ne hanc qui dem ullo cómouet motu.Et importatos, quidem fuccos amplius cốcoquit, at nó adeo tamê, ut ex ijs nihil alijs in uifceribus 


\section{Quod Ani. vniu.ab vnic. Ani.fubat.guber. 43}

ribus concôtis recte uniuerfum an imal nutriri, minus etiã, ut fatus conftitui queat. Vtique iecur haud quaquam nutritorię animę fubiectum; fed organum ipfi in primis Galeno ponendum fuit. At agè, quod reliquim eft, num pugna, que quibufdam propofitis operationibus, in anima fieri uidetur, \& quę iracundia efteruefcente in corde \& in iecinore oblęfo in uniuerfo in animali fiunt immutationes, tationes nimirü, fignạqu;, quę fubftantiā, quæ irafcitur, uindictã q́; , \&r honores appetit, prętera \& que animal nutrit, generató;; \& cibos, uene reaq; appetit, alias à ratiǫnali, \& cordis illä,iecinoris häc naturā effe Galeno pfuafere, unò̀ à fpiritu neruofo in genere cô. této animal uniuerfum fi gubernetur, fieri queãt, intueamur.

Pugna, que quibufdam operationibus propofitis, in anima feri videtur, none diuerfis eam fubftantìs compofa.

tam, nec à pluribus animal gubernari fubftan-

tijs, fed unam omnino illam, eandemǵs

effe, of una ab ea animal uni

uerfum gubernari declarat.

Cap. $X X X V I I$.

ARV 2 VGNA porrò, qua quibufdẩ propofitis ope

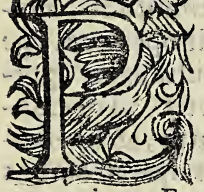
rationibus, in anima interdu oriri uidetur, quæ antiquiores omnes, \& ipfum imprimis impulfit Galenum, ut uel è diuerfis illä cōpo nerêt fubitantijs, uel tres omnino, \& fummopere à fe ipfis differentes, homini inderent animas: Ea imprimis haud quaquam pluribus à fubftantijs, \& diuerfis pofitis in locis, diuerfoque donatis ingenio, fed ab una omnino, eadem que animal uniuerfum gubernari, omnefque, quas animal operatur operationes, \& appetiticnes, quæ animali infunt orines, una modò à fubftantia ędi, \& uni ineffe omnes, declarat. cui enim dubium effe poteft, fi alia honeftum, bonumq́ue, quæ ratio appetenda decernere uidetur; uindictam alia, \& fuper excellentiam : huius enim gratia qua cordis natura Galeno appetit, appetere uidetur; alia voliuptatē appetat, féficturq́;.quin perpetuo fecum ipfis. ex pugnët, decertentq́ue, \& fingulis proprias ad operationes operandas hominem impellentibis, nulla unquam edatur

$$
\text { L } 3 \text { operatio: }
$$




\section{Bernardini Telefii}

operatio; honeftum certè, bonimqúue. qux defiderat, quas turpes, da muofasćrie eie intelligit, numquam eas operari permittat, quavis, qua ijs gaudent, operandiffagrent libidines cur enim quas iofas atuerfatur operationes, \& qux ipfa inuita, quin opem aur fetente nullą di polfunt ratione, ope rari cas permittat, quin ipfatnet eas operetur unquam? neque enim fubftantia alia ula fed qua corporis partes commouet, ea $\rho$ perationes operatur omnes. Nec tuerò fibi ipfis fubotantias, qux dietzefunt, mutuorinterdum obfeçui, \& alir operari appetenti opern fere aliam, tel in eius gratiam, obfequiumq́ xe operati dixerit Galenus ipfi enim proprijs modò actionibus, proprijsq́ue fingulx muneribusintentæe effe, \&caliarum labores, moleftiasque nihil prorfus fentire uifre funt . \& recte quidem qui enim uifcerum adeò à fe ipfis di ftantium, difsidentiumque naturæ aliarum percipiendi potentes uideriqueant, $a c$ aliarum incommoda percipiant, \& $\&$ alix alijs proprias communicent appetitiones? Ar vna eademque fi bonum, honeftumq́ue, \& contemptum propulfare, fuper excellereque, prxterea \& uoluptates appetat . Qioniam qua bonum, fuper excellentiamque afferunt opera tiones, magnis ex plerumque laboribus, magnisq́ue operan$d x$ funt periculis, \& quę voluptatem pariunt, non puram ex femper pariant, finceramque, fed quam vel turpitudo, infamiaque, uel dolor excipiat. Vtique huiufmodi operatura ope rationes à fe ipfa defsideat, indiuerfaque diftrahatur oportet; à rebus nimirum, quas fummoperè appetit, ad operandum illecta \& a ab ijs quas fummopere auerfatur, ab operando reiecta. Itaque qux quibufdam propofitis operationibus fieri in homine pugna interdum uidetur, haud quapiam diuerfarum ea fubltantiarum contentio eft, decertatioǵue, fed unius eiufdemque operari appetentis fimul, \& reformidantis perplexio dubitatioq́ue : cuilufmodi uel ubi ex ædendæ funt operationes, quas uni eidemque Galenus etiam attribuit fub ftantię, fieri itidem uidetur,pluribus propofitis operationibus, ¿z quarum fingulę magnum quippiam bonum, magnamuè polliceantur voluptatem, \& quarum unam modò operari liceat, à reliquis abftinendum omnino fit.non ftatim, fibique ipfi concors \& nihil omnino hafitans operatur hemo, fed anceps, quam unam ex omnibus operandam pracligat, diu interdum à fe ipfo difsidere, \& veluti fecum ipfe pugnare 


\section{Quod Ani.vniu.ab vnic. Ani.fublt.guber. 44}

apparet, æquè à fingulis ad operandam illectus, itaque \& in di uerfa ditractus . Et occultum, ignotumque quid diiudicaturus à fe ipfoitidem difsidere uidetur, contrarijs à rationibus, in contraria diftractus: operationibus nimirum propofitis, quæ non puram bonum, puram que polliceanturuoluptatem, fed quas à malo interdum, doloreue excipi fenferit ani ma: non ttatim operandas eas decern it, fed præfentis prius boni, prafentifquè voluptatis, \& futuri mali, futuriquè doloris magnitudinem, diuturnitatemque ueluti metitur, \& $\mathrm{pln}$ ribus bonis, pluribusq́ue propofitis voluptatibus, quod bona reliqua, \& quę reliquas exuperet voluptates, \& ignotum quip piam diiudicatura, quod diuerf $x$ rationes diuerfum dimoftrent earum firmitatem, roburquè confiderat, \& priufquam præfens bonum, prefentemquè voluptatem futuro malo, $\mathrm{fu}-$ turoque anteferat dolori, uel è contra, \& quod è bonis omnibus, quamque ex omnibus voluptatibus pręeligendam decernat, \& quęratio uerior, firmiorq, fit, cốpectú appareat, ne que operatur, neq; operäd i cogitationê dimittit unquả.itaq; à fe ipfa difsidere, \& fecum ipfa pugnare uidetur, \& uerè fecû ipfa pugnat anima, operationem eadem fimul \& appctens, \& odio habens. Quin \& in fe ipfam indignatur, \& fefe etiam ipfam odit, cruciatquẹ̀ ; ubi quam à prefente uicta uoluptate operatur operationem, malum eam, dolorue confequitur, à quo excipi eam fenferit; \& multo etiam amplius quę genero fa eft, nobilifque, ubi inopix cedens proprijs alios fpoliat bo nis, vel labores, periculaque exhorrefcens, malo fe iniuria affici finit, alijs benefaciendi, \& fuper excellendi, \& fui natura appetentifsima, corrupta, itaque in utroque, \& à propria dimota natura; inqú aliam, \& longe ignobiliorem acta fubftantiam : Eft \& vbi prefentis voluptat is fummoflagrans appetitu, eaque vt fruatur attendens folum, malum, dolorem q; à quo excipi eam fenfit, nihil prorfus confiderans, ad eam fruchendam ruit : nulla igitur ratione, at folo uinere uidetur fenfu, non quidem ratione carens, at ratione uti negligens, quo pacto \& animąlia reliqua, \& pueri uiuere uidentur, illa quidem quod non ea prędita funt intelligendi facultate, ut futura multa prxuidere, perpendereque; hi uero quòd ipforum fpiritus ab afsiduo uaporum confuxu exagitatus, abfentia, remotaquè intelligere, \& cùm pręfentibus ea conferre non potef: non ualde pręfertim id facere affuetus, nec multa 


\section{Bernardini Telefij.}

multa habens, quibus cum conferrè hęc pofsint ; at qui poftea non adeò à uaporibus turbatus, \& ufu edoctus à multis in polterum oblędi, fummoquè affici dolore, à quibus in pręfentia foureri oblectarique, uoluptatem, quam à dolore excipi fenferit, refpuere, \& ratiocinari omnino uidetur; Vt nifi quę iracundia efferuefcente in corde, \& quę iecinore oblęfo wniuerfo in corpore immutationes funt, fubftantiam, quę irafcitur, \& quę animal nutrit, gênerat que aliam à fentientc, intelligenteque, \& mouente, \& cordis illam, hanc uero iecinoris temperiem efle declarat, vna modò à fubftantia animal uninerfam gubernari, fatuendum omnino fit. Age itaque $\&$ illę infpiciantur.

Immutationes, que iracundia efferuefcente in corde, o gue iecinore oblafo, in uniuerfo fiunt animali, haud quaquam illius naturam irafcibilem, buius nero nutritoriam fubfantiam effe declarant. Cap. $X X X V I I I$.

4 \& 80 I quidem in iracundia unum cor, non \& re-

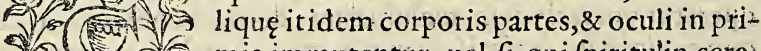
Do 15 mis immutentur, uel fi qui fpiritu'in cere \&ry bro, rebusq́ue cerebro fimilibus inhabitan(1II) $=$ indignato, commotoq́; cor itidem,eiuf(5) 5 (r) qu \& arteriarim motus immutetur, intueri non liceat, haud perperam forte è cordis, eiufque arteriarum motus immutatione, cord is temperiei iracindiam,uindictxq́que appetitum afsignet Galenus. Quoniam uero, \& reli qua partes omnes, \& oculi amplius, quorum immutatio omnis vel Galeno ipfi, iuxta fpiritus infuentis copiam, motum'que fit, fummopere immutantur, \& grandiores, minoreftè, \& nel fereni, tranquillique fieri, \& ueluti pacem,bonumquè pol liceri, uel turbari, malumque minitari pafsim apparent, \&fi Thenphatro credim is, flammas etiam emittunt, \& cor arte riafy te non à cordis natura, facultateque ab ea illis indita; fed à fpirit $ı$; $q$ i cordis ligamentis, fibrifque, \& arterijs om ni bus longe plurimis inexiftit, dilatariconfringique. Et cor vehementius, celcriusǵue fpirıtu iracundia accenfo, uindictam ue 


\section{Quod Ani.vniu.ab vnic.Ani.fubft.guber. 45}

Etamq́ue moliente dilatetur, confringaturque fatis eft (vt exiltimo) fuperius declaratú haud rectè;propterea quòd cor calidius in iracundia fit magisque pulfat, cordis temperiei iracundiam, vindicteque, \& fuper excellendi afsignat appetitum. Non rectè itidem iecinoris temperiei animal nutriendi attribuit munus, \& nutritoriam eam ftatuit effe fubftantiam, quòd eo oblafo alimenti inopia, languefcat tandé animal. fi quidem, \& uentriculo male affecto, \& pinguedine, qux ventriculo, uentrique adhæret abfumpta, multò prius, multoque peius, \& ob alimenti omnino inopiam languet anima!; quin horum nullo quicquam paffo, at intelligente fubftantia trifti quapiam cogitatione diu oppreffa, nihilominus quam illorum quou is prauè affecto, corpus vniuerfum imminuitur, pefsimoque afficitur colore; nec uerò aliam ob caufam, nifi quòd alijs intenta anima operationibus, ciborum concoctio ni,nutrimentiq; degiftioni parum uacat, ut fi uentriculo, pinguedineque, \& iecinore oblęfo non bellè nutrimentum confi citur, non propterea illorum cuiufpiam temperiem nutritoriam fubftantiam, fed animæ omnia effe organa intelligendum fit. qux \& nutrit, \& fentit, \& intelligit, \& mouet, que omnino quas animal ędit operationes, eas ipfa $x$ dit omnes, corpore uniuerfo, fingulifque eius partibus,vt proprijs $v$ fa or ganis:at quarum vni ualde, vbi intenta eft, reliquas fi quidem operari non ceffat, non rectè certè opcratur, \& prauè omnino, vbiorgana quorum ope propofitę operandę funt operationes, prauè affecta funt.

\section{F I N I S.}




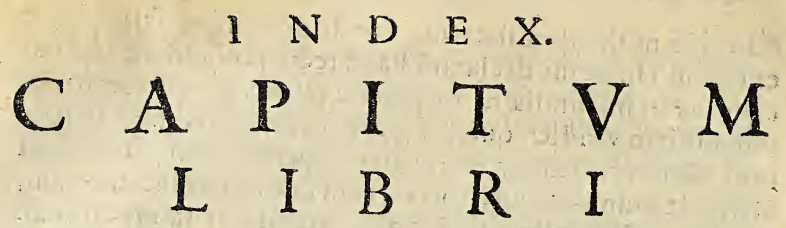

\section{QVOD ANIMAL VNIVERSVM} ab vnica Animę fubftantia gubernatur.

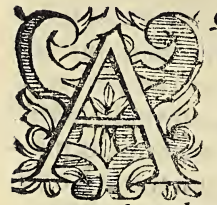

Ouot, qualibufque principüs, of quibus inuifceribus collocatis, \& quomodo, o qux fingulis operantibus homo gubernari, \& cor arteriarum, iecur verò venarum principium effe videtur Galeno. Cap. I. pag. $3 . a$ on quad iecinori inest, ab eo, quod cerebro inex fit, diuerfum effe; o illorum vtrumq; $\mathrm{Na}$ turale, hoc uerò animale videtur Galeno. Cap. II. pag.4.b Principinm cerebro intxiftens ab eo, quod cordi in eft, diuerfum omnino, diftinctumque effe, of nulla alterum alterius opera ad proprias ddendas cperationes opus babere videtur Galeno. Cap.III. pag. 4.6

DVec neruis, nec arterïs à proprïsprincipÿs fubstantix portionem immitti, fed facultatem tantum praberi. Cap. IIII. pag.5.6 Rationalis, Irrafcibilisque, cr app titori.e fubftantiam, non piritum in pentriculis contentum, fed uifceris, cui inboret, temp:riemeffe, unde colligit Galenus. Cap. $\quad V . \quad$ pag.6.a Nec cerebri temperiem, nec Subftantiam aliam in cerebro inbabitantem, Cuius vel cerebrum, vel fpiritus organum fit, fed Jpiritum in cerebri pentriculis contenthim animalizm animam effe. Cap. VI. $\quad$ pag.6.b Rationem, que fpiritum in ventriculis contentum anima Jubfantiamn neffe, d.clarauit Galenus, inaneme effe.Cap.VII. pag. 8.a Senti:ndi, féféque Cornmouendi facultatem partibus nerui Galeno afferunt, non fib siantic portione, fed facultate tantum à principro indita. Cap. VIII. pag.9.a

Rationes, que Siritum neruis non ineße perfuafere Galeno, inanes effe. cap. IX. paz.9.b Qu.e Spiritü neruis inef.e Galeno declarare poterät.Cap.X.pa. I I.a 


\section{N D - E X.}

Terperam Galenus operationes, quas mullas animal operari videtur electione, non anime, fed natura afjgnandas decernit. Cap.XI. pag. I $3 \cdot a$

operationum, que nullo à voluntatis Imperiopendent, multas anime affignari poffe, or affignandas omnino effe. Cap.XII. p. I 5.6 Operationum, quinaturales videntur caleno, multas animeafignandas effe, quod alio affulu, atqu alio, eoque perpetuo aduntur modo, quo propjoftum opus optimè conficitur. Cap. XIII. pag. I $6 . b$

Prixterea o quod organorum funt minifterio $\ldots$ Cap. XIIII. pag. 17.6

Vensriculi appetentiam omnem attractionem, alterationem, of expulfionem non naturalibus facultatibus, fed anime afjignandas effe. Cap. $X V$. pag.I $\delta . a$

$V e \int f c a m$ non à naturali facultate, fed ab anima gibernari Galono exifimandum fuiffe, of a foixitus omnino min ritate gub rnari. cap. XVI.

Preterea \&o podendim.

Cap. XVII.

pag. I $9 . a$ Ip Sum itidem cor, atque arterias, os bas, earumq́; o cordis fibras, ligamentaque à cerebrodeduci Galeno vifum fuiffe.Cap.XVIII. pag. 2 I.'a

Que amplius ab anima in cerebro cor zubernari, Galeno declarare poterant. cap. $X I X$.

pag. 23.6

$V$ el difcrimina, quie inter repirationem, pulfationenique effe $G a-$ leno videntur, pulfationem ab anima feri declarare. Cap. $X X$. pag. 24.6

Pulfus, qui in ea anime perturbatione, que è metu, fo iracundia com pofita est, feri Galeno videtur, animam pulfare manifeftat. Cap. $X X I$.

pag. 25.6

Itidem \& pulfus, qui in triftitia, latitiaque fiunt. cap. XXII. pag. 26. a

Itidem, of pulfus, qui varÿs in morbis, varÿfque funt in animalis difpofitionibus. Cap. XXIII. pag.26.b

corde pulnerato ftatim animal interït, non quod cor ipfum vite fit fons, fed qüod qui eins tunice, fibrisque piritus inexistit, vuineratur. cap. $X X I I I I$.

Animalis operationes omnes una ab anima adi, dr animal uninerfum una ab ea gubernari, in ïs, qua anima affecta bonini eueniunt, infpiciendumeffe. cap. $X X V$ pag.30.6 Que in iracundia, Verecundia que bomini eueniunt animal uno ì fpi ritus 


\section{I $\mathrm{N} \quad \mathrm{D} \quad \mathrm{E} \quad \mathrm{X}$.}

vitugubernari declarant, \& verecundiam eandem iracundix $e ß e$. cap. $X X V I$. pag. 31.6

Preterea o que in timore. Cap. $X X V I I . \quad$ paz.32.6 Itidem of que in moeroribus. Cap. $X X V I I I$. pag.33.a Anime itidem defectuum, deliquiorum q́; caufam innote fcere non pof $\int e, f_{i} \dot{a}$ pluribus naturalibus facultatibus; at manifeftam e $\iint e, \sqrt{i}$ corpus vniuerfum ab unica anima fubstantia gubernetur. Cap. $X X \cdot I X$.

pag. $34 \cdot a$

Deliquia fingula, fingulorumq́qe medela corpus uniner fum $a b$ unice animagubernari,declarant. Cap. $X X X . \quad$ pag.35.a Idem of mors, que dolorem, of qux anime con sequitur perturbatio nes. Cap. $X X X I$.

Corporis partium, attionumq́; confenfus animal vniuerfum $a b$ vni ca anime fubftantia gubernari declarat. Cap. $X X X I I$.pag. 38 .a

Sentiendi, ratiocinandi, mouendique, tùm or irafcendi, pulfandique proterea, nutriendi, generandique vim à diuer is bomines ba bere principijs, è quibus colligit Galenus. Cap. $X X X I 1 I$. p.38.6

2Num que irafcitur, \& que animal nutrit, generatque intelligenti, mouentique eadem, an illarum ab hac diuer $\int a$, o altera cordis, ic cinoris altera temperies fit notum $\nu t$ fiat, conditiones, quibusillarum vtramque donatam eße oportet, inquirendas effe.

cap. $X X X I I I I$.

pag.39.6

conditionibus, quibus, qux irafcitur, pindictamque, of bonorem appetit, donatam effe oportet fubftantiam, Spiritum omnibus, cordis verònaturam nullis prorfus donatam effe. Cap. $E X X V$. pag. 40.6

Nullis itidem iecinoris naturam, Quibus, que animal nutrit, gene ratque, \& cibos, uenereaque appetit, donanda eft, donatam effe; at fpiritum donatum effe omnibus. Cap. $X X X V I$. pag.4I.b Pugna, que quibufdam operationibus propofitis in anima fieri uidetur, non e diuerfis eam fubftantiüs compofitam, nec à pluribus ani mal gubernari fubftantys, fed unam omnino illam eandemq́ue effe, \& una ab ea animal uniuerfum gubernari declarat. Cap. $X X X V I I$.

pag. $43 \cdot a$

Immutationes, que iracundia efferuefcente in corde, of que iecinore oblefo, in uniuerfo funt animali, haud quaquam illius naturam irafcibilem, buius uero nutritoriam fubftantiam effe declarant. Cap. $X X X V I I I$.

pag. $4-6$

\section{F I N I S.}




\section{BERNARDINI

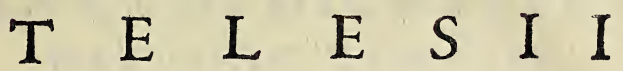 C O N S E N T I N I,}

DE VSVRESPIRATIONIS Liber. CVMPRIVILEG 10 .

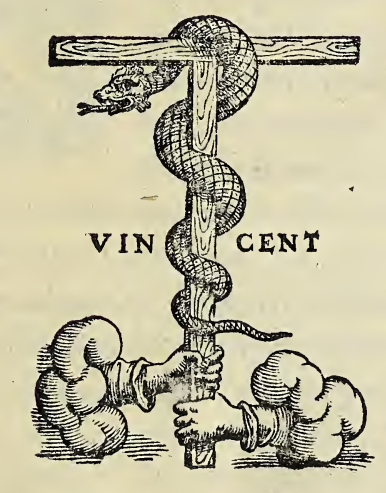

\section{VENETIIS M. D. XC.}

\section{Apud Felicem Valgrifium.}




$$
\begin{aligned}
& \text { 1. CAAWMJZ } \\
& \text { I I I I I I T }
\end{aligned}
$$

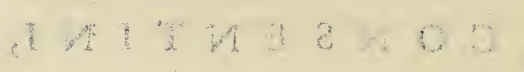

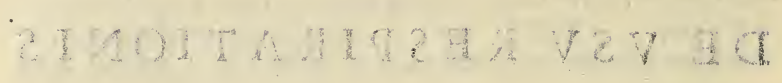

istil

$.0105+10184$ an 


\section{IL LVSTR ISSI MO IOANNI MICHAELIO PATRICIO VENETO,}

EQVIT IPRAECLARISSIMO, AC D. Marci Procuratori meritiffimo

\section{AntoniusPerfius. S. P. D.}

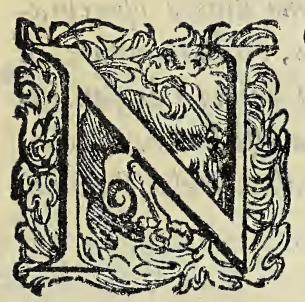

of fi magnis locorum interuallis difinnctum, tanto tamen profequebatur, ac colebat, vt, quamuis decrepi-

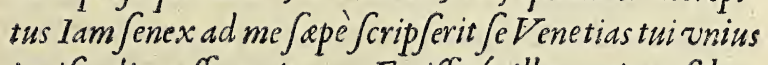

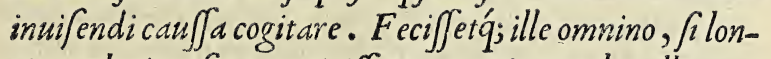
gior eilucis vfura contigiffet, aut ex ingentibus illis moleftiarum, ac perturbationum fuctibus, ex morte, flio, quem unice diligebat, à ficario quodam illata, prefertim obortis, quibus extremaiam atate eft conflictatus, emergere vnquam, ac fe vindicare potuiffet. Nouerat te ille Roma familiariter, felicibus illis, atque eruditis temporibus, mirificum ex mirifica tua fapientia, elo-

$$
\text { A } 2 \text { quentia }
$$


quentia, comitate fructum coperat. Itaque iure abfentis poftea defiderium non nifi cum vita depofuit. Ego igitur quitenon minus Telefio Venetiys, ac Patauy colui, obferuaui, obferuoq́; in dies magis, ac magis tum yjdem, quibus ille, nominibus, tum ob praclara tua in me merita, qui me $\sigma$ publice', $\sigma$ priuatim difputantem auctoritate tua fumma protegerenon fis dedignatus, vt tua in Telefum prius, deinde in me ipfum beneuolentia, gratiq́; vtriusq́; noftrum in te animi Jgnificatio extaret aliqua diuturnior, bunc Telesij ipfius libellum de vfu refpirationis tuo nomini amplifstmo dicare operepretium duxi. Tu pro tua fapientia, Go bumanitate, $f i$ non re, faltem vtriufque noftrum animo tibi Satisfacies, $\sigma$ mea in te officia tibi grata effe boc tuo officio, quod mibi grati]/imum erit, declarabis. Vale. Patauio. 


\section{B E R N A DINL $T \quad L \quad E S I I$ CONSENTINI,}

\section{DE VSV RESPIRATIONIS. II}

Aeris, qui infpiratur, portionem ad cerebri efferriventruculos, ac in $\ddot{y}_{s}$ fpiritus uniuergit ati eam immifceri. Cap. 1.

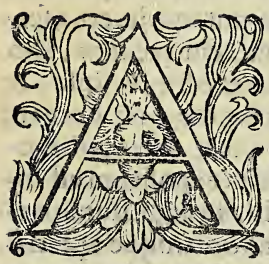

ER IS, qui infpiratur portione m quam piam ad cerebri efferri ventriculos, fpiritusqúc vniuerfitati in ijs immifceri, cùm confpicuus qui, è naribus ad eos fertur meatus, tùm verò odorum, aeris nimirum affection um perceptio, \& quę ab odoribus, 8 fpiritus ipfe, $\&$ uniuer-

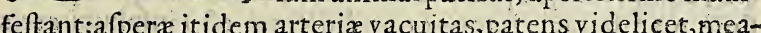
tus, qui ex ore loci fcilicet in quo pulmo, \& cor continentur,poft infpiratum aerem inflatio, tumefactioq́ue eius velu ti uniuerfitatem in pulmones, \& quampiam itidem eius por tionem dictum in cordis finum deferri declarat. portio porrò, qux ad cerebri ventriculos, f firitumque ibicontentum ef fertur, manifefte (ut in commentarijs de reitum natura, \& Lib.6.c.8. de fomno amplius, latiusqúue expofitum eft) propterea ad eum effertur, eique immifcetur,vt non ralde ab eo difsidēs, copiaque ab eo exuperata in eius agatur naturam , itaq; eius \& molem augeat, \& amplius fottè eius ut fertorem temperet,modereturq́ue.fortè enim una ex enaporatione è fanguine in corde, plexuque retiformi amplius elaborato edueta, cö fectus, nimis fit ardens, nimisqúue præceps;nec uerò nifî in fpi ritum angendus fit, immittendusque in eum fit, fum ma inter dum moleftia, fummoq́ue immiffus malo, \& in fpiritum omninò 


\section{Bernardini Telefij}

ninò eum agi diuerffsima fpirituú tenuitas, puritasq́ue ma nifertat, qua fcilicet ijs perpetuò amplior inert, finceriorque, qui finceriore, tenuiore, paucioreq́ ne degunt in aere.quin \& ad fpiritum dictis in uentriculis contentum agitandum, dimouend amqua aerem immitti exiltimare etiam. licet neque enim in arcto coercitus in loco per fe moueri queat, fed immobilis torpeat . itaque corrumpatur aeris more, qui quod motu omnino gaudet, \& manifeftè motu feruatur, angufto in clufus in loco, nihilque ab externo ullo agitatus, immobilis fit, corrumpiturq́ue. præterea \& vt Tunicas, à quibus cerebri moles continetur, quę \& per fe graues, \& à cerebri mole praffx concidant fortè, f piritumq́ue in anguftius comprimant, vel opprimant etiam, itaque \& exitio dent:asfidue fubleuet, fubftineatq́ue, $\&$ dictam omnino aeris portionem hos prafta re vfus, mors declarat, qux, refpiratione adempta ftatim animal corripit, fi quidem quantumuis internarum partium infpiratus aer calorem foueat, augeatq́ue, aut moderetur, feruet omninò, qui tantifper eius illa contactu priuatx, alio malo, alioue incommodo nullo prorfus affect $x, \&$ ipfe, \& animal uniuerfum uita deftituatur, intelligete non licet; \& fpiritum in anguftum actum, nullo temporis extingui momento, itaque animal interire, \& fuo fatis expofitum eft loco, \& flammarum, tenuitatisque cuiufuis in anguftum coaetx, compreffxque prxfens extinctio, fuffocatioqúue apertiffimè manifeftat . itaque (quod dictum eft) inf́pirati aeris portionem, qua cerebri fubit ventriculos, ufus, qui expofiti funt praftare maximè eft rationi congruum, aliam uerò qux in finiftrum illabitur cordis finum, proptereà eum fubire exi ftimandum eft, ut fanguini, qui in eo abfoluitur, immifta eius molem, \& tenuitatem amplius augeat, uel vt tenuior ipfa facta, calidiorque, fpititus affumat naturam;tum, vt quæ eius pars nullo illo temporis momento, quo immiffus aer expiratur, fanguini immifceri, unumqúue ei fieri non potuit, itaque Thorace compreffo exprimitur; Fuligines, qux concoctione in quauis, in uehementi prxfertim cuiufmodi, qua fanguis in corde abfoluitur, exiftit, afsidue fiunt, fecum offerat omnes . eius porrò ueluti vniuerfitas, qux in pulmones defcendit, quoniam nullam in remfertur, inquam agi pofsit, alium omninò ob vfum immittatur necefie eft . is porro ut innotefcat, caloris, frigorisque natura, 
cura, uiresq́ue, \& qux adueniente altero, operatur alterum, \& caloris omnino ingenium infpiciendum eft.

Caloris, Frigorisǵ Ingenium, d aeris infpirationem, calo ris coercendi, introǵs agendigratia animalibus tributan effe. Cap. II.

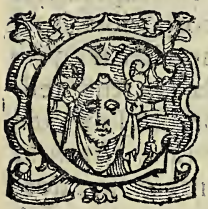

A LO REM, Frigufque è proprijs fefealienas in fedes afsiduè effundere, casq́ue ubi ab altero non reijcitur, alterum occupare utrumq́ue, \& utrumque itidem altero adueniente propriam fe fe in fedem colligere, inq́ue unum agere, vsq́ue adeò manifeftum eft, ut nulli prorfus uifum id non fit, placitumáue, vt \& id feorfum à frigore, calori noftris entibus, \& animalium corporibus, crafsioribus nimirum indito rebus, quam quas fecum vniuerfas euehere queat, ineft, ut afsiduè, quas corum potef partes attenuet, nec id agere curet umquam. Dum non ea illas donet tenuitate, in qua elabi ipfe queat, \& elabatur omnino . arcto in loco immobilis torpere exhorrens, nec fubftinens omninò , qux igitur à calote conftituta funt, uel nullo à frigore oblafa corrugantur, craffefcuntọue, \& cortumpuntur tandem omnia calore videlicet univerfo, cum uniuerfa èlapfo tenuitate, at ea certè facilius, promptiusq́ue è quibus facilius, promptiusq́ue calor elabi poteft. mollia nimirum, at qux non glifchra, uifcofaque, fed. Jaxa fint, apertaque, qux omnino elabenti calori egreflum mi nus abnegant, \& calida, atque ambiente amplius calido. quorum fciliçet proprius calor, \& per fe moliri egreffum queat, \& ab externo cum ad elabendum allectus, inuitatuf que, tum \& patentiorem exitum naqus. nam frigido inambiente, quod obladi fefe ab co, deftrui, quo maiore omnino affici malo, quàm quod ibi torpens patitur, fentit inter nus calor cohibet fefe, quin intrò (ut dictum eft) recipit, $z$ ueluti abdit; \& calorem omninò quemuis, at robuftum amplius mollibus, apertisq́ue inditum rebus, nifi à frigore reijciatur, nullo ferè temporis momento inde elabi, itaque perire, ignis declarat calido accenfus ft $b$ coelo, qui fcilicet nec uigens fieri,nec diu omnino feruari poteft, fed ftatim fexè, materiaq́u genè uniuerfa fuperftite, \& quam frigido in ambiente 


\section{Bernardini Telefij}

ambiente fatis diuturnum, vigentemq́ue ignem idem agat calor euolat, manifeltè enim propterea laguet, peritq; ignis, quod proprius eius calor nihilab externo frigore reiectus, nihil mareriam fubit, \& ab ambientis calore adiutus tenuitatem, quam facit prius abfoluit, ita fcilicet tenuem, leuemque facit, ut euehere eam queat, quàm prxinexiftentem naturam è fuppofita mole deturbet, eamq́ue ipfe occupet : ut fi qui calidifsimis, mollifsimisque animaliu corporibus ineft calor, nullo à frigore detradatur, ambigere non liceat, quin ftatim is elabatur; itaque $\&$ animalia omnia penitus deficiant; minus etiam quin qui animalium corpora fubit aer, quamcunque eorum partem, \& quacumq́ue fubeat ratione hunc, uel in primis præftet ufum, elabentem nimirum caloré retrudat, introque agat.iamque periturum Ignem aer per folles inlectls in lighnam retrudit, itaque feruat, augetq́ue.manife!tè enim propterea is, eique inexiftens calor, non euolat amplius, fed fefe intro recipit quòd immifsi frigoris uires exhorret, reformidatque, \& nequaquam reliqua uifcera, reliquasq́te corporis pattes, fed unum modo pulmonem, qui infpiratur, fibit aer : quòd (ut exiftimare licet) ne è reliquis proprits euolet calor, non tam tum imminet periculam, minus calidis, minufque laxis, è quib is omnino nec euolet, uel a frigore ad pulmones delató retineri, cohiberique poteft: nam ne è fuguine elebatur calido, liquidoque, \& no durifsifimis cótento in tebus àer prohibet, qui diltefis, laxatisq́; ar terijs, \& Venis, etiā Galeni teftimonio fubit, quin \& adiacen tiúfortè part iúcalorem, is itide retrudit, introque agit, nec uero è caloris, frigorisq́ue natuta tantum. Sed ex omnibus, qux refpirationi eueniunt, \& ex ipfus in prim is diuerfitate id declarare licet, quæ fcilicet cú animalis calore ufquequaq; uatiari apparet; talifque perpetuo fieri, qualis ad prafentem eum cohibendum apea eft. at quoniam non retinendi, coercendić le, \& intrò agendi caloris,fed eius imminuendi, debi litandiq́ue gratia refpiratio animalibus fumme tradita eft, Lib.de vili Arltoteli, Galenoque uidetur : itaque nof ra cum corum fen refpir. tentia conferenda eft, \& utra potior fit, ex ijs omnino, qux re fpirationi eueniunt, ex eiusq́ue diuerfitate omnino eft dighofend am . vtique priufquam ea exponatur, illorum fencentia explicanda examinandaq́ue eft. 
Refrigerandi, immingendig caloris gratia refpirationeme animalibus tributam effe Arift.videtur. Cap. III.

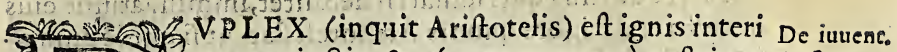

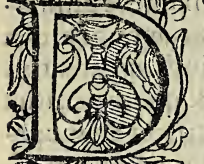

tus, extinctio, \& $\mu x x^{\prime} \alpha \nu \sigma n$, marcor à noftris, at \& fe nunt. que exiccatio dicta, \& extinctio, quidem àcō c.3. \& refpi trarijs fit, marcor verò, \& exiccatio ob caloris copiam, etenim fi excellar quod circum iectum eft, calidum, fiue alimentum non ca- ', piat, interit quod Ignitum eft, non frigore, fed exiccatione, "' quam ob rem neceffe eft refrigerationem fieri, fi falutem affe-" qui debet : id enim auxilio elt contra huiufmodi corruptio-" nem; \& haud ita multo poit refrigeratione, (inquit) anima-" lium natura indiget ob animę in corde feruorem \& uitę prin " cipium definit in ijs qui habent id, ubi calidum illi coniun-" Eum non refrigeratur:nam (vt dictum eft) ipfum à fernet li- " quefcit id (ut fuis uidetur) inumens calorem uidelicet nimis actum, \& à nullo frigore retufum, humidum cui adheret abfu mere omne,priufquam reparari id queat, eo porrò pabulo fci licet,uehiculoq́ue priuatum calorem ulterius uiuere non pof', fe, nimirum itaque cordis calorem refrigerandum fuiffe, at $q$; , imminuendum,ne materia cui is adhæret, depopulata,abfun taq́ue omni, liquefcat, pereatque, id verò \& frigidi aeris immisfione, \& cerebro etiam fuperpofto, quod frigidifsimum Arifoteli uidetur, factum fuiffe.

Eod.c2.13. rat. c2. 10. 》) 


\section{Bernardini Telefij}

quò uehementior fit, qui fcilicet materiam, cui adharet icciùs attenuat, adeoq́aeleuem facity ùt fecinn eùehère eam queat, \& diatiùs quis feruari fi debilitet́, imminuaturuè eius uis:efto \& à frigore quou is A tiftotel fiat: ut fi quidé animalium calori alimentum nullum, à quo reficiatur apponi uidea tur.res, [cilicet nulla animaliim corporibus indi appareat, in quam proprius ipfor um calor fe fe effundat, \& quam penitus fubeat, occupetq $t e, 8$ in abfumptas, in eas, fcilicet agat corporis partes, quas in fummam attas tentituitatem, fecum af fiduè effert;itaque \& illas \& feipfum in fllis ferife, tron teme re in eorum animalitm cor aerem, quint nimirum eius fertorem retundat, imminuatóge-immittendum eñe Arifoteli ui fum fit;at alimentum afsiduè ab animalibus affumi, idq̣́ne a proprio ipforum calore occupari, \& in abfumptas, elappasque corporis partes agi, itaq; \& hos, \& ipfum in his refici, feruart que, \& augeri interdum, atque amplificari : \& fingulis in animalium Generibus ea diuturniora omnia, quibus rebuftio? inelt calor;\& Ignem à Vento nô exuperante, vellanguentem iam iam, iamq́ae periturum, elapfurım que non retineri tnodò, feruarique,fed atigeri, \& uiręs fumere; \& vbi alimentun adeft,eo amplius feruari ignem, quò calor velieméntiôr frt, robuitiorq́ue, \& animalia calidiora omniñơ, robuftiora que frigido fub cxlo intuenti, \& entia quxuis promptius quidem calido inambiente, ferius verò fauiêtibus frigoribus tht qub? uis fub cxlo, prxterea corrumpi tanderrom omia entintianti, quòd prius ipforum calor,promptius quidem ubi ab externo ad euolädum veluti inuitatur, alliciturq́'; , feruuss verò ubi ex ternum, frigus exienti veluti exitiu minitatur, caloris omnino egreffi entia corrúpi, eumque non alia à re, fed vno à frigore tantifper retineri, coercerique, \& intro agi, itidem intuenti:utiq̣; frigidi aeris immifsionê,non imminuëdi,fed in troagendi, uniendiqúue itaque \& augendi caloris gratia animalibus tributam effe exiftimandum omninò fuit . nec uerò fi refrigerandus, imminuend usque fit cord is calor, ufquequa que, \& ubi etiam maximè is languet,maximeque eft debilita tus, ibi itidem imminuendus; fed angen dus omnino tunc, ró borandusquue, itaqúte refpiratio iufta Ariftotelis fententia in termittenda fit, qux languidior quidem, at multo certè crebrior fieri videtur,qualis (vt uidebitur) ad languentem iam iam, iamǵue elapfurum calorem retinendum aptifslma efts fum- 
fummopere certè mirari licet, rerum omnium conditorem deum, qui reliquis fuis in operibus longè fapientifsimus, lon geque folertifsimus Ariftoteli uifus fit, in animalium confttutione Infipientem uideri, atque inertem. talis enim fit, fi ni mium cordi calorem, \& qui tot animalium moleftijs, pericu. lisq́'ue imminuendus fit, crediderit . Age verò ; \& Galeni itidem fententia,uel nihil fere ab Ariftotelica differens explice tur \& ipfa, examineturq́ue.

Refrigerandi caloris gratia respirationem animalibus traditam, or animalium calori frigus commiftrm, o

duplicem illius, flammarumg gómotum eße, vi. detur Galeno. Cap. $V$.

(1) omp

YONIA M (inquit Galenus) vbi am-De ntilita, plior, quam fecundum naturam, caliditas refpira.c.3. in locis circa cor, \& thoracem collecta", fuerit,ftatim \& folito amplius refpirare ap- ," petimus, exiftimare utique licet refrigera-", tionis gratia refpirationem fieri veluti por-", rò fläme omnes duplici mọtu moueri uidêtur, altero è miatec- " ria, è qua accendtuntur, perquem maxime furfim feruntur," \& vndequaque difpergunturaltero huic contrario, ad fui ip-t, farnm principium, \& veluti tadices, ver gente, per quem confi, , dunt, \& contrahantur; quod fi horum alter deficiat, fan mä , omnem extingui nẹceflarium ef, fi fcilicet aut materia, è qua ", alitur,aut altero motu priuetur famma:ob id igitur modera-" te frigido ambiète aere flamma omnis opus habet, gur enim excellenter calidus eft, alterum ipfius motu m im modici ex-, tra extendédo, frigidus uerò alterú intro protrud den do extin-»o, guit:eodem inodo, \& caliditas animalibus infitamateriam, vnde accenditur fanguinem habet, nec non à nattira infitum ', principium motus in utranque partem, ita ut altero prisata,", reliquo etiam exnecefsitate deftituatur:fiue igitur à $\mathrm{r}(\mathrm{f} p \mathrm{ira-}$, tione prohibeas, fiue à fanguine, ftatim corrumpitur. \& alibi, mouetur (inquit) innatum calidum à fuo principio foras ca-.,b, liditatis ratione, intrò uero $\&$ ad principinm illabitur, guta frigiditatis eft particeps, hoc fi quidem cal dum mifum ofts, \& excalore, frigoreque ortum habẹs $j a c$ prima quiden (alli-l, 


\section{Bernardini Telefij}

o, diratio fpontaneum fui ipfrus mobilitatem includit, hacóuce

" ad operand um maxime eget, nil hóninus na gnum quócue

") à frigore adiumentum a ccipit.nam cum innatum calidum $\&$

o, eleuare in altum, \& fecum alimentuin rapere fatum fit, cer-" te fi frigus lationem calidi non coefceat, pęnitus elianefceret, atque difsiparetur.

Frigidi aeris infpirationem non refrigerandi, imminuen

diǵ, fed retinendi augendiǵg caloris gratia animali-

bus tributam fuife, magis eriam Galeno, quàm Ariflotali exiftimandum fuiffe. Cap.VI.

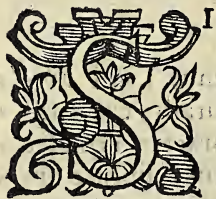

quidem nil aliud in calorem agat frigus, ni fi quod eum imminuat, debilitetóue, ibi copiofiorem aerem infpirati, úbi copiofior cir ca cor factus fit calor, intuitus Calenus, nihil fortè incufaridus foretaeris infpiratione refrigetandi caloris gratia animalibus tribu tam effe ftatuês;at quoniā non id modò̀ in caloré agit frịus, fed manifeftè elabêtem eum retinet, coercetq́ue, it aq; auget, incufandus omninò videri poteft, qui non refrigerandi, the imminuen diquie, an intrò agendi, retinend ique calorís gratia amplior ibi infpiretur aer, $\$$ aeris omnino immifsio dinimalibús tributa fit inquifierit, id certè fáctum çaleno fr fos ret, uel in ijs, qux refpirationi accidere ei uifa funt, ìn eitus q diuerfitate, que ante alios omnes ei pulcherrime confpeta eft, non imminuendi, refrigerandique fed coercendi introg; agendi : itaque \& róborandi calöris gratia actis inmifsione animalibưs tribútam efle liquido confpectum Galeno foret. cui nimirum ubi animalis corpus tialde concalefactum eft, at que apertum, ubi fcilicet ne inexiftens calor onnis elabattur, magnum imminet periculum, non magnam ibi qualis fi imminuendus fit, refrigerandusq́ue calor opus omnino effet, fed minorem \& crebram, qualis elabentem calorem rètru dendum, introque agendum aptifsima eft, \& quali omnino uentilatione elapfurus, iam iam ignis retinçi appăret; \& qui infuper, ut feruetiur calor à frigore omnino retinêd dim eum, $\&$ in materia intro agendum pulcherrime, ut vif th eft conSpexit, ueluti ( inquit) flamma omnis, ut feruetur ambienté mode- 


\section{De Vfu Refpirationis.}

moderatè frigido op: ss habet, qui enim ualde calidus eft, il- De vtilit. lius motr immodicè extra extendendo, flammam omnem reftitut. extinguit, fic \& animalium calor frigidi aeris infpitatione, $\vec{a}$ "” qua eius ad extrema mot:ıs reijciatur indiget . uel ipfi igi- " tur Galeno, refrigerari poftulat calor, non ut imminuatur, " fed ne elabatur, ne:te eiolet, coerceatur,\& ut materix ma-" "” gis uniatar, magifque intro agatur, nec aliud omninò "” quid ambiens frigis calori pręttet, eumuè adiuuet, minus" etiam quod externus calon internum oblędat, intueri licet,ni " ff qiòd ad euolandum ieum in itat, aptioremq́ue ad enolandum facit; materiam cui iuhæret attenuans magis, \& è circumpofita egreffum patefaciens . itaqúu quòd dictum eft-fui ipfius nonlimmemori Galeno, frigidi aeris infpirationem, caloris coercendi, introğue agendi tributam efle, magis etiam quam Ariftoteli omninò exiftimandum fuit . nihilo etiam minus incufandns, fuique ipfius, \& rèrum fenfu perceptarjim oblitis tuideri poteft Galenus, flammarum, animalitiquaiecalori frigusimmifcens; \& duplicem illi tribuēs motum à talorésalterum veró à frigore. nam ( vt in ijfdem declaratú eft commentarijs) ne dum fummo, cuiufmodi flammis ineft; fed calori omnino nulli nullum coire poteft frigus, \& nullum prorfus ens à calore frigoreque fimulagentibus fimulque fibi ipfis coeuntibus conftitutü eft.tum uel fi flammarum, atq; animalium calori frigus immiftum fit, fi quod non audeat ne gâie Calenus, flammarum animaliumq́ue calor immiftum frigus exuperat, unum omninò utriq;, \& proprio omninò mo tum afsignet neceffe eft : compofita cntia quxuis eius vnius naturx, qux reliquss fibi immiftis predominatur, reliquas fecum ueluti trahentis, motu ferri intuitus, nihilque, ut uidetur, in ijs, qux de miftis, eorumque motu ab Ari ftotele tradita funt, diffentiers s. fumum proterea pari eti fulfure illi eo admotum eo nimiram calore fumo adiecto, cui, quin flamma effet deerat accendi, \& flammam fieri, intuito Galeno, nequaquam funum, qui fiperpofita flamma accendi videtur ab eius portione quapiam? ad illum, ut uidetur, defcendente, fed ab ipfius calore accendi exiftimandum omninò fuit.nam illad flammarum ingenio ad cuerfum, maximeque contrarium,ut fumum modico auctum calore fammam fieri, \& in fumo, quifulfori admotus lucidus fit, manifeftifsime intueri potuit, \& maximè fiammarum, fumique nati- 


\section{Bernardini Telefij}

rx congruum eft. neque enim aliud uideri poteft, neque eft omnino aliud flamma, nifi fumus paulo maiore donatus calore. Nec quòd in ipfo in fumum primum, fed in aere, qui flammam, fumumque inter medius eft, flamma, itaque-fuperpofita flammæ portio quapiam defcendere uidetur, propterea fammis defcenfus attribuendus erat ullus. 'nam \& intermedio illo aere fumus eft, at adeò tenuis tandem "factus, ut uifum pęnitus lateat, \& à copiofiore, robuftioreque 'correptus calore tenuifsimorum uaporum ritu, qui in paulò fuperiore aere accenfi ftellx, \& ueluti currentis, cito omnino pereuntis fpeciem aflumunt, uifilis \&ipfe fit, lucidufque. Non igitur ambiens frigus propterea flámas conferuat, quòd? eas ad fuppofitum nutrimentum detrudit, fed quia eius uires reformidans inexiftens calor fe fe intrò recipit, colligitque: ita robultior factus prius quam materiam, cui inharet ita tenuem, leuemo; faciat, ut eu ehere eam queat; fuppofitam exu-s perat, \& infamtinas agit. \& propterea qui maxime languet calor, non quidem magna tiehementique;à qua foilicet extin guatir, \& frequentifsima feruandus eft : \& feruari uidetur uentilatione, quòd nimirú nif immifto frigore afsidue intro. agatur, retineaturg; prius omnino euolet, quam fubiectam materiam exuperet robuftifsimo autem per rara illa fatis eft ftatim:is enim in fuppofitam fe fe molem effundit pęnitufque

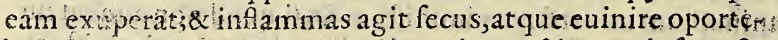
bat, fi, ut Galeno placet, imminuend us, refrigerandufquefit calor: age uero refpiration is differentias intueamur:fi quid enim aliud, ipfacerte, num imminuendi, refrigerandique, an coercendi, $\&$ intro agendi, colligendique, $\&$ augendi omnino caloris gratia frigidi aeris infpiratio animalibus tribu tafit manifeltare poterunt.

Rdpirationem non imminuendi, fed intro agendi, atque

retinendi caloris gratia animalibus tributam ese, eius differentia declarant. Cap. VII.

Deurilit. W

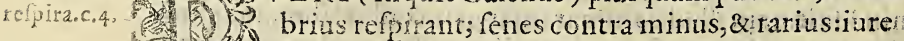

fanewtrumq́u : quoniam enim pueronim quamy exillo elabitur calor, agrius uerò è fenili arefacto iam, indu-: 


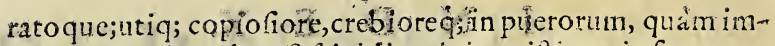
puberum rerinendus eft frigidi aeris immittione:in fenum ue

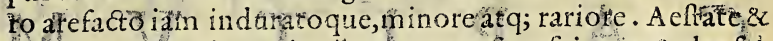
calidis omnino in regionibus magna fit refpiratio a denfa ${ }^{\circ}$. Hyeme uero, \& frigidis in regionibus minor, \& rarior:quod illis periculuni immitiet ne foras elabatur călor ab externo allecus, \& uelutiad duolandum inutatus at non Hyeme à frigore reiectus, \& introactus,pęnitusq; materix unitus.Non quidein, fi vt Galeno, âtq; Ariftoteli placet, imminuédus, refri gerandufq; fit calor, ne nimius factus materia cui inharet fta tim abfumpta, omnino pereat ipfe:uel utrinfq; enim teftimo nio robuftior Hyene, \& fubfrigido ómnino degentibus ceelo ineft calor, quibus itaq; refrigerandus, atq; imminuendas fit magis, Balnea calida uelocem inquit Galenus, magnam \& denfani refpirationem, frigida uerò contrariam faciunt.rectè ", fanè utrum que; illa enim natium calorem euocant amplum-" " "que elabenti exitum patefaciunt. itaq; nifi a ualida is repella" tur, coerceaturque refrigeratione, tatim elabatur hac ucrò calorem retradint, reïjciuntque, \&2 corpus coltipant, conftrin yuntque, nt neque elabi uelit, nec adit:s exeunti pateat. Wbi cunque onnino calor natiutus ab externo quafi allicitur, \& veluti ad cuolandum inuitatur, uel calefacto, ad apertbque corpore calori egrefins patet, uel quatuis occafione adatous is, \&r robutior factus maiore egreffum noliatur ui:quacung; deniqg; ratione itrenue euolet; ualidiore retinendus cft refrige ratione, refpiratione nimirú magna, denfa, \& velcei, à gà in fro agatur, coerceaturq; calor: oq fi magna fieri nequear, uel norboafflictis organis, uel quòd languidior factus calor hu iùimodi fubltinere nequeat, frequêter fit, ut frequentia ufum expleats quem magnitudo explere non potuit tali taque \& magnis in laboribus, \& in areentifsimis utimir febribus, \& maxime languentem iam iam uidelicet elapfirum èltgnis ignem debili quidem, ut dicum efl, at crebra retinemus uen tilatione. At fi natiuns calor ab externo frigore introacto fit, uel minor...... Defunt aliqua.

\section{F I N I 3 ,}




\section{N D E X. \\ C A \\ $P$ I \\ $T$ \\ V \\ M \\ L $\quad I \quad B \quad$ R I}

\section{DE VSV RESPIRATIONIS.}

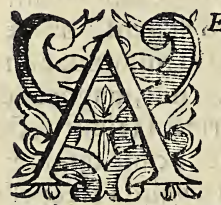

$E R I S$, qui infpiratur, portionem ad cerebri efferri ventriculos, ac in üs Spiritus vniuerfitati eam immifceri. Cap. $I$. pag.3.a Caloris, Frigorisque Ingenium, or aeris infpirationem, caloris coercendi, 'intróque agendi gratia animalibus tributam effe. Cap. I I. pag.4.a Refrigerandi, imminuendique caloris gratia re $p$ pirationem animalibus tributam effe Arift.uidetur.

Cap. III.

pag.5.a Frigidi aeris infpirationem retinendi, augendique caloris gratia animalibus traditam efe Aristotali existimandum omnino fuiße . Cap. II I I. pag.5.a Refrigerandi caloris gratia refpirationem alimalibus traditam, of animalium calori frigus commiftum, o duplicem illius, flammarumq́ue motum eße, videtur Galeno.

Cap. $V$. pag.6.a Frigidis atris infpirationem non refrigerandi, imminuendique, fed retinendiangendique caloris gratia animalibus tributam fuiffe, magis etiam Galeno, quàm Ariftoteli existimandum fuiffe. cap. VI. pag. 6.6 Refpirationem non imminuendi, fed intro agendi, atque retinendi caloris gratia animalibns tributam efse, eius differenti,e declarant. cap. VII. $p \cdot g \cdot 7 \cdot 6$ 


\section{BERNARDINI \\ - T E L E $S$ S I I \\ C ONSENTI N I, \\ DE COLORIBVS \\ Liber.}

CVMPRIVILEGIO.

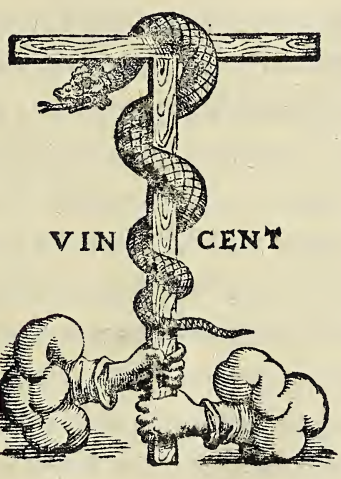

VENETIIS M. D. XC.

Apud Felicem Valgrifum. 
MTGTAKMJA

$1+271$

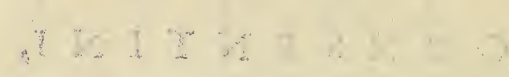

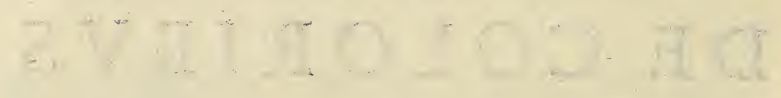

795it? 7

$.0103+604$ क क 16 10

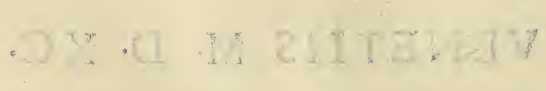

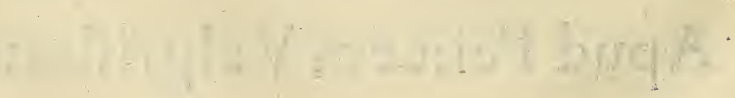




\section{GLARISSIMO VIRO BENEDICTO GEORGIO PATRICIO VENETO}

\section{Antonius Perfius. S. P. D.}

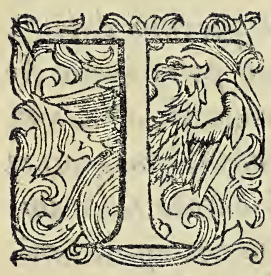

V $M$ Benedicte Clariffime fen. fum, Cum meo in amicis eligendis tam bellè congruere, vt eo/dem tibi familiares optaris, quibus ego per multos annos familiarifime vtor, in magna felicitatis mea parte ponendum exiflimo. Facis enim, vt ego non eos folum, quos tanto antea probarim, tuo iam accedente iudicio, babeam cariores, verum 'o vt de me ip $\int 0$, qui tantum iudicio valuerim, fentiam praclarius. Tuum enim $\mathrm{C} i$ uem eAloyfum Lolinum, ac Patauinum ferè ciuem to annorum Patauij incolam Paulum Aycardum,ex quo primum buc appuli amaui, $\mathcal{G}$ colui ob fummam rerum omnium doctrinam, incomparabile iudicium, bumaniffmos, ac fuauisimos mores amore omnium, atq́; bonorificentiffimo virorum honeftr]fimorum preconio digniffimos. Eofdem poftea cum abfle tantopere diligi, atq; amari fenfi, tuo plus, griam antea, fi modó voluntati mee ergaillos ac ceffio fieri potuit, amare capi. Site igitur nullo alio tuo me rito, hoc certe uno, quod vi mili magis placeam, ac tri-

$$
\text { A. } 2 \text { busmin }
$$


buam, in caus a fueris, fummam debeo benenolentiam sed mei in te fiud $\ddot{y}$, at q́; ob feruantia caufJe alia multa Junt, quibus ego impulfus libellum Telesij de colorum varieta te $\sigma$ caufjis tibi dicatum edere conftiui, ot filicet $\tau$ 'oIuntatem ergate meam Illuftri aliqua fignificatione declararem. cAdbac fivfus venerit, vt eum tua $\sigma$ do Etrina, ¿ eloquentia, tectum fartumq́; praftes ab aculeis repreben forum, libenter curaui, vt nomen tuum clariffimum pre e ferret impreffus. Neque enim dubito, quin maximum apudomnes hoc tuum patrocinium fit pondus habiturum.perfpectumiam enim eft, ac notum, quanto te difcipulo gloriaretur dignus ille magnorum Philofophorum migifer lacobus Zabarella nobis importuna morte prareptus. Cuius farie viri quotics mibi venit in mentem, uenit autem fapiffome, toties ego Patanine, in qua proficebatur Academia ingemifco, que tot, tantisq́; infra paucos annos orbata vinis, ciuem bunc furm, qui facile omnium defiderium leniret, retinere diutius in uita non potuerit, cum tamen ea decefferit atate, qua fencotutem uix à limine attingebat. Verumille alieno quidem Patric, $\sigma$ Amicis, fibi autem, hoceft nomini, G' gloria fux baud quaquam importuno tempore ceffit è uita, relictis ingenij fui monumentis, nunquam intermorituris. Cuius vocem Porticus ille erudita Lycei Patauini fruftra nunc, frufira, inquam defiderant, atq́; eum fipoffent fuum ip $\int$ c ciuem, qui philofophiam non praceptistantum, ac fcriptis, verìm $\mathcal{O}$ factis preclariffimè exprimebat, omnium virtutum, imprimis bumanutatis, ac modeftie, 
3

fingulare exemplum erat, perpetuo lingetent; wt ess contra philofophos riderent, qui non tam in academise porticis pro Peripatet:ce doctrinc primatu, quam in jizblicis hifce, que promifcuè ab omnibus vltro, citróq; co meantibus teruntur, properipatetica, hoc eft, ambulatovia, (vt fic dixerim) prarogatiua tanquam pro aris, $\sigma$ focis ridiculè dimicant, quafi ineo fita fint Grecia: diuitic, ficui occurrens, caput aperias, aut interiorem Porticus partem, uidelicet parietem ambulàti concedas.

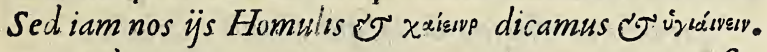
$T$ e verò iterum, iterumque rogo, vt animum tuun familia tua fplendidifjema nobllitate digniffimum mibs be neulum, ac mea Jumma in te obferuantia memorem tue ri,munufculumq́; boc,nouum planè munus (cum libellus bic ita prodeat ab eodem eAnctore iam priden multis: additis, detractis, imutatis interpolatus, ut ficum antea edito conferas, mirum quantum ab co differre deprehendas) tanquam maximum a maximoad te mif um animo gratificandi tibi Jufcipere ne dedigneris. Vale. 


\section{B E R N A D I N I

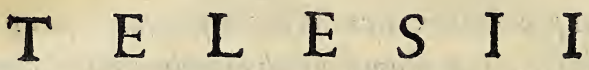 CONSENTINI.}

\section{DE COLOR I B V S.}

Calorem fuinatura alloum, materiam vero nigram, itaque colores religuos vtriuf que caloris, fcilicet album, nigrum materia $\int$ pecies, ¿o velutifacies effe. Cap. Primum.

Lib.r.ca.s. $\&$ in.

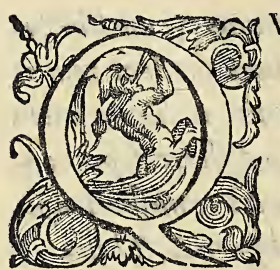

VON I A M longè calidifsimus fol nullis obfito uaporibus cxlo, in quali ipfius calor fpectandus omnino eft, albifsimus confpicitur: \& reliquum cœlam uniuerfum ( $u t$ in commentarijs de rerum natura expofitum eft) fummo \& ipfum à calore conftitutum eft, \& eadem qua fol, idque modo differente donatum eft albedine, quod \& ipfius calor à folis differt calore:quòd fcilicet quia multa in fe ipfam coacta illa eft, robu ftior itidê eft.Itaq; in longü fefe effundit, obuiafq; tenebras, $\&$ fpecies exuperat, \& inexiftentem oculis ipfum propria afficit fpecie; \& per fe omnino uifilis eft, \& Iux dicitur.hac verò quia fummè exilis, proptereaque \& fummè languida eft, mul to in breuius fefe offundit, ftatimque uel ab obuijs tenebris obfcuratur, uel in robuftiore folis albedine latct. It aque fiquidem oculos fubeat, inexiftentem certe fueciem nihil commouet, nihilque propria afficit fyecie, à copioficre nimi rum oppofitorum humorum albedine obfcurata, \& inuifilis facta. Præterea \& quod folis, \& nofter etiam calor, quas terra portiones, \& quæ entia calor penitus fubit, penitufque exuperat, pura fcilicet uniuerfa donat tenuitate, fura itidem do 


\section{De Coloribus.}

nàt albedine. Vt flammx in pura accêfę tenuitate, uaporefq; \& aque etiam declarant omnes . Patet utiq; albedinem omnem, \& qux fcilicet robufta, \& per fe uifilis, \& qux languida eft, \& per fe inuifilis caloris fpeciem, \& ueluti faciem effe. Propterea enim reliqui cẹli, uaporumq́ue, \&aquarum albedo languida eft, \& inuifilis per fe, quòd illorum calor exilis, harum uero imminutus, languidus omnino uterque eft . \& qui ftatim à robuftioribus contrarijs, diuerfifue reiectus viribus nihil fefe, itaque neque propriam effundit fpeciem:nam vapores albifsimos effe omnes, res (ut in ijfdem expofitum eft commentarijs ) in quas fpiffantur, concrefcuntque aqua, grando, nix manifeftifsimè declarant. \& aquas, qux è terra cmanant, \& ipfas etiam marinas è terra folis calore effufa, liquataque effectas, \& calidas om nino omnes effe, 8 in ijfdem fatis eft, ut exiftimo, declaratú commentarijs, \& dulcis earum falfufque amplius manifentat fapor: Quoniam uero fummus folis candor uapores, aquafq; , Lib.r. \& fecratile uitrum, bene albas nimirum, at non fumma dona tas tenuitate permeans res, obfcurari, ad nigrumque agi, coloribus omnino omnibus, qui album inter nigrumq; medij funt, \& ipfo etiam nigro intingi uidetur: \& flammx, qux in non pura funt tenuitate non albę, fed punicę, flaue, ,uirides, cærtulex, purpureæque, \& nigræ etiam funt; \& uclalbæ quæ funt,per fumum confpectx, non albx apparent. Et ignitum fer rum,carbonesque accenfi, fummus nimirum calor, \& crafsio ri inditus materix, uifilis quidem per $\mathrm{fe}$, lucidufque $\mathrm{fe} f \mathrm{f}$, fcili cet propriam effundendi f peciem, at neque albam, nẹ; adeo uigentem, ut quod, qux à fole, flammi fque emanat, agit, à re bus, ad quas accedit fummè reluceat, itaq; \& illarum ad nos referat fpeciem. Et noftrorum entium longè plurima, qura na nifeftè magno à calore contituta, $3 x$ caloris beneque robuti ædunt actiones, non reliquis modo, \& ipfa coloribus, fed que prafertim paulo crafsiora funt, nigro etiã donata funt. Q noniam omnino albifsimus fui natura eft calor, tantufque mate rix inditus, ut nihilab illa obtegatur,candidifsimus fpectatur; at ab ea obtectus obfcuratur, ad nigrnmque agitur, \& noftroram entium longè plurima bene calida, \& longè niger: rima funt. Et naturx uni plures attribuere fpecies non licet, patet utique molem obfcuram etiam, nigramque, \& nigredi né omnino, qua noftris in entibus fpc ftatur molis efie. Itag;

colores 


\section{Bernardini Telefij}

colores, qui alb im internigrumque medij funt, caloris quidem, at non puri, fed a molis nigredine intincti fpecies, \& veluti facies effe.

Frigoris Speciem, \& terre omnino colorem prorfus nobis ignotum effe, at folis eum candori pentus con.

trarium, \& equè agentem, robuftumque efe. Cap. 11 .

Lib.r. Sur RIVORIS porrò fpecies fenfu prorfus ignocap.4.

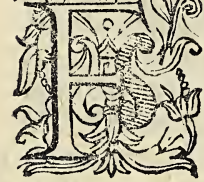

ta eft,fi quidem, ut in ijfdem expofitum eft commentarijs, noftrorum entium nullum à frigore, fed eorum quoduis à calore conftitutun efle, \& ipfa fuprema terrx portio uniuerfo afsiduè à cęlo, \& ipfo interdum oppu gnata à fole, proprijs uiribus fenitus exuta, $\&$ in aliud omnino ens, \& benè id calidum acta eft in ens. Et quod è terra emanat frigus, haud quaquam ( quod calor puram ad ens adueniens per tenuitatem facit) propriam, $\&$ ipfum fecum affert fpeciem; fed fiquidem non terram dum per means, at in aere certè factum (quod calor per crafsitienı ad ueniens quamuis pati nidetur) penitus illa exuitur. Itaque quod dictum elt, frigoris fpecies, \& terræ omnino color nufquā nobis fpectatur.Atquin folis is cãdori penitus cōtrarius, cötrarij $\{$;,$\&$ \&què robuftis donatus fit uiribus, ambigere nö licet. Quniä enim agendi,operandique facultatibus pænitus calor contrarijs donatum eft frigus, $\&$ terra omnino, $8 x$ difpofitione, \& facultatibus, quibus penitus foli cõtraria eft. Víque \& fpeciem contrariã fortita fit, fummè eft rationi con gru im.\& qua igit ır, non ut nigredo, quę materiæ eft fpecies uifa, nuhil folis candorem reijciat, \& n ihil repugnans fibi illú coire, \& fefe ab illo illutrari finat;fed qux fi magnitudine nö exuperetur, ftrenué illum reijciat, nıhilque fibi illum immi fceri, \& fefe ab illo illutrari finat:quę certè fi oculos fubeat nihil uifum fegnias, quam folis cädor perdat, nihilo fegnius inexiltentes h umores, ipfamque ijs immixtum fpiritum con fringens, 8 in angutum cogens, quam ille fundit, dilatatque. Et cuius omnino folifque candoris materix nigredo, ve luti media fit, utrumque enim illorum $x$ què cum moles fufci piat, 
piat,ipfius fpeciem ueluti utriufque mediam effe oportet.No ftram certè nigredinem, nec frigoris fpeciem, nec agentem omnino:fed quod dictum eft, materix, inertis nimirum, nulla que agendi ui dorrat $x$ naturx, fpeciem effe liquido patet. fi quìdem, ut diçum eft, entium lốgè plurimis ea incft, qux ma nifeftè à calore conftituta, beneq; calida funt.Prxterea \& qđ rihil ipfa oculorum humores, ijfque inexiftêtem fpiritum in anguftius cogit, nullumque ijs infert malum. Nam moleftia, qua affici fe illa fpiritus, fentit, non propter nigredi nem afficitur fpiritus, fed quia ubi malum aliquod reformidabat fpi ritus abdit fefe, contrahitque.

2ue entia alba, \& que per fe infuper vifflia, lucidaque, \& que nigra, \& que medÿs colorata coloribus, \& que horum itidem vifflia per fe, infuper lucidaque. Cap. $11 I$.

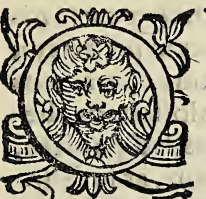

VONI AM igitur albedo caloris, nigredoue materix, ut in noftris entibus fpectatur, qux nigredo uere materix eft fpecies, \& colores reliqui caloris, at non puri, fed à materix nigredine intincti, $\&$ albedo omnino ma serix nigredini commifta.Vtique fi qui molem fubit calor, adeo eam magnitudine exuperet, adeoque extenuet, nihil prorfus ut illa ufquam confpicua fiat, fed pęni tus in caloris lateat copia : itaq; fola puraq; ipfius fpectatur fpecies, quod fit ens album omnino fit, \& per fe infuper uifile fi robutus fit calor; qui omnino ftrenuè fefe in longum eñun dat, nihilq; ab obuijs fpeciebus, tenebrifuè obfcuretur, mini mè uero fi langueat, ftatimg; uel ab obuiis tenebris reiiciatur, uel in robuftiore folis albedine materia lateat. Contra $f_{1}$ tanta,adeouè denfata fit moles in fe ipfum, ut inexiftentē ca lorem penitus obtegat, Iraq; nufquam in illa is, fed fola confpicua fpectetur moles, quod confectum eft, nigrūq; fit oportet at fi ueluti horum medius fit calor, neq; adeo: fcilicet mo lem excedat, ut folus ipfe fpectetur, neq; adeo exuperetur, ut penitus in molis uaftitate lateat, \& molem non adeo in fe ip fam denfatam, ut nullus inexiftenti calori fefe manifeftandi aditus relinquatur, pofueris;quod fit ens, nec nigrum fit, nee-

B album 


\section{Bernaidini Telefij}

album;nam caloris moli fpecies immifcetur, \& è cõtra, ut ne mo fola fpectetur, quod fit ens uel puniceum, uel flauum, uiride;cxruleum, purpurenmque fit oportet;ita albo, nigroq; pro ximius, prout moles calorue magnitudine, feu copia exuperarit, fpectetur eit neceffarium. Et robuftus fi fit calor, beneque materiam extennarit, \& per fe infuper uifile, lucidumque omnino fit oportet ens, fic \& fi materia exuperarit, nigtam ift ens.

Caloris albedinem qua dictum eft ratione à materia obfcurari,ad nigrumque agi.

Cap. IIII.

MNATROPTEREA nimirum albifsimus Iuci-

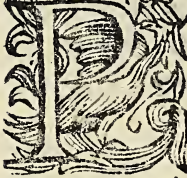
difsimufque eft fol, \& purum per aerem, per feimmam filicet puramque confpectus tenuitatem candidifsimus confpicitur, quod ab integro, copiofifsimoque calore, \& è mo le contitutus eft adeo modica, adeoque exteritata, ut v niuerfa in illius copia latere queat. Qux certè nihil prorfus illum abdat, obfcuretue, \& dum purum per aerem, permolem fcilicet ueluti incorpoream factam, eius ad nos: imago aduenit, \& albifsima fpectatur.Et per albifsimos, beneque etiam tenues uapores, non alba amplius, fed punicea, Flauaque . \& per paulo crafsiores uel per eofdem, at in fe ipfos coastos, obfcura, nigraque.quod aeris moles, ueluti in nó ens acta, nel exilis in folis albedine penitus latet, at non \& va porum corpus; fed opacitas ijs omnino ineft, cuius obfcuritas folis albedini eam permeanti immifceri, \& qux multa in unum acta penitus etiam obfcurare illam queat; longè cnim: tenuifsima, quia prorfus incorporea qua è fole emanat albedo uel ab huiufmodi opacitate foedari, \& penitus et iã obfcurari potelt . nam propterea puniceum, fiaumque fpectarifolem, quod per vaporcs eius aduenit imago, inde manifeltè in telligere licet, quod puniceus fol uentos, flauus uero imbres. pręnunciat, in quos nimirım, qui eius fpeciem obfcurant, diafunduntur,confpifanturuè vapores, \& quod cuius exorië. tis, occidentifque, diu filicet per aerem terris, marique proximum per multos omnino uapores delata ad nos folis fpecies, punicea, Aluaque apparet, meridiani citfdem, per pauciores nimirum, tenuiorefque iam factos uagores alba appa- 


\section{De Coloribus.}

set. Et propterea noftrx flammæ lucid $x$ quidem funt omnes, minimè uero \& albæ omncs, fed incipientes præfertim punicex, flaiıque, \& nigriores, \& quod ab integro omnes calore, $\&$ è modica omnino funt conftitutx mole, at non adeo copio fo illo dum facto, neque a deo extenuata hac uniuetfa, ut penitus hac in illius copia, huiufque obfcuritas in illius lateat albedine; at pleræque tandem, calore nimirum benè accenfo, auctoque, $\&$ materia benè tenui facta, alb $\approx$ fiunt. Et propterea ignitum ferrum, accenfique carbones uifiles quidem, lucidique, at non \& albi, fed punicei,flauigue, \& nigriores etiam, \& qux ex ijs effunditur lux, lang iet omnino; non valde fcilicet fplendet, nihilque à rebus, ad quas accedit relucet. Et qua ex ijs flammulx afsiduè elucêt, albifsimx funt omnes; \& uel qui albis è lignis facti funt, fi finc extinci, nigerrimi; quod copio fifsimus quidé eis inditus eft calor, \& quătus non adeo $a b$ eo rum crafsitic obtegi coercerique potuerit, quin effundat fefe inde, at qui tamen obfcuretur ab illa quidem, debiliteturque. ijfque omnino non prxinexiltens fpetatar; qui nimirum, fi non omnis à fabeunte adiutus elt, in fplendidiore certe illius fpecie penitus later: $\&$ qux illorum portio amplius extenuata, itaque \& in flammulas acta, eft alba prorfas, quod nulla in ijs materix obfcuritas, fed una caloris fpetatur fpecies; extincti uero obfcurifsimi fiunt, atrique, quod calor, quo inexiftente lucidi erant, puniceique, recefsit omnis. Itaque nul la in ijs ipfius fpecies, fed fola fpectatur marerix obfcuritas, \&propterea, qiæ uapores, aquafque, \& ferratilc vitrum permeat folis albedo, puniceo, \& flauo ipfa, \& nigrioribus etiam intingitur coloribus : quodab illorum omnium mole obfcuratur. Itaque \& eò in omnibus perpetuo magis obfuratur, quò profundiora ipfa, crafsioraque, \& luce minus directa, minus fcilicet copiofa fit, robultaque, quo fcilicet minus ipforum exfuperet obfcuritatem, breuifsimaque ab aquis refiliens folis lux, non purum modo folis colorem: fed figuram etiam, \& ipfum omnino refert folem, à paulo uero profundione colorem modo, \& à magis profunda ne hunc quidem purum, fincerumque, fed aqux molis obfcuritati ucluti immittum, eoq́; afsiduè magis, quo è profundiore, craffioreq́; reluceat aqua. Itaq; breuifsimo è mari, quod qux ipfum fubit, ab ipfoq; refilit folis imago, breucm ipfus opacitatem penitus exuperat, ueluti albo ab ípeculo, abanimi-

$$
\text { B } 2 \text { rim }
$$




\section{Bernardini Telefij}

rum à mole, \& quam quia nih il prorfus fubit, nihil prorfus eius immifcetur obfcuritati folis fpecies, \& ipfe ut dictū eft, relucet, fol, à paulo uero profundiore imago nulla, at color tâ. tum, \& pirrus is quidem, at nequaquam \&uigés; èmagis pro fundo ne purus quidem, fed marinę molis obfcuritati,nigredinique immiftus. Itaque quod humile ef, album apparet; uiride, quod paulo profundius; \& caruleum quod magis;poftremo \& nigrum, quod profundifsimum eft. eo fcilicet afsidue nigro proximuius, quo ipfum fubit, ab ipfoque relucet lux, profundiori immifcetur ipfius moli:quin \& quod caruleum eft,purpureum apparet interdum, ibique omnino, ubi non xquabile, fed pluribus diftinctum eft tumoribus . quod nimirum, qux ab ijs relucet lux, non maris modo opacitati, obfcuritatique, fed tenebris, quę è tumorum partibus nihil à folis luce illuftratis emanant, immifta relucet, Et propterea pauonam, columbarumg; penne, \& ferica quàm diuerfis colorata coloribus, \& non benè xquabilia, fed ueluti filis diftin Ėa funt, ijs interdum colorata apparent coloribus, qui-nulli prorfus ipfis infunt, \& fi.ipforum ad folem fitus diuerfus fiat, colores itidem diuerf uidentur, quod qux ab ipfis relucet. lux, non ab ipforú modocoloribus, fed ab obfcuritate itidé, qux ex ipforum partibus, ad quas nnlla aduenit lux,emanat, intingitur, \& quod fitum adipfa diuerfum nacta lux, non xque directa accedit, itaque nec æquè in fe ipfam collecta, nec xquè perpetuo relucet robufta. Præterea \& quod diuerfis intincta relucens coloribus, \& ijs robuftis omnibus, \& quorum finguli propria fpecie reliquos efficere queant, \& afficiăt omnino omnes, longè pluribus, ij fq; omnino, qui rebus non infunt, colorata relucet coloribus:nam non rerum colores ad nos deferri fed propterea ipfos uideri, quod quxad ipfos accedit, ab ipfifq; refilitlux, ipforum intingitur fpeciebus. Itaque ijs coloribus coloratas uideri res, quibus, qux ab ipfis relicet lux, colorata apparet : \& qux robufta intincta eft, eo obuias afficere, fat is ell, wt exiftimo, in ijfdem expofitum commentarijs. Et propterea itidem fi aduenienti folis luci. paulatim oculos occludas, non alba amplius, fed puniceapri mum, mox uero flaua, poftremo \& parpurea, nigraque tandé apparet, quod ì tenebris ex oculi partibus, quas illa non attingit emanantibus, ipfius cādor obfcuratur, eoq; ad nigrum agitur magis, quo ampliores illę fint. Itaq; guoniam fumma folis 
folis albedo albifsimas permeās, fubienfq; res ad nigrum agi tur, \& nigtiores, qux funt flamme, copiofiore donatx.calore at in amplius expanfx tales omnino facta, nihil ut inexiftes calor à circum fura mole obtegatur, nihilque illius fpecies $a b$ huius nigredine intingatur, albx fiunt:\& patet utrique, quod dictum elt, caloris albedinem à materia obtectam propterea obfcurari, ad nigrumque agi, quod obfcura ea eft, nigraque. quod nimirum materix immiftus calor, eius itidem nigredini immifcetur. At age tamen quoniam nix, grando, glacies, cryftallus, argentum, lapides multi, \& alia longè plurima, quę benè frigida, benèg; corpulenta videri poflunt, alba funt, \& fluores multi, \& benè ij calidi,liquidiq;, 3 multi itide lapi des bene tenues, atq; tranfpicui, non albi fed punicei,flaui, uirides, \& nigriores fpectantur, diligentius rem intueri ne gra uemur.

Albedinem omnino omnem caloris, sibil à materia obtecti" spesiemeffe. Cap. V.

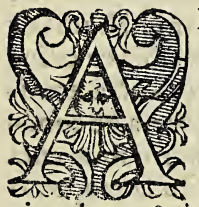

LBEDINEM caloris fpeciem, \& veluti faciem effe, $\&$ alba, qux funt entia, propterea talia effe, quod qui ijs inexiftit calor,adeo materix molem exuperat, ut nihil ipfe ab eius opacitate ocultatur,nec obfcuratur, fed materix tenebricofitas in eius candore, copią̧; latet, \& ipfius tantnm caloris fpectatur fpecies, ambigere non licet. Nigra contra qux apparent, propterea talia ui fa effe, \& uideri omnino, quod inexiftens calor, ita à circum fufa obtegatur mole, ut non caloris, fed materix fpectetur nigredo in ijs omnibus.\& qux coloribus, qui inter album,nigrum q; medij funt, donata apparent,propterea ca ijs.donata videri,quad neq; una coloris inexiftèt is albedo, neq, una fubiecte materix obfcuritas, at vtræq; fimul fibi ipfis cömiftre fpectentur, itaq; magis, minufq; nigra fieri entia, prout magis, \& minus inexiftentis caloris albedo a materizopacitate, tenebrifq; exuperetur.qux omnia, fiamplius inquirenda in ijs omnino entibus, quorum confitutio ncbis manifefta effe poteft, \& quę alba quidem, at frigida, denfaque, \& corpu lëta, uel calida quidë, languidaque, \& tranfpicua, at non alba, fed punicea, flauaque, \& nigra apparét, in quirédum eft.quod 


\section{Bernardini Telefij}

fi horum alba qux funt, corpulêtaq; è mole confituta apparêt, quam calor penitus fubierit vniuerfam, æquè vniuerfam exuperarit, \& cui copiofifsimum effe, \& tantum fefe omnino uniuer $f x$ indiderit, in quanto uniuerfa illius obfcuritas peni tus lateat; \& fluida, tranfpicuaque, at punicea, flauaque, $\&$ nigra qua funt, tenuioribus quidem, albifq; è rebus, at quibus crafsities quxpiam, qux inexiftentis caloris faciem obtegat, obfcuretq; immifta fit, effecta appareant; reliqua itidem, quorum nobis conftitutio confpicua non eft, quin huiufmodi è rebus, dictaq; ratione compactis effecta fint, dubitare penitus non licet:fi quidem quę difpofitione eadem, eademq; do nata funt fpecie, ijfdem è rebus, modoq; eodem conftituta fumme eft rationi congruum .alba porrò, denfaq; \& corpule-ta, quorum conftitutio obfcura nobis non eft, nix, grando, gla cies, lapidefque, qui è fontana, \& quod è marina aqua fal, quodq; ex harundinum fucco conficitur Zuccarum, \& vitrum prepterea, \& animalium offa, dêtes, vngues, carnefque, \& plan tarum ligna videri poflunt, tum \& ono rum albumina, aliaq; longè plurima, qux noftro ab igne alba, corpulëtaq; fiunt, flui da vero, tranfpicuaq; \& non alba, ficci,qui in animalium cor poribus, \& qui à tinctoribus fiunt, \& uitia, qux albis ex cuius expreffa, at diutius cum proprijs corticibus concoeta, punicea fiunt, \& quod coloratur uitrum, gemmæq; qux arte confiNix. ciuntur.at illorum nix ( $u t$ in proprio expofitum comm enta rio)è vaporibus nimirî́ fit,magno à calore, \& nulla propemo dum è mole confitutis, minimeóf; ulla proprix naturæ portione à frigore fpoliatis, nec aliud omnino quid immutatis, Grando. at in un am modo actis, fimulq; concretis: grando uero, \& gla Glacies. cies ex aqua,calida nimirum è re, $\&$ vt alibi fatis eft, vt exifti mo, declaratum, denfata quidem à frigore, gelataq;, at neq; ip fa à propria dimota natura, ut idem vtrarumq; manifeftat $\mathrm{fa}_{2}$ por.reliqua omnia è fluoribus, non eadem quidem uniuerfis, fed bene difsimili donatis difpofitione, at quorum tamen vel crafifsima portio, \& qure à tenniore feorfum facta in ftabi le, corpulétüq; côcrefcat ens, è mole effecta fit, quã calor peni tus fubierit unizersã, \& xquê uniuersä exuperarit, \& cui tan tüfefe uniuer $x$ indiderit, in quâto eius obfcuritas penitus la teat:Neq́; enim nifi è qua effecta funt, moles, penitus \& xquè exuperata fit uniuerfa, eade uniuerfa difpofitione, eadéq; do nata fit fpecie, \& longè à prxinexiftente difsidente utraque 
minus etiam, nifi copiofifsimus ijs omnibus infit calor, dulci, dulciq; proximo, ant etiam falfo, amaroque ijs omnino donata fint faporibis, qui caloris, beneq; actiones uifi funt, \&r ex aqua omnino, fluoribufque dú in grädines illa, glaciemque cogitar, hi uero in Zuccarum, uitrumqne concrefcunt, \& ex ouoram albunine, dum ab igne durantur, non magnam te nuitatis copiam elabi, inde liquido patet, quod eorum nulZucearum. lius moles imminui interea uidetur:è femine itidem, dum in rum. offa compingitur, \& è fuoribus, dum in carnes, lignaq; cócre fcunt per exiguam elabi tenuitatem exiftimare licet : fi quidem uifcofis è rebus vel liquidifsim $x$ ex fi fint, longè $x$ gerrimè elabi uidetur tenuitas, prxterea \& quod è quibus cuolat, tandem nigriora fiunt omnia. Itaque feniorum mortuorumque offa, dentefque, minus quam uirormm iunionumque, \& medix extremæque vngues, minus quàm enafcenOffa. tes apparent albx, \& plantarum cortex nigeromnino ab am- Ligna bientis nimirum aftu inexiftente tenuitate, caloreque è molli dum educto, $\&$ ligna ut dictum eft, $a b$ exuperante ignis calore tenuitate, eique infidente calore fpoliata, atrum affumunt colorem : ij fcilicet albi, qui funt fuores in non alba concrefcunt entia, qui è partibus compoliti funt, non difpofitione tantum, fed natura itidem fiummo pere difsidentibus, \& quarum omnino altera plurimo calore, \& tenuitate donatx fint, qux quidus tenuior facta fratim elabatur. alterx vero per modico donat $x$ fint calore, \& craffiores quidem, at nequaquam uifcof $x$, glifchręque, fed laxiufculz fint, \& è quibus ęlabenti ten!nitati haud ægerrime exitus pateat, \& illx his penitus infixx, immerfaque fint, itaque. ex his illx ueluti exprimend $x$, erruend $x$ que fint. Huimfmodi qui funt fliores à robufto præfertim calore, \&z qui nullo temporis momento inexiftentem tenuitatum omnem fummam faciat; eductaque nihil dum mollitie, cui ex immifta eft tenuiore facta, nec multo donata calore, non albam, ut dieum. elt, concrefcunt in ens:nam qux eorum remanet portio, non benè fui natura alba, $\&$ proprix etiä tenuitatis portione quapiam cum illa expreffa nigrefcat omnino oportet;minimè ue ro \& qui diuerfis quidem \& ipfi è partibus conftant : at quarú crafsiores qux funt plurimo \& ipf $x$, tantoque omnino donatx funt calore, quantus materix, è qua conftant, ob curitatem penitus exuperet:\& quę, quia infuper vifcofę funt, fi qua. 


\section{Bernardini Telefij}

qure efabi queat, ineft tenuitas, retinent eam, \& ueluti coercent, \& tenuiores qux funt, \& qux ut illæ ftabile, corpulêtumque concrefcant in ens, fecernendr omnino funt, $\&$ non peni tus illis infix $x$, fed ueluti appofitx fint; itaque negocio nullo fecerni ab illis, fepararique poffunt. quid enim alba fui natura qux funt, nulli proprij caloris, proprixque tenuitatis, nulla omnino rerum, quartim prefentia alba funt, portione fpoliata, nec alıud omnino immutata; at ab ijs tantum feorfum faeta, quorum commiftione fluida quidem, at non alba erant, non alba fiunt? Itaque quod dictum eft, albedinem omnem caloris faciem effe liquido patet. at age id amplius, \& num, quod dictum eft,nigredo materix obfcuritas, colores reliqui caloris fpecies fint, at non pura, fed materix obfcuritati immilta, \& in earum præcipuè rerum coloribus, quę noftro in corpore fiunt, intueamur.

\section{Nigredinem, qua in entibus à calore conftitutis Spectatur} materie nigredinem, colores reliquos, caloris materia tenebris immiftifpeciem, \& veluti faciem efJe. Caput. VI.

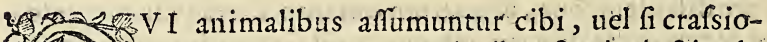
res, duriorefque, \& nigrioribus fint intincti colo ribus, in chilum fimul omnes, in mollem fcilicet liquidamque, \& albam in uentriculo aguntur ré: quòd bene quidem difsimilares funt omnes, at non adeò certè, ut qux à calore uifa funt nigra fieri: \& à blando uentriculi calore fimul tenuior ipforum portio in fluorem \& crafsior in eam agitur molliciem, quã factus fluor fubeat. Itaque copiofiore donati calore, \& longè molliores, quin be nè liquidi facti omnes, difsimilare id quidem, at in ens omni no coeút omnes, quod unum uideri poteft, \& bene id album; at cuius uel ten uifsima portio in iecur importata, $\&$ à robuftiore eius calore liquata, fufaque amplius in multos, longeq́, diuerfos agitur fuccos, \& magis, minụfue albos, prout inexiftens calor magis minufuè à materię mole exuperetur, obfcu returque, in fluorem nimirum benè quidem liquidum, \& ut exiftimare licet, dum fanguini non immifcetur, nullam q; ab co affumit crafsitiem, \& nulla ab eius calore tenuitatis pro- 
prię portione fpoliatur, prorfus album, \& puniceú in fangninem, flauamque, \& nigram etiam in bilem : quod nimirum proinexiftens tenuitas, eique infidens calor, cuius prefentia moles alba uideri poterat, quę non in aquam in uapores acta eft eductaque omnis, \& quę remanfit crafsities, \& pręinexifte tis caloris, eiufque infuper, qui à iecinore ind itus eft fpeciem abdere, obfcureque poteft, quin \& quę in fanguinem agitur portio, non in iecinore quouis uno, eodemque donatur colo re, fed in eo afsiduè nigrior fit, cui robıttior, copiofiorue ineft calor, in quo, fcilicet que in fanguinem agitur res maiore inexiltentis tenuitatis portione fpoliatur. itaque in modice calido, mollique iecinore, cui fcilicet necualdè robuftus, nec ualde copiofus inet calor, paniceus, quin necbenè puniceus, fed albidior fit fanguis : at purpureus in calidiore crafsioreue, \& niger etiam in calidifsimo; crafsifsimoue, cui fcilicet robuftifsimus, copiofifsimufue ineft calor . albidior autem in corde, quod ad ipfum fublatus fan guis, non ut qux in iecur importatur res è longè diuerfifsimis compofitus eft rebus, \& quæ eodem à calore in diueríos aganturfluores, fed benè fimilaris, \& qui perexigua fui portio ne in fpiritum acta, \& nequaquam unitierfo co educlo, reliquius una u niuerfus, eademque donetur difpofitione, \& lon gè omnino tenuior, longeque calidior, itaque \& longè fiat al bidior, in fpirati præfertim aeris portione admifia. Seminarijs porrò in uafis, teitibufque albus, $\&$ in mulierum mamillis longe albifsimus fit fanguis, quod in his copiofiore omnino calore, eaque uniuerfus donatur tenuitate, in qua purus ipfe fpectetur, \& fi quxpiam ipfins portio tenuifsima facta eft, lan guidifsimus, qui ei infidet calor euelere eam minimè poteft, in illis vero à robuftiore mafcul ino calore non eadem uniuer fus donatur difpofitione, fed tenuiore fui portione in fummam acta tenuitaté ita crafsior in fe ipfam cogitur. ita quod opaca fit, vt \& proprium ipfus calorem, \& qui facta ineft tenuitati obfcurare queat quid. itaque robuftior fortè, \& copio for femini ineft calor, at denfiori inditus moli minus, quam qui lacti ineft apparet albus, ut itidem ea perpetuo albior fit, cui languidior inelt calor, \& qui molliciem, humiditatemq; cui infidet egrè adeo tenuem, leuemque faciat, ut euehere eã queat. Itaque qui frigidiore funt corpore, $\&$ qui frigidas inco lant regiones, \& qui fub tecto, atque in ocio uitam degunt al- 


\section{Bernardini Telefij}

bicerte funt omnes, quod nimirum qui ipforum cuti ineft ca $l_{0}$, inel quia propria è natura languidis eft, uel quia $a b \mathrm{ex}$ terno frigore imminuitur ipfis ais, uel quia nihil ufquam commotas, nihil, fcilicet propriam ufquam operans operationem, nihilyue ab externo fotus, excitufque fegnis fit, inerfque, humiditatem, cui infidet, haud quamquam ea donat ten aitate, in qua elabi queat. Itaque quod multus ipfe in ea remanet, nihilque à mollifsima obfcuratur cute. Iure horú omnium albı eft cus : eorum côtra qui calido funt corpore, 82 qui calidas incolunt regiones, \& qui fab dio laboriofam degant uitam, nigra omnium, quod omnium cuti magnus omnino ineit calor, $\&$ molliciê is, cui infidet, tenuifsimam facit, leuifsimamque, \& fecum eam adacic omnem. Itaque modi-

Pili. cus remanet calor, $\&$ in bene conftricta penitus latet. Pili iti dem ita albiores fiunt, nigriorefque, pro ut fluori, è quo fiunt, robuttior, läguidiorue ineft calor, prout, fcilicet maiorem is, minoremue portionem in cam agat tenuitatem, quam cuehe re queat. Itaque in uniuerfum qui calido, ficcoq; funt corpo re, \& qui fub calido degunt calo, nigros habent pilos, \& crifpos, quod modica ijs ineft tenuitas, \& ea à robufto, vel proprio, uel externo calore in fimmam acta tenuitatem, cum co elapfa eft omnis:coutra qui frigido, humidoque funt corpore, \& qui frigidas incolunt terras, flawos habent, \& rectos, quod multa ijs ineft humiditas, \& quam, uel propria natura langiens calor, uel ab externo frigore retufus, non ea donat tenıitate, in qua elabi queat.Nec vero, quod fub frigido degentibus cœlo magnus ine?t in uifceribus calor, externa itidem cuti magnus ineñe uideatur, quin propterea magnus in illis, quod externi frigoris uires reformidans nullus in hac re manfit, fed in ill a confugit omnis, \& humiditatis omnino co pia fla os his, eiufdem uero inopia nigros illis fieri pilos; inde apertifsimè intelligere licet quod crifpi etiam illis, recti his nunt. Fluens cnim fui natura humiditas in rectum omnino fluit, \& qui Igni admonentur pili propterea crifpi fiunt, quod è tenuitate, crafsitieque fibi ipfis imminis compofiti fant, \& temere illa undique, nulloque erumpente ordine hæc itidem fugientem illam, \& mutuum fectans contacum teme re undique, \& ordine n:allo mutuo in fe ipfam fertur.Itaq; pili à reeto recedunt fitı, qui uero medio funt corpore, \& qui medium incolunt tractum, pilos itidem medios habent, mo dicè 
dicè fcilicet nigros, \& minus etiam crifpos; quod à quibus al bi, rectique uel nigri,crifpique fiunt pili media ijs infunt om nia.Flaui itidem, rectique infantium pili, quod multa is humiditas, \& calor minimè eft uehemens: Florentium xtate nigriores crifpiorefque, quod humiditas imminuta, calor uero copiofior factus eft:fenectus cana omnino, quod languidifsimas fimilis calor nullam prorfus fluorum portionem in eam agit tenuitatem, quam euehere ipfa queat. In coloribus itidem, qui arte funt manifente intueri licet, nigredinem qux fpectatur in entibus materia obfcuritatis, reliquas colortim fpecies caloris ab illa obfcurati facies efie. fiquidem non albis, nigrifque è rebus fibi ipfis commiftis medii qui uideri poffunt, fed ex aqua rebufque aliis albis, uel albis proximiori bus nigriores qui funt, $\&$ ipfe etiam fit ater.id verò uel ipfum declarat atramentum, quod nimis exaqua, nitroque, quod quia ab eo precipue ater color atramento inditur,atramenta rium dicitur.\& gumma, gallaque ex albis omnino, uel fubfla uis conficitur rebus : propterea enim qui iis e rebus efficitur fluor niger fit, quod tenuitas, eique infidens calor, quo inexi ftente albx, uel albis proximx uideri poterant è concoctis, contritifque, \& ab aqua amplius liquatis, fufifque elapfa eft omnis.Itaque quæ reliqua facta eft crafsities, quxque ei infidet obfcuritas aqux adiecta, commiftaque atrum ei indit co lorem, \& uina albis ex vuis exprefia \& alba omnino exiften- Vina alba. tia,albaque futura, diutius cum propriis corticibus cöcocta punicea fiunt, \& quod nimirum uel crafsities quapiam affim pta eft, à qua inexiftens caloris facies obtegatur, obfcurcturque, uel proprię tenuitatis, calorifque ei infidentis, quo inexiftente alba uideri poterant, portio quępiam elar fa eft, uel utrumque. \& gemmę que arte fiunt, propterea albis e fluoriAttramestum. bus non albe fiunt, quod quepiam iis crafsities incrat, qua in ampliore illorum tenuitate, albedinequc penitus latebat, in minoribus his fact is confpicua fit. Itaque quoniam manifefte quę e nigriori bus albiora fiút, proprerea talia fiunt, quod vel copiofiore calore, uet maiore donantur tenuitate, uel vtrú que:quod, fcilicet uel copiofior is inditur calor, uel prẹinexi Itens à minore obtegitur opacitate, uel utr ma que qua côtra ex albioribus nigriora funt, propterca talia fiunt, qued uel minus calida, ucl magis opaca fiunt, uel utrunque: quod fcili cet uel inexiftens imminuitur. calor, uel à maiore is obtegi-

$$
\text { C } 2 \text { tur }
$$




\section{Bernardini Telefij}

tur opacitate, uel utrumque patet utique quod dictum eft,al bedinem caloris unius, unius materię obfcuritat is nigredinem, quę noftris in entibus fpectatur, reliquas coloris fpecies utriufque facies effe. At age porro quod reliquum eft, qui colores albo proximiores, qui remotiores fint, culorum omnino ordinem intueamur.

2ui colores caloris minus à materic opacitate fadati, $0^{\circ}$ qui magis faiies, qui omnino albo proximiores, of qui remotiores funt, nec tamen omnes earum differentias inquirendas efe. Cap. VIL.

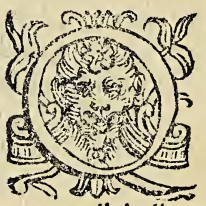

VONIA $M$ calor albus fui natura eft, \& vbi nihil à materia cui incxiltit opacitate, tene brifg; obtegitur, foedaturq; albus apparet; at ab illa obtectus, illiufq; tenebris immiftus ad nigrum agitur . itaq; ibi minus eum obtegi, vbi albo proximior fpectatur; \& è contra ibi albo proximiorem effe, vbi minus obtegitur,exiftimandum eft utiq; puniceus albo proximus tum flaus po-

Puniceus. nendus eft;puniceum uero rubrim appello, minimeq; ad nigrum vergentem, cuiufmodi fang:uini ineft iam diu effufo, \& qui inexiltente tenuitate caloreq; ei infidente fpoliatus omni in grumum iam, in craflam fcilicet nigricantemq; actus eft rem; fed qui in fanguine eftluente minimè;;.in omni, fed in tenui, tum floridoque, \& a calore integro quidem confeeto, at nequaquam robore minus eft etiam copia exuperante, à quali purpureus, ut dictum eft, nigerq; fit fanguis : eum deniq; puniceum appello, qui in cœlo modicis, longèq, tenuif fimis occupato uaporibus non dum exorto expectatur fole:

Flauus. flaum auté non qui albo perfimilis, contiguufque apparet, \& qui ex albidioribus puniceus confici videtur rebus, quem albidum dixerim, fed qui, quad croco ineft, croccus dicitur, \& qui modicum quid confpiffatus in fe ipfum, itaq, obfcur

Duniecus. rior quid factus in viride träfit, \& uirid is omnino fit. \& quod dictum eft, puniceum albo, quàm fauus eft proximiorem effe inde intelligere licet, quod, quæ per ten ifsimos uapores, \& $q$ qui in aquas confpiffari nequeunt folis albedo ad nos aduenit puniceo, per crafsiores vero flauo intingitur colore.Ita 
que vt dicum eft, prniceus fol uentos denuntiat vfq; quaque, in quos fcilicct vapores diffundi uifi funt longè tenuiffimi, at flauns pluuias perfæpe crafsiores nimirum permeans vapores, \& qui haud agre in aquas cog mntur.flaua itidem fecunda iridis Zona, q Ir punicea interdum, uiridifq; media fit:\& albx flammę per tenuiorem confpectę fumum, punicez per minus tenuem flax fpectantur : multo certè psnicex', quàm faux magis uigent, magifque uifum commouent, \& ueluti feriant . ob id nimirum quod fulgens caloris afpectus minus in illis a materix opacitate obtectus ninus eft imminutus, minufq; debilitatus, \& que per ferratile uitrum ad nos aduenit lux, qux quod breuiori alsiduê, profun diorite im $\mathrm{mi}$ fcetur opacitati, albior afsiduè, nigriorq; fiat oportct, mani feftè punicea in flauam, ac fubrufam definere uidetur, $\& \mathrm{~h} x \mathrm{c}$ Viridis. asfiduè magis flaua fieri, magifq, ad uiridem uergere, \& uiri dis tandem fieri.\& ut itidem dictum eft, fi folem intués paulatim oculos contrahas aduenienti nimirtim folis albedini, paulatim aditum occludas, itag; afsiduè à tenebris è rebus, quas illa nihil attingit cmanantibus magis obfcuratur,puniceam primum mox flauam, \& poftremo purpuream intucare. ab exigua fcilicet primum, mox ab afsidue ampliore fodatam, impuratamq; obfcuritate. \& puniceum omnino colorë, caloris faciem effe, qui materix opacitatem, \& materiam ipfam magis extenuarit, magifq; exuperarit, quä,cuius fauus, \& flautum magis, quam cuius uiridis facies eft.\& expofito or- iecure. dine, qui dicti funt, fefe confequi colores, inde itidem perfpicuum fit, quod qui à moderato, ut dietum eft, iecinoris ca lore conficitur fanguis puniceus, flauus uero, qui a languidio re; \& uirid is, qui à langaidifsimo fit, fpectatur:uiridem cxruleus excipit, \& cxruleum purpureus, ut in luse, qux ferratile permeat uitum, in eoque amplius, qux à mari refilit intueri licet.fi quidem ab humili eo, breuique,parum fcilicet opacitati, tenebrifq; immifa lux, \& parum omnino ab ijs impurata alba, a paulo profundiore uiridis, \& cęrulea à magis profun do.eò fcilicet afsidue minus alba, quo ampliori immifcetur obfcuritati, 2 ab eodem, at agente, turbatoque non $x q u a b i-$ Ii omuino, fed ueluti tumoribus diftincto, e quibus ícilicet neluti intertupta, \& tenebris cx illorum partibus nihilà luce confpectis emanantibus obfcurata quid relucet lux, purpureaut dictum eft, relucet interdum:\& cæruleus omnino pau- 


\section{Bernardini Telefij}

lo abfcurior factus in purpureum tranfire apparet; purpureus non in alium benè ab eo diftinctum calorem, fed in nigrum omn ino tranfit, obfcurumq;:ut lux qua à profundifsimo refi lit mari, \& fangnis tenuitate omni fpoliatus declarat. dicti porro colores, \& unius, eiufdemque caloris, at diuerf inditi opacitati , \& diuerficaloris, at vini cidemque inditi opaci-

Flamma tati facies üicieri poteft:fiquidem flamma ab uno c mres, \& fummo eo fąę calore, omnibus donari uidentur coloribus. \&ut dictum eft, directa, robuftaque folis lux aquam permeâs nihil immutatur, at obliqua, \& propterea languidior facta punicea fit, flauaque: quo fcilicet copiofior, robuftiorue materiam fubit calor,eo eius opacitatem exuperat magis. \& in qua multus ipfe, robuftiorue, nihil, aut per exiguum quid occultatur, impuraturue, minor, languidiorue valdè fędatur,ual deque obfcuratur, quin \& impuratur:non $x$ què ta men obfcu ratur, fed fplendidior omnino remanet: Itaque colores fingu li fummopere à fe ipfis nitore differuut, fulgoreque:ijque per petuo fplendidiores fpectantur, qui copiofiori robuftiorifue caloris facies funt : id uero, \& quæ noftro ab igne immutantur, \& fucci, qui in animalium corporibus fiunt, fatis declarant.nam \& illa eo fplendidiora funt, quo diutius immutantur, robuftiufue, guo fcilicet copiofior ijs, robuftiorue indatur calor.\& fanguis Galeni tentimonio, calidioribus in corpo

Gal.li.r.de ribus fplendidior fit, nitidiorque, at uel in ij fdem frigidioribus factis obfcurus, nihilque uifum commouens: Eunuchis, femine. ca. inquit, quod altero natiui caloris fomite priuati funt fan-
s. guis non amplius floridus, non fcilicet in florum more, nec fulgens, nitenfque amplius; fed obfcurus.\& atra, inquit, bilis

"

,

r) fuperaffata fplendorem aflumit: lucidus fcilicet calor quibus copiofiorem fefe robuftioremque indit, lucet in ijs, folédetque magis. Non fimul porrò feedari, obfcurarique caloris faciem, fed bene interdum impuratam nihil fere minus fplendidam, minufque lucidam fieri, \& folis, \& flammarum declarat lux.illa enim uapores, ut dicum eft,permeans \& hac craf fioribus facta in rebus, nihil quidem, quod uidere queas, mi nus fplendida, at punicea, flanaque fit . funt vero \& colorum qui corum, qui dicti funt, intermedij uideri poffunt, \& longe ij quidem plurimi, nihilque à fe ipfis minus, quàm à proximis differentes.quoniam uero non fpacijs quibufdam, \& ueluti faltu, uel calor imminuitur, uel crafsities in teuuitatem agitur: 
agitur: fed per cōtinuŭ, \& ueluti fluxu caloris robur,faciefq; \& materix,cui is indiê, difpofitio immutat,caloris itidē immutatio ueluti fluxu fiat oportet.Itaq; $x$ que proximi $q$ funt colores $x$ que à fe ipfis diuerfi, \& reque fimiles fint oportet.albedo nimirü haudquaquã indiuifibilis, \& vcluti in pücto po fita eft,quo emêfo in rubedinem agatur, fed bene ampla \& quę bene imminuta, impurataque, alba tamen fpectetur,alba omnino qux funt, non rque alba funt omnia: nec vnus omni no color eft albus, nec quiduis fodatus in prniceum, puniceufque in flaum tranfit. fed finguli longe plurimi funt, \& al bus qui puniceo proximus eft, ac contiguus, puro integroque abıalbo magis:quàm à proximo differt punice quod dictú omnino eft. ita fumma albedo in nigredinem agitur, ueluti \& fummus calor in frigus, \& crafsities fummam in tenuitatem, non faltu nimirum nihil colores, qui in medio funt attin gens, fed per continuum, \& ueluti fluxu \& intermedijs omni no coloribus colorata omnibus, ut colorum differentix inn! merx propemodum fiant, plures certe quam, qux caloris, materixque difpofitionum funt : fi quidem calor quiuis cui uis indi poteft materix, minimeque, ut dictum elt, eadem in ma terix difpofitione, qui induntur colores, xque omnes in ea fœedantur. Itaque idem omnino omnium fit color, idq; modo à fe ipfo differens, quod robuftior alius, fplendidiorque, alius uero languidior, obfcuriorque.fed alius omnino robufti, Inguidioris alius, tot porro modis albedo dum in nigredinem agitur,cum immitetur, eius differentias omnes intue ri per obfcurum, \& quod ut nobis quidem uidetur, homin i tentandum non fit.nos certe veluti gradibus quibufdam eius amplitudinem diftinxiffe, uel fi adeo ampli fint finguli, vt alijs multis diftingui queant, contenti erimus : nam \& colorum reliquorum quiuis horum quifpiam paululum quid obfcurior, durioruè factus, uel ex horum quibufdam fibi ipfis immint is compofitus uideri potelt. fatifque in his, ut exiftimo quid fit color, \& quomodo, quę fpectatur colorum diuerfitas, immutatioque fiat, qux omnino ad colorum cognitionem fpectant omnia intueri licet. Itaque quod reliquum eft qux de coloribus, eorumque generatione Ariftoteles, fiue is eius auditor Theophraftus, qui Arifroteles ipfe uideri poteft. tradidit, explicemus, examinemufque. 


\title{
Bernardini Telefij
}

\author{
Aer,aqua, o terra alba;ignis uero, \& fol flawum.niger color \\ reliquis elementis ab igne combuffis : colores reliqui \\ ex horum commiftione fieri Ariftoteli \\ videntur. Cap. VIII.
}

\begin{abstract}
Auetor de $\mathrm{CH}$ IMPLICES, inquit Ariftoteles, colores funt, colorib.ca.

I.

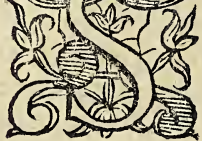
qui elementa, puta ignem aerem, aquam, \& terram confequuntur. Aer enim, \& aqua per fe funt natura aiba:Ignis autem, \& fol fiaui: Terra vero natura alba eft; fed propter tincturam multicolor apparet quod in cinere manifeftum eit. nam exufto colore, qui tincturam, faciebat, "alb as euadit:non tanien omni ex parte, quod fumo, qui niger "eft, tingitur.niger a!tem color confequitur elementa, cum in "fe intricem inmutantur. tum multis interiectis, nigrum, in" quit, colorem fieri contingit, cum aer \& aqua ab igne combu "runtur.quare omnia ambufta nigrefcunt, veluti ligna, \& car" bones igne extincto.fimplices colores tot, talefque funt.reli"qui vero ex horum temperamento, \& maioris minorifque raE.o.t.c.2.

" tione gignuntur.
\end{abstract}

"Noc flaus color fimplex, nec fol, atque ignis flaui, nec terra alba Arifoteli videri debuit.

$$
\text { Cap. IX. }
$$

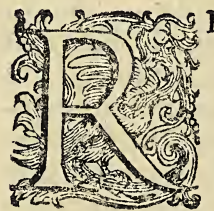

ECTE quidem colores, qui primis infunt corporibus, primi videntur Ariftoteli, \& rectè ad colorum côftitutionem folis, eiufque lucis opera uti videtur;atque neque fol, neque ign is flati, nec fauus omnino color fimplex videri debuit, cum vel Ariftoteli ipfi,\& fol, \& ignis albi uifi fint, vbi per purum ille aerem, hic vero in benè exuperata confricitur re. $\&$ flauus manifeftè albi, nigriq; medius eft. Terræ certè colorê inquirenti Ariftoteli nô in cincre infpiciendus erat, qui vel è crafifsima ligni parte, efto \& gux terrx fimilis, cognataque fit confectus, quam longifsimè tamen à terra dimouerdus eft. Ignique proximus ponendus, cuius nimirum uiribus donatus uiderux:vt aqua per eum percolata declarat, quam nô co- 
Jorem modo, fed calorë etiä flammeum affumit, \& pro dulci longè fit amarifsima:fed in terra \& profunda omnino, \& qua nihil à fole paffa, fit immutataue indagandus. Et nigerrimus. in éa dabio procul confpectus foret, quin vel non talis ineffe vifus, talis omnino indēdus ei erat.fi quidem \& ipfe fimplex, veluti \& albus fimplici omnino \& ipfe corpori indêdus erat. Terrx it aque neceffario, qux nimitum fola, nec alba, nec flaua vifa foret, $\&$ quæ natura vtraque contraria, aeri uifa, contrario itidem coloranda erat colore; Itaque nigro, neq; enim dubium effe Ariftoteli poterat, quin \& colores à primis quatuor qualitatibus manarent, à quibus \& elementa \& entia reliqua omnia, omnefque eorum códitiones ipfi in primis Ariftoteli confitui vifæ funt. At nel nufquam illum infpicienti vel nulla indaganti ratione, ex imis omnino terra latebris eruendus Ariftoteli erat, qui \& effe illum confpiciat, \& ex eius albi,flauique committione reliquos cöftituat. E fimplicibus certè albis corporibus flaui ignis actione nufquam educendus; qux enim in fimilaria præfertim agunt, fi non in propria ea naturam propriamque agunt in fpeciem, in mediam certè agunt.Alba itaque qux funt elementa ab igne flauo paffa, vel flaum, vel colorem affumant, q'ai albi, flauique medius fit, quam longifimè igitur ab nigro dimotum, ac diffsidentem. Itaque qux ab igne paffa non flauum, nec flaui albique medium, fed nigrum affumunt colorem, eius enm entis propriü declarant, cui proximiora ab igne facta funt, terrx nimirum; neque, enim uel aer, uel aqua ab igne foleq́: nigrefcere apparent, fed quix ex illis \& terra compofita Arifoteli uidentur. ibique tantum omnia, vbi aere \& aqua ed sctis fola reliqua facta eft terra.

Nigrum colorem bumidi copia fieri Arifloteli interdum uifumfuife. Cap. $x$.

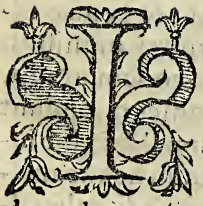

$\mathrm{N}$ eo tum etiam incufandus Ariftcteles uideripoteft, quod qure comburantur, qux videlicet humiditate omni fpoliantur, velalbifsima fi fint, nigra ea ficti cmnia intuitus cum foret; proptereaque nigrum colorm humidi defectu ficri cum natuiffet, quia que dam albiora tieri afpiceret, quix ficciora facta cfe videri yo-

D terant, 


\section{Befnardini Telefij}

terant, priore fententia improbata, nigrum humidi excefis fieri decernit, perpetuo videlicet \& color, \& effectus alius qui: uis eidem omnino agenti afsignaridus eft omnis, contrarijs certè nullis vn q'am. Et quod femel rectè perfpectum eit, atc; ; ftacutum, in dabium id certè nunquam re.tocandam; fed per petio firmim, ftabileque, \& certum manere debet:manifeftè igitur quxdam ob humidi defectum nigrefcere intuitis, uel ii in q tib ifdam is latedt, qux n ngrefcut omnia ob humidi defectum nigrefcere ftatuend am omnino eft, $8 \mathrm{r}$ diu is maltúque inquifitus dubio procul in omnibus tandem manifettus Lib. de co- fiat.Et vel in ijs, qux humidi exceffu nigra fieri Arifteteli vilorib.c.6. fa funt, manifeitus, ut opinor, iat. Errant, inquit, qui exiftmant nigra omnia fieri propterea q ood ipforam alimentum ăcalido comburatur : non nulla enim animalium ftatim als initio fiunt nigra, it canes, \& caprz, \& boues, at que omnince quortumcunque pili, \& cutes initio alimentum habent:proce dente autem xtate, minus: \& puerorum omnium capita inipra. tio rufa, propter alimenti paucitatem, atque id manifertum elt.nam capilti imbecilles funt, \& rari eādemque ob caufam.

" Prxterea etiam primum breues omnibus pueris proueniunt:

? uerum progrediente ætate nigrefcunt : rurfum ijs coloratis, bem \& barbam, cum primum coeperint pubefcere, \& lannginem einittere, hx quoque fiút initio rufx propter humiditatis paucitatem, que in ipfis deficcetur. ubi uero plufculum a'i menti ad locum defertur, rurfus nigrefeunt.Piliautem in cor pore plurimo tempore ruf perdurant propter alimenti inopiam.quoniam quo tempore augetur, \& has fimili ter nigrefcere contingit, quemadmodum,\& pubis, \& capitis pilos.pra pterea autem id eft, nam quæcunque prolixos hab ent pilos, ut pluximum qua parte corpori proximi fuñt, nigriores funt; circa fumma vera flaniores, ut funt ouium, equorum, \& hominum ;.propterea quod ijs paucifsimum alimentum ad hec loca deferatur, \& exarefcat celeriter : fiunt \& penna nigrarım auium, qux propè corpus funt, nigriores omnibus: qua uero in fummis partib as funt, flauiores . codem modo, \& qux circa collum funt, \& omnino qux modicum capiunt alimentum. maxime autem perfpicitur in animalibus fubiugalibus, omnium enim pili albi fiunt.locis enim nequeuntibus fimiliter nutrimentum attrahere propter calidi imbecillitatem 
litatem humidum celeriter exarefcens, fit album.\& qua fune circa tempora maximè omnium canefcút, \& fummam circa infirma \& laborantia loca.

\section{Colorem nigrum bsmidi copia fieri, album vero eius defectuperperam Arifoteli vifum fuiße. cap. $\quad \boldsymbol{I}$.}

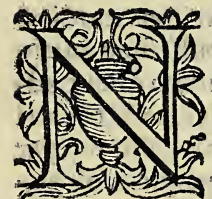

ON quidem propterea album colorem humidi inopia, nigrum uero eius copia fieri Arifoteli exiftimandum fuit ; quod animaliú non nulla enafcentia nigra funt, procedente uero êtate alba fiunt : uere enim Animalium omnium corpora humidiora in ortu funt, \&z verò afsidue ficciora fuút omnia. At animalium pili in uteris maternis enati, ab uterorum calore exiccari, nigriq; fieri potuere: corum ritu qui à fole, igneque nigrefcunt, quę propterea nigriora fiunt, quod ab exuperante illorum calore humiditate omni fpoliantur. At inde, vt uidetur, nigrum humidi copia fieri colligenti Arifoteli, quod animalia in orru humi diora funt, nequaqua puerorum capilli,\& iuniorum pubes ini tio taf $x$ ob alimenti, humidique inquä, poftea uero ob eius copiam nigriores fieri uideri debuere; neq; enim hominum corpora in ortu ficciora, \& poftea humidiora:canum uerò ouiumque, \& bouum initio humidiora, \& poftea ficciora fiút, fed omnium prorfus initio humidiora, progreffu uero ficcio ra fiunt; \& uel Ariftoteli ipfi puerorum capita ob nimiam hu miditatem grauari, nec coalefcere, nec caluarize opinio offa confirmari poffe vidētur.albi itaque rufique, \& molles pue rorum pili, quod è capite enafcuntur longe humidifsimo, $\&$ qux asfiduè ex eis elabitur tenuitas $a b$ asfiduè in eos influen te reficitur, \& tandiu albi, rufique, \& molles durant, quä diu \& corpora humida permanent; minuti porrò , fragilefque, quod corpulentiores, ut fiant capilli, latis opus habent, \& $\mathrm{pcr}$ manentibas poris qui in mollifsima, humidissimaque chte, \& Itatim tenuitate elapfa in fe ipfam decidente fierinon poffunt. Itaque pueri fẹminęque, \& qui omnino humido fus $t$ corpore, pilis, ut plurimum carent; nec barba, aut pubes $f t, n i$ fi partibus paulo ficcioribus factis . \& proptcrea itidem bre-

1) 2 ues, 


\section{BernardiniTelefij}

ues, fragilefque, quod è fluore facti fint hand quaquă craffo, uifcofoqae, qualis promptifsimèconcrefcat, nullaque unquä fui portione in ten uitarem acta, elapfaque in benè corputera; tam, beneq ie longam concrefcunt rem. fed è bene liquido te nuique, qualis longè egerrime concrefcat, \& promptifsime unicer fis in f Immam tentutatem confletur. Itaque in breue, fragilemque concrefcat rem. Funiorum contra crafsiores, nigriores, robuttiores, lohgiores, fpifsiorefque; quod in aridiore iam facto corpore frequentes. Latique pori, \& fluor à ro buftiore calore uifćofus iam factus êft, \& qui in illiüs modicó crefcat capillis Eandem ob caufam batba pubefque initio quidem rufę, \& afsiduè nigriores fiunt, fi quidem è bene adh ic molli, hamidaque cate, \& quę a fsiduę ficcior fiat \& arri dior,exoriuntur.Auniú prẹtereà ceruices, fubiugaliumq; par tes animalium, quẹ â fella atteruntur, haudquaquam ob alimenti humidiq; iropiamalbiores uideri poffunt; neq; enim vel mollifsimas; humidifsimafq; iflas efle, nelin has afsiduè attritu calefactas, adapertafq ; plinin in influere humorems dubitare licet.prolixi itidem pili, \& nigrafum aurum pennę, qux corpori proximiotes funt; 8 nigriores, in extrem is uero partibus albiores fuunt; non quod alimentum modicú, modicufque humor ad extremas deferatur, quo abundent proxi miore's corpori; fed quod calor itiden his multo quam extre mis ineft robintior, \& qui inexiftentem humiditatem in fum manx agat tenuitatem, eamque educat omnem : non fcilices ea alba fiant, in que multa influit humiditas, $f$ a a robuftione calore in fammam agatur tenuitatem, eaq; elabatur omnis, fed ea modo, quibus humiditas multa, \& non is ineft calor; qui in uapores illam agat : $\&$ hac ratione uel Arifotelis teft imonio animalium uarij coloris pili, fub uentre albi fiunt, \& ubi atcritu fellx ulcera iumentis, eneniunt, fi folidentur albus oritur pilus, natiuo, fcilicet proprioque partis calore debilitato, \& plurimum afiluenté humorem etuaporare impotéte: at fi quid apponatur,quod calorem adiunandi, difcutiendique, \& humidum euaporandi vim habeat, pilis reliquis uni colores fiant. \& circa tempora, \& omnino circa, labotantia, \& infirma loca pili omnium primi canefcunt; non quod modicus humor, nam temporalis mufculus omnium hunicifsimis : fed quod humiditas ubique adef multa , \& quam imminutus \& languens calor euaporare minime queat o \& qux

Arifto- 
Ariftotelis teftimonio frigoribus fruientibus alba fiunt aniw malia ; proptetea omninoalba funt, quod proprius corum calor $a b$ externo robuftiore reiectus frigore inexiftentem hus miditate $m$ haud quaquam in eam agit tenuitatem, in qua elabi queat.\& fi quam in talem agit, nihil eam euehit tamen, haudquaquam libens exiliens, ut uel quę nigrum colerem hu midi copia fieri Atiltoteli perfuafere, ea maximè humidi ilJum inopia fieri manifeftent.

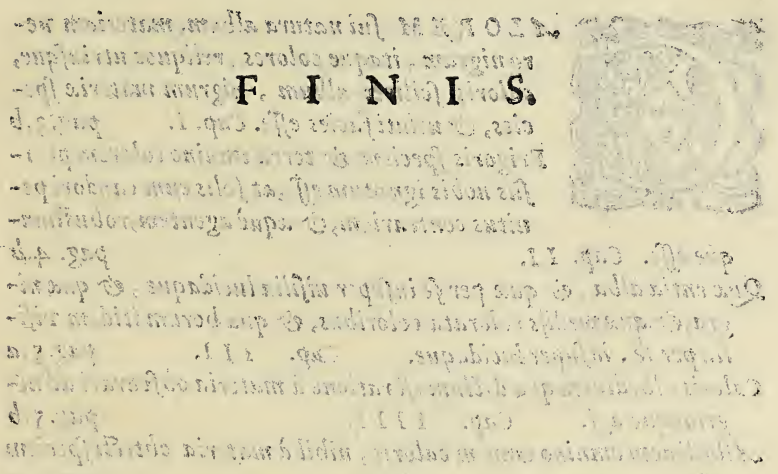




\section{INDEX CAPITVM L I B R I De Coloribus.}

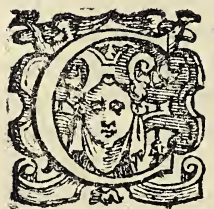

que effe. Cap. II. Que entia alba, \& que per fe infuper uifilia lucidaque, of qua nigra, \& que medijs colorata coloribus, \& qux borum itidim vifiliaper fe, infuper lucidaque.

Cap. III.

paz.5.a Caloris albedinem qua dictum eft ratione à materia ob furari ad nigrumque ario.

Cap. IIII.

Albedinem cmnino cmnem caloris, nibil à matcria obtecti fpeciem eßs. Cap. $V$.

Nigredinem, qux in entibus à calore conftitutis pectatur materie nigredinem, calores reliquos, caloris materia tenebris immisti Spiciem, of veluti faciem eße. Cap. VI. pag.8. b.

Qui colores caloris minus à materia opacitate fadati, \& qui magis facies, qui omnino albo proximiores, of qui remotiores sunt, nec tamen omnes corum differentias inquirendas effe.Ca.VII.p.I o.b Aer, aqua, ¿ terra alba ignis uero \& fol flaum niger color reliquis elementis ab igne combufis, colores reliqui ex borum commistione ficri Ariftoteli videntur.

Cap. VIII. pag.r 2.6 Nec flauns color fimplex, nec fol, atque ignis flaui, nec terra alba Arifoteli wideridebuit.

Cap. IX.

pag. I 2.6

Nigrum colorem bumidi copia fieri arifoteli interdum uifum fuiffe. Cap.X.

Colorem nigrum bumidi copia fieri, album wero eius defecti perperam Ariftoteli wifumfuiffe. cap. $X I$. pag. $4 .{ }^{4}$

\section{F I N I S.}




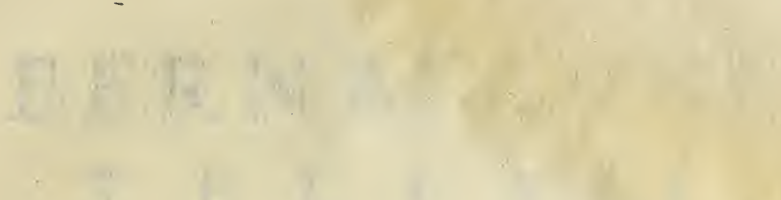

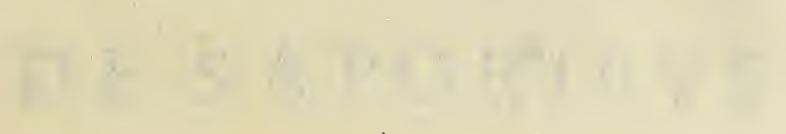

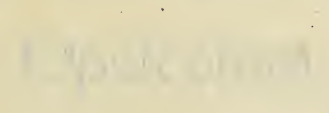

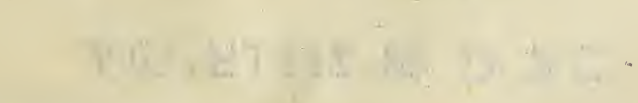

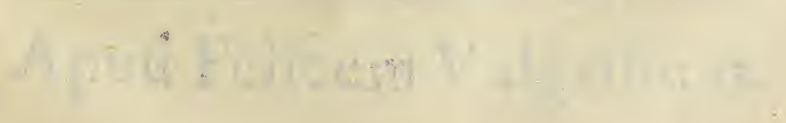




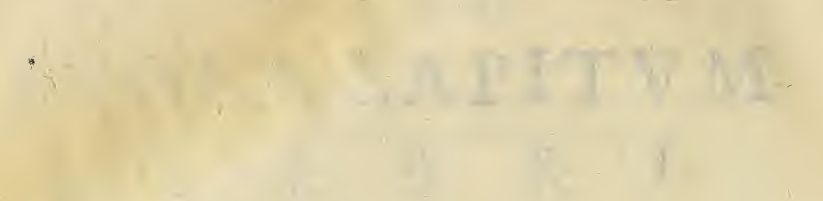




\section{BERNARDINI

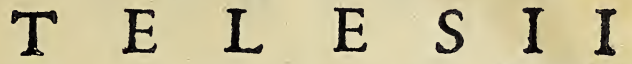 \\ C O NSE N T I N I, \\ DE SAPOR IBVS \\ Opufculum.}

CVMPRIVILEGIO.

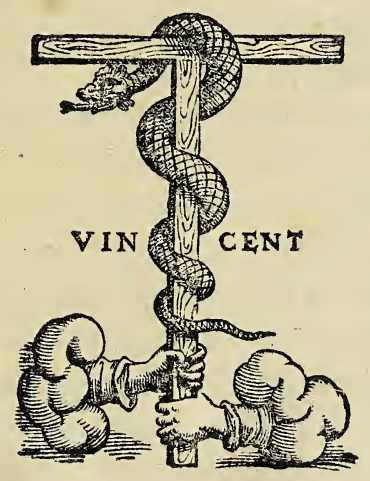

VENETIIS M. D. XC.

Apud Felicem Valgrifrum. 
MUOSAMBHA

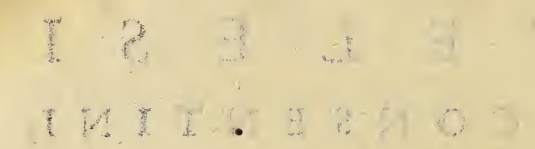

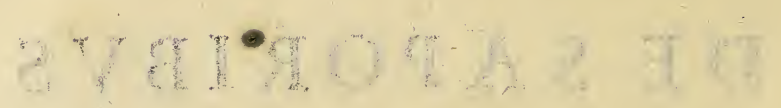

mantastracto

$.0 x+1+214+x+3 y$

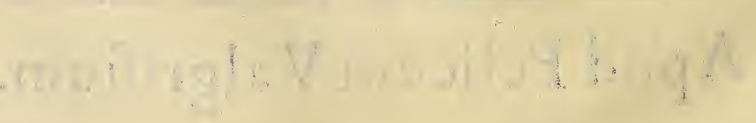




\section{A N T O N I V S P E R I V $S$}

\section{E M I N E N T I $S S I M O$ P H I O S O P H O}

\section{Federico Pendafio. S. P.D.}

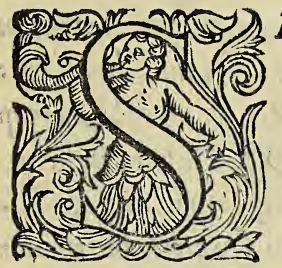

I quantum cAriftoteli philo/opbeo rum fi $\ddot{y}$, tantum tibi, Federice Pen dafi philofophorum memoric noftre facile princeps, ipfum debere Arifotelem dixerim, na ego vera pradicatrim. Illuftrafie etenim publicus tot annos in celeberrimis Italie Gymnasyjs interpres Ariftotelicam vque adeo philofophiam, vt non tibi minus, quam Ariftot elicorum librorum, qui fituobfitiparum $a b$ interitu aberant, erutori, ac vindicatori illigratice de beatur. Quos $\int$ nobis inimicum fatum ad exitium v $q$; inuidiffet, poteras tu nouns illucere mortalibus cArifoteles, Iacturam q́; tantam undequaq́; compen fare. Itaq; Jubinuideo c Afcanio fratri, quod ip fi te Bononia degente, Bononia drgenti fruilicet, ac de te non publicos $\int 0$ lùm, fed, gua tua in omnes, priuatim'́; in ip Jum eft benignitas domeficos haurire fermones. Ferebam ego antea tuidefiderium paullolenius, dum iinerct alterum Italia lumen lacobus Zabarella philofophice fcientia vt tiA 2 bi 
bi uni fecundus (quem filicet ille fibinon folum praferibat, fed auctorem etiam recte philo ophandi fuiffe olim pradicabat) fic ceteris omnibus meo ac multorum iudicio anteponendus. Eo nunc quo familiarifjime vtebar; extincto, nifi tua me aliquando vurum confuetudine perarem, vitam mibi profictio acerbam putakem. In. terim autem quia te libenter, of fisciso /e legere ea fripta, in quibus ingenï, of eruditionis lumina haud vulgaria confpiciantur probe nosi, cuinfmode Junt Telesi pbilofophica monum nia, idcirco ut ex vingue Leon:magnofceres:adbec ut fententiarum nouitate animum turm confuetis feffum contemplationibus recreares, burc eius de faporibus libellum tanquam sonsóous ad reliquam ip fius,philofophiani cognofcendam, Wo $t$ fapiat, iudicandam ad te mittere, adcóq;: 20 irifcriftum nomini publicaredecreui. Accipies igiur bilari fronte banc mea in te bencwolentia, atque cbferuantia fignificationem, wt meum inte fudium nunguam in pofterum oblinifcaris. Uale. Patanï. 


\section{Whor toth ${ }^{3}$ \\ B E R N A R I N I $T$ E L E S I I CONSENTINI}

\section{DE SAPORIBVSOPVSCVLVM.}

Que in lingua entiuntur, ๘ quid fir fapor. Cap. I.

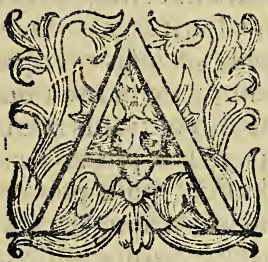

$T$ verò quoniam (ut de rerum natura expofitum eft commentarijs ) cum cor pus vniuerfum, tum ipfe afsiduè immi nuitur fpiritus; itaque, ut uterque reficiatur, nutriaturćue res afsiduè affumend $x$ funt, quix in utrunque à languido animalium calore inuerti posfint. fe cum oporteat, \& uno excepto igne, reliquosum noftrorum entium omnium uires, vel qux robuftifsim $x$ funt, \& qux mol lifsimis animalium uifceribus inditx, penitus ca corrumpät, perdantque, quòd ab amplioribus ambientis uiribus reiectę, retufx́que funt f́piritui durioribus in rebus contento, \& à cutè omnino conte\& to innotefcere non fofunt, nam nec cutem fubire: itaq́'ue externis in corporis partibus propriarum rerum uiribus ${ }_{2}$ nulla prorfus at earum modo, çna ab ambiente ijs inditz funt, fentitur actio. Vtique ne res afinmerentur, qux animalium uires exuperent, organo afti puendę fucre bene molii, beneque laxo, quod fcilicct non extcrux tantum, to buftaque rerum uires, fed proprix itidem, vel quod dictú ef, ab illis imminutx permeent peruadantó: ei igiturinexiftens fpiritus non vigentes modò, uilns sque re rum uires, fed languentes eas penè, \& domortuas, \& ueluti ftertentes, non fcilicet externum modò calorem, externtum q̧; frigus ab ambiente rebus inditum, fed internam itidem $n 3-$ turam, vel, quod dictum eft, ab externa reiectam, exuperatamqge, \& utriusqque actiones fimul percipit fpiritus. Exter- 


\section{Bernardini Telefij}

nus calor, externumque frigus nullum fpiritui faporis fenfum facit, quod abutroq́; qnidé ipfus \& natura, \& difpofitio imm!tatur, calefit nimirü, vel frigefit, \& vel in amplius agit, uel in angufius; Atnon ex xquo immutationes utrafq; perci pit fpiritus, fed illas longè promptius, longeque clarius.quin ubi paulo uehementius ipfius natura immutatur, difpofitionis immutationes nihil fentit, \& ibi omnino tantum mani$f e\{x$ hr funt, vbi fummopere illr languent: id uerò tibi portionefque declarant, qux quibus vis donatæ uiribus, quantú uis fcilicet fapid fint, fi feruentes, gelidxue aflumantur, magno quidem calore, frigoreue, at nullo fpiritum afficiunt fapore; magnu $m$ videlicet fui ipfius naturx, at nullum difpofition is immutation is fpiritui fenfum inferunt: itaque vel fi alienæ, qua perpetuò cibis infunt naturx, fpiritus difpofitionem, 8 ip $x$ immutët, proptereaq́'ue fapidas, \& ipfas efle opor teac;nullum tamen faporis fenfum faciunt; quod in robultiore omnino proprix nature immutatione, difpofitionis immu tatio penitus latet: manifeftifsimaatem fit in proprijs ciborum, potionumq́ue actionibus quibufuis, quod proprix ipforum vires à longe amplioribus ambiétis uiribus reiectx, retufxque adeo languent, ut ( quod externæ naturæ nunquã pati videntur) tactum omnem penitus lateant, nihil linguã, nec inexiftentem itidem fpiritum propria afficiunt natura; quin illorum multa nihil fortè lingua ipfius, \& inexiftentis modo fpiritus difpofitionem immutant;itaque non adeo vehementer propria natura immutata, vt ipfus modò immuta tioni intentus fit fpiritus, difpofition is immutationem per bellè percipit, \& uel cuten ipfam, carnesq́ue quas ea contegit res omnino, quę multo quàm lingua êt, duriores funt, dẻ fioresq́ ıe, nihil à rerum, qux apponuntur uiribus calefactafq́ 'ue frigefactafque molliri ab ijs, liquefie ri, $\&$ in amplius expandi, vel durari, conitringique, \& in angıftius cogi,medicamenta multa nos docent. Saporum porro fenfum huiufmodi immutationis fenfum effe; itaque faporum fenfum propriè ciborum naturx actionum, vel fpiritus pafsionum, \& ipfius omnino dilatationum conftrictionumque fenfum effe, mani feitè imm utationes declarant, quas à proprijs ciborum uiribas in lingua fieri fentimus. manifefte enim fi no a cibis qui bufuis, ab ijs certè, qui panlò robuftioribus dornatifunt uiribus, in qualibus ipforum actiones, \& agendi modus infpiciedus 
dus omnino eft, linguam, inexiftentemq́ue fpiritum dilatari,fundique uel compingi, coltringiớue, \& vel veluti læuigari,vel exafperari, mordicariq́ue, atque erodi,linguæ omnino, fpiritusq́ue difpofitionem immutari, calefieri uerò, frigefieriq; à nılllis hoc quidē, à per yaucis illud, \& ab ijs modò,quibus cuiufmodi aromatú multi, \& ab alijs, cepisq́; in effe appa rent, immoderatus ineft calor; 8 vel fi noftrorum entium nul lum prorfus à frigore, fed eorum, quoduis à calore conftitutum, \& cuinfuis natura calor eft, ciborum tamen nonnulli actiones in nos, qux frigoris funt, xdunt, linguam feificet confringunt, conftipantófie, \& nequaquam inexiftentem humiditarem euaporantes, fed quod frigus agit, in anguftius eam cogentes, \& veluti ligantes, quod diuerfis , 8 minoribus quidem, quàm lingua donati funt uiribus, \& copiofioribus, \& qux ftrenuè eam fubeant, eiusq́ue oppugnêt naturam. niam calores robore, sx copia ampîus differentes mutuò fibi ipfis moleftos effe, rrihiloquie minus fecum ipfis, ac cum frigorc dicertare, mutuoque fefe deturbare, interimereque fatis eft, ut exiftimo fuo loco declaratum, \& ipfe pafsim manifeftat fenfus: Proprio porrò linguæ calori, ciborum caloris, actio molêfta, gratisque cum fit, utique (quod natura agês, vtraq́ue contrasia, \& à qua obledi fe fentiat propriam fedem fubcuntejipfamóue oppugnante parsim agere viderur) fe ipfam, materiäớ; cui infidet colligere, contrahereq́ue, itaque 8 calidis à cibis quod à frigid is fiat, linguam conftringi exiftimare licet. Et propterea omnino qux minus quàm nos calida funt, contingentes, fubeuntesq́ue modò eodem ab ijs, quo frigidis à rebus', \& ipfo omnino à frigore afici, frigefieri, nimirü, contrahiq;, \& tremore etiam corripi, quod nofter color diuerfis à uiribus moleftia affectus fefe; \& vclitit trepidäs interdum, propriamq́; fecum côtrahit molem. Nec verò alia de caufa, qua fummo in febrium occafionibus externx partes frigore afficiuntur; \& quo fummo corripitintur tremore, cas affici, corripiqúue intelligere licet; nifi quod uenis, arterijsq̆ue,\& neruis inexiftens fpiritus, isq́ue infuper quem $\mathrm{mul}$ tum afsidue utroque è fanguine ela $\bar{b} \mathrm{i}, \mathrm{Q} \&$ à quo carnes fummo pere foueri, calefieriq́ue exiftimandum eft, humoris ex illis exudantis uires longè à proprijs diuerfas perhorrefcens, declinansq́ue illius quidem, fanguinisq́ue fuppofitis uenis inexiftentis portio guępiam. Hic uerò uniuerfus in internas 


\section{Bernarđ̊ini Telefij}

partes recefsit, \& qui illis reliquus factus eft, illarum morfim vitans, fefe contrahit, \& huc, illuc trepidans delatus circımpofitas partes varijs exagitat motibus : itaque tremore, \& frigore ipfe corripitur. Quoniam enim manifeitè calor, qui carnibus in effe apparet, non ipfarum eft proprius, fed $\mathbf{a}$ fanguine, fpirituque ex eo elapfo ipfis inditur, vtique illo penitus, aut magna ex parte deftitutx frigidx fiant, oportet; no:trorum entium more, quorum quoduis, ut dictum eft, nullo exrerno à calore detentum, frigidum nobis contingitar, itaque \& fpiritus proximis rebus, inexiftens frigore, \& ipfe afficiatur, oportet. Praterea, \& quod (ut dictum eft) exundantis humoris morfum auerfatus fefe conrrahit fpiritus . itaque fi non, \& ipfius natnra, \& difpofitio certè $a b$ humore, veluti à frigore immutatur; utique fi non penit us idem, at fimilis certè ab vtroque fenfus illi fiat, oportet, \& moleitiam omnino, qua fumma in febrium accefsioni $b$ us à frigore affici fpiritus videtur, non frigoris uilius eam omnem attionem effe, non inde modo patet, quod nullis calidis reb as fuperpofitis ea ceffat vnquam, fed amplius fortè, quod externis partibus à longe vehementiore correptis frigore, non $x$ que ab eo afligimur; 3 quoniam quod illas in accefsionibis occupat frigus, non adeo vehemens contingentibus atque xgris apparet, \& fentitur, frigus itidem, rigorque quo calida aqua refperfi, \& è calidioribus in minus calida loca delati corripimur illorum neutrum frigoris ullius, fed vtrumq́ te firitus opus effé diuerfi caloris uires uitantis, \&z propterea corpus concutientis; At hrc fuo amplius, fi licuet it loco, modò enim, qui fapor, cuius caloris actio fit, inquirendum, \& propofitum omninò opus abfoluendum. 


\section{De Saporibus.}

Acerbum, aufterwmád aidum faporemcaloris actionem effe languidioris, quidem quam nofter eft, at copio-

foris, \& acerborum calorem, magir guain aufterorum, \& acidorum $e f$, a noftro diuerfirm eße. Cap. II.

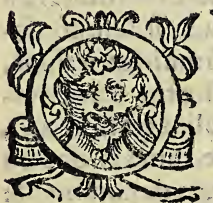

V.ONIAM igitur propterea ling:a cons ftringi uifa eft, qnod propius ipfius dituerfi caloris fenticns actiones, propriamque fecum contrahit fedem, utique quibus à fapo ribus maximè con?tringi apparet, caloris ij actiones fint orortet, qui à no? ro maximè, \& non adeo robore, at copia differat quoniam enim non ualde rehemens noftercum fit calor, \& cibos, fi non eodem omnes, at non valde certè diuerfo, \& breui,nec magno omnino iabore exuperet omnes, \& minore tenuiores, \& quibis robuftus, at exilis, quam cralsicres, \& quibus languidior, at copiofios ineit calor; fiquidem in ore ijs contritis, \& in ventriculo enollitis quid, \&r quid laxioribas fattis ipforum itidem uires la rantur, exoluunturq́ue, \&elang:idiores funt, vti que fi non ijfdem omnes uiribus, at ijs certè donatos effe exi ftimandum eft, quę benè quidem à fe ipfs $s$, \& à nofuris itidem copia, scrobore certè parum differant.k calores omnino non adeo qui robore, at qui copia inter fe differunt, fecum iplis decertare, $\&$ fefe matuò imminuere, interimereque apparēt. an imalium certè fpiritıi igneus calor, \& ab eo afiectus aer ni hil grauis, nihilq́ue eft moleftus:at qui crafsioribus exhalat è rebus, quin qui ipfis à fiammis, ar non benè dum tenuibus factis, effunditur copiofus omnino, qui \& aer ab eo affectus, moleftifsimus eft, 3 lethalis interdum, quod igitur dictum eft faporem, à quo maximè lingua conftringi uidetur, \& qui fpiritui moleftifsimus fit, caloris, qui parum robore, at copia fammopere à noftro difsideat, qui omnino noltro langui dior, at multo copiofior fit, actionem effe exiftimandum eit. tum eum afsidue caloris minus languidi, minusq́a copiofi, à quo minus lingua contringat $\mathrm{r}$, \& minore fpuritus afticiatur moleftia ; vtique fapor acerbus, acerbus enim, quivalentifsime linguam conttringit, maxincọ́ue fpiritui moleitus eft; dicitur, caloris actio lit, oportet, qui noftro languidior

B quidem, 


\section{BernardiniTelefij}

quidem, at multò certè copiofior, maxime omnino à noftro diuerf as eft . Anfterus uerò,qui cotoneis in effe apparet, min:Is forte languidi, minus certè copiofi ; \& acidus minus etiä quàm uterque, nam ab acidis minufquam ab aufteris, $\&$ ab ijs minus quàm ab acerbis lingua contringitur, \& quod dietam elt caloris quorum acerbus, aufterus que, \& acidus, funt actiones, non adeo obuirium, atque ob copix diuerfitatem à no:tro, \& feipfis differre, \& ordine, qui dictus eft, fefe confe$q$ ti inde int elligere licet, quòd acerba, vbi humidiora fiunt, rbi fcilicet, quia ipforum moles magis explicatur, calor exi4. de fi np?. lior tit, aultera frunt; \& Galeni fenfusq́ue amplius teftimonio, medi:a.fa- enafcentes arborum fructus accrbi,crafsiótue,tum afsiduè hu culis. midiores fiunt, afsidueq́ue acerbitatem magis deponunt ; \& ait teri eor!m nonnulli tum acidi, poltremo ix dulces fiunt; \& omnibus certè eò afsiduè minus ling ua confrìngitur, quò calidiores funt, mollioresque, quo fcilicet ipforum calor minus à noftro, \& robore, \& copia difterat. quin Galeni itidem teltimonio non lingua modò, fed reliqux corporis partes $\mathrm{ab}$ acerbis, alfterisqúte \& acidis conftringuntur, conftpanturq́ $x$ e, \& ab acerbis exafperantur, etiam, quia fcilicet, quod duerfa difpofitione donatx, \& ueluti è mollitie, duritieque compofit $x$ funt, vbi ( quod ab acerbis fit) vehemen tius conftringuntur ; itaque mollities magis comprimitur, alia ipfa in fuperficie $y$-in alia uero durities fiat oportet. Propterea itidem acerba kgrius conquoguantur, quòd ipforum calor magis à noftro difsidets $\&$ non adeo, vt exiftimare licet robore, at copia; debilior enim cum fit vtique nifi copia exú peret, minus renitatur. A cida porrò, qux neque auitera, neque ipfa etiam faciunt acerba, quas contingunt partes ignis iftar mordicant, eroduntq́ue, \& urunt, quod mordicatio, erofioque, atcue uftio ron rei alterius, fed vnius funt diunlfionis, fapatationisqúu fenfus. Ea porrò vehementius quidem externo à calore, à quo fcilicet inexiftens humiditas educitur omnis, \& ab interno itidem fiant, of ortet, nbi fcfe is, molemq́ cui infidet contrahit, fi fráfertim faulò contra! at vchumentius, \& non una, cademque illa diffofitione donatx, fed \& il fe veluti e mollitie, duritieque comrofit $x$ Snt, non uno omnino, codemq́ue temporis memento uniuerfa, fed alia ipforum portio promptius, agrius alia contraha:ur, \& un. as acidoruñ câlor ita contrahit; gucd unns ip fe 


\section{De Saporibus.}

illas fubit ; nam acerborum, auferorumque calor languidior omnino eft, quam vt cutem fubire queat. Itaque intcina rum partium calor nihil ab aliorum uiribus offenfus, nihil fe fe conrrahit, at e quibufuis detracta eft ab acerbis e , aufterifque, vehementius illa omnia patiuntur; \& propterea itidé uinis ab acidis, quibus ea immifcentur fermentari, expandi nimirum amplificarique apparent, quoniam fi horum itidem caloriacerborü,aufterorúq; calor grauior eft; at quod nihil is illü attingit, nihil fefe ille côtrahit, colligitá ie, i taq̨; nec robuftior fit; at robuftior aridorü calor ftrenuè illorum molem fubit, ftrenueque in exiftentem calorem oppugnat; itaque illius hic uires exofus reformidansq́ie fefe, propriamque contrahit fedem, \& propterca robuftior factus, haud ita multò poft iuxta proprium agens ingenium expandit eam, amplifi catq́ue. Quod igitur dictum eft caloris languidioris quidem quàm nofter eft, at qui maximè copia exuperet, acerbus, aufte rus verò qui $\&$ robore, $\&$ copia minus, \& acidus, qui minus adhuc utrisq́ue differat aćtio uideri poteft.

Aqueum faporem caloris noftro perfimilis, dulcem, fal fum, amarum, acremǵs nostro robuftioris, copioforifque vel alterummodo, \& quo expofiti

funt ordine fingulos afsidue robustioris, copinfioryfue actiones eße.
Cap.
III.

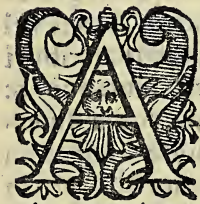

QVEVS porrò, qui infipidus cuiufinodi elt, dicitur manifeftè caloris actio,eft'noftro perfimilis, cognatique:propterea en im nullum, aut longè languidifsimum fui fenfum facit, quod neque ipfe lingux fpiritufue immutat difpofitionem, nec lingux calor eius uitans actionem fefe contrahit quicquam : quid enim uires uitet, qux nihil ipfum turbant, exagitantuè ; \& talis omnino Galeno uifuseft:itaque dilatantium, confringentiumq́ue ca lidorum fcilicet, frigidorumq́ue medium ponit, dulcis uerò plic. medipinguifue paulò, quàm nofter eft robuftioris, copiofiorisq́ue, 2 de alimé. manifeftè enim linguam diffundit, laxatóne, \& perfimilis facult. omnino, cognatique dulcis præfertim. Itaque nihil ipforum

$$
\begin{array}{lll}
-B_{2} & \text { auerfatus }
\end{array}
$$




\section{Bernardini Telefij}

auerfatus actionem, nihil fefe nofter contrahit calor, \& fumma uterq́;,dulcis præfertim fpiritum afficit uoluptate, quod blandèuterque, dulcis prafertim linguam, inexiftentemque fpiritum diffundens blando ipfum commouet motu; narn pinguis eiufdem fortè, \& copiofioris caloris, quòd eft actio, ubi plus iufto excrefcit, moleftus fpiritui fit; minimè verò \& falfus; nam fi robultioris, \&x (vt extimare licet) copiofioris caloris actio elt, ha:tdqlaq $1 a \tilde{a}$, quod pingius facit, linguam, inexiftentemque fpiritum immoderatè diffundit, in amplumque agit ; quin benè fpiritui gratus moderatè enim linguæ immitam humiditatem euaporans, \& modera tè ling to inexiftentem fpiritum commouet motu, forte \& ipf $x$ lingux calor falforum percipiens actionem, quod ipfius uires ea exuperat, fefe cötrahit quid.A t amarus longè moleft isfimus, quod robuftioris, \& multò copiofioris caloris omnino actio elt, qui maxime à noftro difsideat, \& qui è ling a immixtam h.miditatem educat omnem, itaq́ ac \& illam, \& inexiftêtem fpiritum cótringat, in angıttiusq́;.cngat. quin \& ipfe lingue calor, itaq; \& ling ua ipfa, \& ipfe etiā fpiritus amarorü morsứ perhorrefcẽs, fpōtè fefe, trenueq́; cötrahit. A cer poltremo ma nifeftè caloris fummi, ignei omnino eft actio,fiquidé ignis rit acria mordicant, uruntque, at non copiofi;nam fi crafsis in efle apparet rebus, non vniuerf $x$ ipfor $1 \mathrm{~m}$ ineft moli,fed tenuioribus modò ipforum partibus. itaque exiliter is lingram contringit, \& modicum quid à fpiritus natura diffidens, nihil ei ipfus actio molefta, quin iucunda eft, grataque. foucri enim, \& veluti excitari fe abea fentit. At agè vel fi faporam, qui ex pofiti funt fingulos caloris, cui attributi funt, actiones cffe; \& quo locati funt ordine fefe confequi, \& àfe ipfis, \& noftro à calore, non adeo robore, ac copia diuerfos effe in ijs, qua dica funt fatis confpectú uideri queat. in fingulorum actionibus, pafsionbusq́; ; \& m.tua aliorum in alios immutatione amplius intueri ne grauemur; digna enim res, quę fapius, \& magnainfpiciatur diligentia. 
Caloris quorwm qui expofiti funt fapores, actiones funt vz dictum eft,à feipfis, ó à nostro differre, ć fefe
confequi. Cap. ILLI.

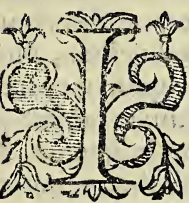

NSIPID ORVM calorem nihil, aut in fen Infipidx: file quid à noltro differre, \& acidis modicủ quid calidiora effe infipida, \& ijs dulcia, pinguiaq;, \& ho rúuires nihil fortè à fe ipfis robore, at copia tãtum disterfas effc, \& acria mas modò ipforum partes, \& exili has donatas effe calore fin gulorum actiones, pasfionesqúu, \& mutua aliorm in alia de clarat immutatio. Quoniam enim infipida ea funt, qux nulla a fui fenfum fpiritui faciunt; utique ipfor:um calor noitro perfi milis, cognatasq́ue fit, oportet;nam fi diuerfis donatus fit ui.

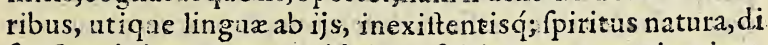
fpofitioǵ; immutetur quid; itaq; fpiritus nen quopiam modo fenfu, fed iacundo eo, triftiue afficiatur. Dulcia verò non Dulcis. linguam modò, fed reliquas itidem corporis partes multa illa duriores emolliunt, funduntáue, itaque \& lauigant: quoniam enim nulla fui parte attollitur fuorvllus, fed cuinfuis fupericies fumme $x$ quabilis, quin vna prorfus, eadcn q q́ cit uni ierfa;\& propterea omnino, quod quę non fumma donata fint tenuitate, fi in quem delabuntur, adfit locus, promptiffime delabıntur omnia, utique vel qux benè inxquabilem, \& veluti tumoribus dittinctam fortita fant fipericiem, fi in fuores foluantur vniuerfa, itaque \& tumores fluidi facti, per fuppofitam diffindi queant fuperficiem, ęquabilia, leuiaque omnino fiant.Pinguia itidem eadem omnia \& quod ut dictum efl, copiofioribus agunt uiribus, immoderatius agút omnia, \& v bi ampliores ille fiunt, moleft if sima f piritui fiut; Itaq́: ne nimis pinguia, qux funt, refpuit ea,euomitǵue, \& vêtriculum adeo relaxant, ni hil ut is vlterius appetat.nam appe tentiam nó pafsionis alterius, fed conftrictionis effe fenfunt, fatis alibi declararatum eit. In fammas preterea, \& bene eas diuturnas, permanentesque pinguia cum agantur, quin non quidem roburtifsimo, at benè o mnino copıofo calore donata fint ambigi non potelt:nam fi robuntus is fit, exilisq́ue. uti que nan cuiafmodi funt vifcofa, opacağue fed benè fluida, 


\section{Bernardini Telefij}

\& eranfpicua etiam fint, \& inexiftente calore ftatim in igneú acto, bellici pulueris ritu nullo temporis momento uniuerfa fimul in flammas agãtur. Propterea enim quantus uis ille fit, quid uis ab igne contactus ftatim accēditur uniuerfus, quod fummus vniuerfo ineft calor, \& qui quid uis aucus ftatim

Salfa. igneus fiat. Salfa porrò,amaraque nihil forte inexiftentis iti dem naturæ robore, fed yna modo eius copia dulcibus, pin-

Amara. guibusque calidiora efle, inde quidem patet, quod quæ hæc moliri non poterant, ftrenuè utraq́ue illa, \& amara pręfertim agunt,crafsiora nimirum, qux funt manifeftos in fluores, \& fluores fummam in teuuitatem, \& quę ftatim elabatur, agunt. Itaq́ue linguam, ventriculumq́ue, non ut illa fundınt, relaxant que \& læuigant, fed confringunt, exafpcrant ́q \& \& diuellunt, infuper difcerpuntque; \& triftiore quàm acida cum fenfu:neque enim horum more tenuitatem ueluti ligant, conftipãtque, fed uerè eam educunt; $\&$ uehementet id, confertimq́ue, \& fordes valentisfimè abftergunt, \& proprerea omnino quod colliquant eas, \& veluti in fluorem agunt, \& benè eum liquidum,fluxilemq́; qui omnino carnibus inhærere minimè queat, fed uel colliquâtibus immiftus rebus ex illis elabatur, exprimaturq́ue omnis.multò porrò, quam pinguia funt,calidiora falfa, amaraque cum fint, non adeo tamen, \& illa prom ptè in flammas, \& continuas eas, permanentesq́ue aguntur. quod quę accendenda, huiufmodiq; in flammas agenda funt non benè modo calida, fed media quadã donata difpofitione, \& benè infu p fimilaria, talia omnino, qualia pinguia funt, effe oportet;nam qux paulò crafsiora funt, quodque in ijs ac cenduntur flammæ, quique ijs inexiftit calor, prius quam fup pofitam molem in flammas agat, ea nimirum donet tenuitate, cui penitus fefe indere queat, \& qur nihil eius abdat.fpeciem, tenuisfimas illas facit, furfumq́ue euehit, permanentes in ijs flammæ fieri nó poffunt.propterea enim uel fi nullo pro pemodũ temporis mométo flamma ulla feruatur, fed tantillu lum morata, \& tenuifsima interea, atq́ue adeo inuifilis facta furfum effertur, tamdiu tamen feruari apparet, quandiu res, in qua accenfa eft, durat, quod dum inexiftens calor ita illam explicat, fuppofitam itidem materiam eo calore, eaq́ue donat tenuitate, quibus donata lucida fiat. minus etiam continux, permanentesq́ue flammx in ijs accendi poflunt, quę uel benè tenuia funt vniuerfa, uel in fummam agi tenuitatem ni- 
hil repugnant, cuiufmodi fumus, liquoresq́ ;nonnulli, \& belli cus, (ut dictum eft) puluis exiftit: huiufmodi enim qux fune quidais quidem ab igne contacta; at vniuerfa fimul, \& in fâmas aguntur, qux ftatim tenuifsim $x$, inuifilesque fiant, \& fur fum erferantur. certa igitur difpofitione ad fammarum generationem, conferuationemq́ue opus cum fit, ut ique quę di uerfam illam fortita fant continuas,permanentesque in flam mas accendi, inepta $\&$ ipfa funt. Acria poftremo ( $v t$ unde di Acria. gresfi fumus redeamus) non modò quæ falfa, amaraque \& multo omnia agunt robuftius, fed ignis ritu, linguam, carnesá íe colliquant, exuruntq́; \& qux ex ijs exprimitur tenuitas a flammis contacta nullo temporis momento flamma fit. Acido porrò aqueum, \& aqueo dulcem, \& dulci pingué contiguum effe, \& non quidem acidum, at reliquos nihil fortè uel modictini quid virium robore, fed earum copia tantum à fe ipfis differre, uél unó in lacte fentire licet, quod nimirum fi non aqueo, at fapore certè donatum eft, quiraqueú inter dulcemqué medius poni queat, modica inexiftent is caloris por tione elapfa acidum fit, \& non concoctum modo, fed coagulatum tantum, nullis nimirum nouis uiribus afsumptis, fed preinexiftentibus magis in feipfis collectis dulcius quid fit; $\&$ fi rurfus foluatur, aqueum rurfus aflumit faporem. liquidifsimx pręterea eius partes aqueo fub dulci, qua magis in feipfas coactx funt, dulci omnino, quxuifcofx iam fact $x$ fint; \& pingui, exdem in cafeum, \& amplius in butirum fpiffatæ, tenuioribus nimirum fui partibus excretis, \& crafsioribus magis in fe ipfas fpiffatis : neque enim à modica ea agi tatione, contritioneque qua in butirum coguntur,adeo proprium ipfarum calorem àugeri, ut è fubdulcibus ( huiufmodi enim funt) pingues fiant; minus etiam lac ex ijfdem uniuerfum rebus, \& ab eodem confectí calore naturæ robore, fed eiufmodo copia à fe ipfo differre exiftimare licet.Ficus certè, \& qui c̀ uenis exudat, $\&$ in carnes, pinguedinem que concreffit fluor, nihil proprij caloris robore ancto, quin imminuto fortè; proptera enim concrefcit hic, \& arefcunt illæ, quod ex vtrisque in exiftens, tenuitas, eique infidens calor elapfus elt omnis, itaque illorum utranque magis quidem in fe ipfum côfpifatum: at nihil prorfus, quod uidere liceat, calidius falfum pro d alci ping ie fit, \& cibi quorum proprius fapor infipidus , aut infipido proximus eit, frumentum, carnes, pifces, 


\section{Bernardini Telefij}

- :1a, ?ac, olera nonsulla, \&nonnulli plantarum fotus, conco Eti'dulcem, $x$ pinguem etiam affum unt faporem; $\&$ non adeo. fortè quòd nouus ijs inditus fit calor, quam quod tenuiores ipforum omnium partes in fummam acta tenuitatem effluxere omnes, \& crafsiores modo, qquibus propria natura copio fior ineft, reliqux fact $x$ funt, ut infipidù à dulci, \& dulcem $a$ pingui excipiet,infipida, dulciaǵ; nihil propriæ naturæ robo re, ut copia modò aucta, magis fcilicet in fe ipfa confpiffata, illa quidem indulcia; $x$ cuerò in pinguia tranfire ambigere non licet . codem itidem modo \& pinguia, nullis fcilicet nouis uiribus affumptis, at præinexiftentibus in fe ipfas magis collectis, magis omnino confpiffatis, falfa primum, mox, \& amara fieri, uel una iecinoris faporis duerfitas fatis declarat. quoniam enim in nuper enatis animalibus, \& dum omnino laxum ideft, molleque dulce eft, aut pingue;progre $\rightarrow$ diente uerò ærate minus laxum afsiduè, minufque molle, \& minus etian dulce fit, minufque ping: 1 ; 8 ingreuefcente de mum xtate, bene denfum, durumq́ue \& falfum amarumq́ue, \& nequaquam proprij ipfus caloris robur anctum effe exiftimare licet. Vtique quod dictum eft, pinguia nihil proprij caloris robore aucto, at tantum magis illo in fe ipfo collecto in falla, amaraq́; tranfire, liquidò patet;nam iecur in nuper enatis laxifsimum, \& exili donatum effe calore, tū afsidue craffus , calidiasqú fieri, $\&$ in fenioribus omnino animalibus calidius, quam in iunioribus effe, fangninis etiam, qui in vtrisq́ re conficitur natura, difpofitioq́ue, \& calor declarat. in dudum enim enatis modicè calidus, \& benè liquidus, nec benè dum puniceus, fed ad album uergens fit fanguis; tum progrediente atate calidior afsiduè, minusqu ue liquidus, \& magis ad nigrum uergens; in fenioribus tandem calidifsimus, crấsifsimusq́: e \& niger iam : \& uel Galeni teftimonio feniorum corpora falfis, amarisq́ue excrementis repleta funt; blando porrò a calore, \& qui factam tenuitatem nihil educat modicè calidum, \& benè liquidum, albid umque fieri fanguinem, \& eo arsidıè magis calidum \& minus liquidum, magifque ad nigrum vergentem, quo robuftior fiat calor, quó. feilicet factre ten iitatis maiorem portionem cducat, \& cali-, disfimum, crafiumque \& nigrum a vehementi, quam facit te-. n ritatem, C.mmam faciat, educatq́ue omnem, nihil eft, quod amplius declaretur : faris fuperius, \& ipfo a Galeno, ipfoq́ue amplius 
smplius manifeftatum à fenfis; quin \& propterea fortè fenes minus bellè affumptos concoquunt cibos, quòd iecinoris ca lor, à quo ij confequuntur, nimis uehemens eft; nam ut rectè concoquatir, moderato eo omnino opus eft calore, qui exuperet quidem illos; at quod lang idior facit zquè uniuerfos non magis fcilicet, (quod uehemens facit) fupremas, quam internas illoram partes, \& qui infuper tenuiores partes minime educat . quod fi nou uni, aut non omnino caloris vehementix concoctionis uitium attribuendum uidetur; poteft id pinguedinis, qux ventriculo fuperpofita eft, \& qux ciborŭ concoctionem mirum adiuuat in modum arefactioni, affum ptionique : At propofitum ad opus redeamus, fuo enim hæc loco, fil licuerit amplius declarabuntur. Saliua infuper infipida dulcisq́ue copiofiore donata calore falfa fit,amaraque;vel Galeni enim teftimonio in longa inedia falfa, in longiore amara fit; nec uerò quod ipfius calori no:uum robur, \& cuius falfus fapor, amarufque actio fit, indatur: neque enim quas lingua uires fortita non eft, faliuę eas indat, fed quod longa inedia faliua nulla fit, \& præinexiftens ten tioribus fui partibus, uel fponte elapfis, vel a lingua calore eductis, crafsior, proptereaque \& calidior fit mel etiam ipfum temporis proceffi , \& nimis concoctum tenuioribus fcilicet partibus, uel fpontè elapfis uel externo a calore eductis amarefcit ; \& mare paleftinum, quod reliquis omnibus crafsius eft ; itaque animalnullum in eo mergi poteft, non ut pleraq́ue alia falfa; fed amarum eft; amara porrò non quidem, ubi crafsiora fiunt, eorumque uires magis in fe ipfas coguntur, fed uelubi tenuiora, \& calidiora fiunt, ubi fcilicet ipforum calor, nel fi exilior fiat, robuftior tamen fit, in acria tranfire, cum res alix,tum vina declarät.quæ vel Galeni, vel fenfus ipfius teftimonio, vbi calidiora fiunt, acria fiunt, \& è contra, vbi ipforum immin:uitur calor, ex acribus in amara redeüt, tenuuius porrò, cali ti usq́ le fit vinum, quòd externus calor fimul, \& immiltam crasfituem in tenuitatem agit, \& in exiftenti calori rob'ur indit; itaque xitiıo precipuè tempore amaritiam vina deponant, acredinemóue affumunt, vel nullo fortè vini calori nouo robore indito ex amaro, tum acrem id fit, quod calor, cuius actio acer elt, fapor prainexiftebat quidcm, at tenuisfimis modò partibus, \& bene ijs minutis, beneq́ue paucis modicus omnino in erat; itaque ipfus acto penitus Ja.

C tebat, 


\section{Bernardini Telefij}

tebat,à longè amplioribus, copiofioribusq́ue calcris, cuius actio amarities eft, reiccta, obfcurataq́ue uirib is; at vel ab ijfdem bona uni portione tenuiore facta, proptereaque in ea prxinexiftente calore exoluto, languidioreq́ ue facto, in cam fefe ille eff andit, \& vniuerfam occupat : itaque ampliore illo facto \& imminuto, hoc una illius fentitur actio, \& uinum ex amaro acrè fit , tum fi hic elabatur rurfus ex acri amarum, quod huius unius fentitur actio.

Cur dulcis fapor valde per fe oblectat, \& amplius, disstius ǵ, alïs commiftus, \& cur noui, varÿǵg.

Caput. $\quad r$.

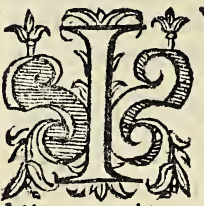

VRE igituriucundifsimus eft dulcis fapor, quia enim caloris actio eft, qui copia fortc̀ tantum,non \& robore itidem, \& illa non ma gnum quid lingux calorem exuperet, \& qui fi longe copiofioribus, at lãguidioribus certè, quàm fpiritus donatus eft uiribus; \& qux à lingua etiam reiectæ quid, imminutxque nihil prorfus illú offendunt, fed uiuificant, fauentq́ue, \& qux blandè linguam, nerıosq́ue, \& ijs inexiftentem fpiritum blandè dilatant, itaque \& blando commouent motu, \& longè omnino fuauior, \& in longius oblectans confringentibus, quauis id agant ratione, aut amplius minufuè dilatantibus, quafi enim asfiduè à propria recedentem fpiritum natura nimis vel confrictum, vel expanfum asfiduè illi ipfum reftituit, leuiq̣ue commouet mot $u$, fummopere vtrumq́:ue fpiritui gratum, iucundumq́ue; nam nuli alij commixtus neutra ratione fatis diu oblectari poteft, quod enim à duici proprix naturæ reftitui dilatarique potuit, reftitutus, dilatatusque, nihil amplius alienis uiribus ab illo exolui, nulloque commoueri poteft motu ; nec dulcis modò conitringãtibus, ampliusque aut minus dilatantibus, fẹ hi illis, \& fibi etiam ipfis commift, fi præfertim certa cömiti fint ratione, fi fcilicet nimias alterorum actiones cohibeant, moderenturóue alteri, agant omnino, \& moderatè vtrique. At amplius fortè \& noui, \& varij, quòd varijs fpiritus moneri aptus motibus varijs moueri gaudet, eoque om nino magis mouetur, à quo à pluribus fimul moueatur, tum guod 
quod ubi fatis diu quouis motus eft motu negligentius co fortè, attentius certè nouo mouetur; itaque \& voluf tate afficitur maiore. manifeftè enim aliud operantem, aliudqú at tendentem uel longe fuauisfimus parum oblectat fapor. Age uerò, vel fi nihil fibi ipfi difcors fenfus uniuersè naturam, cömunemq́ue fentiendi modum, \& fonfuum fingulotum fubliả tiam, modumq́ae, quo finguli fentiant, pofuiffe videatur Ariftoteles, itaque illis expofitis, reiectisqú, quales fenfus fingu li, modufquè, quo hi fentiant, ponatur, nihil amplius exponé dus, reijciendusq́ue videri qiıcat; quoniam qua fingularia funt, non fatis fortè vniuerfali rationi infpici poffunt; multò certius, \& manifeftius fingulari propriaque infpectione innotefeunt, qux feorfum de guftus, fingulorumq́ue fenfuum natu ra, \& de naturali fentiendi ratione tradidit feorfum exponan tuir, examinenturq́ue, \& ipfa, multoque etiam diligentius, que defaporum conftitutione, naturaqque tradidit.

Quomodo anima fapores Arifoteli fentiat, o in quibus is illum explicans incufari poteft. Cap V $\boldsymbol{I}$.

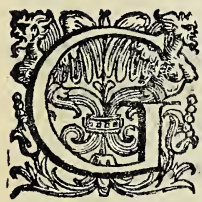

VSTVS (inquit) potentiam habet gufabi 2.De anim. lis excipiendi,iudicandique per fimilitudi- tex. I 44 . nem ap ipfum guftabile, qux fit alteratione ", quadam, \& potentia omnino guftabili fimi- ", lis exiftit, \& eft gufus, fit autem actu frmilis ," pafus ab illo, immutatufque fenfitiuam ani ", mam non magis fenfili potentia effe, quam corn:m, qucduis entia reliqua omnia minimeque fenfum fieri, quod actu id fiat, à quo anima patitur, immutaturǵue; fed ut fentiat, quảuis fenfilis attionem, uel modicam fentiêtis animx pafsionë fatis effe ita declaratum exiftimamus, vt fingulis idem in fen fibus, fi amplius declaremus fuperflua omnino, \& non verita tis manifeftand $x$ ftudio, fed uel A riftotelis odio, vel ambitio ne tracti hominem infectari uideripofsimus:nihil etiam am plius incufandus uidetur Ariftoteles fenfur fingulos à proprijs fenfilibus perfici ftatuēs, quod finguli prop riorñ fenfiliü formas, qua potentia funt fufcipiunt, aci uque e $x$ funt, nihil ab illis corrupti fatis (vt uidetur) damnatus, ferftum uniuerfum, quod dictum eft, ratione perficiens, nifi fortè amplius, quòd fingulorum fenfịlium perceptio nö uniuerfali ratione,

nes 


\section{Bernardini Telefij}

nec verbis omnino, fed propria, \& rebus demonftranda eft, quæ nimirum guftabilium funt form $x$, \& quomodo eas fufci pit,exq́ue anima fit, fingulares fiquidem res fenfui manifeftä dæ funt.aperiendxq́ue : id fi non poteft, vniucrfalis illa ratio improbanda omnino, reiciendaq́ue; vel ipfus enim Ariftote lis teftimonio, ex modò vniuerfales rationes firm $x$ funt, ver $x$ q́ue quibus fingularia cögrunt, confentiuntáue.id etiam cômuniter in fentilium omnium, ac intactitilitm, guftabilium que præcipuè præceptione mitari Ariftotilê licet; quod à guftu ea excipi, iudicarique per fimilitudinem ad ipfum guitabile, quæ alteratione quadam fiat decernens gufum, \& fentientem animam omnem corpoream omnino ponendam effe non animaduertit:qui enim in corporea fi fitformarū,quæe materir penitus immerfa funt omnes, actionem fentiant, eas q́: ie ipfa fufcipiat, \& ea omnino ipfa fiat pafla,immutataq́; ab illis? Age porro faporum conititutionem exponentem audia mus Ariltotelem; \& quoniam quędam alibi pofita fupponës, \& non continuò omnino fermone, nec ordine, ut uidetur, eä explicat, liceat nobis uniuerfam ipfius, ratiocinationem, quo nobis licet ordine exponere.

Saporum materia aque humiditas, efficiens caufa terre ficcitas Arifloteli uidetur, illorumque extremi duL iis, amarusğ, reliqui borum medÿ funt, of ex bis fibi ipfis commixtis fiunt. Cap. VII.

De fenfu \& feabili.c.4

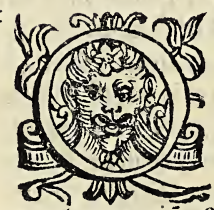

VONIA M quę naturas quafpiam fufcepera ra materia eft; illarum omnium penitus expertem ipfam effe oportet, \& qux nec acta, nec poteftate humida funt, qux fcilicet af fumpta nihil liquefcunt, \& humida oíno nö fiunt, nullŭ ea faporis fenfum faciūt; itaớ; fa poru materiâ, $\&$ infipidã fui natura, $\&$ humidã omnino effe oportet, $\&$ aeris humiditatem illă ponere non ticet; $n a ̈$ fi infipidus, \& ipfe,\& nimis certè tenuis, \& cui lŏge ęgerrime craffities affigi, itaque \& fapor indi queat; nă fapores omnes craf fioribus etiam quam aqua eft, in effe uidentur rebus, utique zqua humiditas faporum materia ponēda eft: $\&$ quoniam ex infipi- 


\section{De Saporibus.}

infipida fapida ut fiat, contraria à natnra, 2 à ficcitate omnino immutäda eft, \& ignis vel fi, \& ipfe ficcus fit, quòd non fic citas, fed calor proprius ipfius eft, \& quod infuper nullam is aqua crafsitiem, (qux fapida ut fiat, adijcienda omnino ei eft.) indit unquam, quin in fummam agit tenuitatem, uirtute illi indere, quam faporem uocamus, non poteft.utique à terre ficcitate illam immutari etiam omninò ficcitatem efficientem effe faporum caufam exiftimandum eft.quoniam verò in epta per fe terræ ficcitas aqux humiditati affigi, \& calor ad faporum confectionem conferre quid uidetur, caloris opera aqux humiditati terræx ficcitas affigi, itaq́ue calor faporum uelut i concauffa Ariftoteli vifus eft; faporem igitur definiēs, fapor (inquit) affectio eft aqux humiditati a terre ficcitate caloris opera indita;id etiam, ut modo, qui ex pofitus eft, fapores conftitui, ftatueret, Arifotele induxifie uidetur, quod infipida per $f e$, propriaq́ue natura aqua per fal,cineresq́; ; per terræ fcilicet fpecies Ariftoteli colata falfa fit, amaraćue , \& \&x quod amaræ, acidxq́ue è terra emanët aquę̨nec verò quod faporem ullum terra fortita fit, (nam \& ipfa, \& reliqua fimplicia corpora veluti; \& aqua faporis penitus expertia, \& fi qua illius portio fapida eft, humiditatis ea admixtione huiufno di facta effe Arittoteli uidetur) fed quod terram pertranfiês ipfius affecta eft ficcitate, diuerfos porrò fapores fieri, quod diuerfa ficcitatis copia, humiditati immifcetur, \& faporum extrenos dulcemeffe, amarumqúue, reliquos horum medios, \& ex horum omnino commiftione, veluti \& colores, ex albi, nigrique complexu exoriri .

Rerum ominim opificis Dei potentiam emulutus, of rerumnature; fibigipficontrarius, ex aqua, terraǵ, , infipida vtraque fapores conflituit Arifioteles. Cap. VIII.

ELIQVIS rebus naturas indens Ariftoteles cü (4) ipfarum opifice Dco mihi quidem de fapientia contendcre uidetur, alias illas faciens, atque à Deo ipfo factx funt, \& fapores confituens modis multis potentiã etiâ illius $x$ mulari ; manifeftè enim ex aqua,\& terrainfipida utraque, \& neutra ipfarúa à C 3 calo- 


\section{Bernardini Telefij}

cálore aliud pafla, quxque, nifi quod per fe fimul uniri inepte illius opera iunctx fint, unitęque, fapores conftituens c̀ non ente omnino, e nihiloque ipfos reducit, creatque, quas pręterea calori Deus indidit uires, penitus ei demit, \& quę fugoris funt attribuit:fi quidem calor, vel ipfus etiam Aritotelis teftimonio, qux diuerfi funt generis, feiungit, fegregatq́ue \& humiditatem perpetuò è ficcitate educit omnem;non huic il lam aglutinat:tum \& calorem cibis inexiftentem, à quo nó entium modo actiones omnes ędi, fed entia ipfa omnia conftitui, Ariftoteli etiam interdum uidentur, ftertentem illis, nihilque agentem ponit: \& ficcitatem, quam fecund is prefer tim in corporibus nulla prorfus agendi ui donat, fed penitus inertem, \& caloris, frigorisq́ue operas effe decernit, actio num multarum, \& benè vehementium potentem facit. \& lan guidisfimus (ut uidetur) rationibus non fcilicet cibi, qui fic: ci fui natura, denfiq́a funt, dum non conteruntur, nihilque molliores funt, nullo ling ram africiunt fapore, quod infipidi funt, \& fapidi, tt fant quepiam ijs humiditas immifeenda ef, \& contritis, adapertisque linguam immutandi,afficié diq́a uis inditur, quę fapor dicitur, quod linguę humiditati, quo illos fubeat patefactus eft aditus, \& illos omnino hęc fubit ( qui enim adeo nullo temporis momento linguę humiditas uim faporéq́; ab illis affumat, qui nullus ipfis inexiftit, att infa faporé illis indat, quã longisfime à proprio difsiden tê,) féd propterea oíno nullo linguă fapore afficiunt;nihilque eam immutăt, quod propria ipforú natura, \& proprius ipforí calor à longè amplioribus ambiétis uiribus reiectus, retufús q́:e, in ipiorum præfertim fuperficic veluti ftertit, \& proprias uires manifeftare, \& agere omnino ut queat, ueluti excitandus, \& veluti in aperto ponendus eft, moles fcilicet, cui ineft imminutisfima fruftula difrumpenda. internus nimirum ca$10 r$, \& qui non adco ab ambientis uiribus retufus eft, excitan dus, \& lingux admouendus.id porrò ubi factum eft, isq́; om nino agit calor, utiq́ue $\&$ eius manifeftatur attio, fapor nimirum, gu proinexiftebat quidem, \& à molis denfitate reiectus: latebat, manifefus fit, \& preinexiftentem omnino faporem in contrit is cibis excitari,uel in mollibus ijs humidisque, \& qui nihil contriti magno tamen linguă afficiunt fapore, fentire licet;id horum itidem fapor magis manifeftius fit, quò magis graciles, magisáue minuti fiant. Quoniä igitur inanis: 
eft Ariftotelis ratio, qux faporum materiam aqux humidita tem cfe altruit, utique nihil ea, qua illorum efficientem ficci tatem declarat, reicienda eit.vniuerfa enim ab illa pendet, \& illam fupponit. At Ariltotcles támé amplius incufandus, qui fcilicet alibi, ut diftum eit, ficcitatem inertem prorfus, \& fe-cundis prafertim in corporibus attionis omnis expertem, \&e fapores non iuxta humiditatis, ficcitatisó;, fed iufta caloris frigorisq́i immutationes immutari, \& alios, atque alios fieri intuitus cum fit, pradicaritq́ae, $\&$ benc̀ diuerfas, beneq́:ue vehementes faporum uires, actionesbure, \& qux caloris, frigo risq́ue proprix, \& calori omnino, frigoriue attribuend $x$ fint, cum perfenferit, veluti fui ipfius, corumq́ue qux fenfu perceperat oblitus, illorum opificium ficcitati attribuerit. Quo- 4 Text. Io niam inquit quatuor determinat $x$ funt elementorum cauf $x$, harum a:ıtem fciendum coniugationes, $8 x$ elementa quatuor", accidit effe, quarum due quidem actiuę caliditas, \& frigidi-" tas, due a!ttem pafsiux ficcitas, \& humiditas; fides autem ho r:m ex inductione:uidentur enim ir omnibus caliditas qui-", dem, \& frigiditas, terminantes, \& copulantes, \& tranfmutantes, \&t que eiufdem generis, \& qux non eiufdem, \& humectan " tes, \& exiccantes, \& indurantes, \& mollificantes: ficca autem, \& hamida terminata, \& aliàs diçtas pafsiones patientia, \& ip ", fa fecundum fe, \& quęcunque communia ex ambobus corpo ra ronftant. Tum alibi perfpicimus (inquit) decerptorum po moram fapores à calore immutari, feu foli, feu igniea exponantur;ut appareat non $a b$ aqua eiufdê factos fapores trahere, fed in ipfis pomis permutari cum aufteros ex dulcibus, tú amaros, \& omnimodo, factos; quin \& excocti ad oia faporú genera (vt ita dicatur) tranfmutantur, \& frigus (inquit) \& cô gelatio fapores obtüdit, \& odores euanefcere fac it, quia calo. ré, qui architectatur, \& mouet frigus, gelioǵ; interimüt. Quin $\&$ id incufandus uideri poteft Ariftoteles, quod qui h:miditate, \& qui ficcitate exuperäte uapores fiät, nufquã declarat. Quoniam enim ficcitas humiditati indita fapores ei indit omnes, itaque horum diuerfitas diwerf ficciratis copie attri buenda omnino eft, utique faporum exortum, confitutionëque exponenti, qui ipforum à maiore, \& qui a minore ficcitatis copia fit:declarandum omnino erat, tum quod fir non reliquorum omnium , at extremorum certè, \& è quorum commixtione reliqui fiunt omnes, natura, \& ratio, quà à fe ipfis disfi- 


\section{Benardini Telefij}

disfident, quam fieri poteft, difinctisfime manifeftanda, tum quod $\&$ fapores modo, quo ipfe fieri decreuit, fieri, ut declaretur : amplius omnino declarandum, \& iuxta diuerfam humiditatis, ficcitatisq́uc copiam differre illos, \& ibi fingulos perpetuó fieri,augeriq́ue, vbi ea illarum excedit, cuius maiori copix afsignatus is fit, demoftrandum. At age quando Ari froteli explicatum id non eft, Aphrodifeum id explicantem audiamus. fortè enim rectè fi id agat, faporu'm confectionem

Alexan. de ficcitati omnino tribuendam declaret.

fenfu util $j_{j}$ Propterea (inquit Aphrodifęus) dulcisfimę hiemales pluuiæ, eftiuæ minus, \& minus etiam autumnales, flante borea " dulces, potabilesq́ue, auftro amariores, falfioresq́ue, dulces "prxterea in alluuionibus, atque inundationibus, in ficcitati" bus verò fqualloribusq́ue falf amarxque; quod hyeme quo" niam humida eft terra exhalationes purx afcendunt, nihilq́; " ipfus ficcitati commiftx : $\mathfrak{x}$ ftate autem, quoniam terra non " adeo humiditate referta eft cum ipfus exalationibus fuper"fluitates itidé afcendunt à quibus aqua inficitur. Flante Bo"rea potabiles fiunt, quoniam à frigidis, humidisque fpirat " locis. Auftro uerò amaræ, quoniam à fquallentibus, acenfi" busq́ue. Itaque terræ naturæ multum cum exhalationibus "afcendit: idem \& in ficcis accidit conftitutionibus; contra"rium in pluuibus, atque inundationibus. Itaque in uniuer" fum humiditas dulcis Aphrodifęo,amara ficcitas uidetur, \& pura illa,impermiftaque dulcisfima effe; amarefcere uerò, \& falfa fieri ficcitati commifta ; puram porrò afcendere humiditatem vbi multa ea terræ ineft, at vbi exigua ea adeft, ficcitatem etiamei immifceri. Rectè quidem Aphrodifxus in rerum faporumqque, qui inis infunt diferentijs, naturas, à quibus conftituantur, inquirit, \& rectè itidem extremos fapo res cótrarijs afsignat naturis;at nö rectè, vt videtur in aquis, ipfarumq́ue illud faporibus, qux fcilicet quales fingulæ à rebus conftituantur, quales omninò fint, non fatis perfpectum; dum, ac ne inquifitum hom in erat, \& quarum fapores langui disfimi funt omnes, \& exile quid incerfe differunt; \& vel in ijs parum naturas, àquibus conftituuntur, quarú operafunt, intuetur. fi in rebus, quibus fapores infunt, \& in faporibus ipfis . ipforumq́'ie differentijs agentes ipforum caufx inquirend $x$ funt, res quarum naturæ manifeft $æ$ nobis funt, \& quib.is fummi, vel fummis proximi benè omnino manifefti fa- 


\section{De Saporibus.}

pores infunt infpeciend $x$, gaftandxọ́; funt, nec uerè integrx modò, nihilǵu ue paffx, fed immutatx amplius, \& à manifeltis omnino immutatx naturis; \& fiquidem humidisfim $x$ qux funt res, exdem dulcisfim $x$ :amarisfimx verò ficcisfimx, qux fiunt, quxcunque vtræque calore, frigoreue donentur, uel fi obfcuras, dum dulcedinis opifex fit, qux nimirum neq; aqux infit humiditati, neque à ficcitate, qux amaritiem inferre vifa eft illi indi queat; licet tamen Ariftotelis pofitiones tueri, faporumq́a opificium, ficcitati attribuere, fin fapores fingu-li æqua dilpofitione in quauis, \& uel dulcisfimus in rebus fic cis, \& in longè liquidisfimis, longè amarisfimus ineffe, at ibi modo finguli, vbi certus adfit calor, itaque íngulos immutari, prout ip forum immutetur calor, deferendx omnino Arifto telis fint pofitiones faporumque efficientia calori omninò asfignanda fit, nec dubitare licet, quin factum id Ariftoteli foret, fi in quibus oportebat faporum difierentix infpectx fo rent. At vel in aquarum differentijs, fi terum, è quibus illæx có ftituantur natura paulò diligentius infpecta foret, quod dictum eit, intueri poterat . non fcilicet ficcis, exuftifque è terris ficce impuraque exalationes, \& ex humid is humidx, nullisq́ 1e cum fuliginibus, fed cötra tenuisfimę, humidisfimęq́á \& parifsime ex illis, crasfisfimx ex ijs, impurifsimxáue afcêdunt:id uerò $\&$ in proprio de pluuijs declaratú eft cốmétario $\&$ uel ipfis intueri licet oculis; manifeftè enim in crasfis, acé tibasq́ te terris tenuis, pąusqúue aer, craftus impurusque in humidis, paluftibusque, craffa nimirum, quẹ eft, denfaque ter ra tenuisfimis tantum uaporibus egreflum prebet, \& è mollis,laxać te \& aquofa, vel crasfisfimi,\& fuligines etiam elabútur.ut amaritiem, qux eftiuis, autumnalibusque omnino in. eी, qux è uaporibus factu fünt, è ficcis, exuftisque terris eductis, nequaquam ab inexiftente crasfitie, fed à nimia uaporú concoci ione facta effe exiftimandum fit. vapores certè, e qui bus falfæ, amaræque aque fieri Aphrodifeo vidētur, nimium concocti funt omnes, ut quod dictum eft, vel ex aquarũ differentijs, e quibus imprimis fapores à ficcitate fieri Peripateticis manifeltari uidet $\lrcorner$, caloris cos, $\&$ benè robufti falfum, amarumǵue actiones efle liquidò pateat. 


\section{Bernardini Telefij}

Dnlcem, amarumǵ faporum extremos non effe, minimique ex ÿs reliquos componi. Cap. IX.

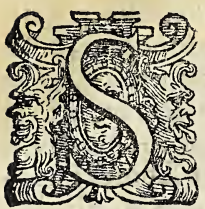

A POR V M porrò extremos dulcem, amarimq́ite, reliquos horum medios Ariftoteles ponens è dulci,amaroq́ ue fibi ipfis commiftis eos educens, fui fimilis uideri poteft, $\&$ idem omnino, qui ex infipidis rebus $f_{a}-$ pores ed ucit omnes. eiufdem enim e fibi ip fis commintis rebus naturam educere, quax illarủ infit nulli, \& è calidis, dilatantibusq́; qux frigoris fenfum prebent, conftringunt certè, A marus dulci penè contiguns, foloq́ue in medio ipforum pinguis, falfusq́ue, quorum ille dulci, hic amaro idem Ariftotcli videtur, vterque certè crasfitiem ( ut dictum eft) emollit, laxatq́ue;nam qux conAringit, duratq́ue, amarus propterea confringit, quod inexi ftentem ijs mollitiem in fummam agit tenuitatem, \& qux Itatim elabatur omnis. Acerbus, aufterusque, \& acidus confringunt, darantq́ue omnes; ut non nifi Ariftoteli, fuisq́ue, qui ipfius fententias, quafuis Dei decretorum iftar uenerancur, è dulci,amaroqúue compofiti uideri posfint.

\section{F I I S.}




\section{INDEX CAPITVM L $\quad I \quad B \quad R \quad I$ De Saporibus.}

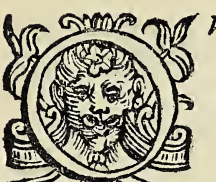

का युग

$V \mathscr{A E}$ in lingua fentinntur, ó quid fit fapor. Cap. $I$. pag.3.8 Acerbum, austerumique o acidum Saporem calo ris actionem eße languidioris quilem quàm noSter eft, at copiofioris; \&o acerborum calorem, stro dinerfum effe. magis quàm aufterorum, \& acidcrum est, à noAqueum Saporem caloris noftro perfimilis, dulcem, falfum, amarum, acremíue noftro robuftioris, copiofiorifque vel alterummodò, \&o quo expofiti funt ordine fingulos affidue robuftioris, copiofiorifue actiones effe.

Cap. III.

pag.6.8

caloris quoium qui expofiti funt fapores, actiones funt ut dictumest à feipfis, \& à noftro differre, ơ fese confequi. Cap. IIII, pag.7.a

Cur dulcis fapor valde per fe obleciat, of amplius, diutiusque alÿs commistus, ér cur noui, varïqúu. $\quad$ Cap. $V$. pag.9.b Quomodo anima fapores Ariftoteli fentiat, \& in quibus is illum ex plicans in cufaripoteft. cap. VI. pag.I O.a

Saporum materia aque bumiditas, efficiens caufa terra ficcitas Ari foteli videtur, illorumque extremi dulcis amarusque reliqui borum medï funt, o ex bisfibi ipfis commistis fiunt. Cap. VII. pag. I 0.6

Rerum omnium opificis Deipotentiam amulatus, \& rerum naturx, fibique ipfi contrarius ex aqua terraque infipida, vtraque Sapores conftituit Ariftoteles.

Cap. VIII.

pag.II.a Dulcem amarumq́ue Saporum extremos non effe, minimeq́ue cx ÿsre liquos componi. Cap. IX.

pag. 3.6

\section{F I N I S.}




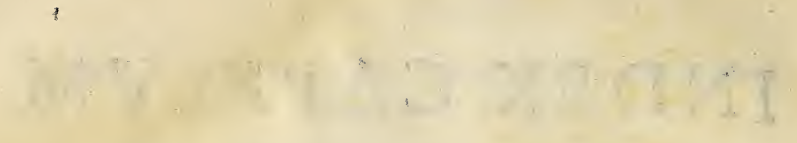




\section{BERNARDINI $T$ E L E S I I CONSENTI N I,}

D E S O M N O Libellus.

CVMPRIVILEGIO.

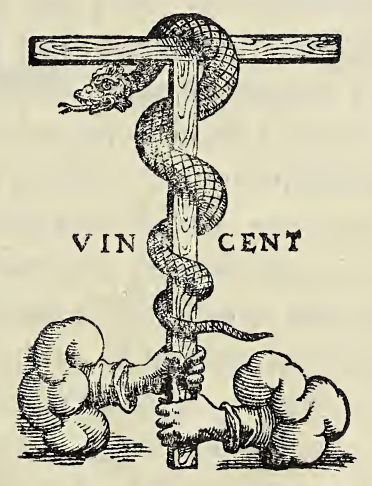

VENETIIS M. D. XC.

\section{Apud Felicem Valgrifium.}




$$
\begin{aligned}
& \text { 11]CMAWDIG } \\
& 1124 I B m
\end{aligned}
$$

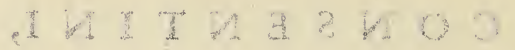

$$
\begin{aligned}
& \text { Q M MO } \\
& \text { - anlodil }
\end{aligned}
$$

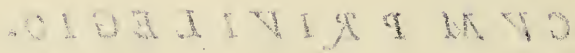

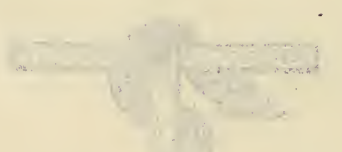

$$
\begin{aligned}
& \text { zese. } \\
& \text { OX O M ETTEYAV }
\end{aligned}
$$

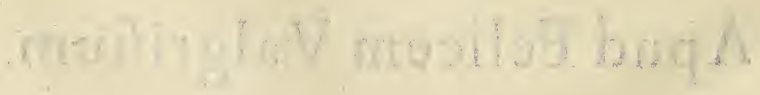




\section{$A N T O N I V S$ P E R S I V S}

P R AE C L A R I S S I MO $\begin{array}{llllll}M & E & D & I & C & O\end{array}$

\section{Hieronymo Mercuriali. S. P. D.}

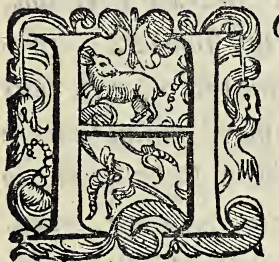

OMERICVS ille Iuppiter, Quod te non fugit, Hieronyme Mercurialis medicorum Coryphee, vt cAzamemnonem de fomno excitaret, mifrffe ipfr fomnium à poeta perbibetur: Ego veròne tus mibi dormias, hoc eft, ne me tibie memoria at que ex $x-$ nimo excidere patiare, tui amantif/mum, ftudiof $f \int_{j-}$ mumque tui ninquamoblitum, non vanum, aut mendax aliguod fomnium, Sed eruditum, ac veridicum fomnum Telefianum a T ele fo tum, cum minimè dormitabat, elucubratum ad te mitto, qui formum arcere, guonis fomnio validius pofjit. Hunc ego, $\sigma v v$ fedulum monitorem, of vt non obfcurum mei inte animi interpretcm ad Te definani, dum alind quaro tibi minemolynon, quo patcat Illugrius non fo'ùm quantum ibi ip fergo debeam, deferamó;, verùm ctiam quanium áb alissomibus effe deferendum xifltmem. Et fitu vni cade te clariffima Bononienfis Academice exifimatio- 
ne (vt communem eruditorum omnium fenfum praier mittam) contentus effe potes, qua te tanto fudio, ac contentione ad eminentifjimam medicina Catbedram ingen tibus, atque ante te nemini propositis premijs pertraxit. Atque boc fapienter Bononienfes, vt alia omnia, $\int a-$ pienter te quoque ip $\int u m$, qui condicionem acceperis, feciffe fapienti]fimus quifque exiftimat, cum tibi in ea or be domicilium ftatueris que bonorum omnium ornatu, ac copia compararicum urbibus omnibus merito poteft. Qü fit ut non iniuria ơ te ego Bononinie, $\sigma$ tibi Bononiam inuedeam, boc eft fummorum virorum doctrina, o bumanitatis laude celeberrimorum Bononic degentium confuetudinem. Peregrinos nunc taceo, ne te plus aquolegentem morer. De ciuium numero vnum tantum bonoris caufja commemorabo, Camillum Palcottum, tuo rum, vt tu temerito gloriaris, principem amicorum. quem virum primim Rome fum contemplatus, allocutus, admiratus, cum in eo omnia maiora opinione, ac fama deprahenderim. Ilague Alexandrum Burghium Jumma infignemtum fcientia, $\sigma$ eloquentia, tum probitate virum amo plurimum, qui vt Roma Palasttum cognofcerem, atque ab eo cogno/cerer $\sigma$ auctor, $\sigma$ inter pres mibifuit. Obfecroigitur te vir preclariffime per bu manitatem, \& comitatem illam tuam, qua vel fola agrotis reficuere valetudinem foles, vt me illi addictiffimum deligentiffime commendes, $\sigma$ à me falutem dicere ne gra ucris. Te vero mei muneris ne paniteat, fiquidem id, quod ab optimo in te eft animo profectum, optimum putas. Vale, $\mathcal{O}$ diu viue, vt diutius al ̈y viuant . Patauio. 


\section{B E R N A R D I N I}

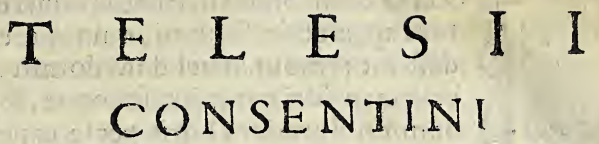

DE SOMNO LIBELLVS。

eA quibus fomni caula babenda funto Cap. I.

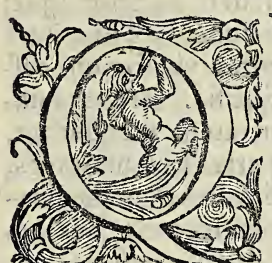

VID fit fomnus, \& quomodò fiat, cuiufque gratia animãtibus tributus fit, in ijs omnino inquirëdum eft, qux dor mientibus eueniunt, tum $\&$ in ijs, qua illum faciunt; quoniam enim in nullis à fe ipfo Vigilate dormiens animal differre uidetur, \& paffum omnino quid in fomnum delabitur, illa omnitio ante oculos primum ponenda funt, tum qux fomnum faciunt, à quibus fcilicet illa euenire exiftimandum fit; poftremò \& modus indagandus, quomodo ab ijs ille fiat; at is minimè notus fiat unquam, nifi fpiritus itidem natura, ingenimmque innotefcat ; qui nimirum ( ut in commentarijs de rerum natura expofitum eft) qux animal pati, operarique nidetur, ipfe ea patitur operaturq́ue omnia, \& cuius fenfus, qui in ani-mali fit, motufque eft omnis . nec uerò dubium fit, quin i qux dicta funt, nota fiant omnia, cuius itidem gratia rributus fit animantibus, notum fiat : Agè igitur qux dormicntibus eueninnt, \& qux fomnum faciunt, $\&$ in homine.ea qui$\mathrm{dem}$, in quo fcilicet multò fiút manifeltiora, intueamur. tùm \& qux de fpiritus natura, ingenioque in dictis expofita funt commentarijs, qua ad propofitum negotium fpectant, repctere ne.grauemur.

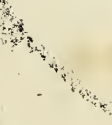




\section{BernardiniTelefii}

\section{2uedormientibuseueniunt. Cap. 11.}

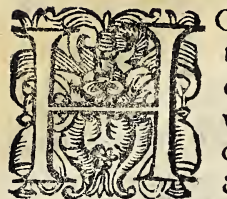

OMO dum fomno detinetur veluti demortaus apparet, fenfu omni, omnique externo deftitutus motu.at uel dum dormit à paulò vehementiori contactu, fonoque, \& paucis omnino dormiens horis per fe experge fit, \& ueluti reuiuifcit, fenfu reftitutus, motuque : \& qui dormientibus internis in partibus fiunt motus, 3.decaur. pulfus nimirum in fomni quidem initio ( fi Galeno credipulf. mus ) minores languidiorefuè fiunt, tum $\&$ tardiores, rario" refque,pofteà verò tarditatem pedetentim augent, \& rarita" tem, præfertim à cibo. At maiores fiunt uehementiorefque;

" quòd fi diuturnior fiat fomnus ad remisfionem, \& paruitatể redeunt, tarditatem, \& raritatem retinent. \& vbi fomnus ceffat, magni, vehementes, celeres, crebriq́ue fiunt, $\&$ cum quadam etiam uibratione; at mox mediocritatem affequuntur. Somni itidem initio extern $x$ corporis partes frigent omnes, $\&$ facies liuidiores, decolorefque, \& pallidiores fiunt; at fomno progrediente, \& partes incalefcunt \& facies propriam fpetiem recipiunt. \& concoctiones omnes, digeftionefque praftantius in fomno, quam in Vigilia fiunt, \& profundis quidé in fomnis infonia aut non fiunt prorfus, aut valdè confufa, in terruptáque fiunt . in fine verò fomni multa beneque diftincta funt : \& qui dum dormiunt, loquantur quidem, moueanturque, at nullam dictorum, factorumque memoriam retineant.

\section{2ue fomnos faciunt, \& quifomniculofi, quiue in fomnes funt. Cap. III.}

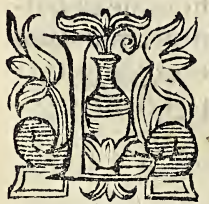

ABORES, diuturni nimirum, vehementefque motus, ì ira, letitiaque, \& Venus, tū \& inedia, Viglliaque fomnum facere videntur. praterea \& nimij, vel vaporof, flatulentique cibi, \& potiones, febrium accefsiones, cogitatio, Lectio, triftitiaque, \& timor, \& quilibet Len is iucũdufque fonus, \& Lenes itidem titillatio nes, contrectationes, \& frictiones, Lenifque agitatio , \& motus denique lenis, blandufque omnis, \& circularis itidem, \& tenebre, 


\section{De Somno Libellus.}

renebr $x$, filentiumque, \& ipfa etiam voluntas. Cerebrum præterea vel contufum, vel tumefactum, vel crasfis vaporibus op pletum, \& magis etiam humoribus, \& pluuix, atque hyems: fomniculofi verò qui frigidis laborant morbis, capit is prxfertim, cerebrique, \& qui paluftria incolunt loca, \& pueri, fęminxque, infomnes contrà calido homines corpore, \& qui calidis laborant morbis, \& qui calidas, ficcafque incolunt ter ras, \& lenes.

\section{Spiritus natura ingeniumque, or pafsiones, operationefque. Cap. IIII.}

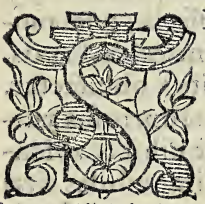

PIR ITVM, fubftantiam fcilicet benè calidam, benèque tenuem, animantium corpo ri inexiftere; $\&$ in cerebri quidem venrricu lis,ut in maximè propria, ac principe fede contineri, at rebus tam è femine conftitutis, vnis exceptis ofsibus, ijfque fimilibus re bus reliquis in effe omnibus. \& fumma fentiendi, fefeque mo uendi facultate donatum efle, \& fummopere motu oblectari, $\&$ à fonis reliquifque fenfilibus noluptate affici, propterea ea affici, quòd à fonis quidem uerè ad motum agatur. \& ab alijs verò blandè, Leniterque dilatetur, conftringaturuè . quo igitur commoueatur pacto, \& fingulas corporis partes fenfir, motuque ab eo donari, fentire nimirum, mouerique omnes; quòd omnibus ipfe inexiftens, in omnibus fentiat, inque omnibus ipfe motus, fecum eas commoueat omnes. \& in eif dem fatis eft ( ut exiftimo) declaratum commentarijs, \& nihilvfque declaratum, perfe manifeftum omnino eft. neque enim nîf huiúmodi fubftátia animantium corpori infit, vel moneri, vel fubftineri queat; fed quod fpiritu elapfo, extinEtouè, aut etiam imminuto euenire apparet, ad cognatam decidat terram, immobiléque ibi iaceat. \& manifeftè medullx cauitate, vel nerui cuiufuis praclufa uia, poris tumore oppletis,fpiritui nimirum, partes, ad quas is fertur fupidx, immobilefque funt; quin: \& ibi itidem id fpiritus ingenium effe declaratin ef ; ut quacunque in corporis parte, quauis eius portio oblixdatur, uniuerfus ad eam $\bigcap_{\text {atim }}$ confuat, nec inde recedat vnquam; nif à quibus ibi infettatur, exuperatis eiectifuè, id quod anim $x$ deliquia manifeftant, qux fcilicet infi- 


\section{Bernardini Telefij}

infignés dolores confequuntur, neque enim ambigi poteft; quin propterea eueniant, fcilicet fenfu, motuque animal deftitnatur, quòd è reliquis eius partibus fubftantia recefferit, a qua fenfin, motuque donantur, ad eafque omnis confluxerit, in qua eius portio diuexatur, ut qux ibi eam infeftat amo liatur, \& nec ibi nihil moueri, nihilque externas retum actio nes fentire, quòd vniuerfa in illis amoliendis intenta fit, occupataque; ea itaque communis deliquiorum omnium cura tio eft, alijs fcilicet in partibus, qui in illis reliquus factus eft fpiritus, cruciatur torqueturque, quo fcilicet in alijs itidem oblædi fc fentiens, ad alias redeat omnes, quin eam itidem ad partem confluere fpiritus uidetur, in qua operatio operanda eft. Valdè laboriofa, vel ualdè neceffaria, qux omnino magna $x$ denda fit diligentia, vel etiam valdè fuauis, valdeque iucunda, \& qua fummopere fpiritus oblxctetur. v bi itaque externus aliquis, vel laboriofus, vel operofus $x$ ditur motus, parum fentire, cogitare certè liceat nihil.\& vbi intentè quid cogitamus penè ftupidi, atque immobiles fieri videmur. \& vbi itidem diligenter, vel magna quid fentimus cum voluptate, nihil cogitare, nihil moueri, nihil alia Sentire poffe videmur,uniuerfo nimirum fpiritu cùm ad ope rationes illas operandas, tùm verò ad voluptatem percipiendam confluxo, ab eaque abftrahi recufante, quo omnino mo do externis in rebus, eodem $\&$ in internis operatur. nam \& cognatos proximosque vel quopiam opreflos malo, quiduè paffuros int siti,ftatim ad eos connolamus, opem, quam poffumus ut feramus : 3 uel maximè Neceffarijs occupati in rebus, tiel grauibus etiam oppresfi malis, fi ingens interea proponatur uoluptas, rebus reliquis poft habitis omnibus, ad eã percipiendam conuolamus. Homins, fcilicet unus fpiritus nihil (ut alibi expofitum eft) ab hominum cœtu differre videtur. celfus praterea fui natura exiftens fpiritus, erectusq; \& proprix conferuationis appetentisfimus, nec iniuria affici, contemptuique haberi, nec pacto ullo corrumpi uult.quòd fi horum quid patiatur, intro fefe abdit;nec quę eum deturpăt, - blęduntuè intueri ipfe, nec ea paffus ab aliis confpici fubftinens.iis contra, à quibus fublimis fiat, à quibufuè feruetur, accedentibus foras exilit, $\&$ ea ipfe intueri, $\&$ fe ipfum is affuentem oftendere appetens: externę itaque corporis partes calent in latitia, rubentq́ue omnes : \& non oculi modo mul- 
tò grandiores, multoq́ue fplendidiores etiam, \& magis uiui apparent; fed os iam \& ipfum uniuerfum, fpiritus nimirú fan guinifque, quem fecum ille perpetuò agit, confuxu. in triftitia contra, metuque frigent ill $x$, albent $q ; \&$ oculi minimi, ac obfcuri, languidique, $\&$ os itidem imminutum apparet, \& veluti demortıú. Spiritus fcilicet abfceffu, cú quo \& fanguis in troactus eft omnis, quod dictum nimirú eft, eodem omnino modo quo in externis, in internis itidem perpetuò operans; bonis enim affluĕtes, beatiq; confpici oês uolumus, \& fpecta re ea ipfi:mala contrà auerfamur, malifque oppresfi ipfos nos abdimus, \& fpectari omnino nolumus. calidus porrò tenuifque, \& ad coelum, ut ad propriam tendens vniuerfitatem, \& modicè calido, mollique inditus corpori, in quo fcilicet ab ambient is frigore oblędatur, \& e quo ab externo calore ad elabendum inuitetur, alliciaturque, \& fpontè etiam elabatur, multis omnino imminuatur modis; omnino \& deficiat, nifi reficiatur, nutriaturque, \& à fimilibus omn ino cognatifq; re bus.neq; enim nó multus ipfe,\& longè tenuifsimus, itaq; per exili, perque languido pręditus calore, quę ualde ab eius natura disfident, exuperet, \& in fe ipfum agat, itaque aere, uapo ribufque reficiendus fuit. Ventricōlos eum omnem efferri exi ftimandum omnino fit, Vtique \& in illis pręcipue, \& iis omnino uniuerfis corporis partibus reficiatur, uideri poteft. in cerebri quidem ventriculis manifeftè ijs refici apparet, fi qui dem patens ad eos per nares facta eft tia aeri; ifque infpiratus, fi fpiritus fubftantix fimilis eft, cognatufque mirifica ipfum afficit voluptate, \& veluti viuificat. Summam contra moletiam, \& exitium etiam affert fummum, difsimilis fi eft, contrariufque, vt ambigere non liceat ad fubftantiam eú deferri, \& fubftantix omnino immifceri, quæ vitæ fit fons, \& uita ipfa, ad ipfam nimirum animam, patens itidem vaporibus qui neceffario in ciborum concoctione, in ventriculo, Ventreque fiunt, ad ventriculos eofdem per œfophagum, perque os, \& meatum, qui ex ore ad nares tendit, facta eft tuia, nô fiquidem nifi exijs itidem illis inexiftens fpiritus nutriatur, ad ipfum efferantur, qui prxfertim à fpiritus natura disfidentes fummopere eum affligant, torqueantque . calidi certè \& ipfi, tenuefque vtique omnino cum fint, cum ei immifti, $8 \mathrm{co}$ pia ab eo exuperati fuerint, cum ipfi fpiritui benè rroximi co gnatique fint, ambigere non liceat, quin in ipfum agantus 


\section{BernardiniTelefij}

fpiritum; ipfis preterea fub ventriculis longifsimam, anguftisfinamque arteriam in re is formam, vnde nomen ei inditun eft, complicatam ita omnino ( $v t$ alibi dictum eft) conftractam ibique locatam cum intueamur, vt longè plurimam ex ea enaporationem éuehi, \& fpiritum refici, nutririque exiftimand tum cmnino eft at $\&$ id precipuum à fpiritu reliquis in partibus contento, eius vniuerfitas in ventriculis inhabitans habere uidetur, non fcilicet eas modò pati pafsiones, ijfque inodò commoueri trotibus, quas ipfa patitur, \& quibus ipfa commouetur. Sed eas infuper omnes pati, ijfque omnibus infuper commolieti, quas quauis eins portio patitur,\& quibus commouetur, \& nihilờ penè fegnius, quàm por tio primùm commota, 8 à qua motus ei communicatur, velu ti uidelicet qui aeris, aquæuè portioni inditur motus, uniuer fo is aeri,\& aque vniuerfx communicari videtur; \& fic, \& mul tò meHerculè promptius, qui fpiritus portioni vbi uis exifté ti dat:ur motus, ad vniuerfum is fpiritum quacunque in parte exiftentem defertur, (longèquam eft aer) tenuiorem, longeque ad motum promptionem, at non alijs in locis, fed in eius modò manifeltatur ventriculis, quòd loggè plurimus ijs inexi ftit, ¿ in benè amplis, quòd alıbi per anguftis inditus poris, nơn poteft quibufuis perbellè agitari motibus, quòd nifi paffiones omnes, omnefque motus ad vnum idemque conferan tur principium, vna fcilicet eademque fpiritus pars illas omthes patiatur, illique commouteatur omnibus eorum differentiæ nihil magis diiudicari queăt, quam corum, qux feorfum, feparatimque à diuerfis perceptx funt : quin non prafentes modò pasfiones pati, præfentibufque motibus commoueri fpiritus vniuerfus uidetur, \& quas ipfa princeps patitur, quibufque ea commotetur;fed prateritas pasfiones omnes, quo cimque eas paffa eft modo, prateritofque motus recolere om ties; \& ex ijs remotarum rerum conditiones, qux ignote funt, in telligere, \& futura etiam præuidere, \& patere ex ijs videtur cur, \& vbi fpiritus intro fefe, ad cerebri recipit ventriculos, at maximè ad fomni caufas manifertandas neceflaria clarius in tueri ea ne grauemur. 
2ue Spiritum intro, \& ad cerebri agunt ventriculos. cap. $\quad V$.

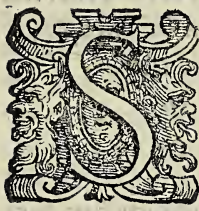

PIRITVM ibi externis é partibus, in internas, \& in cerebri præcipue ventriculos fe fe recipere exiftimare licet, vbi quapiam ip fius uniuerfitatem in illis refidentem infeftant : neque enim ad quamuis fui portioné laboranté accurrere confpectus principem, maximamque fui partem negligat, \& vbi val dè imminutus eft, \& refici opus habet, appetitque fiquidem non alibi magis reficiatur, quàm vbi è quibus refici . poteft, adfunt, \& ipfe uniuerfus adeffe poteft, \& ubi laboriofa, operofauè, uel fuauifsima quxpiam, iucundifsimaque $x$ denda ibi eft operatio, \& vbi quxpiam intueri exhorret, auerfaturque, \& vbi itidë nihil intueri, nihil operari vult, aut quod pasfim euenire apparet, operari amplius non poteft, fiquidem ubi nec neceffaria, nec fuauis alibi $x$ denda eft operatio, propria in fede, \& fibi ipfi unitus, collectufque libens ufque quaque permanet, at multo certè amplius ubi diu externis, vel internis in partibus operatus eft,itaque defatigatus eft. Impotens uerò ineptufuè ad exiliendum fit fpiritus, ubi uel meatus obfruuntur, uel ipfus calor, aut tenuitas imminuitur: nã proprius quidem caloris motus, at calor quiuis, uel fummus, igneufque fi crasfitici indatur, immobilis fit, torpidufque; nö quidem quod moueri non appettat, vel moueri non asfiduè tentet, fed quòd à materix pondere detineatur, opprimaturque, id quod flammx declarant, qux in crasfioribus accenfę rebus contra proprium flanmarum ingenium deorfum delabuntur, a materix nimirum copia detract $x$, ac pondere.age uerò quod teliquum eft, num qux fomnum facere uifa funt, eius fint natura omnia, vt fpiritum intrò, \& in cerebri agant uentriculos.num fcilicet vel qux ipfum diuexant, in illos im mittant, uel ipfum imminuant, uel fpiritum in illis contentumad operationem agant, vcl maxime laboriofam, operofamue, vel maximè fuatem, vel operationis omnis, om$\mathrm{ni}$ in corporis parte vacuum faciant, uel exilere etiam prohibeant, fi quidem hxc operari uifa ca funt, vtique fomni caufz omnes patefactz videri poffunt : neque dubium effe

$$
\text { B } 2 \text { potelt, }
$$




\section{Bernardini Telefij}

potef, quin fubftantix fenfum, motumque partibus afferentis ex ijs abfceflu ille fiat.

Ab $\ddot{y} s$, qua fomnum faciunt, Spiritum ad cerebri ventricus-

los agi omnibus, \& fomniculofis fpiritum talem eßse.

gualis eft, qui ad exiliendum, mouendum-

que impotens, ineptufque vifus eft,

$$
\text { efse. Cap.urn } V I \text {. }
$$

Fi Vehementibus, diuturnifque motibus fum3102 moperè fpiritus defatigatur, imminuitur7 1 (3) que; nam fi qux mobilia fui natura funt, in S17 ta fumere videntur, quoniam non fe ipfum

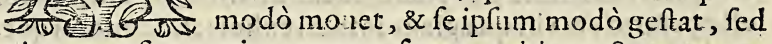
circum pofitum etiam corpus fecum trahit, vectatque graue fui natura, atque immobile, vt ique eius pondere oppreffus debilitetur tandem, defatigeturque preterea \& vt imminuatur oportet; fi quidem ad partes commonendas delatus omnis, minus qux in cerebri ventriculis, ad fui ipfius refectionem illapfa funt conficit, concoquitque.itaque multò quam reficitar, copiofius elabitur èconcalefacto præfertim adapertoque corpore, fortè \& tenuior iple factus. idem $\&$ in iracundia euenire apparet; $v$ t enim corpus.vniuerfum laco non dim mo ieat, at per vniuerfum ipfe, \& magno delatus impetu, $\&$ ip fe tenuior fit, \& partes p quas defertur, Venas præfertim arte riafq;, \& ijs inexiftentê fanguinē exagitat, accédit q;, \& in lęti tia itidê, $\&$ in fpe.lăguidius enim in ijs, quã in iracúdia at \& 2 in ijs libés ad externas cónolat partes, nec ad eas delatus qui efcit, fed asfiduè monetur, fefe, ( $v t$ dictum eft) oftentans, \& ueluti lafciuas, geftienfque, multò etiam in Venere amplius, multoq́ue in ea amplius oblectatus diffúfufque multoq́; pröptius è valdè concalefacto pudendo, in quad plurimus confuxit, ut uoluptate, quæ fumma ibi percipitur, fruatur elapfus.in Vigilia preterea, atque inedia fummopere fpiritus im minuitur, in illa quidem q òd corpus uel fubleuans modò fuftinếque defatigatur, \& copiofius omnino elabitur,quàm reficitur, asfiduè extremis è partibus commotis elabens prxfertim 2 \& non valenter fe ipfum reficiens, modicus in ventricolis 
colis factus, cxternifque intentus operationibus, in hac ver $\hat{\sigma}$ quod (ut dictum eft ) $\&$ in commentarijs de rerum natura amplius declaratum eft, non ea euaporatione tantú, qua è ple xn retiformi in uentriculos effertur, fed è vaporibus itidem refrcitur, qui in ciborm concoctione è ventriculo ad ventri culos efferuncur - qui igiturvbi defunt, minus reficitur fpiritus, \& è vaporibus omnino, qui è cibis elabuntur refici fpiritum inde apertisfimè inselligere licet.quod vel dum cibi,potiónefque ađiumuntur, multò omnino priufquam vel in ventriculo inuerti queant, refici ille uidetur. Labores itaque ( it dictum eft ) \& iracundia, \& latitia, \& fjes, \& Venus, \& Vigilia, Inediaque, quòd fpiritum defatigant, imminuuntque; propterea ipfum in cerebri agunt ventricolos; nimij verò cibi,potionefq; \& uel exigux, ac flatulentx, vaporof $x q u e$, ill $x$ quidem, quòd yaporum copia; hæu uerò, quòd eorum crásitie fpiritum opprimunt, diuexantque; \& meatus obftruunt.Idem \& febrium agunt accefsiones: nam quị in ijs è Venis arterije que exudat humor, quem adeò fpiritus exhorret in maximè acres maximèque moleftos foluitur vapores: cogitatio autë, \& lectio fpiritum ad ventriculos agunt, quòd in v traque qux illius in ijs inhabitat uniuerfitas, fummopere laborat. qucniam enim ( ur in ijfdem declaratum eft commentarijs ) Intellectus, Iudiciumque omne, prateritarum pasín mum, prateritoramque motuum recolitione fit, ibi vtique fieri exifti mandum eft, abi illæ omnes perceptæ, \& hi æditi funt, ubi cö modè recoli poflunt in cerebri nimirum ventriculis; multò preterea illos recolere fpiritus labore videtur; ang ato enin omnino in loco, \& a fuper incidentibus runicis afsiduè oppreffus agrè perfe moueri poteft.itaque propterea itidem aer admitti uifus eft, ut tunicas fubleuaret, $\&$ ipfum impelleret fpiritum, $\&$ ibi omnino motu oblectari videtur, $v$ bi ab externis ad motum agitur rebus, motus itaque quibus olim com motus eft, obfeuros prefertim, \& quorum per exiguaremäfit memoria recolens, laboret neceffe eft, \& manifettè id opcrans, contrahere fefe, $\&$ in fe ipfum confundi, \& veluti fui ip. fus latebras indagare, ut quem inquirit notum lateritem in ijs inueniat; videtur tum motuun cefatio, immutatioque; vbi prxfertim nouus qui fit, precedentifimilis non eft, fummopere fpiritui moleita eft,odiofaque; quòd rerum, qua fentiütur omnium, at fonorum prxcipuè difformitas, inçquabilitasqúue 
litasqque declarat, quæ fcilicet fumma firitum afficit mole. ftia:motu nimirum is oblectatur. at uno eo vniformique, \& continuo, vel qui unus videri pofsit, continuusque, cuiufmodi quibus cogitantes mouenturuideri non poffunt: vt à cogitatione, lectioneque, non in uentriculos modò fpiritum agi, fed diuexari in illis infuper exiftimare liceat; eadem \& nihilo fegniws trift itia, timorque operari videtur, nam \& triftitia, \& timor intellectio qurdam eft,Iuditiumque, \& in illa quidem, qux eueniunt mala, in hoc verò, qux euentura funt intelligit indicatque fpiritus, \& fummopere ea intelligens af fligitur, \& fefe (ut dietum eft) veluti abdit; mifer, abiectufque, \& corruptioni ob noxius videri nolens, in fonis contrà, \& titillationibus, contrectationibus, frictionibufque, in motu denique omni leni,blandoque, $\&$ in circulari infuper quòd ( ut dictum eft) quo quxuis fpiritus portio, \& quauis in corporis parte motu mouetur, cò fpiritus vniuerfitas in cerebri ventriculis inhabitans fimul motetur, \& multò plerunque quàm qux princeps mota eft portio, amplius multò ipfa amplior,amplioremque nacta locum:co itaque fpiritus ut commoueatur in illos confluit vniuerfus, fortè \& circulari motu, ut re infueta turbatur fpiritus . quòd vbicumque ei euenit in cerebri ventriculos fefe in propriam fcilicet principemque fe $\mathrm{dem}, \&$ ad propriam fefe recipit uniuerfitatem. In tenebris au tem,\& filentio, quòd neque à luce, nec à motu ullo euocatus, allectufque fpiritus, \& tenebras fortè exofus, libens fefe ad propriam fedem, propriamque recipit uniuerfitatem:quę quo niam à fe ipfo habere poteft, \& ubi uult itidem, \& fefe in uẽtriculos recipere poteft, \& ubi dormire appetit fpiritus oculos occludere, à motu omni ceffare uidetur, cerebro porrò contufo, tumefactoque, \& crafsioribus uaporibus, \& magis ctiam humoribus oppleto:\& in plituijs, atque hyeme meatus quibus ad externas partes effunditur fpiritus, obftruuntur, itaque iu uentriculis detinetur, \& ueluti coercetur, \& libens ipfe ibi commoratur, qux ibi fpiritum infeftant appugnans, amolienfque, idem \& ijs in uniuerfum euenit, qui frigide, humidoque fant corpore, uel frigidis laborant morbis, cap itis prafertim, cerebrique, \& qui paluftria incolunt loca, \& pue ris,forminifque, fiquidem ( ut in ijfdem declaratum eft commentarijs) in ijs omnibus angufti meatus, $\&$ in omnibus, crasfi omnino, \& frigidi infuper, in quibufdam uapores cere- 
brum fubeint, $\&$ qui madore id fpargant, $\&$ craffus omnibus, vel etiam frigidus, ineptus omnino ad exiliendum, mouendumque ineft fpiritus, quxcunque igitur fomnum facere, in cerebti ea, ventriculos fpiritum agere, uel ne inde egrediatur, obftare videntur: 2 fomniculoforum fpiritus qualis qui ad egrediendum, mouendumque impotens, ineptufuè vifus eft, certè manifeltò exiftit, vt fi qux hominibus in fomno euenire vifa funt, propterea euenirc exiftimare licet; quod firitus intro; $\&$ in cerebri fefe recipit ventriculos, vtiq.ie \& fomni caufas manifeftas effe exiltimare liceat. agè igitur num propterca illorum fingula eueniant confideremus.

Externas corporis partes propterea in fomno ftupidas fie. ri, immobulefque, quod fpiritus ex ys Sefe in cerebri ventriculos receperit; ó Spiritus reficiendi gratia fomnum animalibus tributum effe. Cap. VII.

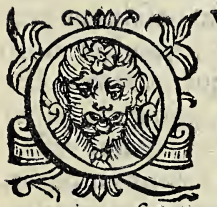

VONIAM dum fornno homo detinetur, ftupidus apparet, immobilifque, \& veluti demortuus, \& vel dum dormit à paulò vehe mentiore contactu, fonoque, \& pancis omni no dormiens horis, perfe expergefit, \& velu ti reuiuifcit, \& fenfu reftituto, motuque. patet utique fubitantix extremis è partibus abfceflu, abfentiaque fomnum fieri, cuius prafentia, accefluque, fenfu ille, motuque donantur, \& uita fpiritus nimirum, neque uniuerfi tan tum.neque enim uniuerfus fi tecedat contactus ullius, ulliufuè plagx fiat fenfus . tantulus itaque reliquis, in partibus fit, quantulus nec corpus fubleuare, nec quafuis externarum rerum actiones, fed uehementes modò percipere queat.quonia ucrò $\mathrm{ab}$ affumptis pracipuè cibis, uaporofis præfertim, flatulentifque, \& à laboribus, uaporibus nimirum, in cerebri uentriculos illapfis crasfioribus prefertim, \& ualdè imminuto, defatigatoque fpiritum in fomnum delabi uidetur;nở aliam omnino ob caufam, neque aliam in parte $m$ fefe in fomno $\mathrm{pi}$ ritum recipere exiftimare licet, nifi ut infeftantes, moleftof- 
que uapores exuperet; uel imminutam, languentemque fefe intrò reficiat, foueatque, \& in cerebri omnino uentriculos, in quos nimirum uapores fublati funt; 8 in quibus ipfius inhabitat uniuerfitas, \& fpiritus omnino quiefcere, \& rerefici uidetur, plurimus porrò in illis factus, nec læuia quxuis fentit, nec ( quod ab externis muneribus ociofus libens facit ) prxteritas pafsiones, præteritofque motus recolit ullos, quòd totus uaporum concoctioni, fuique ipfus intentus refectioni, nihil aliud operari uult, nec poteft, id quod in Vigilia etiam ufú enenire ei uidetur : ubi enim ualde intenta quid operatur, uel qux otiofo, uacuoq́ue ualde molefta, iucundaue forent, ea ne percipere quidem uidetur, è quibus patere itidem uidetur, propterea fomnum animantibus tributum fuiffe, ut fpatium fpiritui adeffet, in quo reliquis à muneribus otiofo, rebus in uentriculos ad fui ipfus refectionem illapfis exuperatis, inuertendifque uniuerfo uacare liceret, itaque copiofius, quàm imminuitur, reficeretur. nam in Vigilia, quòd externis in partibus bonæ fpiritus portioni immorandum eft, exque asfidue commouend $x, \&$ externarum rerum uires fentiend $x$, \& cum ijs confictandum, pugnandumque, \& reliquo in cerebri uentriculis refidenti non præfentes modò partium pafsiones percipiend $x$, fed præteritæ etiam recolend $x$, quòd omnino multus asfidue è commotis, concalefactifque partibus elabitur; \& alijs muneribus intentus, fui ipfus refectioni parum uacat, copiofius asfidue imminuitur, quàm reficitur; itaque id ab animæe deliquijs differre fomnus uidetur, quòd non, ut illa fpiritus portione quapiam in corporis parre laborante, at eamq; fpiritu omni confluente fit fomnus, fed eius uniuerfitate uel diuexata, uel diminuta. 


\section{De Somno Libellus.}

Bulfuum, externarumque partium, que in fomso fit, immu. tationem, \& concoitiones melius in fomno, quam in vigilia pेropterea fieri, quiod fpiritus intrò, \& in cerebri fefe recipit ventriculis. Cap. VIII.

ANC ROPTEREA etiam in fomni initio pul-

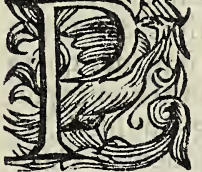
fus minores fiunt, läguidiorefque;quòd ma gna fpiritus portio internas in partes, \& in cerebri prafertim ventriculos recesfit : itaq; qui reliquus in arterijs factus eft,eorum one ri veluti cedit, xgrè omnino eas attollit . 8t tardi infuper rarique:quòd (ut dictum alibi amplius eft)non propterea modò arterias attollit, cornprimitque fpiritus, vt pondus à quo grauari fe, côprimique fentit, reijciat, \& quòd fui natura mobilis cum fit, quo licet moueri gaudet motu, fed \& amplius fortè,ut nimium fanguinis inexiftentis calorem, à quo veluti morderi fe fentit, vitet, amoliaturq; itaque etiam perpetuò celerius, frequentiufque pulfat, quo fanguis calidior fiat, quo fcilicet, maiore ab eo afficiatur moleftia, \& ita omnino ut pulfet vfus pofcit.robuftior enim, \& ad exilien dum promptior factus calor, frequentiore omnino retinédus eft refrigeratione.itaq; magna in fomni initio à fpiritu intrò acta fanguinis portione, moleftia, fcilicet ufuque imminuto, rari, tardique fatis funt pulfus. Nam arterias, uenafque $a b$ inexiftente fpiritu attolli, fanguinemque ijs inditum, quocunque ille fertur, fecum ab illo agi,\& præcipuè caloris prohibédi, retinendique gratia pulfationem, refpirationemque animalibus tributas effe, fatis (ut exiftimo) in de refpirationis $v f u, \&$ de rerum natura, in ijfque amplius declaratum eft $\mathrm{com}$ mentarijs, in quibus animal uniuerfum ab vnica animæ fubftantia gubernari expofitū eft. fomno uerò progrediente pulfus maiores fiunt, uehementioresq́ue; quòd aucto iam in vẽtriculis fpiritu, eius portio qurpiam in arterias, venafque illa bițur:tum \& arterijs in ipfis, ipfifque in venis ex inexiftentis fanguin is elaporatione, $\&$ ex attracto itidem aere, noutus affidue, \&rfomni præcipue tempore fpiritus fit copiofus, isque (ut exiltimare licet) in arterias vadit, omnino fomno progre diente in arterijs factus uniuerfas eas in amplitss, \& magna

C diften- 


\section{Bernardini Telefij}

diftendit ui, at nec uelociter tamen, nec crebro, quin tardius, rariufque prafertim à cibo : itaque pulfus magni, uehementefque, at tardiores fiunt, rarioresque.quoniam enim nec ma gna dum fanguinis copia, in arterias venafq; acta eft, nec par tes benè dum concalefactx, itaǵue nec vehementius mordetur firitus, nec maius, ne calor elabatur, imminet periculum, nec moleftia fcilicet, nec ufus auctus dum eft, non ueloces in fúper,crebrique ędendi funt pulfus, à cibo præfertim ad qué frilicet concoquendum multus confuxit fpiritus, \& dum be nè illo côcocto, minimè dum inde recefferit, itaq; nec quem fecum agit fanguinem, reuexit.Valida omnino exiftente pulfante fub?tantia, fi ufus non urgeat, pulfus magni quidem, uehementefque, at tardi, rarique perpetuò fieri uidentur Galeno;at fi diatarnior fiat fomn us ad paraitatem, \& remifsione redeunt, quòd noui (ut exiftimare licet) vapores uentriculos fubierint:nam fiquidem multx ciborum reliquir, è quibus amplius concoetis noui educuntur vapores uentriculo infunt, è rebus certè educi poffint in uentrem deiectis:illud cer tè ni factum fit, haud quaquam diutius duret fomnus:ad nouos itaque vapores exuperandos rurfus conuolat fpiritus, \& veluti nouus fit fomnus, tum diuturniore à fomno diutius fcilicet, velinti immobilis factus fpús, veluti torpidus fit.expgefactis verò pulfus magni, uehemétes, 'celeres, crebriqq; ¿\& cú quadam etiam vibratione fiunt: quòd diu in cerebri ventriculis à uaporibus ad illos fublatis oppreffus, tum cibis etiam in uentriculo conflictatus fpiritus, \& utrifque exuperatis tan dem, itaq; ea fui parte exuperata, qux externa in vigilia enolarat, copiofior omnino factus, \& à nulla internis eft partibus detentus necesfitate, fuique fortè portionem in externis reli Etam laborantem, \& qux in his obeüda funt munera, $x$ grè obeuntem fentiens, feftinans, \& veluti trepidans ad hos ex illis omnibus euolat, \& quem ex his in illas egerat, \& has fecum retrahit, fanguinem : itaq; quòd fpiritus benè iam copiofus aiterijs ineft, \& ab illapfo iam, \& asfiduè illabente fanguine amplius calefit: pulfantis nimirum fubltantix robur, \& fanguinis calor, itaque \& moleftia, \& vfus aucus eft, arterias be ne in amplum, magnaque ui, \& celeritate magna, nullaque in teriecta expandit mora. \& quia non vniuerfus fimul confluxit, fed nouus asfiduè in arterias iufluit fpiritus, fecumq; cas in longum agit,Iaculorum more ex ferri, \& fubtremere uidétur. 
Inr.pulfus nimirum magni, uchementefque, \& celeres, crebri que, $\&$ cum quadam vibratione expergefact is fiunt, mediocritatem, inquam, mox confequuntur:quòd follicitudine, me tuque omni depofito, non in amplius, vehementiufq; quàm opus eft, fed ita arterias attollit,uti attollend $x$ funt. itaq; nihil maiore, quæ ante fomnú à fanguinis calore affectus moleftia, nihil eã augeri fentiēs, quod ubi fit, maximè fpiritú tur vat, maximeq́ue ad id quod illam infert repellen dum incitat.itaque vel minora qux funt mala; $\&$ que asfidue incremen tum capiunt, magis ea nos, quàm qux maiora funt, at qux ni hil augeri apparent. \& qux pati aflueti fumus, exhorremus, maioreque conatu reijcienda exiftimamus, \& reijcere tentamus : quòd omnino quę ad pulfationem pertinêt res, ad priftinum ftatum reductx funt omnes, priftinú pulfandi modum affumit fpiritus.propterea itidem in fomni initio exter næ corporis partes frigore afficiuntur, \& facies pallidiores, $\&$ liuidiores fiunt, quod fpiritus, fanguinifque, rerum fcilicet, quarum prefentia calent illæx, rubentque, \& benè fiunt, ex illis in internas receffu fit fomnus : fomno verò progrediente, priftinum calorem, colorem que, \& vigorem affumunt . quòd vaporibus fi non penitus, at magna ex parte iam fuperatis, ea fpiritus, fanguinifque portio ad illas redit, à qua quales erāt, fieri queant, \& fiant omnino.

In fomnia itidern, dr qua fomniculofis, In fomnibufque in. funt, fomnum, quomodo dictum eft, fieri declarant. Cap. $I X$.

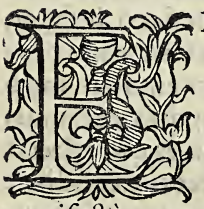

$X$ infomnijs itidem, \& fomniculoforum,at que in fomnium natura,ingenioq;, ex ijs om nino quæ fomniculofis, \& quæ infomnibus eueniunt, Somnum fpiritus externis è partibus abfceffu, \& in internas receffu, ac contra Eione fieri; \& ibi omnino animal dormire manifeltè apparet, vbi fpiritus à vaporum copia, malignitate uè oppreffus, corumque concoctioni totus intentus, nó quaf uis pręfentes externarum rerum actiones, fed vehemétes mo dò percipit, \& quas olim percepit, nihil eas recolit . propterea enim profundis in fomnis, in fomnia non fiunt; \& fi quæ

C 2 fiunt 


\section{BernardiniTelefij.}

funt ualdè ea interrupta, confufaq; fiunt, quòd multis, craffifuè immiftus fpiritus uaporibus, nihil prxteritos recolere motus, nihilque illis, vel fimilibus commoueri curat: $\&$ fi quos recolit, confafos eos inter ruptofque recolit, quòd ab internis uaporibus ipfius motus, \& ipfe itidem confunditur, interrumpiturque fpiritus; at in fine fomni uaporibus nimirum denictis iam, in ptopriamque actis naturam infomnia multa beneq́ue diftincta finnt; quòd à uaporum moleftia liber (quòd vigilans facit) motus, quibus olim commotus eft, recolit fpiritus, ex eorumque fimilitudine alijs quibufunq; commotus eft, mouetur, \& propterea dormiens homo, \& loquit:r, \& furgit, \& mouetur, multaque etiam operatur, nulla dictorum, factorumq́ue fuperfite memoria: quòd nimirum nô adeò à uaporibus oppreflus eft, neque adeò exiguus in par tibus facus, quin eas mouere, illaque operari queat, at occu patus omnino \& fummopere vaporum concoctioni intétus, nihil illorum meminit: tum veluti neque uigilans, at uel intent ifsimè quid cogitans, uel magno quopiam oppreffus ma lo, miltoque debilitatus magis, \& veluti æger factus : \& pro pterea qui frigido, humidoque funt corpore, \& qui frigidis laborant morbis, capitis præfertim, cerebrique, \& fęminę diu fomno detinentur, quòd in omnibus multi, frigidiq; \& craffivapores ventriculos fubeunt: \& qui xgrè à fpiritu quouis, $\&$ in quouis conficiantur cerebro, at multò certè egrius frigi do à fpiritu, cuiufmodi ijs omnibus ineffe exiftimare licet, \& frigido in cerebro, \& qui paluftria incolunt loca, \& pueri, illi quidem quòd craflum infpirant aerem, \& qui ægre à fpiritu exuperetur, ij uerò quòd plurima, asfiduaque, \& bene infuper crafia, in mollisfimo corum corpore euaporatio fit.Infomnes contra, qui calido funt corpore, eoq; amplius fi ficco infuper, \& qui calidis laborant morbis, \& qui calidas ficcafque incolunt terras. Nam (ut in diftis de natura commentariis expo fitum eir) crasfis è rebus tenues educuntur uapores, \& tenuis, qui eft fpiritus $x$ gre à motu ceflat, eó́deægrius qui calidus infuper eft, cuiufmodi ijs omnibus ineffe uidetur è calidis te nuibufque confectus rebus.\& fenes etiam propterea infomnes, quòd crasfifsimus elt ipforum Sanguis, itaque \& fpiritus longè tenuisfimus, \& qui immobilis diù effe nolit.ut ex omnibus, qux fomno eueniunt, fomum fpiritus reliquis è parti bus abfcefiu, $\&$ in ventriculos receffu, ac contractione fieri, 
ita apertè declaratum videri poteft, ut alia fieri ratione fufpicari non liceat. At clarius id ut fiat, modus itidem, quo antiquioribus; \& huius temporis philofophis; \& quam ob caufam fieri placet exponatur,examineturque.

Quomodo Ariftoteli, Galenoque, \& buius temporis philofophisfomnusfiat, \& cur. Cap. $X$.

Nar a XH A L A T I O (inquit Ariftoteles) quxab

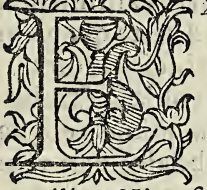
exculentis, poculentifque fit, rurfum ad cerebrum afcendit, tum ab eius frigore con- $"$ tracta, confpiffataque ad interna deuoluitur, \& ipfum petit cor ; \& frigida exiftens eius calorem hebetat, retunditque, vel repellit. Hinc fentireceffat, quod fomnus eft, tam diuque durat fomnus, dum defluxus confequitur, \& fanguis purusab impuro fecernitur, feparaturgue: \& propterea polt affimptos cibos præcipuè fiunt fomni.tributum porrò animätibus fuif fe fomnum ad operationum motuumque quietem, quòd nimirum nec fentire, nec moueri,nec operari perpetuò queant. Galenus autem, quoniam (inquit)fomni tempore, fenfus aut otiofi funt, aut debiliter agunt, confentaneum utique eft, exi guam quamdam à principe parte facultatem in reliquas palilatim partes defluere: quod enim quis profunde, uel minus profande dormit, ex eo eft, ut quotidie dicere folemus, quòd aut plus, alt minus affuit, quippe tantò minus affluere par eit, quanto grauior fuerit fomnus. \& alibi, fit (inquit) grauior fomnus retrigerato primo fenforio, hoc eft cerebro ipfo, Opinio reeò autem vehementius, cum refrigeratio humiditati commi centiorum fta fuerit. Huius verò temporis philofophi ignauia, imperi- ", tiaquí antiquioribus rectè ( ut uidetur) damnatis, qui nec " omnes fomni caufas explicarunt, nec quas attulere veras effe fomni caufas demon trarunt:multis quidem alijs è rebus, \& ab ijs propemodum à quibus nobis dictum eft fomnum fieri declarant.at qux omnes calorem natiuum (qui à corde deriuare, $\&$ in arterijs contineri, eiufque ad externas partes accef fil, \& prafertim fenfum fieri, videtur) ad internas repellunt, vel imminuunt, uel ad motum ineptum faciunt, ut fomni cuiufuis caufa, natiui caloris ab externis partibus abfceffus abfentiaque, \& in internas receffus, contractiog; videri posfit. 


\section{Bernardini Telefij}

cius nimirum fubftantix abfceffus, abfentiaque, cuius acceffu, prafentiaque, fenfu partes donantur; iuxtà fcilicet, finguli principia . quoniam enim id omnino à vigilante dormiens differt animal: quòd vigilantis partes fingulx fentiendi, fefeque mouendi facultate præditx funt, dormientis verò, fi non \& intern $x$, extern $x$ certè 'omnes ftupid $x$ fiunt, immobilefque . itaque nec fentiendi, nec motus ædé di facultas partium propria videri poteft; fed ab alia omnino fubitantia, ij fque illam communicari neceffario exiftimandü eft.Vtiq; quibus non uniuerfo in corpore, fed certa quapiam in parte animam refidere, ob eaque fentien di, fefeq; commo uendi eius partibus communicari vifa eft, ea oblxfa, facultatemque emittendi impotente, ineptauè facta, quibus verò na tiui caloris prefentia partes fentientes, mobilefq; fieri vifa funt, illius in internas receffu, fomnum fieri, omnino eft exiAtimandum.Nifi fortè incoftantix Ariftoteles damnädus fit, qui nimirum non perpetuò vni cordi animam indit, fed uel eius explicans fabftantiam corporis uniuerfi formam efie enuntiat.at agè fingulorum fententię examinentur.

\section{Nec eo modo, quo Ariftoteli placet, nec eius gratia fomnum fieri. Cap. XI.}

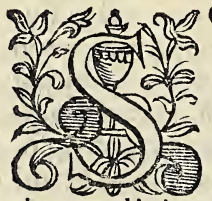

O MNVM propterea fieri, quòd vapores, qui ad caput efferuntur à cerebri frigore, fri gidum in fuorem confpiffentur, if q; ad cor delatus eius calorem hebetet, retundatque ftatuens Ariftoteles; uel fi unis à uaporibus ad caput fublatis, fomnus fiat : multis omnino modis incufandus uideri poteft.primum enim vel inde mortuis iam animantibus calidum omnino eft cerebrú, itaque qui ad ipfum efferuntur vapores frigidum in fluorem, \& a quo cordis calor hebetetur, retundaturque, ab illius frigore fpiffari intelligere non ticet.tum uapores qui è ventriculo, ventreq́ue ad caput efferuntur, quia manifeftè cerebri ventriculos fubeunt, utiq; fi in fluores fpiffentur, in ijs omnino fpif fentur oportet. Nam ut ulterius efferri,\& cerebri corpus inire uelint, nullam prorfus occafionem habent, benè amplum in illis nacti locum, nec fi velint queant; non à tunica modò qux illos ambit, fed ipfo etiam reiecti à cerebro, in illis por- 
rò, in fluores coacti, hand quaquã ad cor, ad quod nimirum inde ex illis, qui funt meatus, longè anguftisfimi funt, longeque perplexisfimi, \& qui uni tantum fpiritui iter prabeãr:fed ipfum omnino delabuntur in ventriculum, ad quem, fcilicet patens, rectaque, $\&$ decliuis eft uia, haud quaquam propterea uel cor, vel que ipfum contegunt res, uel externx etiã corporis partes ulle toto in fomni tempore, fed in principio tatum frigidiores funt; fomno verô progrediente incalefcunt omnes.nec fi propterea fiat fomnus, quod cor a delabentibus fluoribus frigefiat; fanguifque impurus puro commifceatur, quouis $x$ dito fono, \& externa corporis parte quanis uellæuiter contacta, ftatim ceffetineque enim uel fonus ullus, uel huiufmodi contactus cordis calorem excitet, purumque fanguinem ab impuro fecernat. fui certè oblitus $A$ riftoteles corde perfrigerato, \& fanguine inco\&to, impuroque,puro, perfectoque immifto, fenfum animanti adimit, qui illum anim $x$ effe contendat prorfus incorporex, impartibilifque:\& calorem, frigufque attribuere fummopere, exhorret: r. De on. fummopereque eos damnet, qui animam fanguini indunt, nia tex. 32。 \& fanguinem eam effe enuntiant. perperam etiam ad motum, propriarumque operationum ceffationem, quietemque fomnum animantibus tributum effe decernit . quàm longisfimè enim $\&$ animantium anima, \& fubftantia quęuis alia abeft, ut à propria operatione defatigari, uel ab ea ceffare uelit, posfitue, à qua nimirum maxima (ut dictum eft) afficitur noluptate, $\&$ in propria conferuatur natura, \& robur etiam fumit.at qui nec corpus diligentcr infpexiffe, partium certè ufum, aut penitus, aut magna ex parte, multo etiam am plius animæ fubftantiam, fedemque ignorafe uideri poteft. nec quę fit fpiritus operatio, nec quomodo, \& à quo defatigetur opere intueri poteft. neque igitur cur quiete opus habeat: aut quomodo, \& à quibus requiefcat : it aque in horum caufis afsignandis fuetuet, \& abfurda multa, multaçue etiam ridicula aflerat, necefle eft. 


\section{Bernardini Telefij}

Somnum nec facultatis à cerebro emanantis, nec caloris in-

fuentis, ut Galeno,noftrique temporis philofophis placet, fed ipfus omnino anime abfceffu fieri. Cap. XII.

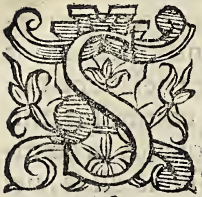

VMMOPERE itidem incufandus Galenus videri potent, qui fcilicet propterea fom num fieri itatuit, quod refrigeratum, humectactumque cerebrum fentiendi facultatem partibıs communicandi impotens, ineptúprimis, fummaque infpiciendum erat diligentia) num res à quibus fomnum fieri uidetur, ita cerebrum afficiendi faculta tem obtineant, intuitus. Nam fi quiduis infpectum id foret, ambigere non licet, quin ab illorum nullis id agi, \& ab omnibus animam externis è partibus intrò, $\&$ ad propriam ipfius fedem, $\&$ ad cerebri omnino uentriculos agi, itaque fomnum externis è partibus abfceflu fieri confpectum Galeno foret:\& in fomno, qui Vigiliam infequitur, uifum non effe mirari li" cet.quando (ipre inquit Galenus) quoniam fomnus abfque " abfumptione cibi fit, hoc accidit ratione caufa finalis, cum

" fit reftauratio uirtutis deperditx in Vigilia . unde dicimus quòd oportet, ut in fomno fit quies animalium operationü, ut robuftiores fiant operationes naturales. quoniam enim ( ut alibi amplius expofitum eft) qux facultate emiffa agunt, agentes nimirum naturx, ea nihil unquam quod asfidue, inceffanterque defatigari, imminuiue uidentur, nam fefe asfidue inceffanterque, amplificandi, multiplicandique facultate donatz, \& fefe omnino asfidue amplificantes, multiplicantelque asfidue fefe cum emictant, nihil tamen imminuuntur unquam. ut non fol modo, terraque, \& ignis, fed entia quxuis, quorum actio manifelta eft, declarät.quę fcilicet proprias asfiduè uires, propriafque cum effundantnaturas, easqueije qux attingunt, exuperantque indant omnibus, nihil ipfa pro pterea defatigari, imminuique uidentur.vtique fi qua fentie di, fefeque mouendi uim partibus communicat fubftantia; diù id agens defatigari, imminuique apparet, $\&$ ne penitus deficiat, at deperditas uires recuperet, \& fefe omnino ut reficiat, actionem intermiktat oportet. haud quaquam faculta- 
tem partibus largiri, fed fui portionem ad eas mictere exiftimandum omnino eft, $\&$ defatigari,imminuique, quòd eas vectans laboret, \& non fatis in ijs coercita, retentaque asfiduè ex ijs elabatur;à motu præfertim concalefactis, adapertifque:itaque fpatio opus habere, in quo ad propriam uniuer fa intrò acta fedem, \& aliud nihil in ea operans, rebus ad fui ipfius refectionem in eam illapfis concoquendis, $\&$ in fe ipfam inuertendis uniuerfa intenta foret, occupataque. Noftri porrò temporis philofophi rectè quidem fonini caufa enume rāt omnes, eiufque rei receffu fomnum fieri decernunt, cuius Cófitatio. In Receracceffu fentiendi, fefeque mouendi facultate partes donantur:at prauè omnino partibus eam communicandi natiuo ca lori uim attribuunt, eumque fanguini in arterijs contento in dunt : itaque eius receffi fomnum fieri ftatuunt . fiquidem qux partes exquifitisfimo donatx funt fenfu,ex minimè arte rijs abundant, \& in quas infignes, plurimæque ferantur arterix, exilisfimus ijs ineft fenfus : partes certè in quibus olfaEtus, uifio, auditusqúue fit, quibus, quòd languidisfimx actio nes, languidisfimique percipiendi erant motus, fentiendi uis longe exquifitisfima indenda fuit, nullę ineffe uidentur arterix.\& peius etiam calori, quem asfidue ad partes, quę eo opus habent; \& talem plerumque, tảtumque accedere intuêtur, qua li,quãtoque opus habêt, ftupidū fui natura, nihilque partium necesfitates percipientem, \& immobilem, vt videtur, itatuut. itaque non fponte fua, \& quibus opus eft viribus ad partes ac cedere, fed ipfis à partibus illum attrahi, repellique, \& augeri, imminuique, decernunt.nihil vfquam (quòd maxime oportebat) modum quo ea partes operentur, declarantes, fingula (inquiunt) partes vbi operari volunt, calorem commune or ganum ad fe ipfas trahunt,alliciunt que, \& contrahunt fimul, \& extramietunt, \& aftumunt, \& feruofem excitant, tali denique eo intentus, quali opus eft, \& cor feorfum certas pasfiones, certofque habet motus, qui peculiari quadam ratione ca lorem contrahit, ut in timore, \& triftitia, quofdam itidem qui ipfum expandunt, vt in ira, \& gaudio. fiquidem non id eft caloris ingenium, vt vel à partibis quibus ineft, vllo ipfarum motu repellatur, uel aliarum motu allectus, inde ad alias migret, \& excitari quidem, augerique, à rerum, quibus ineft motu, at imminui, \& ueluti in torporem deijci nunquam apFaret: \& fummopere mirari licet, quibus ftupidus fui natura,

D immo- 


\section{Bernardini Telefij}

immobilifque videtur, partes ipfius prafentia fentientes, mobilesq́uefieri videri:itaque facultatibus ab eo, quibus ipfe penitus caret, donari, \& magis etiam quòd obftructis, clau fifque cerebri uentriculis, animal fopiri, $\&$ oppleri,eos propte rea fenfu, motuque priuari, quod cerebri uentriculi, cauitatefque occlufx fint.itaque fentiendi, motufque adendi facul tatem, à re part ibus afferri, quę ventriculis omnino inexiftat, \& ab ijs ad illas accedat, \& à fpiritu nimirum in illis contēto. neq; enim Res alia vlla illis ineffe videri poteft;non perpetuò a fpiritu fentiendi, fefeq́; commouendi uim partibus indi,ita que \& fomnum, eius è partibus abfceffì ftatuát fieri.cùm præ fertim nulla id ponentib;s incommoda fuftinenda,nullæque fubeund $x$ fint difficultates, qux innumerę, inexplicabilefque pofitiones alias quas vis excipiant.Sed pofitionis tenaces Spi ritui calidum innatum immifcent, \& fanguini indunt in arte rijs contento, quod igitur nullum prorfus ventriculis ineffe poteft . quoniam inquiunt, nerui viforij è cerebri parte, qux uentriculos conftituit, ferè enafcuntur, fpiritus, \& calidum natiuum, cuius merito fomnus fit, magna ex parte in illis con tinetur, optima ratione fit, $v t$ in corpore magis afficiantur, quàm cerebri ipfius fubftantia;argumento quòd cerebro pro. pter vulnera, aut infammationes affecto, non affectis ventriculis fopores haudquaquam fequuntur; at ventriculis claufis, atque obftructis illafo cerebro animal fopitur,adeò vt ue rè dicere pofsimus ob ventriculorum affectionem calidum. impediri, \& perpetuò fomnos fieri.tum alibi aplopletici,inquiunt, omni fenfu, motuque priuantur, quia cęrebri uentriculi, \& cauitates occluf funt, quia nimirum fubftantix quz in ipfis refidet, \& qux partibus motum, fenfumque affert,pre clufa fit via. non ut ipfi pofitionis tenaces fubdunt, quod per illos facultat1 \& calido uia non pateat, neque enim vel ipforum confenfu, res alia ulla, qua omnino facultas emittenda effet, fed unus ineft fpiritus.

\section{F I N I S}




\section{I $\mathrm{N} D \mathrm{E} \mathrm{X}$ \\ C A P I T \\ L I. B $\quad E$ L L L I \\ D E SO M NO.}

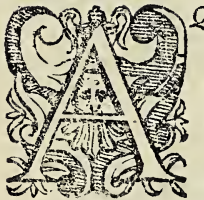

Quibus fomni canfe babendx funt. Cap. I. pag. $3 \cdot a$

Quedormientibus eueniunt. Cap. II. pag.3.b Qux fomnos faciunt, \& qui fomniculofi, quiue in fornes funt. Cap. III. pag.3.b tionefque. Cap. IIII.

Que piritum intro, \&o ad cerebri agunt ventriculos. Cap.V.pa.6.a $A b$ ijs, que fomnum faciunt, Spiritum ad cerebri usn triculos agi omnibus, \& fomniculofis fpiritum talem eße, qualis eft, qui ad exiliendum, mouendumque impotens, ineptufque uifus eft, effe. Cap. VI. pag.6.b

Externas corporis partes propterea in fomno fupidas fieri, immobi lefque, quod fpiritus ex ijs fefe in cerebri uentriculos receperit; of fpiritus reficiendi gratia fomnum animalibus tributum. effe. Cap. VII.

pag. 8.a Pulfuum, externarumque partium, que in somno fit immutationem, of concoctiones melius in fomno, quim in uigilia, propterea fieri, quòd fpiritus intrò, \& in cerebri fefe recipit uentriculis.

Cap. VIII.

pag. $9 . a$

In fomnia itidem, of que fomriculofis . In fomnibufq; infunt, fons num, quomodo diEtum eft fieri declarant. Cap. IX. pag. I o.a Quemodo Ariftoteli, Galenoque, ¿゙ buius temporis philofofis fommus fiat, \& cur. Cap. $X$.

pag. I I.a Nec eo modo, quo Arifoteli placet, nec eius gratia Somnum fieri. cap. $X I$.

pag. I I.b

somnum nec facultatis à cerebro cmanantis, nec caloris influentis, ut Galeno, noftrique temporis pbilofopbisplacet, fed ipfius omnino anima abfeffufieri. Cap. XII. pag.1 2.6

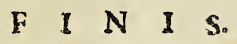



Errata fic corrigantur; Numerorum autem prior, paginam, a primam, b, fecundam columnam fignificat.pofterior lineam. indicat:In lineis autem numerandis hon eas tantum, qua fcriptx funt, fed etiamillas, qux funt uacux, numerato.

Errores in libro de Cometis, of $\mathrm{La}$ ead. 37. Reipfo. Reipfos. Eteo circule.

Pa. Co, Lin.

8. bo 38 . fpetiem.

3. 2. 5. fpeties

4. b. 15. colorem.

7. b. $x_{0}$ at.

ead. 7. xe.

ead. 26. compręffionem. fionem.

8. a. is compręfionem. sôprer fionem.

ead.b. 25. vel ue,

ead. 29. qui.

9. 2. 32 . illis.

cad.b. 5. diuifam.

ead. 7. actum.

ead. 29. apparer.

ead. 34. hęe.

20. 2. 19. refpondeo.

ead. 22. coniunctas.

etis.

ead.2. 24. Orizontis。 tis.

ead. b. I. Hęc annotatio debet efle

Iin, 7 .

ead. 14. Hexamor.

ii. b. 17. qui.

cad. 18. queant,

1.2. b. 9. lacteum circulü. queant circulus.

cad. 19. Atelas.

ead. 24. fummendum fumed

ead. 32. in circulo alio. in circu lo aliquo.

cas. 32. hacq;

13. 2. 5. inft2.

Exrores de his, que in Aere fiut .

P. C. Li.

1.4. 2. 32. niuens.
Corrigito.

rpeciē.

fpecies. ead.b. 7 .

calorê . 17. b. 9 .

ut.

ex. 18. 2. 20. ulfe.

27. conftriguuntur. cóftringuntur.

appettant.

eftibus.

proterea.

rez.

ead. 36. ulceris.

ead.b. 25. planiq;

que.

19. 2. 30. fumme

velne. ead.b. 4. annis.

qui. 20. b. 28 . concrectionem. tionem.

diu iã. 23. a. 8 . nequat.

aptum . b. 2. emitat.

apparet 24. a. 2. plunias.

hęc. ead. 40 craffioribns.

xespolio

coniun-

Horizo̊

ead.b. r. ettefias ead. b. 18. finmmis.

appetär ętibus. propte on

uifzo.

ulterius planif-

fumme. anni. concrenequeat emittar. pluuias. craflio-

etefias. fummis

\section{Errores in libro de Iride.}

Pa. C. Li.

uero. Pa. C. Li. Corrigito.

Hexa- 2o a. 19. illuftriffing: Illuftrif ead fime.

ead. 23. beneficijfq; benefi cijq;.

ead.b. 7. hornare.

3. b. 8 . leucm.

20. leuibus.

4. b. 5. Iride.

5. b. 16. Ariftotiles. teles.

ead. 23. fit.

6. a. 20. Iridem.

ead.b. 22. crocenfg; eft.

ead. 24. medijs. que, qui eft,

ornare.

Ixuem.

lruibus

in Iride

Arifto -

fic,

itidem .

croceur

medius,

allata. 
5. 2. 10. appolita.

oppof - 3. b. 8. teuuifiman.

renuifi:

ta. mum.

ead.2. 10. Necualde quosnec ead. 32. fepiternum. sépiterlucidos, nec ualde:

nam.

9. 2. 19. radijs.

ead. 3.1. centum.

ead.b. 8, in marg. 3.Re-

fpondeo Recé

fiorum.

ead. 30. proximus.

32. 2. 19. praterca.

rea.

ead.b. 7. portiorem.

nem.

ead. 18. itam.

14. 2. 3. crafitie.

ead. 9. qą̧.

2d. 14. reducentes.

tes.

e2d. b. 14, relucentem.

ead. 3I. fphericus.

cus.

16. 2. 17. calore.

cad. 20. quantumlifuis, quantulifuis.

ead. $2 \mathrm{r}$ : calores.

ead. b. 14. folis.

cad. 15. nube.

17. b. 17. fuperfitic. cise.

o.d. 29. fperie.

cêtiorá.

pximú.

propte -

item.

qux.

cęruleü.

relucer.

relucếs.

nubes. ead: 10. putiori.

15. a. 2. ceruleum.

ead. 29. oblique.

radij. 4. 2. in tit. de Maris.

cétrum . ead.a. 30. vafx.

3 Refpó b. 15. tencat.

fio $\mathrm{Re}-5$.

a. 8. in marg.cyl.

b. 2 r. pluuis.

3r. callidiffimofa. calidifr mofq;

7. 2. 20. fluuifque.

portio-8. a. pen. loeum.

- 20. in marg.ca.4.

27. concanitatem.

tate.

craffitie 9

fphęri- Ic. a. tit. Mare.

16. fperica.

33. fieri immobitate. fieri, \&. immobilitate. 36. conrinere. nere.

conti-

Mari.

fphęri-

\section{ca.}

b. 23. fpetics.

35. è cafor.

colores. 12. 2. 7. fole.

foli. 13. 2. 22. Legufti cum.

oblique

fuperfi-

b. 4. menfium.

y. Hellefponte.

fponto.

fpecie. I4. 2. 2. uendicaret.

ret.

In Indice capitum de Iride.

Pa. Co. Li:

19. a. 26 . calores.

ad: 32. colore.

39. incufandum.

dus.

ead. b. 2. necuidelicet. rium.

e2. 22. calorum.

ead. 25. cum.

\section{In Libro de Mari:}

3r. eftum.

fpecies.

2 calore

à fole.

Ligufti.

menfiủ.

Helle -

uendita

eftum.

b. 17. in mar. Sentétijs. fentëtie

15. 2. tit. Mare.

b. 33 . alabi.

Mari.

colores.

2. 16. oppreffi.

incufan 17. 2. 26. Ponfus.

alibi.

oppreffi

Pontus.

necefia- In libro quod anim. vniu. ab colorü. rnic.ani.fubft.guberna. cur.

Pag. Col. Lin.

2. 2. 27. ifta

cad. b. 4. cxterz.

18. cum.

21. inditium.

$\begin{array}{ll}\text { Patrici } & \text { 22. infe. } \\ \text { stafmifi 30 } & \text { b. 1\%. prædiazo. }\end{array}$
Corrigito.

iftęe.

cetera.

cum.

iudicin

in te.

predite 
30. diftributlonem. diftribu 14 a. 8. poftit. polcic. tionem. 17 . uidentpr.

$\begin{array}{llll}\text { 4. 2. 4. appellar. } & \text { appellar } & \text { 3. uidentpr. in marg.fenno. fomno. } \\ \text { 24. fememq; } & \text { feréq; } 15 . \text { b. 7. oninio. } & \text { omnino }\end{array}$

37. impallidum. i pallidú 31 . digenerem. degene-

b. 16. eligenti eligẽte.

17. eletionem. electio- 16. 2. 1. euenefit. etreniüt nes.

3. ruperficie.

22. attribuete. attribue 8. in muitis.

re.

fupficie.

inuits.

5. b. 2. inferioris. inferiori

19. exhylaretur. exhila-

31. difciuncti.

difǚti.

32. aliquantis per-aliquan

mouteri. rifp mo-

ueri.

38. in infenfibilis. is infen fibilis.

6. a. 1. ut ea fiftratus. Erafi -ftratus.

9. Goleno.

13. inheret.

Galen".

32. corpori. corpore

I7. retur.

conco-.

b. 3. fomnus.

5. poffit.

19. a. 2. 20 attrattionem. fpiritui.

fonus.

pofcit.

fpiritui.

b. 26. corebri. cerebri.

7. 2. 9. quoniã quã enim quî em̃.

35. diuifo, \& sé fu, \&c. diuifo. aial deftituit, \& fenfu, \& ctionem.

27. fcuros.

36. cefophagi.

fuccos.

ocfopha

24. torpideq;

que.

torpide

urina-

rium.

25. uefficx.

26. uefficam.

uefice.

ueficầ.

b. 5. feforia. motu,at uétriculis, \&c.

13. afterunnt.

sëforia. 35. immaginari.

afferunt

19. b. 25. prexiftentis.

prxexiftentis.

imagina 36 . affidue.

8. 2. 10. ætherensq;. ęthereuf que.

36. in oporteat. iriopor teat.

b. 4. fugeant.

25. inquam.

9. b. 17. fpiritus.

10. a. 12. afferre.

b. 6 poctione.

8. aęri.

38. commentaris. tarijs.

11. 2. 2. cuius.

b. 17. propteręa.

5. illis,ue.

10. ius.

19. abounda.

ultina. percepit.

32. b. 35 . qui.

percipit fugiant.

inq;.

fpiritu.

afferre.

portion:

2eri.

commé.

cuiuis.

spterea.

natura.

illisuè.

uis.

obeũda. 23.2

quî. ces.

34. externunt. nunt.

affidaè.

fimpli -

excer-o

ead. b. 12. appetita;ftringit, appetit, aftringitur.

16. coherent.

16. coherêt dum.

ultima. incolligendi. : intelligendi.

22: a. 12. a qưo.

16. medullę. las.

a qua.

inedul -

inuifiles

efferet.

vidénur.

perter-.

i37. perterre fit.

penitus.

quod.

14. quid.

29. prouide.

E proinde

affiduę 
24. 2. 22. affituę. affiduc.

cad. b. 15. inflamatas. inflam macas.

16. moritur.

18. inflamatus. matus.

35. 3. 4. inflamatas. matas

8. præcipuę.

ead. II. inflamatorum. matorum.

28. obliuifiores. fiores

ead. b. 25. fubfantiain. fubitátia 26. 2. 4. quam licet. bet.

5. exiguas.

b. 7. mittete.

24. pręuidit.

37. 2. 2. ementitaq; tamque.

I7. euexatur. \& magni. celores.

29 prouide.

ead.b. 19. nulla.

37. b. 27. longum. 34. grauemini. mur.

38. 2. I. uitatis.

11. uimirum。

21. quî.

22. e contra:

sad.b. Io quid.

34. utranque.

37. Paraclitorum. ticoruin.

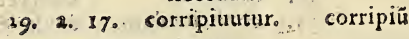
cur.

23. proptera.

cad. b. 28 . plexa.

30. 3. 3. offenfionem. - offentio nem.

6. interijt.

37. exhylarato. exhilasa to.

3x. 2. 15. ut.

24. fupplitium.

cad. b. 10. at ipfoinon folú, atcif́ci. fum folum:

obliuio.

exigutus

mittere

puidet.

erneari-

diuexat

magni.

celeres.

proinde

nullam.

in lógú.

quî.

e corra?

gitod.

utrunq;

Parali-

fuppli -

ulcifci.
17. qui

3.2. qui

32. 2. 5. calidioreque calidio refque.

34. deprehendartix. deprehë datur.

inflam-ead. b. 17. qui

ead. 33. qui

quî.

quî.

pcipuè. 33. a. 2. albe ilbr.
inflam-ead. iz. ipfa ipfr.

15. hylares

hilares.

16. immaginanre imagina re.

24. qui

qุû.

39.

ead. b. 4. . fumuo, fcilicer fumme

graue 55 . fcilicer,

II. contraria

Is. itis

contrat

7. qui nuslo quî.

18. exhylaratum exhilara tum.

38. omnis on onnes.

34. a. 4. propriam propria.

6. Iungatur. Re iunga

I2. ammoliri amoliri.

b. 1o. authoracem, aut tho-

b. 6. intercutens intercuti.

a. I. mędele medelx.

racem.

30. uel quibinfuis rebus qui

buruis.

conflexu

cófluxu .

quã fcili

cet.

b. 7. opprefium

oppref--

16. fepa

Sxpe.

pprerca 37. 2i.2. Nam

non.

5. ipfam ipfum.

6. diffunditure, difiundit que;

19. perire periere.

exhilasa b: 5. vefpitinis, .. deleas;vt

2t. 38, b. 33 . diverfe

39. 2

23. fequute.

diverfx. fecuto.

vinum.

29. auxiliaturque auxilieturque.

30. fpetiem

Speciem. fimili- 
b. 29. finilibus Gmilib. 40. modeftse. medeftic 35. temperies têperię 3. 2. 4. comeantib cómeãrib.

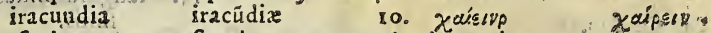

40. b. 2x. fuplex ofupplex.

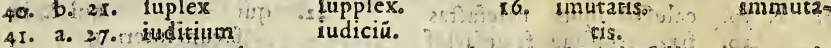

5. b. ap apptendeque appeten 40 b. 25 . Atquin foliso As quin 42. 2. 42. egrius agrius. 5. 2. 20. nigredous : aigredo

23. æmulgatue emulgat.
b. 32. fubftanria fubitatia

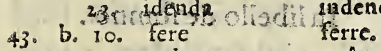
10. tere 36. nigrumqi jigrum

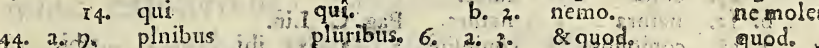

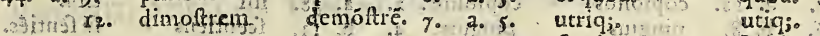

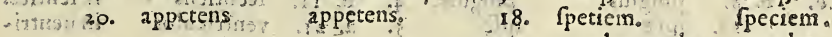

In libello de Vifu refpirationis. In tit. de ufu refpirationis $\mathrm{I}^{*}$ iber. P. C. Li. de ufu refpirationis Libellus

3. 20,35. fotte shis forte. b. 6. neque in arcto stequeiti. 18. illa contalu. illie.

4. b. 1. rigentemqjigne in ignen 24. elabatur. elabetur.

ร. 2. 5. Mápavan Mápaijss

5. in marg.fe ušt. fenectute

17. inuuens. innuens.

b. 20. viręs.

27. feruus.

28. exienti.

5. a. 36. \& alibi marg.de tremore cap.6.

b. 1. fpontaneum. fpótaneã

2. vilhominus nihilomi nus.

8. refrigerandine. refrigerã diue.

g. 2. 2o. in mar.reftit n refpira tionis.
8. frigis
39. fulfori
b. 5. portio.

\section{In libro de coloribus.}

P. C. $L_{0}$.

2. 2. 38 . ipfe ciuem, ipfa.

frigus.

rulfuri.

portione
13:2, 2

24. occultaturobo Eeruatur,
b. b. prxpterea $^{2}$
2. I. uiria
- 2ato ditia.
.3utis 24. expofitum.
eft.

8. a. 7. in marg.Albo.

b. 10. fiunt?

9. 2. 7. obfcureq;:

Li ique.

22. reliquius.

28. ipfins.

29. euelere

b. 13. aducir

22. coutra

10. a. 17. atramentarium tarius.

b. 38 . ten iffunos tenuiffmos.

15. 2. 25. in marg. fangui fanguis $i$ in iecure,

27. perfpicuun fit

38. $\mathrm{cx}$

b. 3. abfcurios

occulte.

cur obfer

uetur.

preterea.

vina.

ex uuis.

expofitit

Albuns.

fiant?

obfcura-

reliquus

ipfrus.

euehere.

educit.

contra.

atramen iecore.

fit.

exs

obfcus - .

2. calorem.

8. copiofiori

colorem.

copiofro-

clariorue

faporem

fir,

aliment?

34. 3. 23. inquam

29. opinjo inopiam.

omnino.

In 


\section{In libro de Sapoxibus.}

Pa. C. Iin.

3. b. 30 . calefadafque calefactas

3o. frigetactafque frigefactaf

34. ipfins

4. 2. 18 . dicertare

82. obledi

23. videarur

29. color

b. 13. natnra

5. 2. is. copiofios

6. b. 8. pingius

13. ipfe

7. 2. 2. caloris

20. multa

29. leuia

8. 2. 32 . concreffit

9. a. 36. acrem

40. in erat

40. pęnitus

b. 30. duici

ro. 2. 11. rationi

23. ap.

31. ita

b. 8. intactililium

13. qui ipfius.

decerta--

obledi.

videtur.

calor.

natura. Pag C. Lin.

copiofior. 2. 2. 38 . ibi pinguis." ipfe calores. multo.

lauia.

cócrefcic.

acre.

inerat.

penitus.

dulci.

racione.

ad.

ita

intactiliú

quî. utili,

29. $2 t$
Ex. B. 4. fugoris

15. languidiffimus tagoris. fimis.

22. qui qûे \& in ficum interrog.

12. b. 10. hiemales hyemales in marg.defenfis defenfu,

83. 2. 24. acentibus

\& fenfili.

2rétibus.

\section{In libello de fomno.}

4. b. 11. fcentiens

5. ventriculos in uentri culos.

b. 20 reis retis.

19. promptionem promptio

6. 2. 33. natura

6. b. 9. lafciuus

naturz.

7. b. 8. iuditium iudicium.

$3^{2}$. apptignans oppugnãs

8. b. 5. leuia leuia.

ad.

I2. 2. Ir. leuiter. leuiter.

18. in marg.omnia. Anima.

13. 9. sanfa. 
Alia errata, qua ad interpunctionem pertinent, licèt innumera ea fint, quia facilius animaduerti poffunt, confulto negleximus, ea omnia tibilector humanisfime emendanda relinquentes. Ego certè fi tot operarum lapfus prouidere potuiffem, nullam tibi hre opufcula in hoc genere moleftiam nunc exhiberent. excudendo enim operi meam operam præfens addixiffem. Vale.

Ratuig" Rn.. - 


\section{In Epifola ad Iectorem.}

pa. Col. Lin.

3. b. 7. efpicatis. ive expifeatus et i. I lo exacatio agexatatiog onum

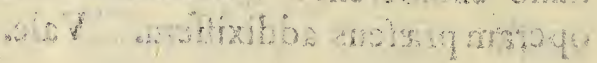
$\therefore \quad \therefore x+$ 



